This report has been reproduced directly from the best available copy.

Available to DOE and DOE contractors from the Office of Scientific and Technical Information, P.O. Box 62, Oak Ridge, TN 37831; prices available from (615) 576-8401, FTS 626-8401.

Available to the public from the National Technical Information Service, U.S. Department of Commerce, 5285 Port Royal Rd., Springfield, VA 22161.

This report was prepared as an account of work sponsored by an agency of the United States Government. Neither the United States Government nor any agency thereot, nor any of their employees, makes any warranty, express or implied, or assumes any legal liability or responsibility for the accuracy, completeness, or usefulness of any information, apparatus, product, or process disclosed, or represents that its use would not infringe privately owned rights. Reterence herein to any specific commercial product, process, or service by trade name, trademark, manutacturer, or otherwise, does ilot necessarily constltute or imply its endorsement, recommendation, or favoring by the United States Government or any agency thereof. The views and opinions of authors expressed herein do not necessarily state or reflect those of the United States Government or any agency thereot. 


\title{
DISPOSAL OF CHEMICAL AGENTS AND MUNITIONS STORED AT PINE BLUFF ARSENAL PINE BLUFF, ARKANSAS, FINAL PHASE I ENVIRONMENTAL REPORT
}
J. T. Ensminger
C. R. Boston
E. L. Hillsman
D. B. Hunsaker
R. D. Johnson
E. Liebsch
J. A. Morrisey
L. W. Rickert
W. P. Staub
V. R. Tolbert

G. P. Zimmerman

Date Published: September 1991

\author{
Research supported by \\ Program Manager \\ for Chemical Demilitarization
}

Aberdeen Proving Ground, Maryland 21010-5401

Prepared by the

OAK RIDGE NATIONAL LABORATORY

Oak Ridge, Tennessee 37831

Managed by

MARTIN MARIETTA ENERGY SYSTEMS, INC.

for the

U.S. DEPARTMENT OF ENERGY

under Contract No. DE-AC05-84OR21400 
TABLE OF CONTENTS

\section{Page}

LIST OF FIGURES $\ldots \ldots \ldots \ldots \ldots \ldots \ldots \ldots \ldots \ldots \ldots \ldots \ldots \ldots \ldots$

LIST OF TABLES $\ldots \ldots \ldots \ldots \ldots \ldots \ldots \ldots \ldots \ldots \ldots \ldots \ldots \ldots \ldots \ldots$

ABBREVIATIONS AND ACRONYMS $\ldots \ldots \ldots \ldots \ldots \ldots \ldots \ldots \ldots$

FOREWORD $\ldots \ldots \ldots \ldots \ldots \ldots \ldots \ldots \ldots \ldots \ldots \ldots \ldots \ldots \ldots \ldots \ldots \ldots$

EXECUTIVE SUMMARY $\ldots \ldots \ldots \ldots \ldots \ldots \ldots \ldots \ldots \ldots \ldots \ldots$

PREFACE $\ldots \ldots \ldots \ldots \ldots \ldots \ldots \ldots \ldots \ldots \ldots \ldots \ldots \ldots \ldots \ldots \ldots \ldots \ldots \ldots \ldots$

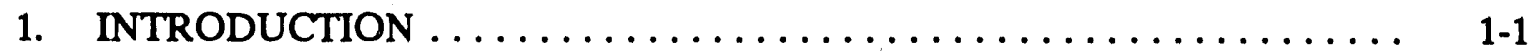

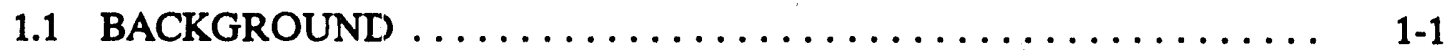

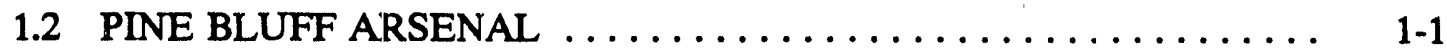

1.3 OBJECTIVES AND SCOPE $\ldots \ldots \ldots \ldots \ldots \ldots \ldots \ldots \ldots \ldots \ldots \ldots \ldots$

1.4 REFERENCES .............................. 1 .9

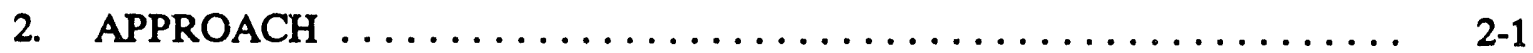

2.1 IDENTIFYING THE PROGRAMMATIC ENVIRONMENTALLY

PREFERRED ALTERNATIVE . . . . . . . . . . . . . . . . 2-1

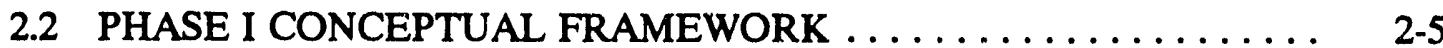

2.3 DATA COLLECTION AND AGENCIES CONTACTED . . . . . . . 2 .

2.4 REFERENCES ............................ $2-11$

3. COMPARISON OF SITE-SPECIFIC AND PROGRAMMATIC DATA ... . 3-1

3.1 REEXAMINING THE IDENTIFICATION OF ON-SITE

DISPOSAL AS THE ENVIRONMENTALLY PREFERRED

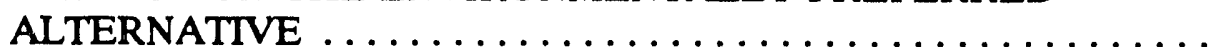

3.1.1 New Values for Programmatic Data and Assumptions and

Their Significance ...................... 3-2

3.1.1.1 Accident database $\ldots \ldots \ldots \ldots \ldots \ldots \ldots \ldots \ldots \ldots . \ldots \ldots$

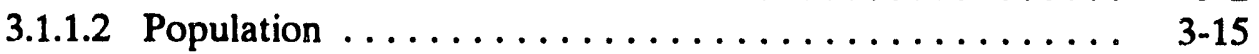

3.1.1.3 Summary $\ldots \ldots \ldots \ldots \ldots \ldots \ldots \ldots \ldots \ldots \ldots . \ldots \ldots$ 3-20

3.1.2 Evaluating Measures of Risk with Data Collected During

Phase I . . . . . . . . . . . . . . . . . . . . . . 3-20

3.1.2.1 Differences in the measures of risk from those in the 


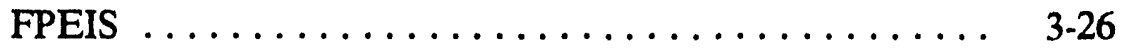

3.1.2.2 Effect of various meteorological conditions upon measures of risk . . . . . . . . . . . . . . . . . . 3-27

3.1.3 Identifying the Site-Specific Environmentally Preferred Alternative ........................... 3-28

3.2 NEW INFORMATION AFFECTING IMPLEMENTATION OF ON-SITE DISPOSAL AT PINE BLUFF ARSENAL . . . . . . . . . 3-29

3.2.1 Meteorology/Air Quality . . . . . . . . . . . . . . . . . 30

3.2.2 Water Resources ....................... 3-33

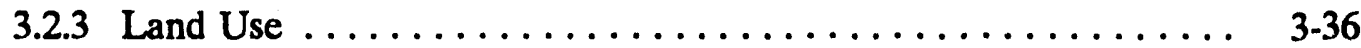

3.2.4 Ecological Resources ..................... 3-37

3.2.5 Social, Economic and Cultural Resources . . . . . . . . . . . . . 3-42

3.2.6 Aircraft Activity ....................... 3-47

3.2.7 Emergency Planning and Preparedness ............. 3-48

3.3 TECHNOLOGY STATUS/MATURITY $\ldots \ldots \ldots \ldots \ldots \ldots \ldots \ldots .3 . \ldots \ldots$

3.3.1 BZ Demilitarization Operations $\ldots \ldots \ldots \ldots \ldots \ldots \ldots \ldots \ldots$ 3-54

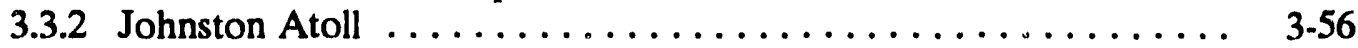

3.3.3 1989 VX Test Program at CAMDS . . . . . . . . . . . . 3-60

3.3.4 1990 Mustard Agent (HD) Test Program at CAMDS ........ 3-61

3.3.5 Award of the Systems Contract for the Chemical Demilitarization Training Facility ............... 3-61

3.3.6 Award of the Systems Contract for the Tooele Chemical Agent Disposal Facility .................... 3.62

3.3.7 Equipment Acquisition Contracts $\ldots \ldots \ldots \ldots \ldots \ldots \ldots \ldots \ldots$ 3-62

3.3.8 Individual Equipment Advancements $\ldots \ldots \ldots \ldots \ldots \ldots \ldots \ldots$ 3-62

3.4 RISK ASSURANCE . . . . . . . . . . . . . . . . . . . . . . 3.64

3.4.1 Rationale and Basis for Risk Assurance at the Pine Bluff Arsenal . . . . . . . . . . . . . . . . . . . . . . . . . 3-65

3.4.2 Design Changes Requiring Reexamination of Risk at the Pine Bluff Arsenal ........................... 3.65

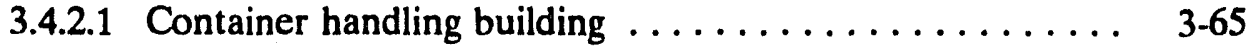

3.4.2.2 Redesigned on-site container ............ 3-67

3.4.2.3 Use of the existing BZ facilities at Pine Bluff Arsenal . . 3-68

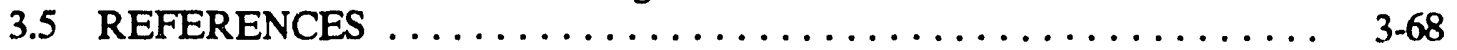

4. FINDINGS AND CONCLUSIONS $\ldots \ldots \ldots \ldots \ldots \ldots \ldots \ldots \ldots \ldots$ 4-1

4.1 REEXAMINING ON-SITE DISPOSAL AS THE ENVIRONMENTALLY PREFERRED ALTERNATTVE $\ldots \ldots \ldots \ldots$ 4-1

4.2 RESOURCE DATA RELATED TO IMPLEMENTATION OF

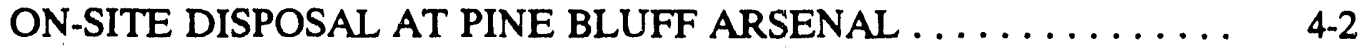

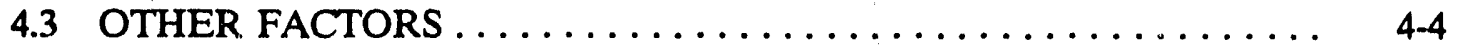

APPENDIX A. IMPACT ANALYSES IN THE FINAL PROGRAMMATIC ENVIRONMENTAL IMPACT STATEMENT ......... A-1

APPENDIX B. DESCRIPTION OF SITE-SPECIFIC COMMUNITY RESOURCES ........................ B-1

APPENDIX C. DESCRIPTION OF SITE-SPECIFIC SURFACE WATER AND GROUNDWATER RESOURCES . . . . . . . . . C C-1 
APPENDIX D. DESCRIPTION OF SITE-SPECIFIC LAND USE $\ldots \ldots \ldots \ldots$ D-1 APPENDIX E. DESCRIPTION OF SITE-SPECIFIC ECOLOGICAL RESOURCES $\ldots \ldots \ldots \ldots \ldots \ldots \ldots \ldots \ldots \ldots \ldots \ldots$ E 1

APPENDIX F. RESPONSES TO COMMENTS FROM STATE AND

FEDERAL AGENCIES ...................... F F-1 


\section{LIST OF FIGURES}

Page

1. Map of the vicinity of the Pine Bluff Arsenal, Jefferson County, Arkansas ... 1-2

2. General layout of the Pine Bluff Arsenal, Pine Bluff, Arkansas $\ldots . \ldots \ldots \quad 1-4$

3. Location of the chemical agent disposal facility at Pine Bluff Arsenal, Pine Bluff, Arkansas $\ldots \ldots \ldots \ldots \ldots \ldots \ldots \ldots \ldots \ldots \ldots \ldots$

4. Potential impact region of Pine Bluff Arsenal, Pine Bluff, Arkansas . . . . . . $1-8$

5. Flowchart illustrating selection of the Chemical Stockpile Disposal Program environmentally preferred alternative $\ldots \ldots \ldots \ldots \ldots \ldots . \ldots \ldots$

6. Conceptual overview of data types used in selecting the programmatic environmentally preferred alternative $\ldots \ldots \ldots \ldots \ldots \ldots \ldots \ldots \ldots \ldots .4$

7. Flowchart illustrating the Phase I concept $\ldots \ldots \ldots \ldots \ldots \ldots \ldots \ldots \ldots$

8. Federal Energency Management Agency 1988 seismic risk map . . . . . . . . 3-7

9. Historical record of strong-motion earthquakes from 1699-April $1989 \ldots$. . . . 3-11

10. Risk with mitigation, in the vicinity of Pine Bluff Arsenal (PBA) for programmatic alternatives $\ldots \ldots \ldots \ldots \ldots \ldots \ldots \ldots \ldots \ldots \ldots \ldots$ 3-25

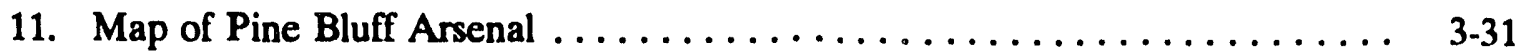

12. Wind roses (annual joint frequency distribution of wind speed and wind direction) for data collected at Pine Bluff Arsenal and at Pine Bluff,

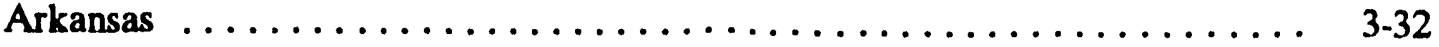

13. Location of important ecological resources within the $100-\mathrm{km}$ (62-mile) zone around Pine Bluff Arsenal $\ldots \ldots \ldots \ldots \ldots \ldots \ldots \ldots \ldots \ldots \ldots \ldots$ 3-41

14. $50-\mathrm{km}(31 \mathrm{mile})$ zone for Pine Bluff Arsenal $\ldots \ldots \ldots \ldots \ldots \ldots \ldots$ 


\section{LIST OF TABLES}

Page

1. Joint frequency distribution (in percent) of stability and wind speed for the Pine Bluff Arsenal Tower 6 station $(15 \mathrm{~m}) \ldots \ldots \ldots \ldots \ldots \ldots . \ldots \ldots$

2. Summary of site-specific and programmatic earthquake parameters at Pine Bluff Arsenal compared to earthquake engineering design parameters . . 3-8

3. Estimated peak ground acceleration at Pine Bluff Arsenal ......... 3-14

4. Residential population distribution around the Pine Bluff Arsenal proposed plant site as given in the Final Environmental Programmatic Impact Statement ...... 3-16

5. 1986 residential population distribution around the Pine Bluff Arsenal proposed disposal facility site using data collected during Phase $I \ldots \ldots \ldots \ldots \ldots$

6. 1986 residential population distribution around the Pine Bluff Arsenal chemical agent storage area $\ldots \ldots \ldots \ldots \ldots \ldots \ldots \ldots \ldots \ldots \ldots \ldots \ldots$

7. Estimated fatalities by downwind distance for selected meteorological conditions for Pine Bluff Arsenal proposed disposal site using data collected during the Phase I process $\ldots \ldots \ldots \ldots \ldots \ldots \ldots \ldots \ldots \ldots \ldots \ldots \ldots \ldots \ldots \ldots$

8. Estimated fatalities by downwind distance for selected meteorological conditions for Pine Bluff Arsenal, as given in the Final Programmatic Environmental Impact Statement $\ldots \ldots \ldots \ldots \ldots \ldots \ldots \ldots \ldots$

9. Estimated fatalities by downwind distance for selected meteorological conditions for Pine Bluff Arsenal storage area using data collected during the

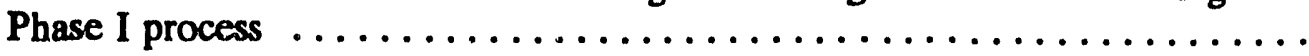

10. Pine Bluff Arsenal existing air emissions summary $\ldots \ldots \ldots \ldots \ldots \ldots$

11. Number of protected ecological resources within the no-effects distances for the most serious on-site accidents under worst case meteorological conditions at Pine Bluff Arsenal 
12. Ecological resources within the $100-\mathrm{km}$ (62-mile) impact zone around Pine Bluff Arsenal as identified during the Phase I process

13. On-post housing capacity and occupancy $\ldots \ldots \ldots \ldots \ldots \ldots \ldots \ldots \ldots$

14. Population of incorporated areas within the $50-\mathrm{km}$ (31-mile) zonc for Pine Bluff Arsenal

15. Projected chemical agent stockpile destruction schedule

16. Summary of Army's experience in industrial-scale chemical agent/munitions disposal

17. Comparison of JACADS PCB emissions with three commercial EPA-permitted PCB incinerators

18. Summary of major changes in design and operating procedures for the proposed disposal facilities at the Pine Bluff Arsenal 


\section{ABBREVIATIONS AND ACRONYMS}

$\begin{array}{ll}\text { ACAMS } & \text { automatic continuous air monitoring system } \\ \text { agl } & \text { above ground level } \\ \text { ANAD } & \text { Anniston Army Depot } \\ \text { APG } & \text { Aberdeen Proving Ground } \\ \text { ATC } & \text { Applied Technology Council } \\ \text { BZ } & \text { nonlethal but incapacitating agent } \\ \text { CAMDS } & \text { Chemical Agent Munitions Disposal System } \\ \text { CML } & \text { conservative most likely } \\ \text { CONUS } & \text { continental United States } \\ \text { CSDP } & \text { Chemical Stockpile Disposal Program } \\ \text { CY } & \text { calendar year } \\ \text { DATS } & \text { Drill and Transfer System } \\ \text { decons } & \text { decontaminating solutions } \\ \text { DFS } & \text { deactivation furnace system } \\ \text { DHHS } & \text { U.S. Department of Health and Human Services } \\ \text { E } & \text { east } \\ \text { EIS } & \text { environmental impact statement } \\ \text { ENE } & \text { east-northeast } \\ \text { EPA } & \text { U.S. Environmental Protection Agency } \\ \text { EPGA } & \text { effective peak ground acceleration } \\ \text { ERCP } & \text { Emergency Response Concept Plan } \\ \text { ESE } & \text { east-southeast } \\ \text { FEMA } & \text { Federal Emergency Management Agency } \\ \text { FPEIS } & \text { final programmatic environmental impact statement } \\ \text { ft } & \text { feet } \\ \text { FTEs } & \text { full time equivalents } \\ \text { FWS } & \text { U.S. Fish and Wildlife Service } \\ \text { g } & \text { acceleration due to gravity } \\ \text { GB } & \text { chemical nerve agent, also called Sarin } \\ \text { H } & \text { chemical blister agent, also generally called mustard } \\ \text { ha } & \text { hectare } \\ \text { HD } & \text { chemical blister agent, also generally called mustard } \\ \text { h } & \text { hour } \\ \text { HT } & \text { chemical blister agent, also generally called mustard } \\ \text { I } & \text { modified Mercalli intensity } \\ \text { IRZ } & \text { immediate response zone } \\ \text { JACADS } & \text { Johnston Atoll Chemical Agent Destruction System } \\ \text { kg } & \text { kilogram } \\ \end{array}$




$\begin{array}{ll}\text { km } & \text { kilometer } \\ \text { L } & \text { liter } \\ \text { LBAD } & \text { Lexington-Blue Grass Army Depot } \\ \text { lb } & \text { pounds } \\ \text { LIC } & \text { liquid incinerator } \\ \text { m } & \text { meter } \\ \text { Mb } & \text { magnitude } \\ \text { MDB } & \text { Munitions Demilitarization Building } \\ \text { mg } & \text { milligram } \\ \text { Mgd } & \text { million gallons per day } \\ \text { min } & \text { mixute } \\ \text { mm } & \text { millimeter } \\ \text { mph } & \text { mile(s) per hour } \\ \text { MPF } & \text { metal parts furnace } \\ \text { MSL } & \text { mean sea level } \\ \text { N } & \text { north } \\ \text { NAAP } & \text { Newport Army Ammunition Plant } \\ \text { NBC } & \text { Nuclear Biological Chemical team } \\ \text { NCTR } & \text { National Center for Toxicological Research } \\ \text { NE } & \text { northeast } \\ \text { NEPA } & \text { National Environmental Policy Act of 1969 } \\ \text { NF } & \text { national forest } \\ \text { NNE } & \text { north-northeast } \\ \text { NNW } & \text { north-northwest } \\ \text { NP } & \text { nacional parks } \\ \text { NRC } & \text { Nuclear Regulatory Commission } \\ \text { NRS } & \text { National Register Sites } \\ \text { NW } & \text { northwest } \\ \text { NWA } & \text { national wilderness area } \\ \text { NWR } & \text { national wildlife refuge } \\ \text { OMC } & \text { operations and maintenance contractor } \\ \text { ORNL } & \text { Oak Ridge National Laboratory } \\ \text { OVT } & \text { Operations Verification Test } \\ \text { PAZ } & \text { protective action zone } \\ \text { PBA } & \text { Pine Blufi Arsenal } \\ \text { PCB } & \text { polychlorinated biphenyl } \\ \text { PGA } & \text { peak ground acceleration } \\ \text { PMCD } & \text { Program Manager for Chemical Demilitarization } \\ \text { PSD } & \text { prevention of significant deterioration } \\ \text { Pt. } & \text { Part } \\ \text { Pub. L } & \text { Public Law } \\ \text { PUDA } & \text { Pueblo Depot Activity } \\ \text { RCRA } & \text { Resource Conservation and Recovery Act of 1976 } \\ \text { R\&D } & \text { research \& development } \\ \text { RMA } & \text { Rocky Mountain Arsenal } \\ \text { ROD } & \text { Record of Decision } \\ & \text { recreation visitor days } \\ \text { second } \\ \end{array}$




$\begin{array}{ll}\text { S } & \text { south } \\ \text { SAIC } & \text { Science Applications International Corporation } \\ \text { SE } & \text { southeast } \\ \text { SOP } & \text { Standing Operating Procedure } \\ \text { SP } & \text { state park } \\ \text { SSE } & \text { (1) south-southeast } \\ & \text { (2) safe-shutdown earthquake } \\ \text { SSW } & \text { south-southwest } \\ \text { SW } & \text { southwest } \\ \text { SWMA } & \text { state wildlife management areas } \\ \text { TC } & \text { toxic cubicle } \\ \text { TEAD } & \text { Tooele Army Depot } \\ \text { TSCA } & \text { Research and Development Toxic Substance Control Act } \\ \text { TWA } & \text { time weighted average } \\ \text { UAPB } & \text { University of Arkansas at Pine Bluff } \\ \text { UBC } & \text { Uniform Building Code } \\ \text { UMDA } & \text { Umatilla Depot Activity } \\ \text { VX } & \text { chemical nerve agent } \\ \text { W } & \text { west } \\ \text { WC } & \text { worst case } \\ \text { WMA } & \text { wildlife management areas } \\ \text { WNW } & \text { west-northwest } \\ \text { WSW } & \text { west-southwest }\end{array}$




\section{FOREWORD}

Under the Chemical Stockpile Disposal Program (CSDP), the U.S. Army proposes to dispose of lethal chemical agents and munitions stored at eight existing Army installations in the continental United States. In compliance with the National Environmental Policy Act (NEPA), the Army initiated a site-specific NEPA review of this proposed action at the Pine Bluff Arsenal (PBA), near Pine Bluff, Arkansas. The environmental compliance documentation was prepared in two phases.

In Phase I, the overall CSDP decision to dispose of PBA stockpile by an on-site reverse-assembly and incineration process was further considered, and its validity at PBA was reviewed with data that were newer and more detailed than those that provided the basis for the final programmatic environmental impact statement (FPEIS) (completed in January 1988) for the CSDP. A Phase I Environmental Report is prepared to present the findings of the Phase I review.

Thas: II [the preparation of a site-specific environmental impact statement (EIS)] focuses on the site-specific implementat on-site disposal at PBA. It should be emphasized that the Phase I Environmental Report was the starting point for the site-specific decision-making process, and it provided the environmental information by which the impacts of the proposed action could be assessed in the site-specific EIS.

A final Phase I Environmental Report for PBA was issued by the Army in May 1990 (Chemical Stockpile Disposal: Final Fhase I Environmental Report for Pine Bluff Arsenal, Pine Bluff, Arkansas, Program Executive Officer-Program Manager for Chemical Demilitarization, Aberdeen Proving Ground, Md.). The report concluded that the FPEIS environmentally preferred alternative (on-site disposal), which is also the Army's preferred alternative, is indeed valid for PBA. No new or unique site-specific information was found that would change or contradict the conclusions of the FPEIS with respect to PBA. The report recommended that preparation of the site-sperific EIS should proceed and should focus on implementation of on-site incineration and should not consider other alternatives for disposing of the PBA stockpile.

The PBA Phase I.report was independently reviewed by Argonne National Laboratory (ANL), and the review was summarized in a report (Chemical Stockpile Disposal Program: Review and Comment on the Phase I Environmental Report for the Pine Bluff Arsenal, Pine Bluff, Arkansas, ANL/EAIS/TM-34, Argonne, Ill., October 1990). Additional recommiendations for the content of the site-specific EIS were included in the ANL review. On November 28, 1990, the findings and conclusions of the PBA Phase I report and the independent ANL review were certified to Congress by Aisistant Secretary of the Army Susan Livingston. Preparation of the site-specific EIS for PBA was initiated following the Phase I certification.

This Oak Ridge National Laboratory Technical Memorandum consists of the May 1990 Final Phase I report. It was prepared to document the Phase I process for disposal of chemical agents and munitions stored at PBA. 


\section{EXECUTTVE SUMMARY}

The Pine Bluff Arsenai (PBA) near Pine Bluff, Arkansas, is one of eight continental United States (CONUS) Army installations where lethal unitary chemical agents ${ }^{\circ}$ and munitions are stored and where destruction of agents and munitions is proposed under the Chemical Stockpile Disposal Program (CSDP). The chemical agent inventory at PBA consists of approximately $12 \%$, by weight, of the total U.S. stockpile, including ton containers of $\mathrm{HD}$ and $\mathrm{HT}$ mustard agent, M55 rockets and ton containers of agent GB, and M55 rockets and M23 land mines containing agent VX. All of the agents or munitions at PBA were manufactured prior to 1968; currently about 20 munitions have been observed to be leaking. All items that have been verified as leaking have been containerized and placed in isolated storage. The destruction of the stockpile is necessary to eliminate the risk to the public from continued storage and to dispose of obsolete and leaking munitions.

In 1988 the U.S. Army issued a Final Programmatic Environmental Impact Statement (FPEIS) for the CSDP that identified on-site disposal of agents and munitions as the environmentally preferred alternative (i.e., the alternative with the least potential to cause significant adverse impacts). In some instances, the FPEIS included generic data and assumptions that were developed to allow a consistent comparison of potential impacts among programmatic aliernatives and did not include detailed conditions at each of the eight installations. The environmentally preferred alternative was identified using a method based on five measures of risk directed at potential human health as well as ecosystem and environmental effects; the adequacy of emergency response aiso played a key role in the selection process. In the Record of Decision following the FPEIS, on-site disposal was selected for implementation of the program.

The purpose of this report is to examine the proposed implementation of on-site disposal at PBA in light of more recent and more detailed data than those on which the FPEIS is based. Two principal issues are addressed: (1) whether or not the new data would result in rejection of on-site disposal at PBA as the environmentally preferred alternative (using the same selection method and data analysis tools as in the FPEIS), and (2) whether or not the new data indicate the presence of significant environmental resources that could be affected by on-site disposal at PBA. In addition, status reports

Unitary agents are so named because they alone can produce their desired hazardous effect on human health in their forn: as stored; they do not require mixing with another component to become hazardous (as is the case with binary chemical agents). 
are presented on maturity of the disposi)! technology (and how it could affect on-site disposal at $\mathrm{PBA}$ ) and on the effort in tracking changes in technology to ensure that the overall levels of risk of on-site disposal, as identified in the FPEIS for PBA, do not change in a manner that could revise the relative ranking of the various FPEIS alternatives. Confirmation of on-site dispcsal in Phase I allows the site-specific environmental impact statement (EIS) (addressing on-site disposal) to begin under Phase II.

More recent and more detailed site-specific data of the same types used in the FPEIS to identify the environmentally preferred alternative were gathered during the Phase I process. These new data were then examined and compared with the FPEIS data to determine if they have changed enough to warrant recomputation of the five measures of risk used to select the programmatic environmentally preferred alternative. Of all of the data types examined, only two were identified as having changed enough to warrant recomputation of risk: changes in residential population (caused primarily by population growth and a change in the location of the residents in relation to the disposal facility) and the selection of a most likely meteorological condition. Additionally, the disposal facility location has been more accurately presented in the Phase I Report. For the areas of meteorite/tornado frequency, seismicity, aircraft activity, and agent on-site transport distance, either new data were not identified during the Phase I process or, if located, were not sufficiently different from data used in the FPEIS risk assessment to warrant reevaluation of risk.

The new population data were used to compute fatalities using the same computation methods and values for all other parameters as in the FPEIS. The revised fatality estimates were then used to compute the five measures of risk for on-site disposal, continued storage, and on-site activities associated with off-site transport of the PBA stockpile. Results indicate that all alternatives are indistinguishable when the potential health impacts to the PBA community are considered. However, risks from on-site disposal are in all cases equal to or less than risks from other alternatives. If one adds the off-site transportation risks (not addressed in this document because they were addressed in the FPEIS), the on-site alternative is clearly preferable given the opportunity for risk reductions associated with emergency planning and preparedness activities that are underway at PBA. The conclusion is that on-site disposal remains valid as the environmentally preferred alternative for PBA. On-site disposal is at least equivalent to all other alternatives in terms of the potential for human health impacts.

During the Phase I process, data on resources that could be affected by on-site disposal at PBA were gathered to determine if any significant new or site-specific resources are present that could prevent or delay construction and operation of the onsite disposal facility (including incident-free operations and accident scenarios). The resources that were considered are population, meteorology and air quality, surface and groundwater, land use, ecology, socioeconomics, and aircraft activity. Some of these resources were examined in the FPEIS in assessing potential impacts of the programmatic alternatives, whereas others represent new information that was not appropriate for examination on the programmatic level. No assessment of potential impacts was performed during the Phase I process. Rather, the data were examined to help identify potential issues to be analyzed under Phase II. No unique resources with the potential to prevent or delay implementation of on-site disposal at PBA have been identified. However, the new data will add to the understanding of potential impacts in the sitespecific EIS. 
Technology status and maturity and technology risk assurance were also examined during the Phase I process, although neither factor was instrumental in reaching the conclusions for PBA identified in the previous paragraphs. Four principal technology developments have occurred since the publication of the FPEIS: (1) the disposal of nonlethal chemical agent by incineration at PBA, located near Pine Bluff, Arkansas; (2) construction and testing of facilities for disposal of lethal chemical agents stored at Johnston Atoll, located about $1300 \mathrm{~km}$ ( 800 miles) south of Hawaii in the Pacific Ocean; (3) disposal tests with lethal chemical agent at the Chemical Agent Munitions Disposal System pilot plant at Tooele Army Depot, Utah; and (4) equipment advances. The experience gained during the "proof-testing" of the CSDP disposal technology should be of value in the implementation of on-site disposal at PBA.

Efforts are also under way within the Army to identify and examine major changes to facility designs and operating procedures that have occurred since the FPEIS. These changes are being reviewed and evaluated to ensure that the relative ranking of alternatives as presented in the FPEIS risk pictograms for PBA will not change; hence, the phrase "risk assurance" has been applied to this effort. No currently proposed design changes have been found that result in increases above those levels of risk presented in the FPEIS for PBA. 


\section{PREFACE}

The U.S. Department of the Army proposes under the Chemical Stockpile Disposal Program (CSDP) to destroy the nation's total stockpile of lethal unitary chemical agents and munitions. The unitary chemical agents to be destroyed under the CSDP include nerve agents that directly affect the nervous system and blister agents that produce blisters on exposed tissue. Unitary agents are so named because they alone can produce their desired hazardous effect on human health in their form as stored; they do not require mixing with another component to become hazardous (as is the case with binary chemical agents). These agents are stored in munitions (e.g., rockets, land mines, mortars, cartridges, and projectiles) that in addition to agents contain various explosive components (e.g., fuses, propellants, and bursters). Agents are also stored in bulk steel one-ton containers, none of which contains any explosives.

The proposed action is being carried out in response to a congressional mandate in Title 14, Part B, Section 1412 of Pub. L. 99-145, the Department of Defense Authorization Act of 1986, which directs that the destruction of the agents and munitions be accomplished by September 30,1994, in conjunction with the acquisition of binary chemical weapons. In March 1988, the Army received from Congress an extension of the 1994 deadline to April 1997, under Pub. L. 100-456. Under emergency conditions or if there is a significant delay in the acquisition of an adequate number of binary chemical weapons to meet the requirements of the Armed Forces, Pub. L. 99-145 allows the Secretary of Defense to defer, beyond April 1997, the destruction of not more than 10\% ("useful 10\%") of the existing unitary stockpile. In April 1990 the Army officially requested a 20-month extension of the April 1997 completion date.

Congress has directed the Army to accomplish the proposed destruction in a manner that provides (1) maximum protection of the environment, the general public, and the personnel involved in the destruction process; (2) adequate and safe facilities designed solely for the destruction of the lethal chemical stockpile; and (3) cleanup, dismantling, and disposal of the facilities when the disposal program is complete.

The existing unitary chemical munitions are stored at eight U.S. Army installations located in the continental United States: Aberdeen Proving Ground (APG), near Edgewood, Maryland; Anniston Army Depot (ANAD), near Anniston, Alabama; Lexington-Blue Grass Army Depot (LBAD), near Lexington, Kentucky; Newport Army Ammunition Plant, near Newport, Indiana; Pine Bluff Arsenal, near Pine Bluff, Arkansas; Pueblo Depot Activity, near Pueblo, Colorado; Tooele Army Depot, near Tooele, Utah; and Umatilla Depot Activity, near Hermiston, Oregon. None of the agents or munitions currently in storage has been manufactured since 1968, and 
although some of them are "like new," others are in various stages of deterioration (about 20 items at PBA have developed leaks). All items that have been verified as leaking have been containerized and placed in isolated storage.

At each of the eight sites, the Army proposes to remove the agents and munitions from existing storage, transport them to a proposed on-site disposal facility, disassemble them, and incinerate the agents and explosive components while thermally decontaminating the metal munition bodies and bulk containers. No stockpiled agents or munitions are proposed to be transported to other storage installations or sites for destruction. Incineration, the selected disposal technology, has been endorsed by the National Research Council as the safest means of destroying these lethal chemical agents. For the purpose of this Phase I report, "on-site disposal facility" refers to the incinerators and all associated structures and equipment for storing, handling, and processing the munitions and agents.

A federal program such as the CSDP requires a National Environmental Policy Act of 1969 (NEPA) review to ensure that environmental factors are given adequate consideration early in the decision-making process. For the CSDP, a NEPA review strategy has been structured to address two levels of decision making: (1) the programmatic level and (2) the site-specific level.

Implementation of this NEPA review strategy for the CSDP began in January 1986 with initiation of the programmatic environmental impact statement (EIS). In January 1988, the Army issued the final programmatic EIS (FPEIS). The FPEIS discussed five alternatives: four for destroying the stockpile and the no action alternative [required by regulations implementing NEPA (40 CFR Pt. 1500-1508)]. The five alternatives are as follows:

1. continued storage of the stocks at their present locations (the no action alternative);

2. On-site destruction of the stocks at their present storage locations;

3. relocation of the stocks to regional disposal centers at ANAD and TEAD for destruction;

4. relocation of the stocks to a national disposal center at TEAD for destruction; and

5. relocation of the inventories at some sites to alternate sites, with the remainder destroyed at their present storage locations (this alternative includes air movement of the APG and LBAD inventories to TEAD for destruction).

The FPEIS identified on-site disposal as the environmentally preferred alternative (i.e., the alternative with the least potential for significant adverse impacts). In addition, the Army's Record of Decision (ROD) for the FPEIS selected on-site disposal for implementation. The ROD stated that environmental impacts, including the hazards and risk analyses presented in the FPEIS, were a contributing but not the determining factor in the decision. Other factors considered included the feasibility and effectiveness of emergency response measures, vulnerability to terrorism and sabotage, and logistical complexity. 
On-site disposal, having been selected for implementation, will require that the Army prepare eight site-specific NEPA-compliance documents for each installation to assist with the site-level decision making. The programmatic ROD stated that the sitespecific NEPA documents would focus on the implementation of the programmatic decision at a given site and on specific issues and concerns related to imfiementation at a given site. 


\begin{abstract}
ARSTRACT
The Pine Bluff Arsenal (PBA) near Pine Bluff, Arkansas, is one of eight continental United States (CONUS) Army installations where lethal unitary chemical agents" and munitions are stored and where destruction of agents and munitions is proposed under the Chemical Stockpile Disposal Program (CSDP). The chemical agent inventory at PBA consists of approximately $12 \%$, by weight, of the total U.S. stockpile. The destruction of the stockpile is necessary to eliminate the risk to the public from continued storage and to dispose of obsolete and leaking munitions.

In 1988 the U.S. Army issued a Final Programmatic Environmental Impact Statement (FPEIS) for the CSDP that identified on-site disposal of agents and munitions as the environmentally preferred alternative (i.e., the alternative with the least potential to cause significant adverse impacts). The purpose of this report is to examine the proposed implementation of on-site disposal at PBA in light of more recent and more detailed data than those on which the FPEIS is based.

New population data were used to compute fatalities using the same computation methods and values for all other parameters as in the FPEIS. Results indicate that all alternatives are indistinguishable when the potential health impacts to the PBA community are considered. However, risks from on-site disposal are in all cases equal to or less than risks from other alternatives. Furthermore, no unique resources with the potential to prevent or delay implementation of on-site disposal at PBA have been identified.
\end{abstract}

\footnotetext{
Unitary agents are so named because they alone can produce their desired hazardous effect on human health in their form as stored; they do not require mixing with anothe: component to become hazardous (as is the case with binary chemical agents).
} 


\section{INTRODUCTION}

\subsection{BACKGROUND}

This Phase I Environmental Report has been prepared by the U.S. Department of the Army to assist in the development of site-specific National Environmental Policy Act of 1969 (NEPA) (Pub. L. 91-190) compliance documentation for disposal of the lethal unitary chemical agents and munitions stored at the Pine Bluff Arsenal (PBA) located near Pine Bluff, Arkansas. PBA is one of the eight U.S. Army installations where on-site disposal of agents and munitions is proposed under the Chemical Stockpile Disposal Program (CSDP). Following the issuance of the Record of Decision (U.S. Army 1988a) for the CSDP Final Programmatic Environmental Impact Statement (FPEIS) in February 1988 (U.S. Army 1988b), the Army began site-specific NEPA reviews for the installations involved in the CSDP. The U.S. Department of the Army proposes under the CSDP to destroy the nation's stockpile of lethal unitary chemical agents (nerve and blister) and munitions.

The Army has developed a two-phase process for conducting the site-specific NEPA studies. In Phase I, the programmatic decision of on-site disposal is to be given further consideration by a review of its validity at each storage installation using more detailed and more recent data than those used in the FPEIS. Phase II (the preparation of an EIS) is to address potential impacts from site-specific implementation (plant construction and operation) of on-site disposal.

The site-specific NEPA reviews for the CSDP began with Tooele Army Depot (TEAD) (U.S. Army 1988c; Argonne National Laboratory 1989). The process has continued with Anniston Army Depot (ANAD) (U.S. Army 1989), Umatilla Depot Activity (U.S. Army 1990), and with this report for PBA. This Phase I Environmental Report is the starting point for the site-specific decision-making process at PBA, and it provides the environmental information by which the site-specific impacts of the proposed action are to be assessed in Phase II.

\subsection{PINE BLUFF ARSENAL}

PBA is located in Jefferson County, Arkansas, $48 \mathrm{~km}$ (30 miles) southeast of Little Rock and $13 \mathrm{~km}$ (8 miles) northwest of Pine Bluff (Fig. 1). The PBA reservation covers $6052 \mathrm{ha}\left(14,956\right.$ acres; 23 miles $\left.^{2}\right)$ on a tract of government-owned land $18 \mathrm{~km}$ (11 miles) long and $5 \mathrm{~km}$ ( 3 miles) wide; of this area, 82 ha (203 acres) is improved grounds, 789 ha (1,949 acres) is semi-improved, 750 ha (1,854 acres) is unimproved, and 

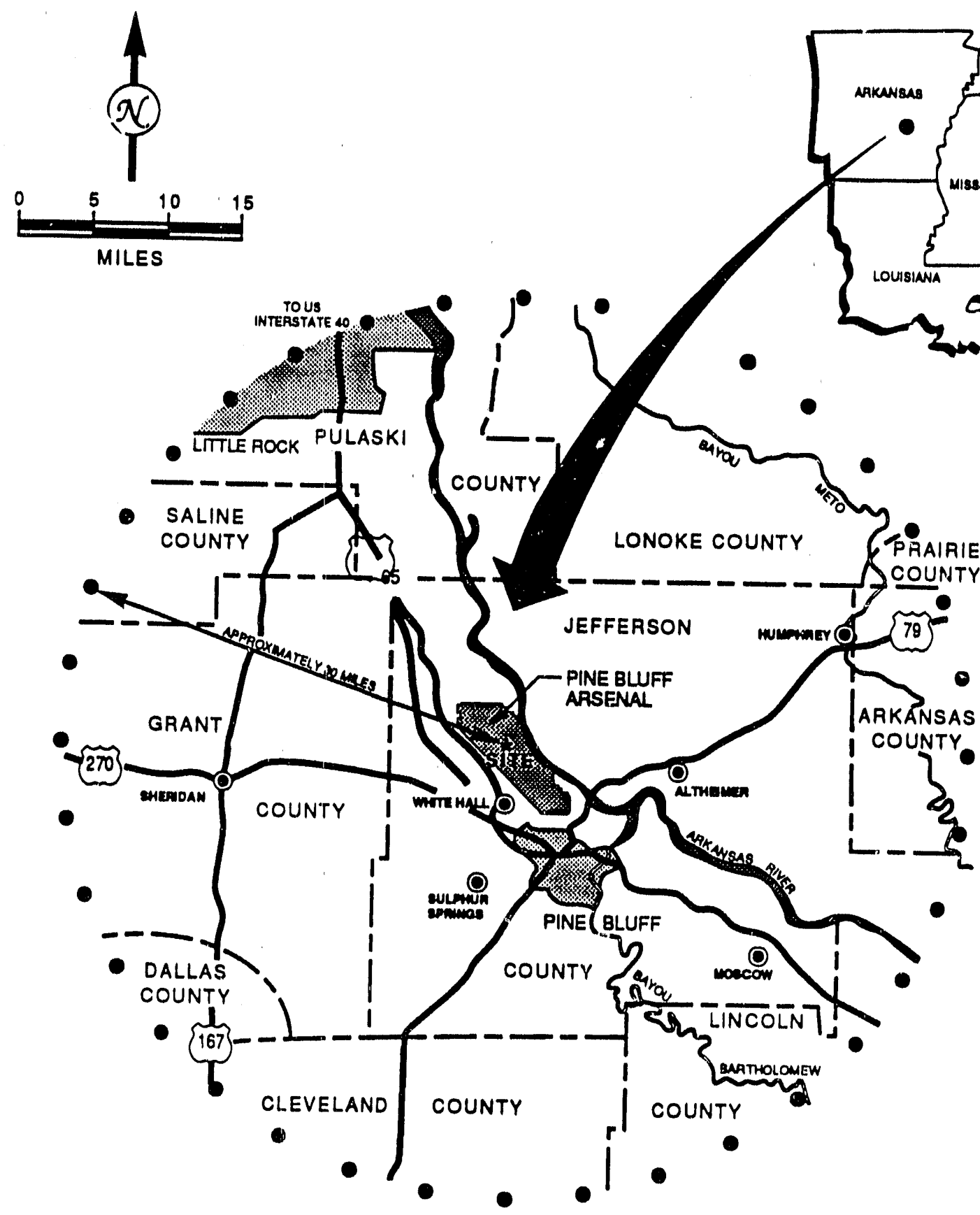

Source: U.S.A. Chemical Research Development and Engineering Conter, Programmatic Environmental Impact Statement, Binary Chemical Munitions Program, Docomber 1981.

Fig. 1. Map of the vicinity of the Pine Bluff Arsenal, Jefferson County, Arkansas. 
4,431 ha (10,950 acres) is managed for forest products under an active timber management program. A 202-ha (500-acre) site at PBA is under the control of the U.S. Food and Drug Administration and is operated as the National Center for Toxicological Research.

The northern boundary of PBA is adjacent to privately owned farms and timberland; the southern boundary adjoins undeveloped industrial property and Mid-America Packaging. The western boundary is adjacent to the Missouri-Pacific Railroad right-of-way, and the eastern boundary runs generally along the Arkansas River (Fig. 2). The PBA chemical stockpile is stored in the northern part of the facility in a chemical storage area with 86 igloos (earth-covered, reinforced-concrete bunkers). Ton containers of the mustard blister agent are stored in an open area.

PBA's principal missions reflect its position as the production arm of the Chemical Research, Development and Engineering Center. Project efforts are focused on (1) manufacturing technology to improve product and process, to modernize technologies, and to enhance production methods; (2) munitions production; (3) mobilization readiness by maintaining production lines and planning for support of current and mobilization requirements; (4) testing of PBA-produced munitions, testing of canister and filters used in protective masles, and certification of chemical defensive test equipment and operators; (5) storage, demilitarization, and maintenance activities such as shipping and receiving, maintaining and rebuilciing protective masks, demilitarizing nonlethal chemical material, and managing the chemical stockpile; and, most recently, (6) chemical munitions disposal. Munitions currently produced at PBA include smoke munitions, white phosphorous projectiles, and other incendiary projectiles.

A production base for binary munitions, the Integrated Binary Production Facility, is being constructed at PBA. Several plants are under construction that will perform fill and close operations for several types of munitions. The facilities are in various stages of readiness, ranging from complete and available for operation, to still under design. Continued development will be affected by ongoing negotiations related to weapons limitation treaties.

The chemical agent inventory at PBA consists of approximately $12 \%$, by weight, of the total U.S. stockpile including ton containers of HD and HT mustard agent, M55 rockets and ton containers of agent GB, and M55 rockets and M23 land mines containing agent VX. All of the agents and munitions of the types stored at PBA were manufactured prior to 1968 , and a few have deteriorated to the point of leaking. All items verified as leaking have been containerized and placed in isolated storage. The destruction of the stockpile is necessary to eliminate the risk to the public from continued storage of the agents and munitions.

The proposed disposal facility at PBA is planned to be constructed adjacent to the BZ disposal facility (Fig. 3) that was constructed to incinerate chemical-warfare agent BZ (a nonlethal but incapacitating agent), BZ-filled munitions, and BZ-contaminated residues. Under the proposed action new construction would take place on the north and east sides of the existing facility, and would provide for the use of certain BZ support facilities by the proposed disposal plant. 


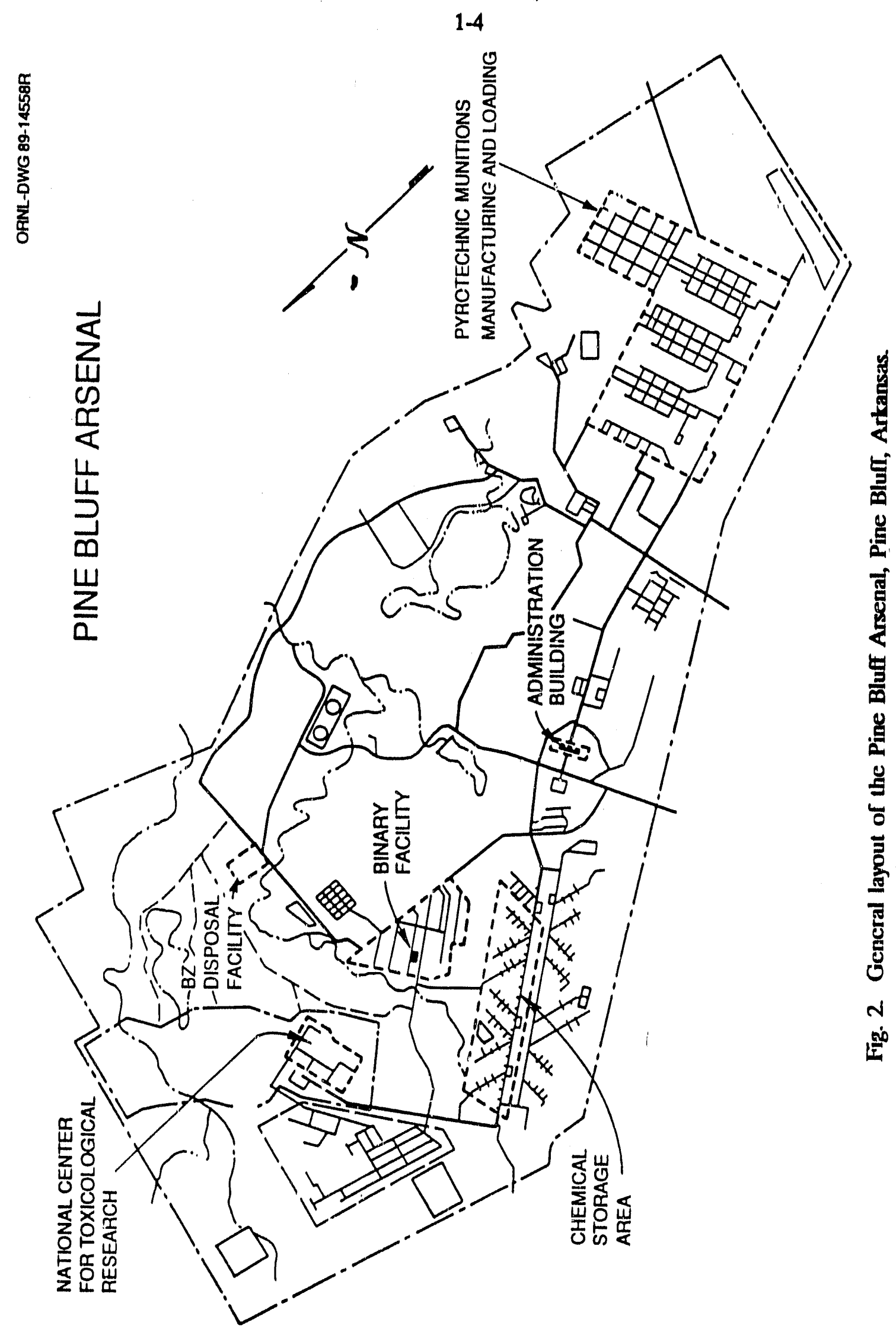




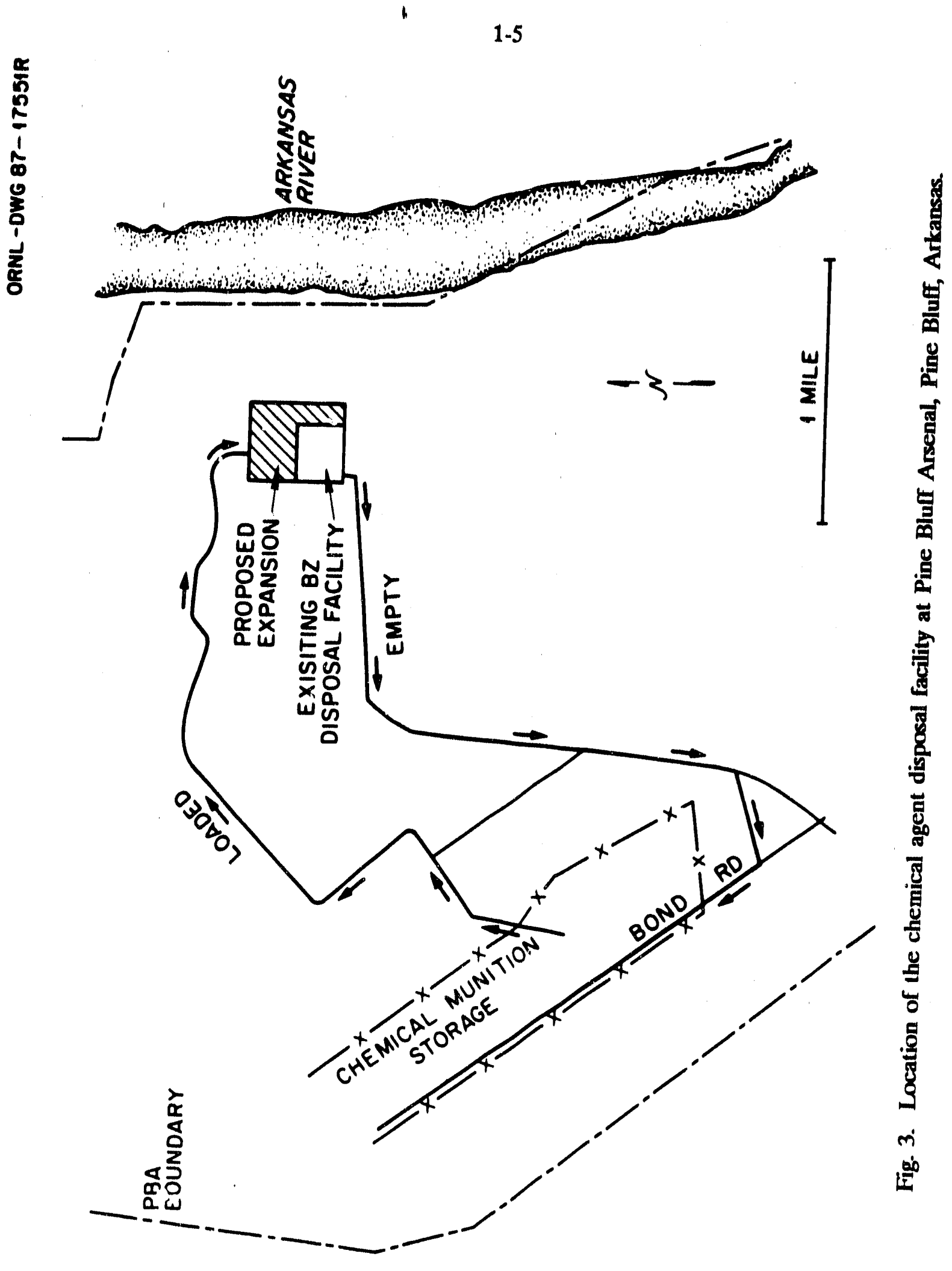




\subsection{OBJECTIVES AND SCOPE}

To reasonably and objectively compare the various programmatic alternatives, the FPEIS employed some generic assumptions and inputs such as process and handling descriptions, on-site transport characteristics (such as transport distances and road conditions), and certain meteorological data. Other assumptions and inputs were more site-specific, as appropriate, to allow a reasonable comparison of alternatives. For example, the actual chemical munitions inventory, as well as the residential population, at each site were incorporated into the FPEIS accident analysis.

The purpose of this report is to examine the proposed implementation of on-site disposal at PBA in light of more recent and more detailed data than those on which the FPEIS is based. Two principal issues are addressed: (1) whether or not the new data would result in the rejection of on-site disposal at PBA as the environmentally preferred alternative (using the same methods and data analysis tools as in the FPEIS), and (2) whether or not the new data indicate the presence of significant environmental resources that could be affected by implementation of on-site disposal at PBA. For the first issue, the data are confined to those used to identify the environmentally preferred alternative. To address the second issue, existing data on all environmental resources that could be potentially affected by on-site disposal at PBA are examined and summarized. In addition, status reports are also presented on the technical progress and maturity of the disposal technology (and how it could affect on-site disposal at PBA) and on the tracking of changes in plant design and operating procedures. A risk assurance study is under way that examines the ramifications of major design changes on risk.

This Phase I Environmental Report is not intended to validate the Army's programmatic ROD for the CSDP; it can only confirm or reject the environmentally preferred alternative (on-site disposal) as identified in the FPEIS for PBA. Data gathered during Phase I include (1) any new information that was not available for use in the FPEIS, (2) more detailed information than was required for the programmatic purpose of comparing alternatives in the FPEIS, and (3) any information that may have been overlooked in the FPEIS.

In light of the first issue to be addressed in Phase I, the scope of this Phase I Environmental Report is limited to reexamining the FPEIS environmentally preferred alternative (i.e., on-site disposal) in light of more recent and detailed data. The scope of the reexamination is limited to on-site activities associated with the PBA stockpile: continued storage, on-site disposal, or any packaging, on-site movement, and temporary storage associated with off-site disposal. This report does not address potential risks or impacts from possible actions taken outside the installation boundary (e.g., transportation from one installation to another, unloading at the receiving installation, etc.). However, on-site activities associated with the regional disposal alternative are considered in the reexamination and comparison of risks among alternatives at PBA. Technological and procedural characteristics used to reexamine the environmentally preferred alternative in the Phase I Report are the same as those given in the FPEIS (U.S. Army 1988a, Vol. 1, 
Sect. 2 and Appendices A, C, and G) and in support studies referenced in the FPEIS. In terms of the second major issue to be addressed in Phase I, the scope is limited to potential resources that could be affected by on-site disposal at PBA.

The potential impact region addressed by this document is limited to the area within $100 \mathrm{~km}$ (62 miles) of the site of the proposed disposal facility at PBA (Fig. 4). This area [which is also referred to as the 100-km (62-mile) zone] is the largest credible zone of potential human health impacts as identified in the FPEIS. At PBA, the continued storage alternative was postulated in the FPEIS to result in potential human fatalities to a distance of $100 \mathrm{~km}$ (62 miles). In fact this radius would apply to all alternatives because each would require storage until completion. However, for the purposes of analysis and comparison of the risks of the various alternatives, the incremental risks of each alternative are used here.

The on-site disposal alternative at PBA was estimated in the FPEIS to result in human fatalities to a distance of $50 \mathrm{~km}$ ( $31 \mathrm{miles})$, and the regional and national disposal alternatives were postulated to result in human fatalities to a distance of $100+\mathrm{km}$. The latter were classified as such because they have the potential to travel beyond $100 \mathrm{~km}$ based on the amount of agent released. However, it is virtually impossible that meteorological conditions would allow it.

Thus, different impact zones are applicable to different alternatives. Also, in the FPEIS, information on some of the resources was collected for zones of different sizes [e.g., socioeconomic information was collected for the 10-km (6.2-mile) zone]. This Phase I report addresses resource information to the minimum distance applicable for the alternatives under consideration. Some resources are described for larger regions as appropriate (e.g., ecological impacts do not necessarily coincide with the zone for human fatalities; economic impacts are more appropriately described on a multi-county or regional basis).

Section 2 describes the approach taken to reassess the programmatic data for PBA. It defines and outlines the framework under which the reexamination of FPEIS data is to be performed. The section also provides an overview of the method employed in the FPEIS to arrive at the selection of an environmentally preferred alternative (more detail is given in Appendix A).

Section 3 presents and compares the newly collected site-specific information and data for PBA. Data are organized according to those affecting the programmatic selection process for identifying the environmentally preferred alternative (Sect. 3.1) and those relevant to site-specific implementation (Sect. 3.2). Section 3.3 addresses technological considerations such as maturity of the incineration process, and Sect. 3.4 discusses technology tracking and risk assurance.

A summary of Phase I findings is given in Sect. 4, along with conclusions regarding preparation of the site-specific EIS for PBA. 


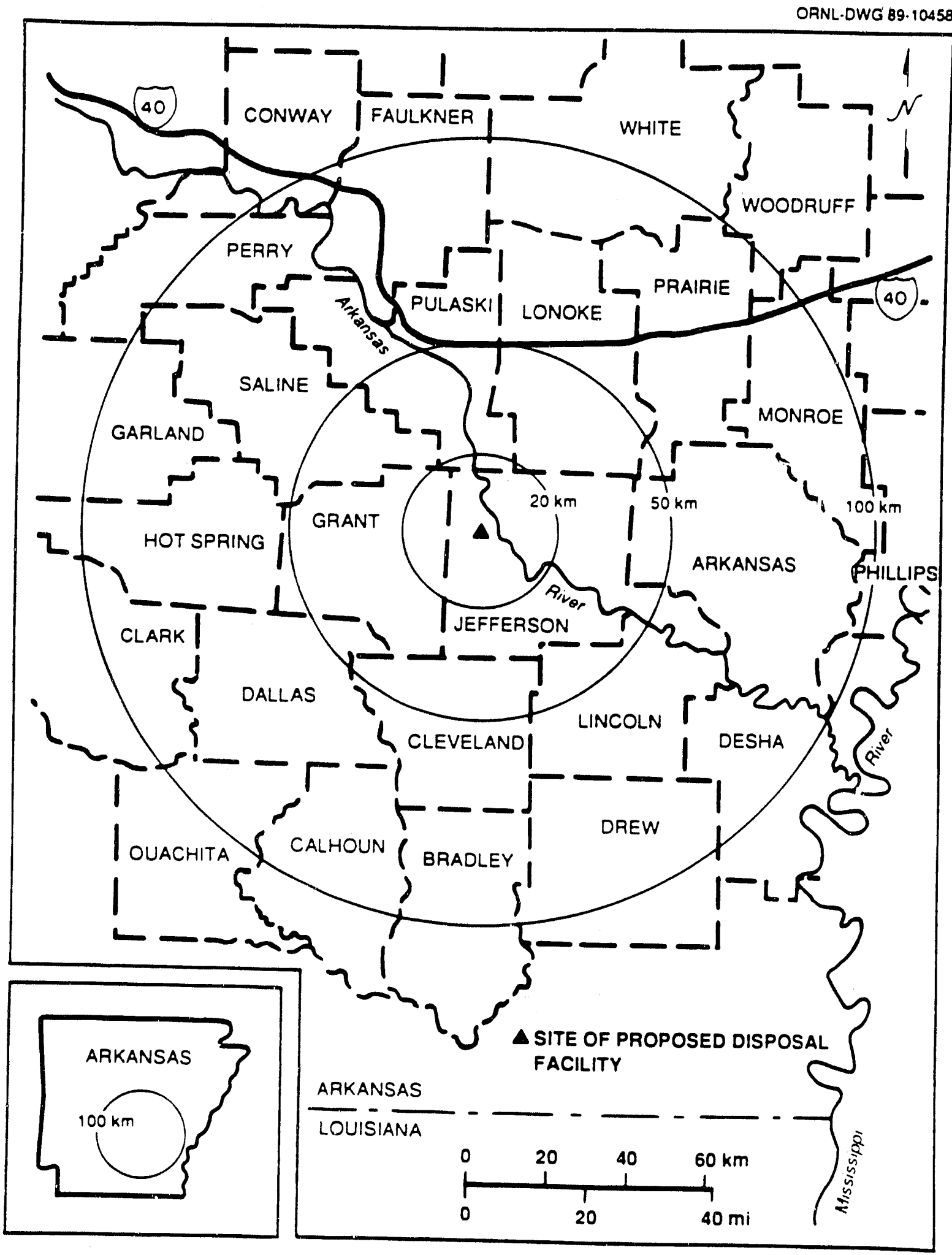

Fig. 4. Potential impact region of Pine Bluff Arsenal, Pine Bluff, Arkansas. 


\subsection{REFERENCES}

Argonne National Laboratory 1989. Chemical Stockpile Disposal Program: Review and Comment on the Phase I Environmental Report for the Tooele Army Depot, Tooele, Utah, ANL/EES-TM-359 Argonne, Ill., January.

U.S. Army 1988a. Chemical Stockpile Disposal Program Final Programmatic Environmental Impact Statement, Vols. 1, 2, and 3, Program Executive Officer-Program Manager for Chemical Demilitarization, Aberdeen Proving Ground, Md., January.

U.S. Army 1988b. Record of Decision for the Chemical Stockpile Disposal Program, Office of the Under Secretary of the Army, Feb. 23.

U.S. Army 1988c. Chemical Stockpile Disposal Program-Final Phase I Environmental Report for Tooele Army Depot, Tooele, Utah, Program Executive Officer-Program Manager for Chemical Demilitarization, Aberdeen Proving Ground, Md., September.

U.S. Army 1989. Disposal of Chemical Agents and Munitions Stored at Anniston Army Depot, Anniston, Alabama -Final Phase I Environmental Report, Office of the Program Manager for Chemical Demilitarization, Aberdeen Proving Ground, Md., July.

U.S. Army 1990. Disposal of Chemical Agents and Munitions Stored at Umatilla Depot Activity, Hermiston, Oregon-Final Phase I Environmental Report, Office of the Program Manager for Chemical Demilitarization, Aberdeen Proving Ground, Md., February. 


\section{APPROACH}

This section of the report provides a general discussion of the process used to identify the environmentally preferred programmatic alternative in the FPEIS (U.S. Army 1988), and the types of data, assumptions, and information that were used. This then provides a basis for a conceptual overview of the Phase I Environmental Report. The approach used to gather data and information during the Phase I process for PBA is also discussed.

\section{IDENTIFYING THE PROGRAMMATIC ENVIRONMENTALLY PREFERRED ALTERNATTVE}

During preparatio of the FPEIS, a method was developed to systematically compare programmatic alt. natives to identify an environmentally preferred alternative. Alternatives are compared with respect to potential impacts from implementing the alternatives under normal operations and accident scenarios.

The FPEIS concluded that potential impacts from normal operations would be minimal and mitigable and would not be significant in distinguishing among program alternatives. Consequently, potential effects from accident scenarios figured prominently in identifying the environmentally preferred alternative. The method consists of sequential examination and comparison of factors reflecting the programmatic goals of no fatalities and minimal environmental insult. The comparison involved three consecutive tiers of examination for each programmatic alternative: (1) human health impacts, (2) ecosystem and environmental impacts, and (3) feasibility and potential effectiveness of emergency planning and preparedness. Appendix A presents details on how the method was developed and used in the FPEIS. Figure 5 provides an overview of how the method was used to identify on-site disposal as the programmatic environmentally preferred alternative (i.e., the alternative with the least potential for causing significant adverse impacts). alternatives:

For the first two tiers, five measures of risk were developed to compare

- Probability of one or more fatalities is the sum of probabilities for only those credible accidents (i.e., accidents with a probability of occurrence greater than one chance in $100,000,000)$ that could result in one or more fatalities under conservative most likely meteorological conditions. (See Appendix A for description of these conditions.) 
ALL PROGRAMMATIC ALTERNATIVES:

CONTINUED STORAGE, ON-SITE DISPOSAL.

PARTIAL RELOCATION, REGIONAL DISPOSAL, AND NATIONAL DISPOSAL
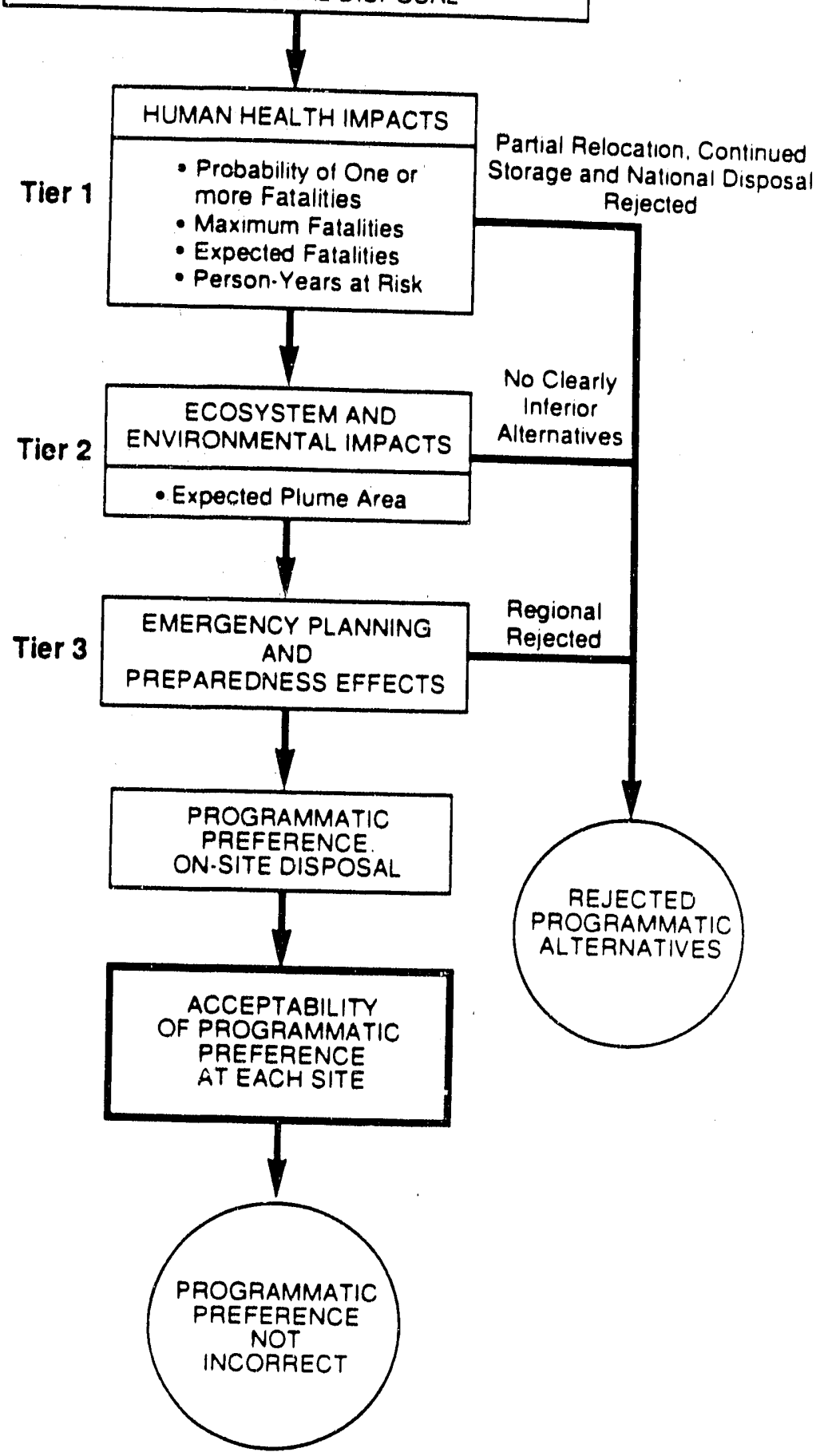

Fig. 5. Flowchart illustrating selection of the Chemical Stockpile Disposal Program environmentally preferred alternative. 
- Maximum number of fatalities is the largest number of potential fatalities from accidental releases of chemical agent. It is the consequence of that single credible accident having the greatest lethal downwind distance and one in which the wind is directed toward the area of maximum population under worst-case meteorological conditions (see Appendix A for description).

- Expected fatalities are computed as the sum of the produrts of probabilities and consequences (potential fatalities) for all credible accidents under conservative most likely meteorological conditions.

- Person years at risk are computed as the product of the number of people near a site at risk from that credible accident with the greatest downwind distance and the length of time during which that accident could occur.

- Expected plume area is computed as the sum of the products of plume areas and associated probabilities for all credible accidents under conservative most likely meteorological conditions.

Figure 6 presents a simplified generalization of the types of data used to formulate the five measures of risk. The risk measures can be thought of comprising two types of data: residential population and accident probabilities/agent release quantities (the risk measure "expected plume area" is the only one of the five that does not reflect population estimates and is represented solely by the physical characteristics of the accident data base). Within the population data category, the number of people and their location are of primary interest. Within the accident category, two types of data are of interest: internal and external. Internal data are the technology factors affecting the accident probabilities and agent release quantities: the types of equipment in the technology, the procedures by which the technology is used, and the transportation of agents and munitions on-site. These are termed "internal" data because they are internal to the Army-that is, the Army can control these through design changes, procedure changes, or location changes of the proposed disposal facility (or railhead loading facility in the case of national disposal). External data, those over which the Army has little (if any) control, are meteorological factors; the amount of aircraft activity (which can be controlled over an installation through the use of prohibited airspace but which cannot be controlled outside this airspace); the frequency and intensity of earthquakes (seismicity); and the frequency of meteorite strikes. The assumptions and information used for the external data are described in more detail in Appendix A, as are the mathematical processes used to analyze the data for the computation of measures of risk.

Of the five risk measures discussed above, the first four were used for the health effects tier, and the fifth risk measure was used for the ecosystem/environment tier. No risk measures were deemed necessary for the third tier, which dealt primarily with the adequacy of emergency planning and preparedness. The FPEIS method thus consisted of comparing a particular risk measure for a given alternative with the same risk measures for the other alternatives. To avoid presenting classified data on the stockpile at any particular site, the exact numbers calculated for these risk measures were not 


\section{$2-4$}

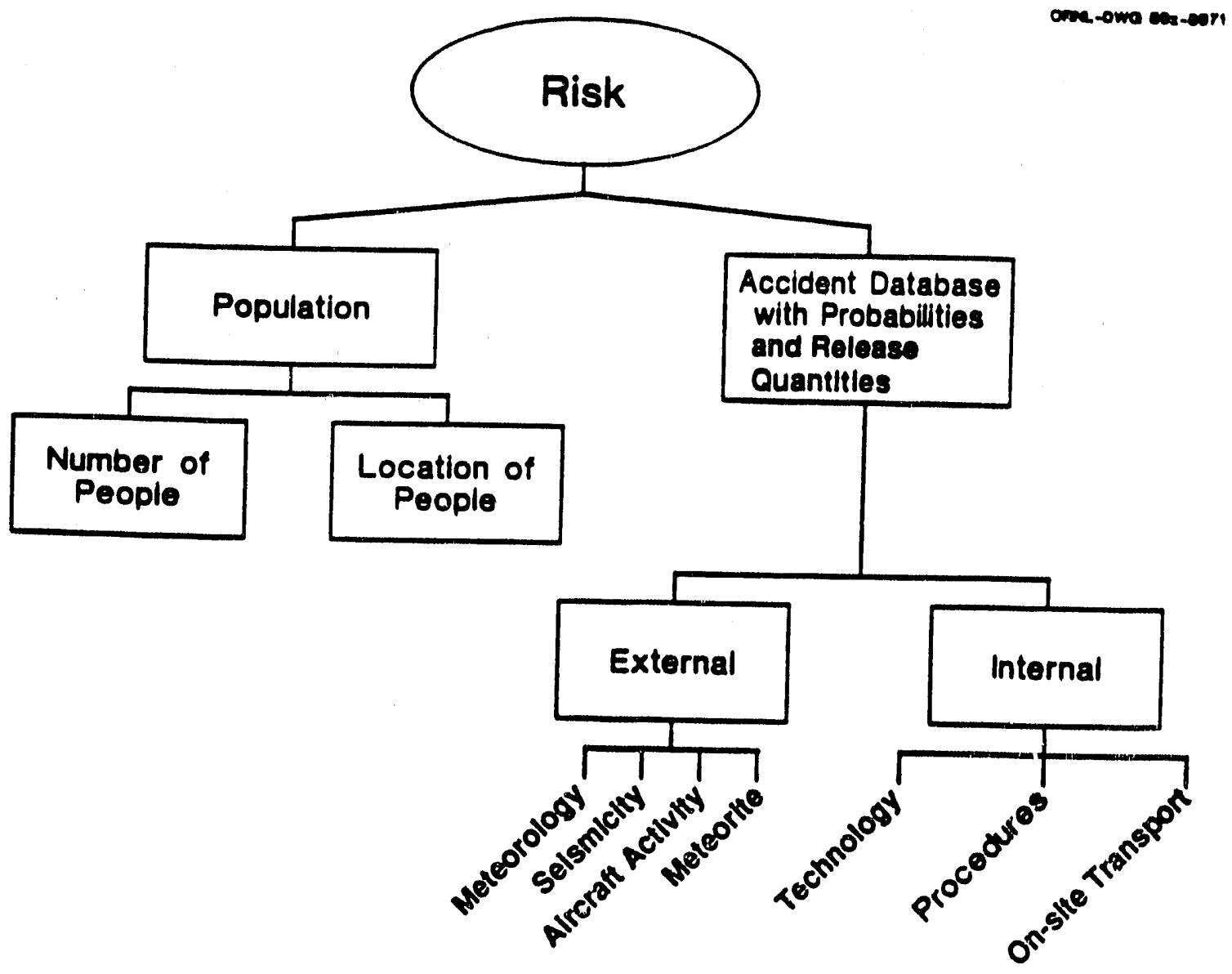

Fig. 6. Conceptual overview of data types used in selecting the programmatic environmentally preferred alternative. 
used on a site-by-site basis. Site-specific numbers were translated into shading patterns in the form of pictograms (Appendix A).

Because of the uncertainty in the computational value of each measure or risk, it was determined that if the numerical values of risks between alternatives were different by at least a factor of ten, then this would represent a "significant difference." Because the pictogram shading patterns were developed to avoid disclosing classified information, a difference of at least two pictogram shading patterns (such as the difference between the single-diagonal shading and the all-black shading) was thus used as the FPEIS criterion against which a "significance difference" could be determined. If a one-shading difference had been used as the criterion, then the pictograms could not be used to guarantee the factor of ten difference, because the numerical range assigned to each pictogram shading pattern spanned a factor of ten from its lower limit to its upper one. Accepting or rejecting alternatives at a given tier was therefore based upon the fact that a difference between risk measures of at least two pictogram shading patterns represented a "significant difference."

As shown in Fig. 4, all five programmatic alternatives were examined at the first tier (human health) of the process using the first four measures of risk. The FPEIS rejected partial relocation by air, continued storage, and national disposal based on the first four risk measures, leaving regional disposal and on-site disposal for consideration in the second tier. Examining the regional and on-site disposal alternatives in light of ecosystem and environmental impacts did not distinguish between alternatives.

In the third tier (emergency planning and preparedness), regional disposal was rejected because of the greater difficulties in providing adequate emergency response along transportation corridors vs. on-site. On-site disposal thus survived the three tiers to become the preferred alternative.

The FPEIS went one step further and examined the preferred alternative, using the above process and programmatic-level data for each site, to show that the risks from on-site disposal were no greater than the risks from the other alternatives considered. Note that the method for identifying the environmentally preferred alternative was never used to identify on-site disposal at a given installation. Rather it was used to identify a programmatic alternative and then show that the identified alternative was not incorrect for any given installation. This completed the impact analysis that served as input into the decision process for identifying on-site disposal as the programmatic environmentally preferred alternative.

\section{PHASE I CONCEPTUAL FRAMEWORK}

Figure 7 presents an overview of the Phase I process. The figure is directed at the use of the Phase I to reexamine the environmentally preferred alternative. The second function of Phase I-examining site-specific resources-is not unique to the Phase I/Phase II process and thus is not highlighted in the figure. In the first step, the data, information, and assumptions used to identify the environmentally preferred 


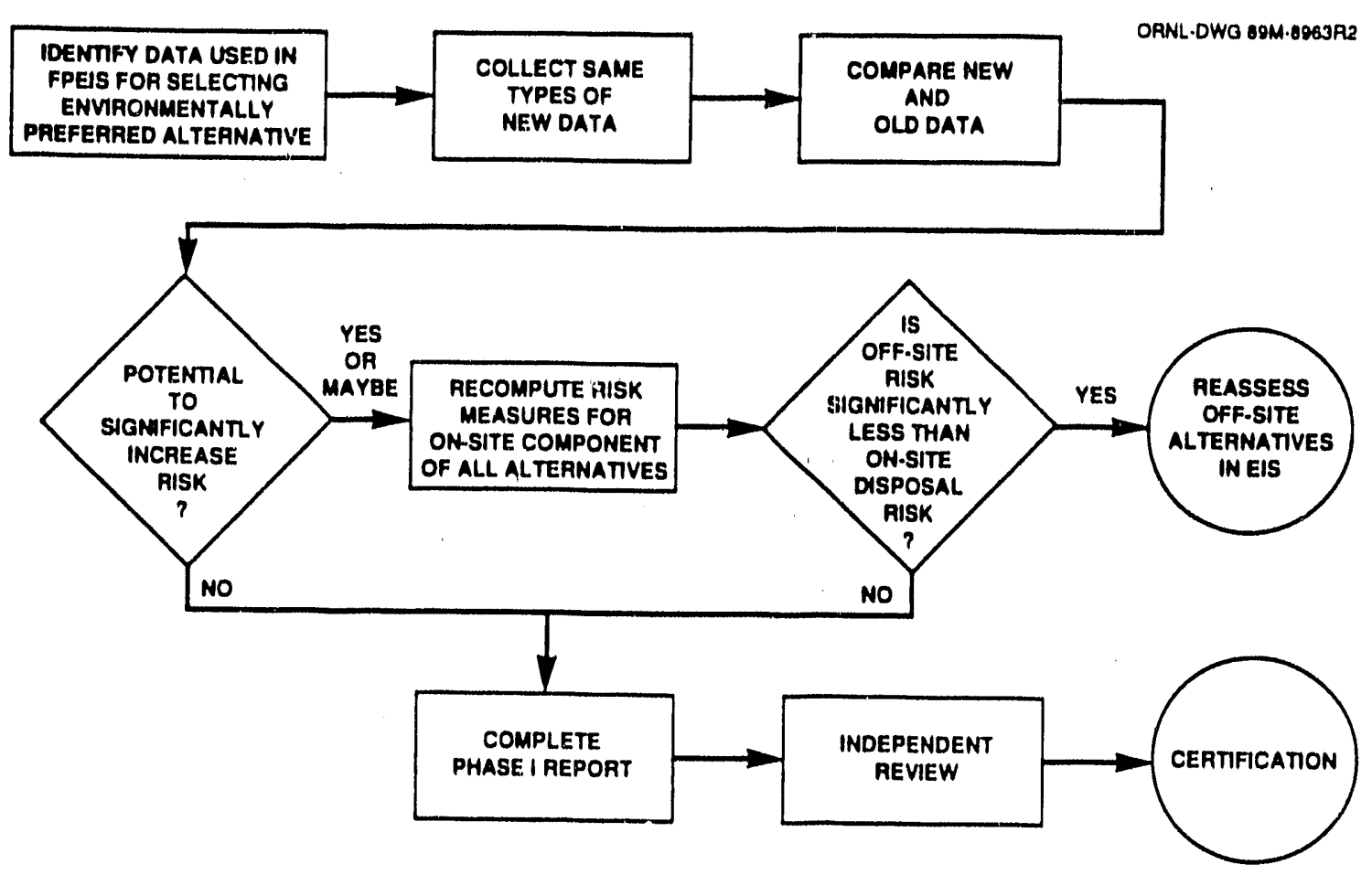

Fig. 7. Flowchart illustrating the Phase I concept. 
alternative are identified (see Sect. 2.1). More recent and site-specific data in these areas are then gathered (from scoping meetings, installation visits, contacts with agencies, and other sources) and examined to determine if any changes have occurred that warrant repeating the process for identifying the environmentally preferred alternative. This type of screening function is done to avoid the complex task of recomputing measures of risk "from the ground up" using every piece of new information. The changes in data that show no potential to significantly change risk for one alternative over another are merely mentioned in the Phase I report. For example, if a given risk measure significantly increases for on-site disposal without increasing the same for the other alternatives, then the programmatic results (that risks from on-site disposal are no greater than those for other alternatives considered) could be changed, thereby triggering reevaluation of offsite alternatives with more recent and detailed data. Thus, major changes in the data are not the sole criterion for recomputing risk measures; the data must also demonstrate a potential to affect one alternative more than the others.

New data judged to have significant potential to increase risk or judged to have an uncertain effect on risk are fed into the risk computation. The new data are used to compute the five measures of risk for each applicable alternative (continued storage, onsite disposal, and on-site activities associated with off-site disposal). Those risks are incorporated into the FPEIS method for identifying the environmentally preferred alternative. The results are examined to determine if risk from off-site disposal is significantly less than risk from on-site disposal. If the answer is no, the Phase I report is completed and the Phase I process is certified (thereby allowing preparation of the site-specific EIS). If the answer is yes, then an EIS with a different scope is begun-one that addresses continued storage, on-site disposal, and off-site transportation and disposal at another installation as alternatives.

The use of the FPEIS method is expected to differ slightly in the Phase I report from that in the FPEIS. In the FPEIS, emergency planning and preparedness played an important role in identifying the environmentally preferred alternative, as shown in Fig. 4. For the scope of this Phase I report, which is directed at distinguishing among disposal alternatives with respect to the population near PBA, emergency planning will not be an important factor because the Army has begun enhancements of emergency planning and preparedness for PBA and vicinity (as well as for the other seven installations). Because the population near PBA will benefit from the effort to enhance emergency planning and preparedness regardless of the alternative under consideration, emergency planning has limited, if any, potential to affect the identification of the environmentally preferred alternative. For the population along a transportation corridor to an off-site disposal location, the planned enhancements to local emergency preparedness would provide no benefit. For these reasons, the reexamination of the environmentally preferred alternative in this Phase I report is based primarily on the five measures of risk and the first two tiers of the selection method.

As discussed in Sect. 2.1, the risk measures can be thought of as comprising two principal types of data: internal and external. The internal data in the accident database can change as the Army revises procedures and modifies the technology of the disposal 
process. However, a risk assurance study is under way (see Sect. 3.4) that examines the ramifications of design changes on risk and makes modifications if the FPEIS risk ceiling is expected to be exceeded. Thus the risk assurance study is performing the function of Phase I with a slightly different approach-instead of assessing the risk ramifications of changes, it is ensuring that changes resulting in risk above a celling do not occur. Thus, data on technology and procedures are not examined in this Phase I report. The Phase I approach can thus be considered as conservative in that allowances are not made for technology changes that have been made to enhance public safety. On-site transport is examined in this Phase I Environmental Report because it is concerned with factors that can change due to the characteristics of each installation and its associated stockpile (even though they are still factors over which the Army has control). Primary factors associated with on-site transport are the conditions of the roads and the distances over which agents and munitions would be transported.

External data represent factors largely beyond Army control that could affect risk and, therefore, identification of the environmentally preferred alternative. Each of these data types is examined in this Phase I report to determine if FPEIS data are representative of actual conditions at a given installation. For example, the extent to which meteorological conditions (mixing height, atmospheric stability, and wind speed) at an installation are representative of the values generically assumed in the FPEIS analyses is evaluated. Recent and more detailed data on earthquake, tornado, and meteorite frequencies are examined to see if they reflect the values given in the FPEIS. Data on levels of aircraft activity, including the presence of restricted areas, the type of aircraft, the type of airspace use, and flight frequencies are also evaluated.

\section{DATA COLUECTION AND AGENCIES CONTACTED}

This document is supported by data collected by the authors during a site visit April 10-12, 1989, to the Pine Bluff, Arkansas, area. A scoping meeting was also held on April 11, 1989, at the PBA Visitor's Center Auditorium to solicit public input to the NEPA process and to determine the significant issues relating to the proposed action. No verbal comments were received during the scoping meeting. Only one written comment was subsequently received, that being from the U.S. Department of the Interior. The letter provided points of contact for specific issues that are of interest to the Department.

To support the identification and assessment of issues in the FPEIS, the Army funded community studies for five of the eight storage sites. (The other three sites declined the opportunity to prepare such studies.) PBA was one of the five sites for which studies were prepared. The PBA community study (Demecs 1987) has been reviewed for this Phase I report. The document basically supports the conclusion of the FPEIS that on-site disposal is the environmentally preferred alternative. It also recommends extension of the original program completion deadline of September 30 , 1994, to allow for additional technology development and optimization of safety and cost effectiveness. The completion date has since been revised to 1999 . Information 
presented by the community study, relating to such areas as atmospheric dispersion modeling, probabilistic risk assessment, and threatened and endangered species will be incorporated into the site-specific EIS for PBA.

Input was also solicited from the cooperating agencies, which include the U.S. Department of Health and Human Services (DHHS); the U.S. Environmental Protection Agency (EPA); the Federal Emergency Management Agency (FEMA); and many agencies of the state of Arkansas. Information obtained from these agencies was considered in conducting this analysis. Additionally, each agency reviewed the draft Phase I document prior to its release. Their comments and written responses are presented in Appendix $F$.

In addition to the documents referenced throughout this report, contact was made with the following agencies during the collection of data for the Phase I process.

Arkansas Boys Training Unit, Pine Bluff, Arkansas (W. Ferrell).

Arkansas Department of Corrections, Little Rock, Arkansas (D. White, Assistant to the Director).

Arkansas Department of Human Services, Office of Longterm Care, Little Rock, Arkansas (S. Frazer).

Arkansas Department of Pollution Control and Ecology, Little Rock, Arkansas (S. Coldwell).

Arkansas Geological Commission, Maps and Publication Section, 3815 West Roosevelt Road, Little Rock, Arkansas 72204.

Arkansas Historic Preservation Program, Little Rock, Arkansas (C. Buford, State Historic Preservation Officer).

Arkansas Law Enforcement Standards and Training, Little Rock, Arkansas (B. Brown).

Arkansas Louisiana Gas Company, Little Rock, Arkansas (E. Davis).

Arkansas Office of Emergency Services (J. Witt, Director).

Arkansas Power and Light, Little Rock, Arkansas (D. Webb).

Arkansas School for the Blind, Little Rock, Arkansas (J. Duke).

Arkansas School for the Deaf, Little Rock, Arkansas (A. Attington).

Arkansas State Parks, Little Rock, Arkansas (J. Hendric, Dept. of Revenue;

R. Freedman, Planning and Development). 
City of Altheimer, Altheimer, Arkansas (secretary to the mayor).

City of Pine Bluff Planning Office, Pine Bluff, Arkansas (J. Hawkins, G. Garner).

City of Pine Bluff Zoning Department, Pine Bluff, Arkansas (D. Birdsong).

City of White Hall, White Hall, Arkansas (T. Ashcraft, mayor).

Clearlake Footwear, England, Arkansas (L. Miller).

Cotton Belt Railroad, Pine Bluff, Arkansas (M. Bradley, Superintendent).

Delta Career College, Pine Bluff, Arkansas (K. Mezger).

Federal Emergency Management Agency, Region VI, Denton, Texas (G. Jones).

General Waterworks, Pine Bluff, Arkansas (E. McElhanon).

Grant County Civil Defense Division, Sheridan, Arkansas (J. Wynne, Coordinator).

Greater Pine Bluff Chamber of Commerce, Pine Bluff, Arkansas (E. Gaines, J. Blankenship).

Hardin Water Association, Pine Bluff, Arkansas (R. Rhodes).

Hogan State Fish Hatchery, Lonoke County, Arkansas (D. Fiegel, Assistant Hatchery Manager).

Jefferson County Judge, Jefferson County Courthouse, Pine Bluff, Arkansas (Judge J. Jones).

Jefferson County Office of Emergency Services, Pine Bluff, Arkansas (J. Palmateer, Coordinator).

Jefferson Regional Medical Center School for Nursing, Pine Bluff, Arkansas (B. Font).

Ladd Water Users Association, Pine Bluff, Arkansas (M. Hanes, manager).

Maranatha Christian Schonl, Pine Bluff, Arkansas.

New Life Christian School, Pine Bluff, Arkansas (J. Rushing).

Pine Bluff Christian School, Pine Bluff, Arkansas (M. Wallace). 
Pine Bluff Parks and Recreation, Pine Bluff, Arkansas (J. Jumper).

Pine Bluff Wastewater Utility Sewer Department, Pine Bluff, Arkansas (K. Johnson, Treatment Director).

Pines Mall, Pine Bluff, Arkansas (R. Rechter, Assistant Manager).

Sheridan Wastewater Departraent, Sheridan, Arkansas (D. Fitzgerald, Manager).

Shickel Development, Pine Bluff, Arkansas (T. Mitsch).

South Central Career College, Pine Bluff, Arkansas (M. William).

Southeast Arkansas Economic Development District, Inc., Pine Bluff, Arkansas

(S. Trotter, A. Skinner).

St. Peter Catholic School, Pine Bluff, Arkansas.

Trinity Episcopal School, Pine Bluff, Arkansas.

U.S. Fish and Wildlife Service, Endangered Species Office, Jackson, Mississippi

(D. Jordan, Fieid Supervisor).

United States Geological Survey, Books and Open-File Reports, Federal Center, Building 41, Box 25425, Denver, Colorado 80225.

Vocation and Technical Educational Division, State Department of Education,

Little Rock, Arkansas (M. Braswell).

Watson Chapel Water Association, Pine Bluff, Arkansas (B. Ross).

White Hall Sewer Service, White Hall, Arkansas (R. Ducey).

\section{REFERENCES}

Demecs, D. D. 1987. Final Report on DPEIS and Related Drafts, U.S. Army Community Review, University of Arkansas at Pine Bluff, Pine Bluff, Ark.

U.S. Army 1988. Chemical Stockpile Disposal Program Final Programmatic Environmental Impact Statement, Vols. 1, 2, and 3, Program Executive OfficerProgram Manager for Chemical Demilitarization, Aberdeen Proving Ground, Md., January. 


\section{COMPARISON OF STIESPECIFIC AND PROGRAMMATIC DATA}

The two major parts of this section deal with (1) reexamining the identification of on-site disposal as the environmentally preferred alternative at PBA using recent and more detailed data than those in the FPEIS and (2) describing recent and detailed data on environmental resources that could be affected by on-site disposal.

As discussed in Sect. 2, the reexamination of the FPEIS environmentally preferred aliernative in this Phase I report is largely based on the evaluation and cusparison of human health risks. Two major components of this comparative analysis are population data and atmospheric dispersion modeling.

The choice of an atmospheric dispersion model in the FPEIS was limited by the nature of the accidentally released chemical agents and the complexity of the disposal program. One requirement of the model or models selected for use in estimating environmental impacts was to calculate the downwind doses from agents emitted to the atmosphere from accidents (e.g., spills of liquid agent, detonation of munitions, and vapor releases from fires). In addition, the model was required to analyze the effects of thousands of potential releases under various meteorological conditions.

The atmospheric dispersion model D2PC developed by the U.S. Army's Chemical Research, Development and Engineering Center (Whitacre et al. 1986) was used to assess the potential impacts of the proposed action and alternatives in the FPEIS. The D2PC model assumes a Gaussian distribution of agent in the vertical and cross-wind directions as the agent disperses downwind. This assumption has been documented extensively in the literature and is used by a multitude of current models. Although more sophisticated dispersion codes are available, the assumption of straight-line downwind transport of chemical agent with non-varying meteorological conditions results in conservative estimates (i.e., overpredictions) of the effects of releases. A specific point of release was not identified in the D2PC analyses, but instead a generic location was used. This assumption was made due to the number of potential release sites at each facility as well as the potential for release during the transportation alternatives analyzed. Therefore, identical downwind distances were obtained for identical accidents for all alternatives. This simple approach, while inappropriate for estimating the impacts of any given release under real-time conditions, is appropriate for analyzing and comparing the potential effects of the many postulated accidental releases.

To ensure consistency between the FPEIS and the site-specific EISs, and to allow direct risk comparisons among the site-specific and programmatic documents, the same model (D2PC) is used in this Phase I report. Use of a model other than D2PC could result in a risk estimate different than in the FPEIS due solely to the new model 
and not to any significant changes in facility design or the incorporation of site-specific data into the assessment.

Section 3.1 uses data collected during Phase I with the FPEIS method for identifying the environmentally preferred alternative to reexamine the five FPEIS measures of risk. Section 3.1 is thus an extension of Sect. 2.6.3.3.5 in the FPEIS, which used programmatic data to examine on-site disposal at PBA using human health impacts, ecosystem and environmental impacts, and emergency planning and preparedness effects. Section 3.2 presents data collected during Phase I for site-specific resources that could be affected by construction and operation of a disposal facility at PBA. Potential effects on these resources will be addressed in the site-specific EIS for PBA. Section 3.3 addresses maturity of the disposal technology, and Sect. 3.4 discusses technology risk assurance.

Only highlights concerning the newly collected data are given in this section. For some of the resource areas, a more complete presentation of detailed, site-specific information is contained in appendices to this report.

\subsection{REEXAMINING THE IDENTIFICATION OF ON-SITE DISPOSAL AS THE ENVIRONMENTALLY PREFERRED ALTERNATTVE}

Identification of the environmentally preferred alternative was based on a risk analysis for accident conditions. As discussed in Sect. 2, the two types of data germane to the selection process are population and the accident data base. Population data are concerned with the number and location of people. The accident data are concerned with the probabilities and agent release quantities of various accidents associated with each alternative; the probabilities and release quantities can in turn be thought of as being affected by external factors (e.g., meteorology, earthquakes, meteorites, etc.) and internal factors (technology, procedures, facility location). This section examines population and accident data base information collected during Phase I for its potential to affect the programmatic selection at PBA. Using those data that have appreciable potential to preferentially affect a given risk measure for a gr.in alternative, this section then reevaluates the risk measures with the new data for the three alternatives applicable to Phase I. Last, the new risk measures are used in the FPEIS method for identifying the environmentally preferred alternative to determine if off-site disposal risk is significantly less than on-site disposal risk.

\subsubsection{New Values for Programmatic Data and Assumptions and Their Significance}

\subsubsection{Accident data base}

As discussed in Sect. 2, of the two major types of data that affect the accident data base (internal and external), most of the focus in this Phase I report is directed toward the external data because they represent factors over which the Army has little or no control. Internal data, however, reflect factors over which the Army does have 
control. This section discusses those factors that could have changed from the assumptions in the FPEIS: on-site transport (as determined from the location of the proposed on-site disposal facility as compared to the location of the existing storage area), meteorological factors, earthyuakes (seismicity), aircraft activity, tornadoes, and meteorite strikes, as discussed below.

\section{On-site transport}

As considered in this Phase I study, the probability of an accident occurring during on-site transportation of agents and munitions is directly related to the number of miles travelled. Therefore, on-site transportation distance is an important parameter in assessing FPEIS risk measures at PBA. The proposed site of the agent disposal facility is as depicted in the FPEIS: immediately west of the Arkansas River in the northern part of the installation and approximately $4 \mathrm{~km}$ ( 2.5 miles) east-northeast of the existing storage area. This is within the 3-mile transportation distance that was assumed in the FPEIS. The route from the storage area to the disposal facility will be constructed or upgraded for an 85,000 pound haul load. Currently, some of the route is paved, some unimproved gravel, and some sections have yet to be constructed. The return route, on which the trucks will be empty, will use existing roads (personal communication from Lt. C. Sachs, PBA, to T. Ensminger, ORNL). No new information concerning on-site transport was identified that would invalidate the conclusions of the FPEIS.

\section{Meteorology}

The principal type of meteorological data of interest to the selection of the environmentally preferred alternative is the applicability of meteorological conditions assumed in the FPEIS: wind speed, atmospheric stability and mixing height. Tornadoes are discussed in a separate section (below) in conjunction with meteorites.

Meteorological data for PBA were examined to evaluate the appropriateness of the conservative most likely (CML) and worst case (WC) meteorological conditions that were used in the FPEIS. The CML scenario represents a frequently occurring meteorological condition that results in relatively large doses of agent release compared with other frequently occurring conditions. Specifically, neutral atmospheric stability (Class D) with a wind speed of $3 \mathrm{~m} / \mathrm{s}(6.6 \mathrm{miles} / \mathrm{h})$ was selected for the CML condition. The WC scenario represents a credible condition that results in near maximum doses. Specifically, a stable atmosphere (Class E) with a wind speed of $1 \mathrm{~m} / \mathrm{s}(2.2 \mathrm{miles} / \mathrm{h})$ was chosen for the WC condition.

Accurate measurements of wind speed and derivations of stabilities are needed to evaluate the appropriateness of the two conditions for PBA. Quality control procedures were performed to determine the accuracy of the wind data collected at two towers located at PBA. The quality of the wind data appears reasonable, and the data should be quite representative of conditions at the site of the proposed disposal facility. The stabilities which are derived from PBA data using methods based on the standard deviation in horizontal wind direction (sigma-theta method) appear reasonable for 
Tower 6, both by time of day and for the overall period of record. For Tower 1, the distribution of stabilities appeared biased in the direction of heing too unstable and was not used further.

The joint frequency distribution of stabilities and wind speed classes was constructed to determine the applicability to PBA of the CML and WC meteorological conditions (Table 1). The distribution indicated that neutral atmospheric stability (Class D) occurs more often (35\% of the time) than any of the other classes, and D stability with winds between 2.1 and $3.6 \mathrm{~m} / \mathrm{s}(4.7$ and 8.1 miles $/ \mathrm{h})$ occurs more than $10 \%$ of the time, a greater occurrence than any other wind speed class within D stability except the $12 \%$ occurrence of winds less than $2.1 \mathrm{~m} / \mathrm{s}(4.7 \mathrm{miles} / \mathrm{h})$. Because the range (upper bound minus lower bound) of the former wind speed class is only $1.5 \mathrm{~m} / \mathrm{s}$ while the range of the latter wind speed class is $2.1 \mathrm{~m} / \mathrm{s}$, a wind speed of $3 \mathrm{~m} / \mathrm{s}$ is expected to occur more frequently than lower wind speeds for D stability. Class D stability with higher wind speeds also occurs frequently but results in less conservative predictions (i.e., it would result in smaller doses for a given downwind distance). However, the lower wind speeds have the potential to be associated with higher doses of chemical agent and, therefore, potentially larger estimated fatalities from accidents. The implications of using a lower wind speed for CML conditions are addressed in Sect. 3.1.2.2.

With regard to WC conditions, although maximum predicted doses result from Class F stability with low wind speeds and F stability occurs almost $7 \%$ of the time at PBA, F stability intentionally was not used for the WC scenario because predicted doses are greater than doses realistically expected in a credible scenario. During F stability, a puff or plume meanders along a serpentine path rather than moving downwind in a line;

Table 1. Joini frequency distribution (in percent) of stability and wind speed for the PBA Tower 5 station (15 m)

\begin{tabular}{crrrrrrrr}
\hline & \multicolumn{7}{c}{ Wind speed $(\mathrm{m} / \mathrm{s}) a$} \\
\cline { 2 - 8 } $\begin{array}{c}\text { Stability } \\
\text { class }\end{array}$ & $0-2.1$ & $2.1-3.6$ & $3.6-5.7$ & $5.7-8.7$ & $8.7-10.8$ & $>10.8$ & Total \\
\hline A & 3.9 & 2.5 & 0.3 & 0.0 & 0.0 & 0.0 & 6.7 \\
B & 4.1 & 5.5 & 2.2 & 0.3 & 0.0 & 0.0 & 12.1 \\
C & 5.8 & 8.8 & 7.0 & 1.9 & 0.1 & 0.0 & 23.6 \\
D & 12.2 & 10.5 & 9.1 & 3.2 & 0.1 & 0.0 & 35.1 \\
E & 10.9 & 3.6 & 0.9 & 0.5 & 0.0 & 0.0 & 15.9 \\
F & $\underline{5.9}$ & $\underline{0.7}$ & $\underline{0.0}$ & $\underline{0.0}$ & $\underline{0.0}$ & $\underline{0.0}$ & $\underline{6}$ \\
Total & 42.8 & 31.6 & 19.5 & 5.9 & 0.2 & 0.0 & 100.0 \\
\hline
\end{tabular}

"Multiply by 2.237 to convert to miles per hour. 
therefore, actual maximum doses at given locations would be reduced compared with predicted doses that assume continuous exposure along a centerline downwind axis. As the puff from an instantaneous release expands because of diffusion, it becomes subject to changes in wind direction within the increasing volume of air that it occupies as it travels downwind. Therefore, although the effect is not as pronounced as for a continuous plume, actual maximum doses in a puff are also less than predicted doses because of stretching and shearing occurring along its meandering path.

Class E stability with low wind speeds produces the next highest predicted doses, and the meandering plume is not as pronounced for $\mathrm{E}$ stability. For this reason, E stability with low wind speeds was selected as the WC scenario. Class E stability with winds less than $2.1 \mathrm{~m} / \mathrm{s}(4.7$ miles/h) occurs approximately $11 \%$ of the time. Based on these results, it is concluded that the CML and WC meteorological conditions used in the FPEIS are appropriate for PBA.

The height of the mixed layer is another important meteorological factor affecting predictions of dispersion. Lowering this value would tend to decrease the volume of the atmosphere available for dispersion of agent and potentially increase predicted concentra-tions of agent in the atmosphere. Data on the height of the mixed layer at PBA are obtained on-site by an acoustic sounder, but the instrument is currently being used on an experimental basis only [W. F. Rostek, PBA Meteorologist, Pine Bluff, Arkansas, personal communication with R. L. Miller, Oak Ridge National Laboratory (ORNL), Apr. 11, 1989]. Therefore, the best available estimates for this parameter are calculated using data from the nearest National Weather Service station with upper-air data at Little Rosk, Arkansas, $48 \mathrm{~km}$ (30 miles) north-northwest of PBA. Because the height of the mixed layer usually is quite uniform throughout central Arkansas at any given time, these estimates of the height are representative of PBA.

The FPEIS used a value of $750 \mathrm{~m}(2475 \mathrm{ft})$ for accidental release scenarios. An examination of morning and afternoon mixing heights by season (Holzworth 1972) for Little Rock reveals that mean morning mixing heights range from $342 \mathrm{~m}(1129 \mathrm{ft})$ in the autumn to $544 \mathrm{~m}$ (1795 ft) in the spring, and mean afternoon mixing heights range from $1101 \mathrm{~m} .(3633 \mathrm{ft})$ in the winter to $1851 \mathrm{~m}(6108 \mathrm{ft})$ in the summer. Note that the mean morning mixing heights are lowered considerably by ground-level inversions during stable conditions and usually would be higher for the CML scenario of neutral atmospheric stability. For the WC scenario, the height of the mixed layer is not of concern because it is unlikely that more intense stable conditions would occur above the surface inversion that causes the stable conditions. Based on mean values reported by Holzworth, the selection of a height of $750 \mathrm{~m}$ (2475 ft) is appropriate for PBA; however, for conservatism, risks associated with a lower mixing height of $500 \mathrm{~m}(1650 \mathrm{ft})$ are evaluated in Sect. 3.1.2.

\section{Seismicity}

Seismic risk analysis in the FPEIS was based on probabilistic earthquake data provided by ATC 1978. According to ATC an effective peak ground acceleration (EPGA) equal to $0.05 \mathrm{~g}$ has a $10 \%$ probability of being exceeded at least once in 
50 years at PBA. Probabilities of exceeding larger design EPGAs [0.20 g and $0.81 \mathrm{~g}$ for the main munitions demilitarization building (MDB) and the toxic cubicle (TC), respectively] were extrapolated from data provided by ATC and used in the FPEIS risk analysis. Based on ATC data, EPGA $=0.20 \mathrm{~g}$ has approximately a $10 \%$ probability of exceedance at least once in 1000 years and EPGA $=0.81 \mathrm{~g}$ is screened out of the FPEIS risk analysis on the basis of extremely low probability (less than one chance in a million annual probability of occurrence).

Based on currently available data, the seismic risks for the MDB and TC remain unchanged. FEMA's 1988 seismic risk map (Fig. 8) is essentially the same as that of ATC (1978), both having been based on an earlier seismic risk analysis by Algermissen and Perkins (1976). A more recent analysis by Algermissen and others (1982) suggests no significant change in seismic risk for PBA. Both Algermissen studies were national, rather than site-specific, in scope and may not necessarily be good representations of seismic risk at PBA. Nevertheless, the Algermissen studies are the best available sources of information available at this time. A site-specific probabilistic risk analysis as described by EPRI (1988) for use in electric power plant studies has not been done for PBA.

Seismicity data collected during Phase I supplement those in the FPEIS in three important respects. First, regional WC earthquakes and their associated peak ground accelerations (PGAs) have been estimated and compared with earthquake engineering design parameters. Second, foundation conditions (an uncertainty discussed in general terms in the FPEIS) are now known in greater detail. Finally, corroborating evidence has been compiled that is consistent with the FPEIS assertion that on-site surface rupture along a fault beneath PBA is unlikely. Table 2 summarizes several sources of information. The Army contractor's (Jacobs Engineering Group, Inc., and URS/ John A. Blume and Associates 1987) summary is presented separately at the end of this section.

When the FPEIS was prepared, very little site-specific information was available. The worst-case PGA had not been estimated. Furthermore, liquefaction and ground motion magnification were considered feasible, but the presence of faults capable of producing on-site surface rupture was considered highly unlikely (based on region-wide geology and professional judgement, rather than site-specific geotechnical data).

Data collected during Phase I (U.S. Army open-file data) show that the proposed disposal facilities would not be damaged by earthquake-generated soil liquefaction, assuming they are constructed on terrace deposits similar to those on which the BZ site is located. Construction on the Arkansas River flood plain would be avoided. The BZ site is on high ground where the water table is nearly $15 \mathrm{~m}(50 \mathrm{ft})$ below the surface. Surficial soils ( $3 \mathrm{~m}$ or $10 \mathrm{ft}$ thick) are stiff clay-silts and hardpan. They are underlain by 3 to $8 \mathrm{~m}$ (10 to $26 \mathrm{ft})$ of hard sandy clay and very dense fine silty sand of Pleistocene age which, in turn, lie on semiconsolidated Eocene age shale as determined by lithologic logs and standard penetrometer tests. Dense soils with a deep water table are not likely to liquefy (Seed and Idriss 1971).

Information collected during Phase I confirms the FPEIS assertion that on-site surface rupture along an active fault at PBA is unlikely. No confirmed surface ruptures have been Hiscovered in strata of the Mississippi embayment region (Thenhaus 1983). 
$3-7$

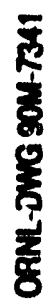

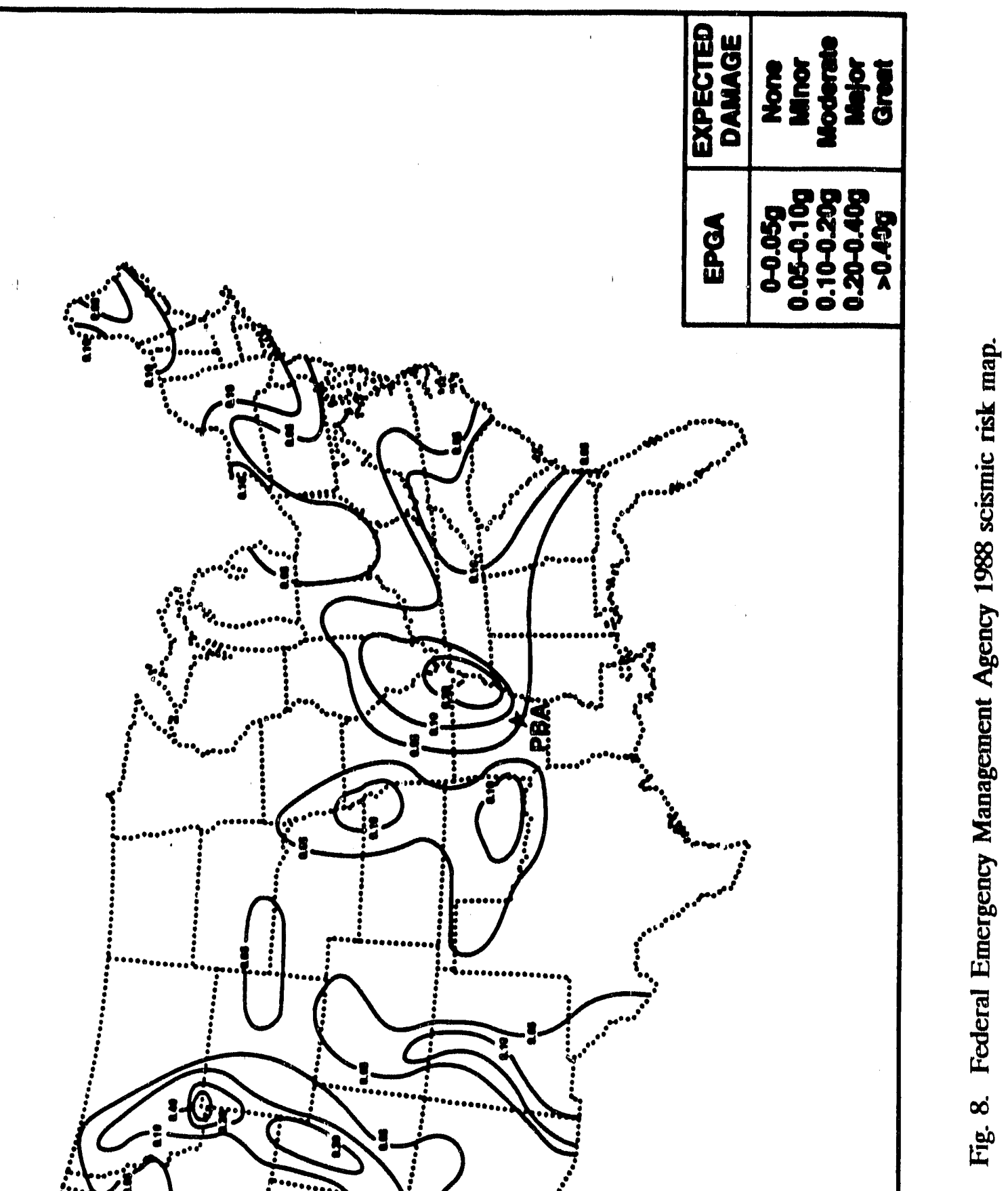




\section{3-8}

Table 2 Summary of sitempecific and programmatic carthquake parameters at Pine Bluff Arsenal compared to carthquake engineering design parameters

\begin{tabular}{lll}
\hline $\begin{array}{l}\text { Earthquake } \\
\text { parameter }\end{array}$ & \multicolumn{1}{c}{$\begin{array}{c}\text { Programmatic } \\
\text { EIS }\end{array}$} & $\begin{array}{c}\text { Site-specific } \\
\text { data }\end{array}$ \\
\hline $\begin{array}{l}\text { Effective peak ground } \\
\text { acceleration (EPGA) } \\
10 \% \text { probability of } \\
\text { excedance at least }\end{array}$ & $\begin{array}{l}\text { Seismic Zone } 1^{b} \\
\text { EPGA }=0.05 \mathrm{~g}^{\mathrm{b}}\end{array}$ & $\begin{array}{c}\text { Seismic Zone } 1^{\mathrm{b}} \\
\text { EPGA }=.05 \mathrm{~g}^{\mathrm{b}}\end{array}$ \\
\hline EPGA $=0.06 \mathrm{~g}^{\mathrm{d}}$ &
\end{tabular}
once in $\mathbf{5 0}$ years

Maximum historical earthquake in Wichita - Ouachita Province

Peak ground acceleration (PGA) for above earthquake, assuming it occurs on-site

Worst case (WC) earthquake in Wichita-Ouachita Province

PGA for above earthquake, assuming it occurs on-site

Maximum historical WC earthquake in the Reelfoot Rift

PGA for the maximum historical WC carthquake $(\mathrm{Imm}=$ XII) assuming it occurs near Marked Tree, Ark; $130 \mathrm{~km} \mathrm{NE}$ of PBA
Not provided

Not provided

$$
P G A=0.18 g^{i j}
$$

Tulsa, Okla.; $1956^{\circ}$

Paris, Tex.; $1882^{\prime}$ northwest Miss.; $1931^{\mathrm{b}}$ Modified Mercalli body. wave Intensity $(\mathrm{Imm})=$ VII, magnitude $\left(m_{b}\right)=-5.5^{a .1 j}$ exceedance $\sim 10 \%$ in

Not provided

Not provided

Not provided

Not provided

$$
\begin{gathered}
\text { Imm }=\text { VIII; } \mathrm{m}_{b}= \\
\sim 6.0^{j} \\
\operatorname{Imm}_{\sim 6.2^{b}}=\mathrm{IX} ; \mathrm{m}_{\mathrm{b}}=
\end{gathered}
$$

$$
\begin{aligned}
& \text { PGA }=0.18 \mathrm{~g}^{f_{1}}, 0.25 \mathrm{~g} \\
& \text { PGA }=0.28 \mathrm{~g}^{j_{j}}, \\
& \text { PGA }=0.34 \mathrm{~g}^{h_{1}}
\end{aligned}
$$

New Madrid, Mo.

Feb. 7, 1812;

$\mathrm{Imm}=\mathrm{XII}$

$m_{b}=7.4^{e, b_{h} n}$ (700- and 1400-year recurrence intervals northeast and soutbwest of Marked Tree, Ark., respectively)

$$
\begin{aligned}
& \text { PGA }=0.32 \mathrm{~g}^{\mathrm{h}_{1}} \\
& (\text { on-site Imm }=\mathrm{IX}) \\
& \left(\text { on-site Imm }=\text { VII }{ }^{q}\right. \\
& \text { PGA not given }
\end{aligned}
$$

Main munitions demilitarization building, MDB $P G A=0.20 \mathrm{~g}$ Seismic Zone 3 (Probability of 1000 years)

General purpose support facilities Selsmic Zone 2 $E P G A=0.10 \mathrm{~g}$ (probability of exceedance $10 \%$ in 250 years) 
$3-9$

Table 2 (Continued)

\begin{tabular}{|c|c|c|c|}
\hline $\begin{array}{l}\text { Earthquake } \\
\text { parameter }\end{array}$ & $\begin{array}{c}\text { Programmatic } \\
\text { EIS } \\
\end{array}$ & $\begin{array}{l}\text { Site-specific } \\
\text { data }\end{array}$ & $\begin{array}{l}\text { Slte-specific } \\
\text { design } \\
\text { parameters" }\end{array}$ \\
\hline $\begin{array}{l}\text { PGA for the maximum } \\
\text { historical WC } \\
\text { earthquake (Imm = } \\
\text { XII) assuming it occurs } \\
\text { at Stuttgart, Ark.; } \\
50 \mathrm{~km} \mathrm{NE} \mathrm{of} \mathrm{PBA}\end{array}$ & Not provided & $\begin{array}{l}\text { PGA }=1.0 \mathrm{~g}^{W} \\
\text { (on-site Imm }=X I \text { ) }\end{array}$ & $\begin{array}{l}\mathrm{PGA}=0.81 \mathrm{~g} \text { (toxic } \\
\text { cubicle inside } \mathrm{MDB})\end{array}$ \\
\hline $\begin{array}{l}\text { Potential for } \\
\text { liquefaction }\end{array}$ & $\begin{array}{l}\text { Yes (Professional } \\
\text { judgment) }\end{array}$ & $\begin{array}{l}\text { None }^{p} \text { (Drill logs, standard } \\
\text { penetrometer tests) }\end{array}$ & \\
\hline $\begin{array}{l}\text { Potential for ground } \\
\text { motion magnification }\end{array}$ & $\begin{array}{l}\text { Yes, based on regional } \\
\text { geology and depending } \\
\text { on structural design }\end{array}$ & $\begin{array}{l}\text { Yes, based on local } \\
\text { geology and depending on } \\
\text { structural design }\end{array}$ & $\begin{array}{l}\text { Appropriate design } \\
\text { response spectra } \\
\text { consistent with design } \\
\text { PGA and duration of } \\
\text { shaking }\end{array}$ \\
\hline $\begin{array}{l}\text { Potential for surface } \\
\text { rupture (capable faults) }\end{array}$ & $\begin{array}{l}\text { None (Professional } \\
\text { judgment) }\end{array}$ & Unlikety $y^{h m, n}$ & \\
\hline
\end{tabular}

${ }^{a}$ B. Ross, design engineer, U.S. Army Corps of Engineers, Huntsville Division, personal communication with W. P. Staub, geotechnical engineer, Oak Ridge National Laboratory, August 31, 1989.

ATC (Applied Technology Council), Tentative Provisions for the Development of Seismic Regulations for Buildings, Applied Technology Council/National Bureau of Standards, Special Publication 510, U.S. Department of Commerce, Washington, D.C., 1978.

'More stringent (conservative) interpretation of ATC (1978).

${ }^{d}$ S. T. Algermissen, et al., Probabilistic Estimates of Maximum Acceleration and Velocity in Rock in the Contiguous United States, U.S. Geological Survey, Open-File Repori 82-1033, Denver, Colo., 1982.

-Arkansas Power and Light, Safery Anabysis Repor for Arkansas Nuclear One, Unit 2, U.S. Nuclear Regulatory Commission Docket No. 50-368, Ofrice of Nuclear Reactor Regulation, Washington, D.C., 1976.

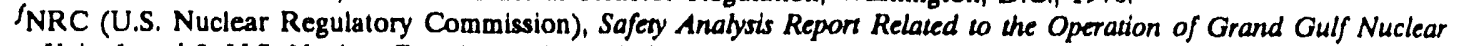
Station, Units 1 and 2, U.S. Nuclear Regulatory Commission, Docket Nos. 50-416 and 50-417, NUREG-0968, Office of Nuclear Reactor Regulation, Washington, D.C., 1981; NRC (U.S. Nuclear Regulatory Commission), Safery Evaluation Repon Relased to the Operation of Comanche Peak Steam Electric Station, Units 1 and 2, U.S. Nuclear Regulatory Commission, Docket Nos. 50-445 and 50-446, NUREG-0797, Office of Nuclear Reactor Regulation, Washington, D.C., 1981

hJacobs Engineering Group, Inc. and URS/John A. Blume and Associates, Geological-Seismological Investigation of Earthquake Hazards for a Chemical Stockplle Dispasal Facility at the Pine Bluff Arsenal, Arkansas, contractor report by engineers to U.S. Army Engineer Division, Huntsville, Ala., contract no. DACA87-86-0085, prepared for the Office of the Program Manager for Chemical Demilitarization, Aberdeen Proving Ground, Md., 1987.

'PGA calculations are based on ground motion attenuation curves of Herrmann 1981 (on-site earthquakes) and Murphy and O'Brien 1977 (off-site earthquakes) as provided by Jacobs Engineering (1987).

PBA Environmental Impact Statement (EIS) analysis.

${ }^{k}$ Worst-case location [NRC (1981)].

'P. C. Thenhaus, Summary of Workshops Conceming Regional Seismic Source Zones of Parts of the Conterminous United States Converied by the U.S. Geological Survey 1979-1980, Golden, Colorado, USGS Circular 898, Alexandria, Va. 1983.

mU.S. Geological Survey, Investigations of the New Madrid, Missouri Earthquake Region, Professional Paper 1236, U.S. Government Printing Office, Washington, D.C., 1982.

"O. W. Nuttli, "Similarilies and Differences Between Western and Eastern United States Earthquakes, and Their Consequences for Earthquake Engineering," in Proceedings of Earthquakes and Earthquake Engineering: The Eastem Uniced Stazes, ed. J. E. Beavers, Ann Arbor, Mich., 1981.

PSeed, H. B. and I. M. Idriss, 1971. "Simplified Procedure for Evaluating Soil Liquefaction Potential," Journal of the Soil Mochanica and Foundations Division, American Society of Civil Engineers.

'A Agermiwen, S. T. and M. G. Hopper 1984. "Estimated Maximum Regional Seismic Intensities Associated with an Eneemble of Greal Earthquakes that Might Occur Along the New Madrid Seismic Zone, East-Central United States," U.S. Geological Survey miscellaneous field studies, Map MF-1712, Reston, Virginia. 
In the northeastern end of the Mississippi embayment (the New Madrid region where major earthquakes have been historically recorded), Eocene age faults have been discovered in the subsurface by seismic reflection profiling, but none has reached the surface (USGS 1982). According to Nuttll (1981), major earthquakes in eastern United States seldom, if ever, cause surface rupture.

Although surface rupture at PBA during a near-field, strong-motion earthquake is unlikely, foundations might be destabilized by sand blows. Geologic conditions at PBA are similar to those in northeastern Arkansas where widespread sand boils associated with the 1811-1812 sequence of great earthquakes have been reported (Heyl and McKeown 1978). Russell and Parks (1975) describe numerous sand dikes in the Porters Creek Formation in the eastern Mississippi embayment region of Tennessee. The occurrence of these sand dikes suggests that the potential for sand blows exists over a wide area of the Mississippi embayment.

Although not expected, foundation conditions at the PBA site may require that some process facilities be supported on deep foundation systems. If deep foundation systems are used on process facilities, the potential for magnification of earthquake induced ground motions would exist. Magnification is a design consideration under the control of the U.S. Army. Appropriate design response spectra would be selected consistent with design peak ground acceleration (PGA), duration of shaking, and foundation systems to be constructed.

Site-specific analysis considered potential WC earthquakes in two seismotectonic provinces, the Wichita-Ouachita Province (where PBA is located) and the Reelfoot Rift Zone (a nearby region which is considered to be the most seismically active in the eastern United States). There is disagreement with respect to the modified Mercalli intensity $\left(I_{\mathrm{mm}}\right)$ for the WC earthquake in the Wichita-Ouachita Seismotectonic Province and the location of the WC earthquake in the Reelfoot Rift Zone.

Various investigators assert that the WC earthquake in the Wichita-Ouachita Province could occur anywhere within that province, for example, on the PBA site as shown in Fig. 9. However, the $I_{m}$ for the WC earthquake varies between VII (NRC 1981) and IX (Jacobs Engineering 1987), based on $\mathrm{I}_{\mathrm{mm}}=$ VI-VII and VII, respectively, for the maximum historical earthquake in the province. PGAs for the WC earthquake in the Wichita-Ouachita Province (occurring at PBA) range from $0.18 \mathrm{~g}$ to $0.34 \mathrm{~g}$.

Various investigators agree that for the maximum historical WC earthquake in the Reelfoot Rift Zone, $I_{\text {ma }}=$ XII. For the Reelfoot Rift Zone, the maximum historical earthquake $\left(\mathrm{I}_{\mathrm{mm}}=\mathrm{XII}\right)$ and $\mathrm{WC}$ earthquake are synnnymous because $\mathrm{Imm}=\mathrm{XII}$ is the highest value provided in the modified Mercalli intt ssity scale. There is disagreement, however, regarding how near major earthquakes within this zone may be to PBA. According to Jacobs Engineering Group, Inc., and URS/John A. Blume and Associates (1987) major earthquakes may be expected no closer than $130 \mathrm{~km}$ ( 78 miles). In contrast, NRC (1981) takes the more conservative position that major earthquakes may be expected throughout the length of the Reelfoot Rift rather than being separated by a $100 \mathrm{~km}$ (62 miles) corridor of minimal seismic activity which characterizes the Central United States Stable Region. According to Thenhaus (1983), the southern terminus of modern seismic ar'ivity in the Reelfoot Rift Zone is uncertain, either terminating 

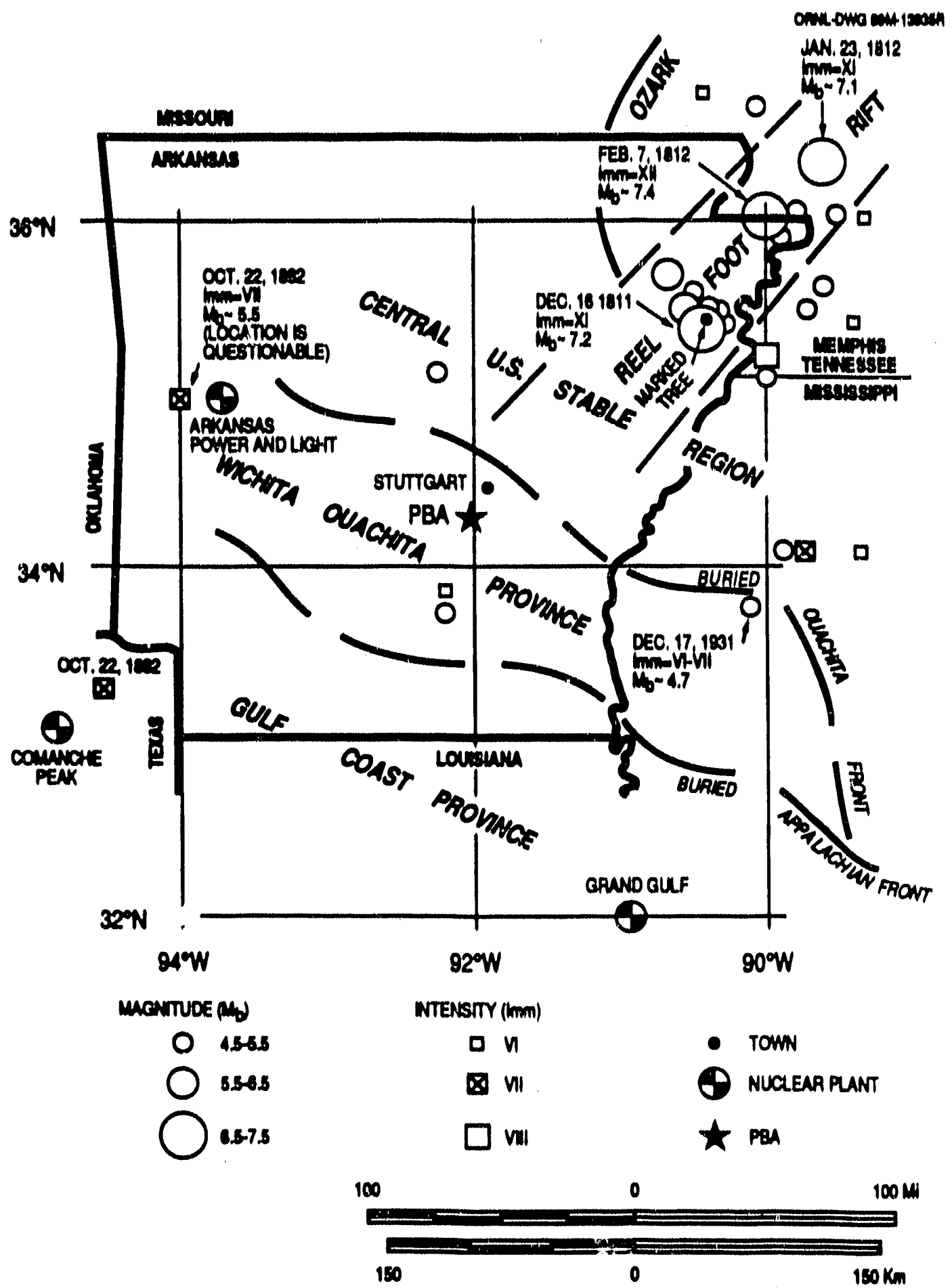

Fig. 9. Historical record of strong-motion carthquakes from 1699-April 1989. [Based on National Oceanic and Atmospheric Administration data, Arkansas Power and Light, Safety Analysis Report for Arkansas Nuclear One, Unit 2, U.S. Nuclear Regulatory Commission Docket No. 50-368, Jffice of Nuclear Reactor Regulation, Washington, D.C., 1976; NRC (U.S. Nuclear Regulatory Commission), Safety Analysis Report Related to the Operation of Grand Gulf Nuclear Station, Units 1 and 2, U.S. Nuclear Regulatory Commission, Docket Nos. 50-416 and 50-417, NUREG-0968, Office of Nuclear Reactor Regulation, Washington, D.C., 1981; O. W. Nuttli, "The Mississippi Valley Earthquakes of 1811 and 1812 Intensities, Ground Motion, and Magnitudes," Seismological Sociery of America Bulletin 63(1), 227-48 (1973).] For clarity, selected smaller earthquakes in the Reelfoot Rift Zone are not shown. 
near Marked Tree, Arkansas, about $50 \mathrm{~km}(31 \mathrm{miles})$ west of Memphis, Tennessee, and about $150 \mathrm{~km}$ (93 miles) from PBA or near Stuttgart, Arkansas, at the southwestern end of the Reelfoot Rift and about $50 \mathrm{~km}$ (31 miles) from PBA. A majority of professional seismologists convened at a workshop chaired by Thenhaus believe that the southern termirius of seismic activity is near Marked Tree, citing the historical pattern of seismicity as shown in Fig. 9. All participants at the workshop agreed that if indeed the southwestern end of the Reelfoot Rift Zone is seismically quiescent rather than inactive, the recurrence of large earthquakes would be less frequent in the southwestern part of the zone (on the order of 1400 years in comparison to approximately 700 years in the region north of Marked Tree, Arkansas).

PGAs at PBA were estimated for two large earthquakes in the Reelfoot Rift Zone. The first estimate was for a maximum historical earthquake $\left(I_{m m}=X I I\right)$ occurring $130 \mathrm{~km}$ (92 miles) northeast of PBA near Marked Tree, Arkansas. It was assumed that the $\mathrm{I}_{\mathrm{ma}}=\mathrm{IX}$ at $\mathrm{PBA}$, for which the $\mathrm{PGA}=0.32 \mathrm{~g}$, based on data provided by Jacobs Engineering Group, Inc., and URS/John A. Blume and Associates (1987). Data provided by Algermissen and Hopper (1984) suggest that $\mathrm{I}_{\text {ma }}=$ VII at PBA (Jefferson County) but $I_{m m}=1 X$ in an adjacent county (Arkansas County) from such an earthquake. The second estimate was for a maximum historical earthquake $\left(I_{m m}=X I I\right)$ occurring $50 \mathrm{~km}$ (31 miles) northeast of PBA near Stuttgart, Arkansas. In the second case it was assumed that the $I_{m m}=X I$ at $P B A$, for which the $P G A=1.00 \mathrm{~g}$. Based on the Thenhaus (1983) workshop's majority opinion that major earthquakes are not likely to occur in the Reelfoot Rift Zone south of Marked Tree, the first case is the most likely WC estimate (PGA $=0.32 \mathrm{~g}$ ) at PBA. It is conceded, however, that some professional seismologists believe this estimate is too low. In any event the TC would be designed to shut down safely in all cases but a WC earthquake at Stuttgart.

Table 2 compares estimated PGAs with earthquake engineering design parameters. As indicated in the table, general purpose support facilities (nonhazardous) would be designed to withstand an earthquake with a $10 \%$ probability of exceedance at least once in 50 years or a $63 \%$ probability of exceedance in a 475 -year return period. The main munitions demilitarization building (MDB) would be designed to shut down safely in the event of any earthquake except on-site maximum historical earthquakes in the Wichita-Ouachita Province or anywhere within the Reelfoot Rift Zone ( 700-year and $\sim 1400$-year recurrence intervals north and south of Marked Tree, Arkansas, respectively). The toxic cubicle inside the MDB would be designed to shut down safely in the event of a most likely maximum historical WC earthquake in the Reelfoot Rift Zone but may fail under an absolute WC scenario (a WC earthquake occurring near Stuttgart, Arkansas).

The above engineering design parameters exceed Uniform Building Code (UBC) standards. Although PBA is located in seismic zone 1 (potential for minor earthquake damage), all process facilities (except the TC) inside the MDB would be designed in accordance with UBC (1985) standards for seismic zone 3 (potential for moderate earthquake damage). As such, seismic zone 3 standards are more stringent than those for seismic zone 1 . The MDB has been assigned the highest importance 
factor (I-1.5) permitted by the 1985 UBC. To reduce the risk associated with a seismic event, the TC would be a clone of the TEAD TC. The TEAD TC is designed for a WC earthquake response spectra defined by the maximum PGA and duration of shaking at TEAD (0.81 g and $20 \mathrm{~s}$, respectively). Jacobs Engineering Group, Inc., and URS/John A. Blume and Associates recommended a less stringent design for the TC at PBA $(P G A=0.34 \mathrm{~g}$ and duration of shaking $=20 \mathrm{~s}$ for a WC New Madrid earthquake 130 $\mathrm{km}(78 \mathrm{mi})$ from PBA.

Jacobs Engineering Group (1987) and its subcontractor (URS/John A. Blume and Associates) provides a detailed deterministic (but no probabilistic) seismic risk analysis for the Pine Bluff Arsenal. This analysis includes a comprehensive literature search. A total of 81 references are cited by Blume.

The following information is Jacobs Engineering Group, Inc., and URS/ John A. Blume and Associates (1987) deterministic seismic risk summary for Pine Bluff Arsenal:

"In the vicinity of PBA, surface exposures consist predominantly of unconsolidated sediments of Tertiary or Quaternary age. These sediments thin gradually to the north as they approach the boundary of the Gulf Coastal Plain province and thicken to the south as they approach the Gulf Coast. The Tertiary materials are underlain by poorly indurated Cretaceous sediments which similarly dip seaward and thicken to the south, but are rarely exposed on the surface. Bedrock in the area consists of buried Paleozoic shale and sandstone, which are thought to be similar, but not identical, to the Paleozoic rocks outrropping throughout northern Arkansas. The unconformable contact between Palc ozoic formations and the overlying Tertiary or Cretaceous sediments dips moderately downward to the south and is at a depth of about

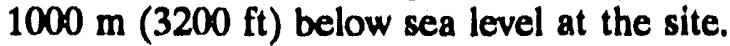

"There are no known faults at or near the PBA, and therefore there is no apparent hazard due to possible surface fault rupture. The nearest known faulting is not active and is seen in Paleozoic rocks near Little Rock, Arkansas, about $49 \mathrm{~km}$ (30 miles) from PBA. The New Madrid Seismic Zone, located about $130 \mathrm{~km}(92$ miles) northeast of the site, is the dominant source of major earthquakes in the region. Active faulting associated with seismicity has been identified in the New Madrid Seismic Zone, and it was the source of extremely destructive and far-reaching earthquakes in 1811-1812. The maximum earthquake at the site would be a repetition of the December 16,1811 event having a magnitude (body-wave) of about 7.5 and creating Modified Mercalli Intensity of IX at the site. It is estimated that this event would produce $0.34 \mathrm{~g}$ peak ground acceleration at the site. The same PGA would be produced by the maximum earthquake for the Wichita-Ouachita province $(\mathrm{mb}=6.2)$ located at the site. An appropriate response spectrum and time history for this event, which envelopes ground motions that would be produced by both a near-field and a far-field earthquake, are given in the PBA report. The duration of strong shaking is estimated to be $20 \mathrm{s."}$

The design response spectra referred to in Blume's summary are the simplified 84th percentile spectra of Seed and others (1976) for stiff soil and rock. Table 3 provides salient facts with respect to maximum expected earthquakes in tectonic zones and provinces near PBA and expected mean peak ground accelerations generated at 
PBA by these earthquakes. As indicated by the table, maximum expected earthquakes in the Wichita-Ouachita and New Madrid tectonic zones produce the largest peak ground accelerations at PBA. The epicenter of the Wichita-Ouachita earthquake is assumed to be on-site and the epicenter of the New Madrid earthquake is assumed to be located at the closest distance $[130 \mathrm{~km}(92 \mathrm{mi})]$ from PBA.

Table 3. Estimated peak ground acceleration at Pine Bluff Arsenal

\begin{tabular}{lcccc}
\hline $\begin{array}{c}\text { Tectonic } \\
\text { zone or province }\end{array}$ & $\begin{array}{c}\text { Maxinum } \\
\text { earthquake } \\
\left(\mathrm{m}_{\mathrm{b}}\right)\end{array}$ & $\begin{array}{c}\text { Minimum } \\
\text { distance } \\
\text { to PBA } \\
(\mathrm{km})\end{array}$ & $\begin{array}{c}\text { Intensity at } \\
\text { PBA } \\
\left(\mathrm{I}_{\mathrm{mm}}\right)\end{array}$ & $\begin{array}{c}\text { PGA } \\
(\mathrm{mean})\end{array}$ \\
\hline Wichita-Ouachita & 6.2 & at site & $\mathrm{IX}$ & $0.34 \mathrm{~g}^{\mathrm{a}}$ \\
Central United States & 5.5 & 40 & $\mathrm{VI}+$ & $0.08 \mathrm{~g}^{\mathrm{a}}$ \\
Gulf Coastal & 5.5 & 160 & $\mathrm{IV}$ & $0.01 \mathrm{~g}^{\mathrm{a}}$ \\
Ozark & 6.5 & 110 & $\mathrm{VI}+$ & $0.08 \mathrm{~g}^{\mathrm{a}}$ \\
New Madrid & $\mathrm{m}_{\mathrm{b}}=7.5$ & 130 & $\mathrm{IX}$ & $0.32 \mathrm{~g}^{\mathrm{b}}$ \\
\hline
\end{tabular}

'Based on Herrmann, 1981.

'Based on Murphy and O'Brien, 1977.

Source: Jacobs Engineering Group, Inc. and URS/John A. Blume and Associates, 1987.

In conclusion, no significant differences exist between the FPEIS seismic data and the seismic data gathered during Phase I that would warrant recomputation of risk. The potential for on-site liquefaction is less in the site-specific analysis than was the case for the FPEIS and the potential for surface rupture during an earthquake at PBA remains unlikely as presented in the FPEIS.

\section{Aircraft activity}

A review of the PBA accident data base indicates that aircraft crashes have the potential to significantly affect only continued storage risks. Because of the relatively large amounts of chemical munitions being stored over an extended period of time, air space restrictions could reduce the risks of continuous storage. For example, consideration in the FPEIS risk analysis of airspace restriction for PBA as a mitigative measure indicated that such action would have no significant impact on risk at PBA for 
any alternative other than continued storage (see U.S. Army 1988). For this reason, any new data on aircraft activity would not have the potential to preferentially affe $t$ measures of risk at PBA from on-site disposal or on-site activities associated with transportation (i.e., only continued storage would be affected). Consequently, new information would have little potential to affect risk among alternatives and thus are not considered further in this section.

\section{Meteorites and tornadoes}

Data used in the FPEIS for expected frequencies of tornadoes and meteorite strikes in the PBA vicinity are contained in Appendix A (Table A.1). These data were examined and found to be reasonable. No more recent or detailed data for these parameters beyond those in the FPEIS were located.

\subsubsection{Population}

The FPEIS presented the residential population around PBA as of the 1980 Census by radial sector and distance out to $100 \mathrm{~km}$ (62 miles), as shown in Table 4 (U.S. Army 1988). As stated in Sect. 2, the FPEIS method for identifying the environmentally preferred alternative is based on residential population only and does not include place-of-work or on-post populations. Because the 1980 census data will be over 10 years old by the time construction and operation of the proposed disposal facility begins at PBA, the latest population estimates (i.e., for 1986) have been used to adjust the 1980 census data. Population estimates in non-census years are limited to county populations and populations within incorporated areas. A two-step process was used to estimate the population change at the enumeration district level in this assessment. First, the estimated population changes for incorporated areas in each potentially affected county were equally apportioned among enumeration districts comprising the named area. Second, the unaccounted-for change in county population was equally apportioned among enumeration districts comprising the nonincorporated areas.

As in the FPEIS, these population estimates were assigned to a grid. Whereas the estimates used in the FPEIS considered only population and enumeration district location in creating the grid-based population, the Phase I estimation method excludes population from areas that are clearly not residential (e.g., installation boundaries of PBA, Lake Pine Bluff, Arkansas River, state parks, wildlife management areas, etc.). The effect of using this exclusion information is to create population distributions with larger concentrations of population than were in the FPEIS. However, these concentrated population areas are now accompanied by areas that were described as having small, but nonzero, populations according to the FPEIS.

The revised residential population data are presented in Table 5 in the same format used in the FPEIS. The effect of using the 1986 population estimates is to increase the total population within the $100-\mathrm{km}(62-$ mile) zone by about $2 \%$. An 
Table 4. Residential population distribution around the Pine Bluff Arsenal proposed plant site as given in the Final Programmatic Environmental Impact Statement

\begin{tabular}{|c|c|c|c|c|c|c|c|c|}
\hline \multirow[t]{2}{*}{ Direction } & \multicolumn{8}{|c|}{$\begin{array}{l}\text { Incremental population data at specified distances } \\
(\mathrm{km})^{\mathrm{b}}\end{array}$} \\
\hline & $0-1$ & $1-2$ & $2-5$ & $5-10$ & $10-20$ & $20-35$ & $35-50$ & $50-100$ \\
\hline $\mathbf{N}$ & 2 & 3 & 26 & 115 & 459 & 1,218 & 12,536 & 77,010 \\
\hline $\mathrm{NN}_{3}$ & 2 & 2 & 8 & 54 & 198 & 3,281 & 1,120 & 22,061 \\
\hline NE & 2 & 1 & 7 & 51 & 232 & 1,663 & 1,133 & 11,415 \\
\hline ENE & 1 & 1 & 7 & 71 & 304 & 1,918 & 2,537 & 17,982 \\
\hline $\mathrm{E}$ & 1 & 1 & 8 & 18 & 534 & 2,186 & 776 & 9,623 \\
\hline ESE & 3 & 3 & 10 & 2 & 73 & 879 & 792 & 6,319 \\
\hline SE & 3 & 4 & 62 & 244 & 16,866 & 2,147 & 1,768 & 14,158 \\
\hline SSE & 2 & 1 & 134 & 2,069 & 41,801 & 5,340 & 1,812 & 18,791 \\
\hline$S$ & 2 & 1 & 102 & 1,114 & 4,141 & 1,660 & 2,418 & 14,824 \\
\hline SSW & 1 & 1 & 16 & 564 & 612 & 767 & 753 & 12,751 \\
\hline SW & 2 & 3 & 39 & 246 & 516 & 639 & 396 & 7,110 \\
\hline WSW & 3 & 10 & 163 & 35 & 441 & 2,261 & 949 & 15,754 \\
\hline W & 3 & 16 & 203 & 12 & 511 & 3,912 & 1,927 & 58,424 \\
\hline WNW & 3 & 17 & 184 & 246 & 770 & 766 & 13,960 & 41,829 \\
\hline NW & 3 & 11 & 111 & 304 & 647 & 4,808 & 23,055 & 18,415 \\
\hline NNW & 3 & 9 & 78 & 192 & 707 & 4,169 & 145,350 & 136,557 \\
\hline Total & $\overline{36}$ & 81 & $1, \overline{158}$ & 5,337 & $\overline{68,812}$ & $\overline{37,614}$ & $\overline{211,282}$ & 483,023 \\
\hline
\end{tabular}

'Latitude $34.34^{\circ} \mathrm{N}$; Longitude $92.11^{\circ} \mathrm{W}$.

'Multiply by 0.6214 to obtain miles.

Source: U.S. Department of Commerce, Bureau of the Census, County and City Data Book, U.S. Government Printing Office, Washington, D.C., 1986. 
Table 5. 1986 residential population distribution around the Pine Bluff Arsenal proposed disposal facility" site using data collected during Phase I

\begin{tabular}{|c|c|c|c|c|c|c|c|c|}
\hline \multirow[t]{2}{*}{ Direction } & \multicolumn{8}{|c|}{$\begin{array}{l}\text { Incremental population data at specified distances } \\
\qquad(\mathrm{km})^{\mathrm{b}}\end{array}$} \\
\hline & $0-1$ & $1-2$ & $2-5$ & $5-10$ & $10-20$ & $20-35$ & $35-50$ & $50-100$ \\
\hline $\mathbf{N}$ & 0 & 0 & 54 & 135 & 305 & 1,392 & 1,634 & 63,461 \\
\hline NNE & 0 & 0 & 26 & 70 & 172 & 4,028 & 2,074 & 21,206 \\
\hline NE & 0 & 0 & 30 & 97 & 344 & 1,641 & 1,175 & 12,514 \\
\hline ENE & 0 & 0 & 20 & 100 & 371 & 1,812 & 4,724 & 14,217 \\
\hline E & 0 & 0 & 3 & 73 & 615 & 2,028 & 538 & 8,728 \\
\hline ESE & 0 & 0 & 1 & 3 & 205 & 1,007 & 547 & 5,072 \\
\hline SE & 0 & 0 & 2 & 1 & 1,493 & 1,572 & 1,806 & 15,417 \\
\hline SSE & 0 & 0 & 0 & 2 & 45,449 & 4,084 & 1,831 & 18,671 \\
\hline $\mathbf{S}$ & 0 & 0 & 0 & 2,078 & 13,702 & 2,561 & 2,000 & 14,646 \\
\hline SSW & 0 & 0 & 27 & 1,016 & 1,207 & 1,235 & 1,351 & 12,564 \\
\hline SW & 0 & 0 & 14 & 378 & 447 & 731 & 351 & 7,084 \\
\hline WSW & 0 & 0 & 30 & 301 & 431 & 1,862 & 1,238 & 15,478 \\
\hline W & 0 & 0 & 10 & 376 & 391 & 4,486 & 1,876 & 67,828 \\
\hline WNW & 0 & 0 & 0 & 249 & 795 & 1,006 & 8,460 & 45,146 \\
\hline NW & 0 & 0 & 11 & 187 & 679 & 4,582 & 42,656 & 25,214 \\
\hline NNW & 0 & 0 & 53 & 167 & 712 & 3,452 & 137,388 & 157,147 \\
\hline Total & 0 & 0 & 281 & 5,233 & $\overline{67,318}$ & 37,479 & 209,649 & 504,393 \\
\hline
\end{tabular}

'Latitude $34.36^{\circ} \mathrm{N}$; Longitude $92.08^{\circ} \mathrm{W}$.

'Multiply by 0.6214 to obtain miles.

Source: U.S. Department of Commerce, Bureau of the Census, County and City Data Book, Washington, D.C., 1986. 
estimated 17,007 additional people are located in the potentially impacted population zone around PBA compared with that population described in the FPEIS.

The data collected during Phase I have revealed that no persons live within $2 \mathrm{~km}$ (1.2 miles) of the proposed disposal facility, whereas the FPEIS assumed that 120 persons live within the 2-km zone. Approximately 877 fower people live in the 2-to $5-\mathrm{km}$ (1.2- to 3.1-mile) range than were assumed in the FPEIS. This change primarily results from including the installation boundary, thus excluding residents within the boundary, and from shifting the coordinates of the proposed disposal site to reflect its location more accurately. The on-site population will be included in the site-specific environmental impact statement. Additionally, it was determined during the Phase I process that the nearest off-site resident to the proposed disposal facility is located $2.3 \mathrm{~km}$ (1.4 miles) to the northeast; across the Arkansas River.

Even though the relative change in residential population is not large, it does warrant reexamination of the FPEIS measures of risk for two reasons: (1) the absolute number of people affected is important, regardless of percentages, when dealing with potential fatalities and (2) the relocation of the population resulting from use of the actual boundary of PBA could affect the FPEIS measures of risk. An examination of the accident data base for PBA shows that at least $46 \%$ of the total accidents at PBA have no potential to produce fatalities beyond distances of $2.3 \mathrm{~km}$ (1.4 miles) from the site of the proposed disposal facilities. Eliminating population in this distance category by using actual installation boundaries could thus have a substantial effect on reducing the magnitudes of some of the FPEIS measures of risk for PBA. Also, because the alternatives are represented by accidents in different distance categories, there is a potential for the new data to preferentially affect a given risk measure for a given alternative.

At PBA the chemical agent storage area is located approximately $4 \mathrm{~km}$ ( 2.5 miles) from the proposed disposal site and approximately $0.6 \mathrm{~km}(0.4 \mathrm{mile})$ from the PBA northwest installation boundary. Private, residential housing is situated just outside the boundary in this area, with the nearest off-site resident approximately $0.8 \mathrm{~km}(0.5 \mathrm{mile})$ from the storage area. The FPEIS assumed that potential accidents at PBA would affect the population closest to the disposal facility. However, accidents occurring at the storage area and the proposed disposal site could involve different populations. A number of potential short-distance events (including transport accidents) under CML weather conditions would result in different fatality estimates based on releases from the two locations.

Table 6 presents the same type of population data for the storage area as is presented in Table 5 for the proposed disposal site. A transportation accident could occur anywhere within the storage area or along the route to the proposed disposal site. However, for conservatism (worst case) in risk data development, a point was selected in the northwest corner of the storage area, as close as possible to the largest number of offsite residents. These data indicate that 379 people live within $2 \mathrm{~km}(1.2 \mathrm{miles})$ of the storage area. Furthermore, 6413 more people are located in the $100-\mathrm{km}$ (62-mile) potentially impacted population zone of the storage area than are located in the same zone of the disposal site. 
Table 6. 1986 residential population distribution around the Pine Bluff Arsenal chemical agent storage area"

\begin{tabular}{|c|c|c|c|c|c|c|c|c|}
\hline \multirow[t]{2}{*}{ Direction } & \multicolumn{7}{|c|}{$\begin{array}{l}\text { Incremental population data at specified distances } \\
(\mathrm{km})^{\mathrm{b}}\end{array}$} & \multirow[b]{2}{*}{$50-100$} \\
\hline & $0-1$ & $1-2$ & $2-5$ & $5-10$ & $10-20$ & $20-35$ & $35-50$ & \\
\hline $\mathbf{N}$ & 0 & 0 & 55 & 105 & 704 & 1,682 & 21,774 & 79,933 \\
\hline NNE & 0 & 0 & 49 & 210 & 201 & 2,523 & 1,357 & 24,928 \\
\hline $\mathrm{NE}$ & 0 & 0 & 17 & 161 & 132 & 2,527 & 1,162 & 12,149 \\
\hline ENE & 0 & 0 & 0 & 117 & 238 & 2,074 & 1,879 & 17,357 \\
\hline $\mathrm{E}$ & 0 & 0 & 0 & 18 & 345 & 2,302 & 861 & 8,683 \\
\hline ESE & 0 & 0 & 0 & 4 & 33 & 859 & 1,020 & 5,447 \\
\hline SE & 0 & 0 & 1 & 477 & 19,965 & 11,077 & 1,702 & 13,291 \\
\hline SSE & 0 & 4 & 30 & 1,897 & 27,747 & 7,720 & 1,652 & 19,524 \\
\hline$S$ & 0 & 17 & 43 & 690 & 1,993 & 1,728 & 2,472 & 14,492 \\
\hline SSW & 17 & 36 & 110 & 364 & 356 & 795 & 618 & 13,093 \\
\hline SW & 9 & 54 & 106 & 145 & 287 & 801 & 530 & 7,318 \\
\hline WSW & 19 & 54 & 35 & 53 & 451 & 2,343 & 1,031 & 16,706 \\
\hline W & 13 & 53 & 31 & 61 & 522 & 3,856 & 2,185 & 66,907 \\
\hline WNW & 9 & 41 & 64 & 162 & 761 & 695 & 20,448 & 35,891 \\
\hline NW & 0 & 32 & 71 & 201 & 649 & 5,999 & 20,332 & 16,699 \\
\hline NNW & 0 & 21 & 72 & 187 & 646 & 8,002 & 174,718 & 108,679 \\
\hline Total & 67 & 312 & $\overline{684}$ & $\overline{4,852}$ & $\overline{55,030}$ & 54,983 & 253,741 & $\overline{461,097}$ \\
\hline
\end{tabular}

'Latitude $34.35^{\circ} \mathrm{N}$; Longitude $92.13^{\circ} \mathrm{W}$.

'Multiply by 0.6214 to obtain miles.

Source: U.S. Department of Commerce, Bureau of the Census, County and City Data Book, Washington, D.C., 1986. 
The risks of all the disposal alternatives, as well as continued storage, could potentially be increased because of the proximity of the storage area to the boundary at PBA. The risks associated with the on-site disposal alternative could also be affected by the 4- $\mathrm{km}(2.5-\mathrm{mile})$ separation of the proposed disposal site from the storage area and the different populations that could potentially be reached by an accidental release. It was determined, therefore, that the PBA levels of risk should be reevaluated to assess the effects of potential storage area releases on the measures of risk.

\subsubsection{Summary}

Evaluation of data collected during Phase I for PBA indicates that in terms of information used to develop the five FPEIS measures of risk, the new residential population data, the choice of CML meteorological conditions, and the location of the chemical agent storage area warrant recalculation of risk. The accident data base did not undergo sufficient change to be factored into computation of risk and thus is not further considered in this Phase I Environmental Report. No significant new information was found for on-site transport, seismicity, aircraft activity, or meteorites and tornadoes that would warrant recomputation of risk; therefore, these factors are not examined further in this report.

\subsubsection{Evaluating Measures of Risk with Data Collected During Phase I}

As discussed in Sect. 2, comparison of FPEIS and Phase I data is used as a screening tool to identify those factors that should be incorporated into a recalculation of the FPEIS measures of risk. Recomputing the five measures of risk with the data collected during Phase I and evaluating the results using the FPEIS decision method allows an evaluation of the suitability of on-site disposal.

As discussed in the previous section, changes in population data were found to be large enough to warrant reestimation of fatalities and recomputation of the five measures of risk. To maintain consistency with the FPEIS, only residential population is used. On-post population data have been gathered for use in the PBA EIS and are presented in Sect. 3.2.5. All population data will be considered in estimating fatalities for the site-specific EIS. The discussion that follows addresses the effect of updated population data for the region around PBA, the effect of the distance separating the storage area and proposed disposal site (see Sect. 3.1.2.1), and the effect of using a CML meteorological condition different from that used in the FPEIS (see Sect. 3.1.2.2).

Risks for the continued storage and off-site disposal alternatives involve the storage site previously discussed, approximately $0.8 \mathrm{~km}(0.5 \mathrm{mile})$ from off-site population. For on-site cisposal, transport accidents were assumed to occur at the storage area site; population numbers were developed, and potential fatalities were calculated. The same procedure was carried out for the proposed disposal site using the population specific to that site [2.3 km (1.4 miles) to the nearest off-site resident]. The potential fatalities for the two sites were then assessed together to develop the measures of risk for the on-site disposal alternative. 
The first step in evaluating the measures of risk is to compute estimated maximum and average fatalities. For each distance category, average fatalities are computed by calculating the mean fatalities for 360 equally spaced plumes around the site of the proposed disposal facility, and potential maximum fatalities are taken to be the largest number of fatalities from these 360 plumes.

Overlaying the updated population of Table 5 with the plumes from the same assumed meteorological conditions used in the FPEIS (see Appendix A, Fig. A-3) gives new fatality estimates for accidental releases of agent at the PBA disposal site. These revised fatality estimates are presented in Table 7. For comparison, Table 8 repeats the original PBA fatality estimates from the FPEIS (see FPEIS, Table 4.3.6).

In Table 7, the major difference between the revised and the FPEIS fatality estimates is that the number of fatalities for distances of $2 \mathrm{~km}$ (1.2 miles) or less drops to zero because, contrary to what was assumed in the FPEIS, there is no actual off-post residential population that close to the site of the proposed disposal facility. For distances to $50 \mathrm{~km}$ ( 31 miles), the fatalities are less than those estimated in the FPEIS for all meteorological conditions. For distances beyond $50 \mathrm{~km}$ (31 miles), the potential maximum fatality estimates based on the new residential population estimates are somewhat larger than those in the FPEIS. These differences are attributable largely to the increase in population since the 1980 census and to the consideration of population exclusion areas as described previously. The greatest numerical increase in the estimated fatalities in Table 7 is in the $100-\mathrm{km}(62-$ mile) potential maximum WC category, where the estimate increases $3.2 \%$ (from 15,500 in the FPEIS to 16,000 in Phase I). The next largest increase (400 persons) in the average $100-\mathrm{km}$ (62-mile) WC category is also the largest percentage increase at $17.4 \%$.

Another factor identified as warranting reevaluation of risks is the potential for an accident in the chemical agent storage area that is located close to the PBA boundary. To assess the risks associated with releases from the storage area conservatively (worst case), in the current analysis, all of the transport accidents were assumed to occur there. Thus the impacts to the population located closest to the storage area were maximized. In the FPEIS, transportation accidents accounted for approximately $85 \%$ of the risk associated with on-site disposal. Plant operations events resulted in $15 \%$ of the on-site risk, with handling events contributing only less than $1 \%$. A transport accident could occur anywhere along the on-site transport route; however, most of the route for on-site disposal is outside the storage area in an easterly direction, toward the center of the PBA facility and away from the off-site population. Table 9 provides fatality estimates for the new storage site using 1986 census data. These data confirm the fact that fatalities could occur within $1 \mathrm{~km}(0.6$ mile) of the storage area.

The fatality estimates given in Tables 7 and 9 were used to compute each of the five measures of risk for on-site disposal, continued storage, and on-site activities associated with off-site transport. The revised risk pictogram is shown in Fig. 10b along with values from the original FPEIS pictogram (FPEIS, Fig. 4.3.5) for comparison (Fig. 10a).

Examination of the PBA Phase I fatality estimate table for the 5-km (3-mile) distance category shows that there is an approximate 5-fold maximum increase in the 
Table 7. Estimated fatalities by dowwwind distance for selected meteorological conditions for Pine Bluff Arsenal proposed disposal site using data collected during the Phase I process

\begin{tabular}{|c|c|c|c|c|}
\hline \multicolumn{5}{|c|}{ Phase I fatalities } \\
\hline \multicolumn{3}{|c|}{ Average } & \multicolumn{2}{|c|}{ Potential Maximum } \\
\hline $\begin{array}{l}\text { Downwind } \\
\text { distance } \\
(\mathrm{km}) \\
\end{array}$ & $\begin{array}{l}\text { Conservative } \\
\text { most likely (CML) } \\
\text { meteorological } \\
\text { conditions }^{c}\end{array}$ & $\begin{array}{l}\text { Worst case (WC) } \\
\text { meteorological } \\
\text { conditions }\end{array}$ & $\begin{array}{l}\text { Conservative } \\
\text { most likely } \\
\text { meteorological } \\
\text { conditions }^{\mathrm{c}} \\
\end{array}$ & $\begin{array}{l}\text { Worst case } \\
\text { meteorological } \\
\text { conditions }^{\mathrm{c}}\end{array}$ \\
\hline 0.5 & 0 & 0 & 0 & 0 \\
\hline 1.0 & 0 & 0 & 0 & 0 \\
\hline 2.0 & 0 & 0 & 0 & 0 \\
\hline 5.0 & 1 & 1 & 4 & 2 \\
\hline 10.0 & 10 & 5 & 50 & 20 \\
\hline 20.0 & 130 & 50 & 1,200 & 600 \\
\hline 50.0 & $\mathrm{NA}^{\mathrm{d}}$ & 500 & $N A^{d}$ & 4,600 \\
\hline 100.0 & $N^{d}$ & 2,700 & $N^{d}$ & 16,000 \\
\hline
\end{tabular}

The number of deaths is rounded.

The average fatalities equals the mean of fatalities from all possible plumes in a $360^{\circ}$ arc around the site. The potential maximum fatalities equals the fatalities from a plume traveling over the greatest population density.

'Conservative most likely (CML) conditions are D stability and a windspeed of $3 \mathrm{~m} / \mathrm{s}$; worst case (WC) conditions are E stability and a wind speed of $1 \mathrm{~m} / \mathrm{s}$. Note that the fatality entries in this table are organized by downwind distance and not by the quantity of chemical agent released. The fatality estimates are larger for an accident in the same downwind distance category under CML conditions than for WC conditions because the CML plume is larger and hence covers a larger area. However, for a given quantity of chemical agent released in an accident, the WC conditions would produce a larger downwind distance than CML conditions and would therefore give a larger number for estimated fatalities.

${ }^{d} \mathrm{NA}=$ not applicable; the largest credible accident does not travel this distance under CML conditions. 
Table 8. Estimated fatalities by downwind distance for selected meteorological conditions for Pine Bluff Arsenal, as given in the Final

Programmatic Environmental Impact Statement

\begin{tabular}{|c|c|c|c|c|}
\hline \multicolumn{5}{|c|}{ FPEIS fatalities ${ }^{2, b}$} \\
\hline $\begin{array}{l}\text { Downwind } \\
\text { distance } \\
\text { (km) }\end{array}$ & $\begin{array}{c}\text { Conservative } \\
\text { most likely (CML) } \\
\text { meteorological } \\
\text { conditions }^{\circ}\end{array}$ & $\begin{array}{l}\text { Worst case (WC) } \\
\text { meteorological } \\
\text { conditions }^{\mathfrak{c}}\end{array}$ & $\begin{array}{l}\text { Conservative } \\
\text { most likely } \\
\text { meteorological } \\
\text { conditions }^{c}\end{array}$ & $\begin{array}{l}\text { Worst case } \\
\text { meteorological } \\
\text { conditions }^{\circ}\end{array}$ \\
\hline 0.5 & $1^{d}$ & 0 & $1^{d}$ & $1^{d}$ \\
\hline 1.0 & 1 & 1 & 2 & 1 \\
\hline 2.0 & 1 & 1 & 5 & 3 \\
\hline 5.0 & 6 & 2 & 25 & 20 \\
\hline 10.0 & 32 & $1 \overline{5}$ & 95 & 40 \\
\hline 20.0 & 275 & 100 & 2,000 & 925 \\
\hline 50.0 & $\mathrm{NA}^{\circ}$ & 500 & $N^{e}$ & 5,400 \\
\hline 100.0 & $\mathrm{NA}^{e}$ & 2,300 & $N^{e}$ & 15,500 \\
\hline
\end{tabular}

The number of deaths is rounded. FPEIS = final programmatic environmental impact statement.

The average fatalities equals the mean of fatalities from all possible plumes in a $360^{\circ}$ arc around the site. The potential maximum fatalities equals the fatalities from a plume traveling over the greatest population density.

${ }^{\circ}$ Conservative most likely (CML) conditions are $\mathrm{D}$ stability and a windspeed of $3 \mathrm{~m} / \mathrm{s}$; worst case (WC) conditions are E stability and a wind speed of $1 \mathrm{~m} / \mathrm{s}$. Note that the fatality entries in this table are organized by downwind distance and not by the quantity of chemical agent released. The fatality estimates are larger for an accident in the same downwind distance category under CML conditions than for WC conditions because the CML plume is larger and hence covers a larger area. However, for a given quantity of chemical agent released in an accident, the WC conditions would produce a larger downwind distance than CML conditions and would therefore give a larger number for estimated fatalities.

'The 1's shown for the 0.5 distance in the FPEIS resulted from a typographical error. All columns should have contained 0's for that distance.

'NA = not applicable, because the largest credible accident does not travel this distance under CML conditions. 
Table 9. Estimated fatalities by downwind distance for selected meteorological conditions for Pine Bluff Arsenal storage area using data collected during the Phase I process

\begin{tabular}{|c|c|c|c|c|}
\hline \multicolumn{5}{|c|}{ Phase I fatalities } \\
\hline \multicolumn{3}{|c|}{ Average } & \multicolumn{2}{|c|}{ Potential maximum } \\
\hline $\begin{array}{l}\text { Downwind } \\
\text { distance } \\
(\mathrm{km}) \\
\end{array}$ & $\begin{array}{c}\text { Conservative } \\
\text { most likely (CML) } \\
\text { meteorological } \\
\text { conditions }^{\circ}\end{array}$ & $\begin{array}{l}\text { Worst case (WC) } \\
\text { meteorological } \\
\text { conditions }^{\complement}\end{array}$ & $\begin{array}{l}\text { Conservative } \\
\text { most likely } \\
\text { meteorological } \\
\text { conditions }^{\circ} \\
\end{array}$ & $\begin{array}{c}\text { Worst case } \\
\text { meteorological } \\
\text { conditions }^{c}\end{array}$ \\
\hline 1.0 & 0 & 0 & 1 & 3 \\
\hline 2.0 & 1 & 0 & 8 & 5 \\
\hline 5.0 & 8 & 2 & 40 & 20 \\
\hline 10.0 & 30 & 10 & 80 & 40 \\
\hline 20.0 & 130 & 50 & 1,500 & 750 \\
\hline 50.0 & $N^{d}$ & 504 & $N^{d}$ & 5,300 \\
\hline 100.0 & $N^{d}$ & 2,700 & $\mathrm{NA}^{\mathrm{d}}$ & 17,000 \\
\hline
\end{tabular}
impact statement.

The number of deaths is rounded. FPEIS = final programmatic environmental

The average fatalities equals the mean of fatalities from all possible plumes in a $360^{\circ}$ arc around the site. The potential maximum fatalities equals the fatalities from a plume traveling over the greatest population density.

'Conservative most likely (CML) conditions are D stability and a windspeed of $3 \mathrm{~m} / \mathrm{s}$; worst case (WC) conditions are E stability and a wind speed of $1 \mathrm{~m} / \mathrm{s}$. Note that the fatality entries in this table are organized by downwind distance and not by the quantity of chemical agent released. The fatality estimates are larger for an accident in the same downwind distance category under CML conditions than for WC conditions because the CML plume is larger and hence covers a larger area. However, for a given quantity of chemical agent released in an accident, the WC conditions would produce a larger downwind distance than CML conditions and would therefore give a larger number for estimated fatalities.

${ }^{d} \mathrm{NA}=$ not applicable, because the largest credible accident does not travel this distance under CML conditions. 


\subsection{5}

\begin{tabular}{|c|c|c|c|c|c|}
\hline Alternatlves & $\begin{array}{l}\text { Probubillity } \\
\text { of One } \\
\text { of More } \\
\text { Fatulitios }\end{array}$ & $\begin{array}{l}\text { Maximum } \\
\text { Number of } \\
\text { Fatulitios }\end{array}$ & $\begin{array}{l}\text { Expeoted } \\
\text { Fintultites }\end{array}$ & $\begin{array}{l}\text { Peraon- } \\
\text { Yeare } \\
\text { of Plok }\end{array}$ & $\begin{array}{l}\text { Expooted } \\
\text { Plume } \\
\text { Arra } \\
\text { (kmin) }\end{array}$ \\
\hline \multicolumn{6}{|l|}{$\begin{array}{l}\text { Contrued Storape } \\
2 B \text { Yra. (STR) }\end{array}$} \\
\hline $\begin{array}{l}\text { On-Site Disposal } \\
\text { (ONB) }\end{array}$ & & & & $\therefore$ & \\
\hline $\begin{array}{l}\text { Regional Dlaposal } \\
\text { (REG) }\end{array}$ & & & & & \\
\hline
\end{tabular}

A. ORIGINAL PICTOGRAM (FROM THE FPEIS)

\begin{tabular}{|c|c|c|c|c|c|}
\hline Alternatlves & $\begin{array}{l}\text { Probuablity } \\
\text { of One } \\
\text { of More } \\
\text { Fatulitios }\end{array}$ & $\begin{array}{l}\text { Maximum } \\
\text { Numbor of } \\
\text { Fatulition }\end{array}$ & $\begin{array}{l}\text { Expected } \\
\text { Fatulities }\end{array}$ & $\begin{array}{l}\text { Perron- } \\
\text { Years } \\
\text { at Pisk }\end{array}$ & $\begin{array}{l}\text { Expected } \\
\text { Phume } \\
\text { Arun } \\
\text { (kmin) }\end{array}$ \\
\hline $\begin{array}{c}\text { Conthued Storage } \\
25 \text { Yrs. (STR) }\end{array}$ & & & & & \\
\hline $\begin{array}{c}\text { On-Bit Disponal } \\
\text { (ONS) }\end{array}$ & & & & & \\
\hline $\begin{array}{l}\text { Regional Dlsposal } \\
\text { (REG) }\end{array}$ & & & & & \\
\hline
\end{tabular}

B. REVISED PICTOGRAM (USING PHASE I FATALITY DATA)

\begin{tabular}{|c|c|c|c|c|c|c|}
\hline \multirow[b]{2}{*}{ Legend } & \multicolumn{6}{|c|}{ Numerical Equivalents } \\
\hline & $\begin{array}{l}\text { Relativo } \\
\text { Shading }\end{array}$ & $\begin{array}{c}\text { Probability } \\
\text { of One } \\
\text { or More } \\
\text { Fatalities }\end{array}$ & $\begin{array}{l}\text { Maximum } \\
\text { Number of } \\
\text { Fatalitles }\end{array}$ & $\begin{array}{l}\text { Expected } \\
\text { Fatalities }\end{array}$ & $\begin{array}{l}\text { Person- } \\
\text { Years } \\
\text { at Alisk }\end{array}$ & $\begin{array}{c}\text { Expected } \\
\text { Plume } \\
\text { Area } \\
\text { (km') }\end{array}$ \\
\hline Higher & & $>10^{-3}$ & $>10,000$ & $>10^{-4}$ & $>10^{\prime}$ & $>10^{\prime}$ \\
\hline & & $10^{-4}-10^{-0}$ & $\begin{array}{l}5,000 \\
10,000\end{array}$ & $10^{-3}-10^{-1}$ & $10^{9}-10$ & $10^{-2}-10^{-4}$ \\
\hline & & $10^{-4}-10^{-4}$ & $1,000-5,000$ & $10^{-4}-10$ & $10^{4}-10^{4}$ & $10^{-4}-10^{-5}$ \\
\hline Lower & & $<10^{-}$ & $<1,000$ & $<10-$ & $<10^{4}$ & $<10^{-4}$ \\
\hline
\end{tabular}

Fig. 10. Risk with mitigation, in the vicinity of Pine Bluff Arsenal (PBA) for programmatic alternatives. (Risk along transportation corridors or at a national destruction site is not included.) 
number of estimated fatalities when the transportation accidents are assumed to occur inside the chemical agent storage area. However, the increase over the FPEIS numbers in Phase I fatalities in the 5-km (3-mile) distance does not result in an increase in the on-site disposal risk sufficient to cause a pictogram shading increase for the three probabilistic risk measures. In fact, a one shading level decrease occurred in the probability of one or more fatalities for on-site dispossal. This resulted from the placement of the current disposal site farther away from the off-site population effectively deleting the risk of the short-distance events associated with disposal operations. If a one-shading increase had occurred in the Phase I pictogram, it would not be significant when compared with risks associated with the other alternatives. The one shading increase for the continued storage "probability of one or more fatalities" occurred because the storage yard accident for all alternatives was moved closer to the facility boundary and closer to the off-site population.

\subsubsection{Differences in the measures of risk from those in the FPEIS}

Figures $10 \mathrm{a}$ and $10 \mathrm{~b}$ present a pictogram depicting the five measures of risk for appropriate alternatives at PBA using FPEIS and Phase I data, respectively. National disposal is not shown because the risks of off-site transport would be the same for both the regional and national alternatives. Partial relocation was not considered in the FPEIS for PBA. Details on the computation of the measures of risk presented in Fig. 10 are discussed in Appendix A. The discussion below is limited to the differences between the FPEIS risks and the risks computed from newly collected data collected during Phase I. Site-specific conclusions are presented in Sect. 3.1.4.

- Probability of one or more fatalities. As shown in Table 5, there are no off-post residents within $2 \mathrm{~km}$ (1.2 miles) of the proposed disposal site at PBA. This value should be compared to the 120 residents specified in the FPEIS for the same region. As explained in Sect. 3.1.1.2, the difference is due to the use of the actual PBA installation boundary to locate the site-specific population. The FPEIS generically assumed that this distance was $500 \mathrm{~m}$ (0.31 miles).

The significance of this difference in population is directly reflected in the revisions to fatality estimates (Table 7) from those presented in the FPEIS (Table 8). As a result of fewer people living close to the proposed disposal site, small accidental releases of chemical agent, which in the FPEIS were predicted to cause fatalities within $2 \mathrm{~km}$ (1.2 miles) of the disposal facility, now would be predicted to produce no fatalities.

Table 6 indicates, however, that 379 persons reside within $2 \mathrm{~km}$ (1.2 miles) of the storage area. In order to develop a worst-case scenario, all transport accidents associated with on-site disposal were assumed to occur in the storage area as they would for all other alternatives. The specific transport accident site selected was $0.8 \mathrm{~km}(0.5 \mathrm{mile})$ from the nearest off-site resident.

Combining the potential fatalities from transport accidents and disposal operations accidents resulted in a one-shading decrease in the probability of one or more fatalities for the on-site disposal alternative. Disposal operations accidents, 
which accounted for $15 \%$ of the risk for on-site disposal, are all short-distance events, l.e., less than $2 \mathrm{~km}$ (1.2 miles). Thus, moving the proposed disposal site $4 \mathrm{~km}$ ( 2.5 miles) further away from the off-site population essentially deleted $15 \%$ of the risk. Transport accidents are longer distance events and affect approximately the same population as in the FPEIS.

Conversely, the continued storage alternative showed a one-shading level increase for the probability of one or more fatalities. The increase was less than one order of magnitude; however, the probability of one or more fatalities was near the top of the range for the continued storage alternative in the FPEIS, thus the increase was enough to place the revised value in a higher range on the pictogram. Regional disposal was low enough in the range that no change occurred in the pictogram shading.

- Maximum number of fatalities. Based upon newly collected population data for both the proposed disposal site and the storage area at PBA, the "maximum number of fatalities" for a $50-\mathrm{km}$ (30-mile) accident would be 4600 and 5300 , respectively (Tables 7 and 9). For a 100-km (62-mile) accident the numbers would be 16,000 and 17,000, respectively. These numbers can be compared to the FPEIS maximum fatality estimates of 5400 for the $50-\mathrm{km}$ (30-mile) accident and 15,500 for the $100-\mathrm{km}$ (62-mile) accident (Table 8). The pictogram shading does not change for this measure of risk for any of the FPEIS alternatives.

- Expected fatalities. Although "expected fatalities" were reduced somewhat, based on the Phase I population data, none of the alternatives changed significantly.

- Person-years at risk. The total population within the $100-\mathrm{km}$ (62-mile) potential impact zone increased by about $2 \%$ over the population data presented in the FPEIS for the PBA area. Since the periods for disposal or off-site transport operations at PBA are the same as they were in the FPEIS, "person-years at risk" for each alternative increased by only about $2 \%$. Therefore, the pictogram representation of "person-years at risk" does not change from that presented in the FPEIS.

- Expected plume area. Since neither the probability of an accident nor the resulting plume area was changed by the collection of data collected during Phase $I$, the "expected plume area" measure of risk did not change from that presented in the FPEIS.

\subsubsection{Effect of various meteorological conditions upon measures of risk}

As discussed in Sect. 3.1.1.1, high wind speeds are associated with a more effective atmospheric dispersion of chemical agent and result in a lower estimated dose than do low wind speeds. It is therefore not necessary to study the effect of atmospheric 
dispersion of chemical agent under meteorological conditions in stability class $D$ with wind speeds higher than $3 \mathrm{~m} / \mathrm{s}$ (the FPEIS choice for CML conditions) or in stability class $E$ with wind speeds higher than $1 \mathrm{~m} / \mathrm{s}$ (the choice for WC conditions). Based on the meteorological data in Table 1, it does appear that D stability and wind speeds below $3 \mathrm{~m} / \mathrm{s}$ warrant further study in regard to atmospherically dispersed doses of chemical agent and the recomputation of risk. The results of such a study are presented in this section.

A new site-specific CML meteorological condition was selected for study. Instead of $D$ stability and a wind speed of $3 \mathrm{~m} / \mathrm{s}$, the new CML condition was defined as $\mathrm{D}$ stability and $1 \mathrm{~m} / \mathrm{s}$. To further amplify any effect of the new CML condition compared with the FPEIS CML condition, the height of the niixed layer was chosen as $500 \mathrm{~m}$ for the new CML condition (as compared with $750 \mathrm{~m}$ in the FPEIS). The use of the new CML condition provides very conservative results (i.e., high-fatality estimates) compared with the FPEIS CML which is closer to the weighted average of the meteorological conditions provided in Table 1.

The combined effect of the lower wind speed and reduced height of the mixed layer produced higher doses of chemical agent at greater downwind distances than were reported in the FPEIS. New plume contours and new downwind accident distance categories (see Appendix A for a discussion of the concept) were generated from the D2PC atmospheric dispersion model with the new CML condition as input. The FPEIS methodology of computing estimated fatalities and then computing the five measures of risk was used to study the implications of the new CML meteorological condition at PBA.

Two sets of pictogram results were computed using (1) the new CML condition with the population distribution from the FPEIS (Table 4) and (2) the new CML condition with the updated population distribution (Table 5). The new pictograms were virtually identical to those in Fig. 10. Only the shading pattern for "expected plume area" for the on-site disposal alternative changed; it increased by one shading pattern in both of the two new sets of pictograms. This is not a significant difference from the FPEIS estimated risks. None of the other shading patterns changed for any of the other alternatives.

It is concluded that the choice of meteorological conditions to compute risks at PBA is inconsequential; it has no potential to change the FPEIS ranking of the alternatives.

\subsubsection{Identifying the Site-Specific Environmentally Preferred Alternative}

Figure 10b presents the revised, site-specific measures of risk from the perspective of the population residing near PBA. The regional disposal alternative is included as a surrogate for off-site transport from PBA. Cross-country transportation risks for an off-site disposal alternative are not shown but are assumed to remain the same as presented in the FPEIS for a regional or national disposal option. Results for the five measures of risk are as follows. 
Measure of risk

Probability of one or more fatalities

Maximum number of fatalities

Expected fatalities

Person-years at risk

Expected plume area
Result

All alternatives indistinguishable.

Continued storage shows somewhat higher risks than the other alternatives but not at a significant level.

All alternatives indistinguishable. On-site disposal appears to be somewhat preferable to the others, but not at a significant level.

All alternatives indistinguishable.

All alternatives indistinguishable.

All alternatives indistinguishable.

Based on an examination of Fig. 10b, the alternatives are indistinguishable (i.e., none of the alternatives showed a difference of two levels of shading, or two orders of magnitude, for any of the measures of risk). However, it should be noted that the risks from the proposed action (on-site disposal) are in all cases equal to, or less than, the risks from other alternatives.

The conclusion is that on-site disposal remains valid as the environmentally preferred alternative for PBA. From the perspective of the population near PBA, the risks from on-site disposal are in all cases equal to, or less than, the risks from other alternatives. If one adds the off-site transportation risks (not shown in Fig. 10 and beyond the scope of this report), the on-site alternative is preferable given the opportunity for risk reductions associated with emergency planning and preparedness activities that are under way at PBA.

\section{NEW INFORMATION AFFECTING IMPLEMENTATION OF ON-SITE DISPOSAL AT PINE BLUFF ARSENAL}

As discussed in Sect. 2, some of the resources and information, although considered in the FPEIS, were not overriding factors in comparing programmatic alternatives and in identifying the environmentally preferred alternative. These factors are air quality; surface water and groundwater; land use; ecology; and social, economic, and cultural resources. Some types of resource data (e.g., meteorology and aircraft activity) are germane to both Sects. 3.1 and 3.2 in that they were used to select the environmentally preferred alternative and were also used to assess potential environmental impacts not considered in the risk-based selection methou. Aspects of these data types are discussed in this section to the extent that they pertain to potential 
impacts from construction, to incident-free operation, and to accident scenarios. In this Phase I review, these resources are again being examined to determine if significant resources are present that could be affected by the proposed on-site disposal facilities. Emergency response is also discussed to provide a status of planning and preparedness activities at PBA.

\section{Meteorology/Air Quality}

Since the completion of the FPEIS, on-site meteorological data, including wind speed and direction, have been obtained for CY 1988 from two meteorological towers (Towers 1 and 6) located within the PBA installation. Towers 1 and 6 are part of a 7-tower meteorological network at PBA (Fig. 11). Tower 5 is somewhat closer to the proposed facility than Tower 6; however, Towers 1 and 6 are preferred because they house instruments that monitor winds at 15,30 , and $60 \mathrm{~m}$ above ground level (agl) while instruments at the other towers monitor winds at $60 \mathrm{~m}$ agl only, above the general height of interest for most applications in the site-specific EIS. The wind data from these towers can be compared with data that were used in the FPEIS from Pine Bluff Municipal Airport, located approximately $21 \mathrm{~km}$ (13 miles) southeast of the site for the proposed disposal facility, to determine which are more representative of the wind at the site of the proposed facility. Because the on-site towers are much nearer the facility, they should be more representative unless the data are inadequate or inaccurate. Althougt the available period of record is longer at Pine Bluff Airport, it is less recent (January 1950 to December 1954). Winds were measured at approximately $11 \mathrm{~m}(37 \mathrm{ft}) \mathrm{agl}$ at Pine Bluff Airport.

The wind data from Towers 1 and 6 at $15 \mathrm{~m}$ (49 ft) agl, nearest the general height of interest for most applications in the site-specific EIS, were used in the comparison. Quality control procedures were performed and determined that the quality of data appears reasonable. The wind data can be compared most easily in the form of uind roses that summarize the wind direction and speed at the sites. Figures $12 \mathrm{a}$ and $12 \mathrm{~b}$ present wind roses for PBA Towers 1 and 6 , and Fig. $12 \mathrm{c}$ displays the wind rose for Pine Bluff Municipal Airport that was used in the IPEIS. The wind roses depict the annual joint frequency distribution of wind speed and wind direction. In these graphs, winds blowing from each direction are plotted as individual bars that extend from the center of the circular diagram. Wind speeds are denoted by bar widths; the frequency of wind speed within each wind direction is depicted according to the length of the bar. Note that the points on the wind roses represent the directions from which the winds cume. The frequency is given as the percentage of the total number of measurements at the location.

A comparison of the two wind roses for PBA reveals a similar pattern: prevailing winds are generally from the south-southwest or north-northeast. This similar pattern suggests that the quality of data appears reasonable. The terrain at PBA is quite flat, and no dominant topographic feature broadly influences the wind direction. The small aifferences among wind roses are probably due to extremely localized flows. 


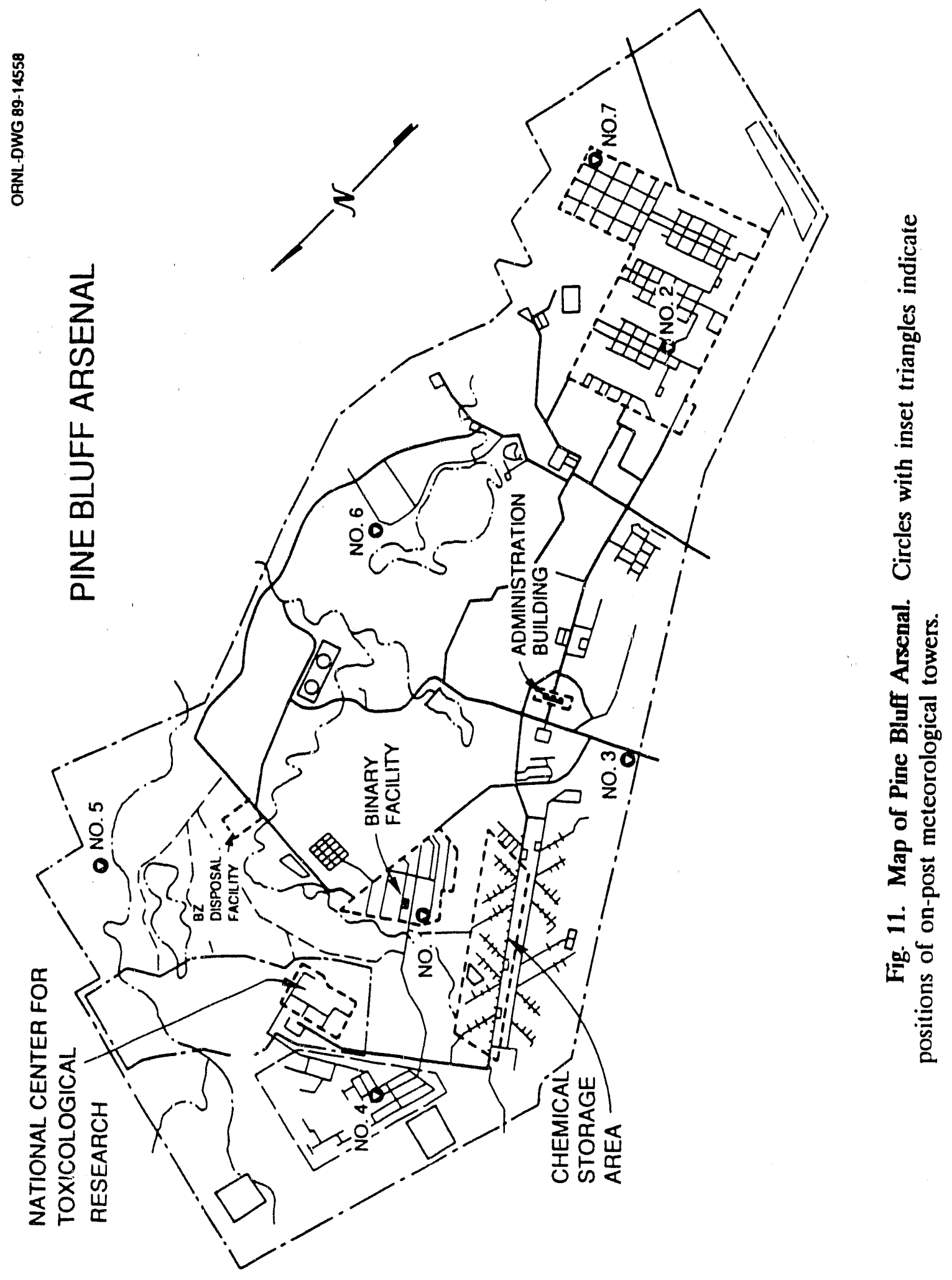


ORNL-DWG 87M-15363R2

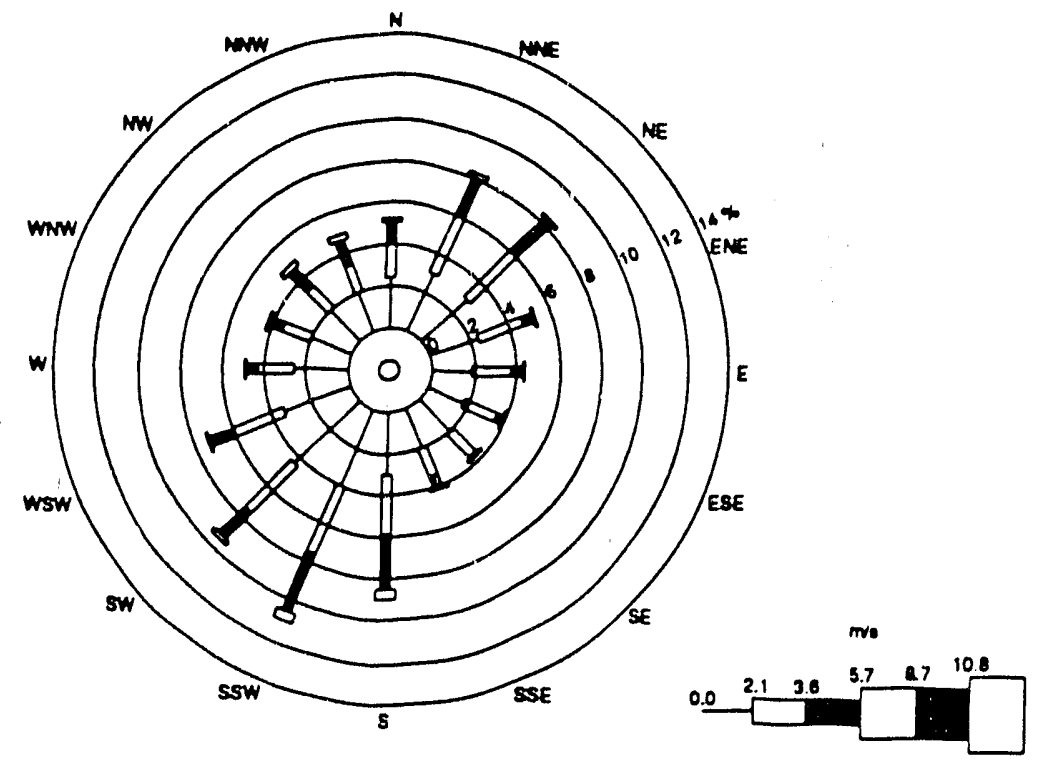

A. WIND ROSE FOR POST 1 TOWER

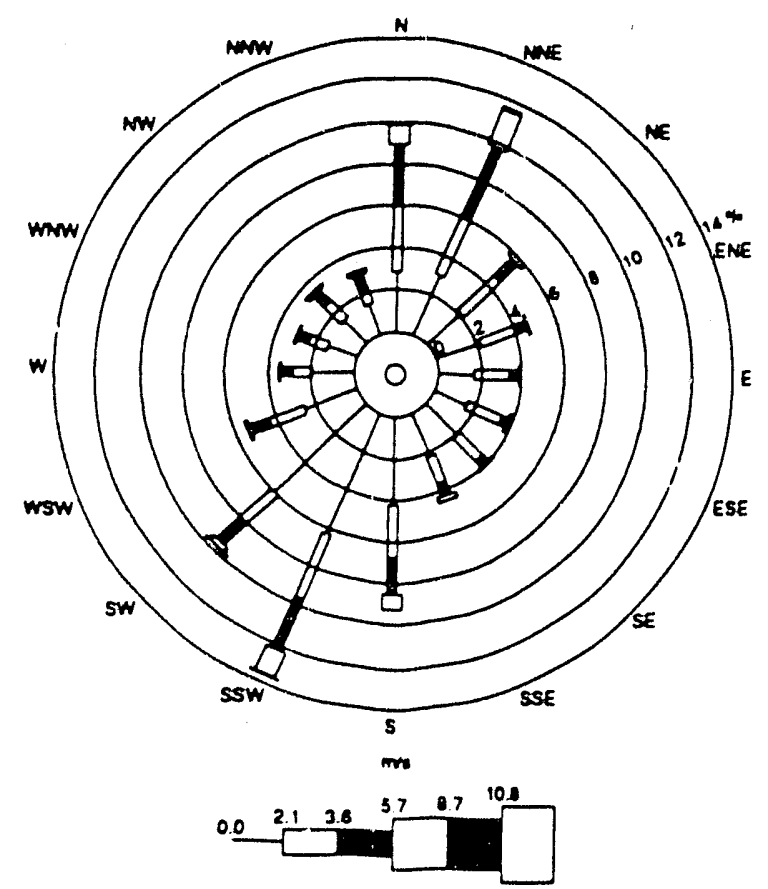

B. WIND ROSE FOR POST 6 TOWER

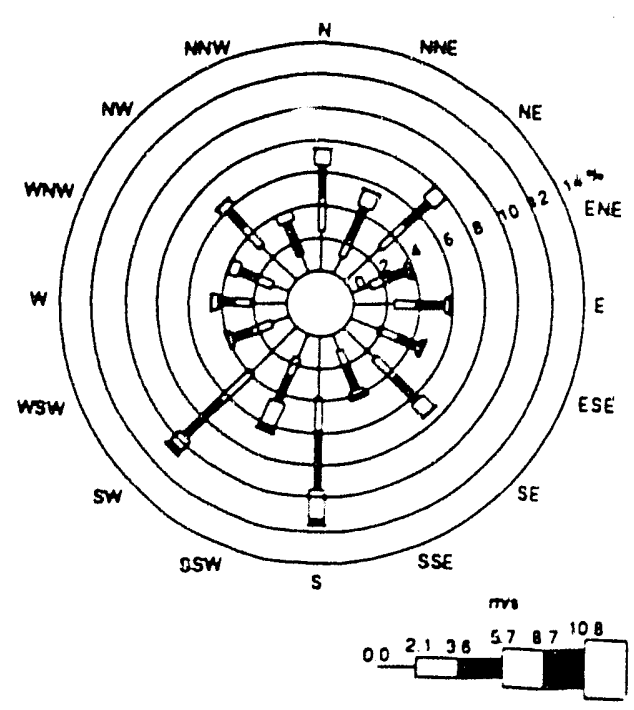

C. WIND ROSE FOR PINE BLUFF ARKANSAS AIRPORT, JAN 1, 1950-DEC 31, 1954

Fig. 12 Wind roses (annual joint frequency distribution of wind speed and wind direction) for data collocted at Pine Bluff Arsenal and at Pine Bluff, Arkansas. 
The prevailing wind direction from the north-northeast exhibits a slightly different pattern, and a somewhat larger frequency of high wind speeds occurs at Tower 6.

In contrast, the wind rose for Pine Bluff Airport displays a different pattern from the wind roses for PBA. The prevailing winds are not as dominating, but appear to be generally from the south. The wind rose for Pine Bluff Airport displays a bias toward the eight principal points of the compass because of the method in which the observers took the readings. A comparison of the wind speeds indicates a similarity between Pine Bluff Airport and Tower 6.

Data within the PBA installation are more representative of the wind at the site of the proposed disposal facility. Stabilities derived from PBA data using methods based on the standard deviation in horizontal wind direction (sigma theta method) appear reasonable for Tower 6, but the distribution of stabilities for Tower 1 appeared biased in the direction of being too unstable and was not used further (see Sect. 3.1.1.1). For the PBA site-specific EIS, wind data from Tower 6 will be used in assessing impacts during incident-free operations. Results will be compared with applicable ambient air quality standards.

With regard to existing ambient air quality, the Pine Bluff area is currently designated as an attainment area for all criteria pollutants (S. Coldwell, Arkansas Department of Pollution Control and Ecology, Little Rock, Arkansas, personal communication with R. L. Miller, ORNL, Oak Ridge, Tenn., June 30, 1989). The nearest Class I Prevention of Significant Deterioration (PSD) area, designated to greatly restrict the degradation of ambient air quality, is Caney Creek Wilderness Area, located $184 \mathrm{~km}$ (115 miles) west of the proposcat disposal facility. The potential effects of the proposed facility on air quality at Caney Creek Wilderness Area will be considered in the site-specific EIS.

At present, seven air permits covering approximately 20 discreet emission points have been issued to the Pine Bluff Arsenal. Total air emissions of about 121 tons/year are summarized in Table 10. All permitted sources are within allowable emission limitations as established by the Arkansas Department of Pollution introl and Ecology.

\subsection{Water Resources}

Water resources in the vicinity of PBA can be impacted by large accidental releases of chemical agent through two environmental pathways: (1) surface water can be directly impacted by atmospheric dispersion and subsequent deposition of agent and (2) groundwater can be directly impacted by chemical agent spills. Because assessment of impacts is beyond the scope of this Phase I report, the size of the accident has been used to quantify the potential impact to water resources near PBA and to determine the significance of water resource data.

The size of the largest hypothetical accident for each alternative at PBA is representative of the size of the potential area for surface water impacts (i.e., for atmospheric dispersion and deposition impacts). Regardless of the location of the surface water resource, higher concentrations of chemical agent could potentially be deposited onto surface water bodies during large accidents than for smaller accidents. 
Table 10. Pine Bluff Arcenal cristing air emissions summary

Pollutant

Acetone

Methylene chloride

Particulates

$\mathrm{SO}_{2}$

Hydrogen fluoride (HF)"

Hydrogen chloride ( $\mathrm{HCl})^{\star}$

Methylphosphonic difluoride (DF)"

Xylene

Permit Number

445-I

(Pit incinerator)

S05-A

( 5 boilers, $3 \mathrm{P}_{2} \mathrm{O}_{3}$ scrubbers,

3 acetone scrubbers)

719-A

(Binary DF manufacture)

731-A

(BZ demilitarization)

748-A

(Open burning ground)

924-A

(FS transfer)

958-A

(M819 red phosphorus mix facility)
Tons per year (CY 1988)

$$
51.6
$$

58.35

8.452

0.0004

0.0004

0.0004

0.39

Pollutant

Particulates

Acetone, particulates, $\mathrm{SO}_{2}$ methylene chloride

Particulates, xylene, hydrogen fluoride (HF), hydrogen chloride ( $\mathrm{HCl}$ ), methylphosphonic difluoride (DF)

Particulates, $\mathrm{SO}_{2}$

Particulates

Sulfuric acid mist (shown as $\mathrm{SO}_{2}$ )

Acetone

"Emission totals based upon maximum allowable DF emission rate $(.001 \mathrm{lbs} / \mathrm{hr})$

Source: G. Thomasson, Pine Bluff Arsenal, Pine Bluff. Arkansas, personal communication with M. Mitckes, Ebasco, Inc., Oak Ridge, Tenn., July 18, 1989. 
On-site disposal has a 50-km (31-mile) accident as its worst case; the other alternatives-continued storage, regional disposal, and national disposal-have larger accidents that fall into the $100-\mathrm{km}$ (62-mile) downwind accident category. Based on the relative size of the worst case accident for each alternative, there is a greater potential for surface water impacts to oscur for the continued storage, regional disposal, and national disposal alternatives. The on-site disposal alternative presents the least potential for surface water impact.

The potential for impact to groundwater resources can be represented by the quantity of chemical agent spilled during a hypothetical accident. From the FPEIS accident database, the WC spill quantities can be obtained for PBA. The maximum credible spill for the continued storage alternative could occur as a result of a plane crashing into the storage area, with no fire resulting. An estimated $154,051 \mathrm{~kg}$ $(339,625 \mathrm{lb}$ or $32,082 \mathrm{gal})$ of mustard agent could be spilled. For the regional and national alternatives, the maximum credible spill involves $1311 \mathrm{~kg}$ (2890 lb or $273 \mathrm{gal}$ ) of mustard agent spilled as a result of an aircraft crash into the transport containers in the holding area. For on-site disposal, the spill involves $63 \mathrm{~kg}$ (139 lb or $15 \mathrm{gal}$ ) of agent GB. This spill accident results from the detonation of M55 rockets resulting in the puncture of adjacent rockets. Probabilities for all these events are very low. However, based on the relative size of the largest accidental spill for each alternative, it can be determined that on-site disposal presents the least potential for groundwater impact.

A description of the site-specific surface water and groundwater regimes is summarized in Appendix C. The FPEIS provides a similar description of the surface water and groundwater regimes (U.S. Army 1988; Vol. 1, Section 3.2.5.4). Additional information collected since publication of the FPEIS has revealed several differences that could not be ascertained without a detailed inspection of site-specific data.

PBA is situated in the Caney Bayou-Arkansas River watershed. As discussed in the FPEIS, the two bayous and six creeks that drain the arsenal ultimately flow into the Arkansas River. The preferred disposal site, adjacent to the BZ site, is located on the northern half of the arsenal. Runoff from this area can drain to the Arkansas River through Phillips Creek. Runoff from the facility will be collected, controlled, and monitored before being released into Phillips Creek.

The site adjacent to the $\mathrm{BZ}$ site is a particularly favorable location because these runoff pathways are directly traceable, and they do not flow through the city of Pine Bluff. Moreover, there are no public water supply intakes downstream of PBA that withdraw surface water directly from the Arkansas River. The sustained flow of the Arkansas River can dilute small instantaneous (as opposed to continuous) spills of chemical agent that may enter it as runoff before they reach the Mississippi River which serves as a public water supply.

Runoff from the southern half of PBA drains into Caney Bayou which passes through the city of Pine Bluff before discharging into the Arkansas River. The disposal facility should not be located on the southern half of the arsenal because accidental spills of agent would follow this pathway that flows past residential areas. Furthermore, Caney Bayou has a complicated, dendritic drainage system in which flow tracing of spills would be difficult, if not impossible to carry out. 
The FPEIS did not discuss the Cockfield-Jackson Aquifer which resides between the Quaternary Aquifer along the surface and the deeper Sparta Sand Aquifer. Most wells tapping the Cockfield-Jackson Aquifer are located in the western part of Jefferson County upgradient from Pine Bluff and PBA. Total pumpage is approximately $1360 \mathrm{~m}^{3} / \mathrm{d}$ (0.36 million gal/d), which is used primarily for domestic and small public water supplies. The geological formations which define the Quaternary and Cockfield-Jackson aquifers have outcrops on PBA. In the unlikely event of a large uncontrolled release of chemical agent, agent could enter these two aquifers by the route. The flow of groundwater in the Quaternary Aquifer is coupled to Bayou Bartholomew and the Arkansas River. Inflows and outflows to and from each of these three hydrologic units create a complex flow regime.

The FPEIS stated that there was no hydraulic interconnection between the Sparta Sand Aquifer and the overlying water-bearing formations. Evaluation of this statement should account for the presence of the large cone of depression centered at Pine Bluff caused by pumpage from the Sparta Sand Aquifer. Vertical hydraulic gradients formed by this cone of depression could induce water leakage downward through the aquitard separating the Cockfield-Jackson Aquifer from the Sparta Sand Aquifer. Such leakage is not likely to occur because the aquitard consists of relatively thick, silty to sandy clay. The aquitard reduces the likelihood of contamination of the Sparta Sand Aquifer in the event that an accident-related spill does occur.

A detailed discussion of the factors (i.e., water temperature and $\mathrm{pH}$, agent solubility, volatility, hydrolysis rate, and soil retention) affecting the potential for contamination of surface water or groundwater following a spill of chemical agent is presented in the FPEIS (U.S. Army 1988; Vol. 3, Appendix N). Spill containment procedures and decontamination measures following such an accident would, however, minimize the impacts of such a spill (U.S. Army 1988; Vol. 1, Sect. 4.5.2.1). A spill prevention control and countermeasures plan has been implemented at PBA (U.S. Army 1986; Appendix B).

The design of the facility at PBA, which has not been finalized, will include a system of curbs, berms, and sumps to contain, control, and collect any spills of chemical agent that might occur. Furthermore, the Army has made a firm commitment to a program of rapid response so that impacts from a spill would not occur or, in a worst case, would be minimized. The final design of the disposal facility will be submitted to the state of Arkansas for review and, if acceptable, will be incorporated into the state's hazardous waste permit for PBA. The final design is also made available to the National Research Council for review. However, the final responsibility for the facility design, including the system of curbs, berms, and sumps, will remain with the Army.

Additional information on site-specific water resources collected since the FPEIS was published does not invalidate the conclusions that were reached.

\subsubsection{Land Use}

Supplemental information for the PBA area indicates that there has been little change in the data presented in the FPEIS. No unique land-use resources have been 
identified for the region around PBA that would delay or prevent implementation of on-site disposal. Additional, detailed information about the site-specific land use is given in Appendix D.

\subsection{Ecological Resources}

Ecological resources are of interest because they provide the backbone of support for the human population, including employment (e.g., agriculture, lumber, industry, etc.) and recreational opportunities (e.g., fishing, hunting, and outdoor sports). Threatened and endangered species are of particular interest because of their greater sensitivity to extinction given their limited numbers. Protecting species from extinction is important because of the need to maintain biodiversity which has direct bearing on the quality of the human environment. Furthermore, the Endangered Species Act of 1973 (Pub. L. 93-205) requires federal agencies to ensure that their actions do not jeopardize the continued existence of endangered or threatened species, nor destroy or adversely modify designated critical habitat for such species. Resource areas of special ecological interest include wilderness and wildlife areas, nature conservancy areas and national parks.

The distances for the no-effects and human no-deaths zones are based on the most serious accident for each alternative under worst-case meteorological conditions (see Appendix A). For releases of agents GB and VX, the no-effects zones usually reflect distances that are about seven times greater than those used for the no-deaths zones (U.S. Army 1988). For PBA, the no-deaths distance is $100 \mathrm{~km}$ (62 miles) for continued storage, and $50 \mathrm{~km}$ ( 31 miles) for on-site disposal. The no-effects distances would thus extend hundreds of kilometers from the site of the proposed disposal facility at PBA for the alternatives of interest. Due to the uncertainties associated with dispersion modeling at distances beyond $100 \mathrm{~km}$ (62 miles), ecological resources located beyond this distance will not be considered. Within the human health no-effects zones, impacts to ecological resources could result.

For releases of mustard, no-effects distances are not considered because the agent is a carcinogen, and the human no-effects concentration is unknown (U.S. Army 1988). Thus, the no-deaths zone for mustard agent $[5 \mathrm{~km}$ ( 3.1 miles)] is used to identify potential ecological resources for this type of agent.

Additional information on ecological resources obtained since the FPEIS is shown in Tables 11 and 12. The locations of these resources are shown in Fig. 13. Information on ecological resources included in the FPEIS was based on data from the GEOECOLOGY data base at Oak Ridge National Laboratory (ORNL). Use of a standardized data base allowed the same level of coverage for all sites and transportation options and reduced potential bias in determination of the ecologically preferred 
Table 11. Number of protected ecological rewources within the no-effects" distances for the mont serious on-site sccidents under wont case meteorological conditions at Pine Bluff Arenal

\begin{tabular}{|c|c|c|}
\hline \multirow[b]{2}{*}{ Resource } & \multicolumn{2}{|c|}{ Agent roleased } \\
\hline & $\mathrm{H}, \mathrm{HD}, \mathrm{HT}^{\dagger}$ & $G B$ and $V X^{c}$ \\
\hline National park units & 0 & 1 \\
\hline Wilderness areas & 0 & 0 \\
\hline National forests & 0 & 1 \\
\hline Threatened and endangere & & \\
\hline species $^{d}$ & 5 & 8 \\
\hline Wild and scenic rivers & 0 & 0 \\
\hline Designated natural areas ${ }^{\circ}$ & 2 & 15 \\
\hline National wildlife refuges & 0 & 1 \\
\hline State parks & 2 & 6 \\
\hline State wildlife management & & \\
\hline areas & 1 & 8 \\
\hline Fish hatcheries & 1 & 1 \\
\hline
\end{tabular}

No-effects distances are approximately 7 times the no-deaths distances.

'No-effects distances for mustard are unknown; thus, analysis is based on accidents with no-deaths distances of $5 \mathrm{~km}$ for the on-site disposal alternative. alternative.

'Analysis based on accidents with no-deaths distances of $33 \mathrm{~km}$ for the on-site disposal

${ }^{\mathrm{D}}$ Does not include candidate species.

-Arkansas Natural Heritage Commission. 
Table 12 Ecological resources within the 100-km (62-mile) impact zone around Pine Bluff Arsenal (PBA) as identified during the Phase I process

Public areas within $100 \mathrm{~km}$ of PBA site

\begin{tabular}{|c|c|c|c|}
\hline Area & County & $\begin{array}{l}\text { Distance } \\
\text { from site }\end{array}$ & $\begin{array}{c}\text { Area } \\
\text { (acres) }\end{array}$ \\
\hline \multicolumn{4}{|c|}{ National Forests (NF) } \\
\hline Ouachita NF & $\begin{array}{l}\text { Saline } \\
\text { Perry }\end{array}$ & $80 \mathrm{~km} \mathrm{NW}$ & $\begin{array}{l}53,463 \\
93,530\end{array}$ \\
\hline \multicolumn{4}{|c|}{ National Parks (NP) } \\
\hline Hot Springs NP & $\begin{array}{l}\text { Garland } \\
\text { National } F\end{array}$ & $\begin{array}{l}90 \mathrm{~km} \text { WNW } \\
\text { tes }(N R S)\end{array}$ & $5,839.2$ \\
\hline Arkansas Post NMem & Arkansas & $80 \mathrm{~km}$ ESE & 389.2 \\
\hline
\end{tabular}

National Wildlife Refuges (NWR)

White River NWR

Desha

$90 \mathrm{~km}$ ESE $\quad 112,348$

Arkansas

Phillips

Monroe

State Fish Hatcheries

Hogan State FH

Lonoke

$50 \mathrm{~km} \mathrm{NNE}$

267

State Parks (SP)

DeGray SP

Lake Catherine SP

Pinnacle Mtn. SP

Toltec Mounds SP

Jenkins Ferry Battleground Hist. Mon.

Marks Mill Battleground Hist. Mon.

Hot Spring

Hot Spring

Pulaski

Lonoke

$100 \mathrm{~km} \mathrm{~W}$

$80 \mathrm{~km} \mathrm{~W}$

$65 \mathrm{~km} \mathrm{NW}$

$30 \mathrm{~km} \mathrm{~N}$

$45 \mathrm{~km}$ WSW

$65 \mathrm{~km} \mathrm{~S}$

939

2,180

1,801

182

Grant

Cleveland

\section{0}

6 
Table 12 (Continued)

\begin{tabular}{|c|c|c|c|}
\hline Area & County & $\begin{array}{l}\text { Distance } \\
\text { from site }\end{array}$ & $\begin{array}{c}\text { Area } \\
\text { (acres) }\end{array}$ \\
\hline
\end{tabular}

State Wildlife Management Areas (SWMA)

Bayou des Arc WMA Bayou Meto State Game Area

Bell Slough WMA

Camp Robinson WMA

Dagmar WMA

Harris Brake WMA

Trusten Holder WMA

Wattensaw WMA
Prairie

Arkansas

Jefferson

Faulkner

Faulkner

Monroe

Perry

Arkansas

Prairie
$90 \mathrm{~km}$ ENE 954

$35 \mathrm{~km} \mathrm{E} 33,901$

$70 \mathrm{~km} \mathrm{NNW2,800}$

$60 \mathrm{~km}$ NNW5,000

$90 \mathrm{~km} \mathrm{NE} 8,062$

$95 \mathrm{~km} \mathrm{NW} \mathrm{2,866}$

$90 \mathrm{~km}$ ESE 5,206

$70 \mathrm{~km} \mathrm{NE} 17,461$

Locks and Dams, Arkansas River

Lock \& Dam 1

Lock \& Dam 2

Lock \& Dam 3

Lock \& Dam 4

Lock \& Dam 5

Lock \& Dam 6

Lock \& Dam 7

Lock \& Dam 8

$\begin{array}{lc}\text { Arkansas } & 90 \mathrm{~km} \text { ESE } \\ \text { Arkansas } & 85 \mathrm{~km} \mathrm{ESE} \\ \text { Jefferson } & 45 \mathrm{~km} \text { ESE } \\ \text { Jefferson } & 25 \mathrm{~km} \mathrm{ESE} \\ \text { Jefferson } & 5 \mathrm{~km} \mathrm{~N} \\ \text { Pulaski } & 35 \mathrm{~km} \mathrm{~N} \\ \text { Pulaski } & 55 \mathrm{~km} \mathrm{NNW} \\ \text { Perry } & 90 \mathrm{~km} \mathrm{NNW}\end{array}$

Arkansas

$85 \mathrm{~km}$ ESE

$45 \mathrm{~km}$ ESE

$25 \mathrm{~km}$ ESE

$5 \mathrm{~km} \mathrm{~N}$

$35 \mathrm{~km} \mathrm{~N}$

$90 \mathrm{~km}$ NNW

Sources: U.S. Forest Service, Land Areas of the National Forest System, as of September 30, 1988, Government Printing Office, Washington, D.C, 1988 . U.S. National Park Service, National Park Service Statistical Abstract 1988, Government Printing Office, Washington, D.C., 1989. 
A. OUACHITA NATIONAL FOREST

B. LAKE OUACHITA STATE PARK

C. HOT SPRINGS NATIONAL PARK

D. LAKE CATHEIIINE STATE PARK

E. DE GRAY STATE PARK

F. ARKANSAS POST NATIONAL MONUMENT

G. BAYOU METO WILDLIFE MANAGEMENT AREA (WMA)

H. TRUSTEN HOLDER WMA

I. WHITE RIVER NATIONAL WILDLIFE REFUGE

J. LOUISIANA PURCHASE HISTORICAL MONUMENT

\section{K. DAGMAR WMA}

L. WATTENSHAW WMA

M. BAYOU DES ARC WMA

N. REX HANCOCK BLACK SWAMP WMA

O. HENRY GRAY HURAICANE LAKE WMA

P. CAMP ROBINSON WMA

Q. PINNACLE MOUNTAIN STATE PARK WMA

R. BELL SLOUGH WMA

S. HARRIS BRAKE WMA

T. TOLTEC MOUNDS STATE PARK

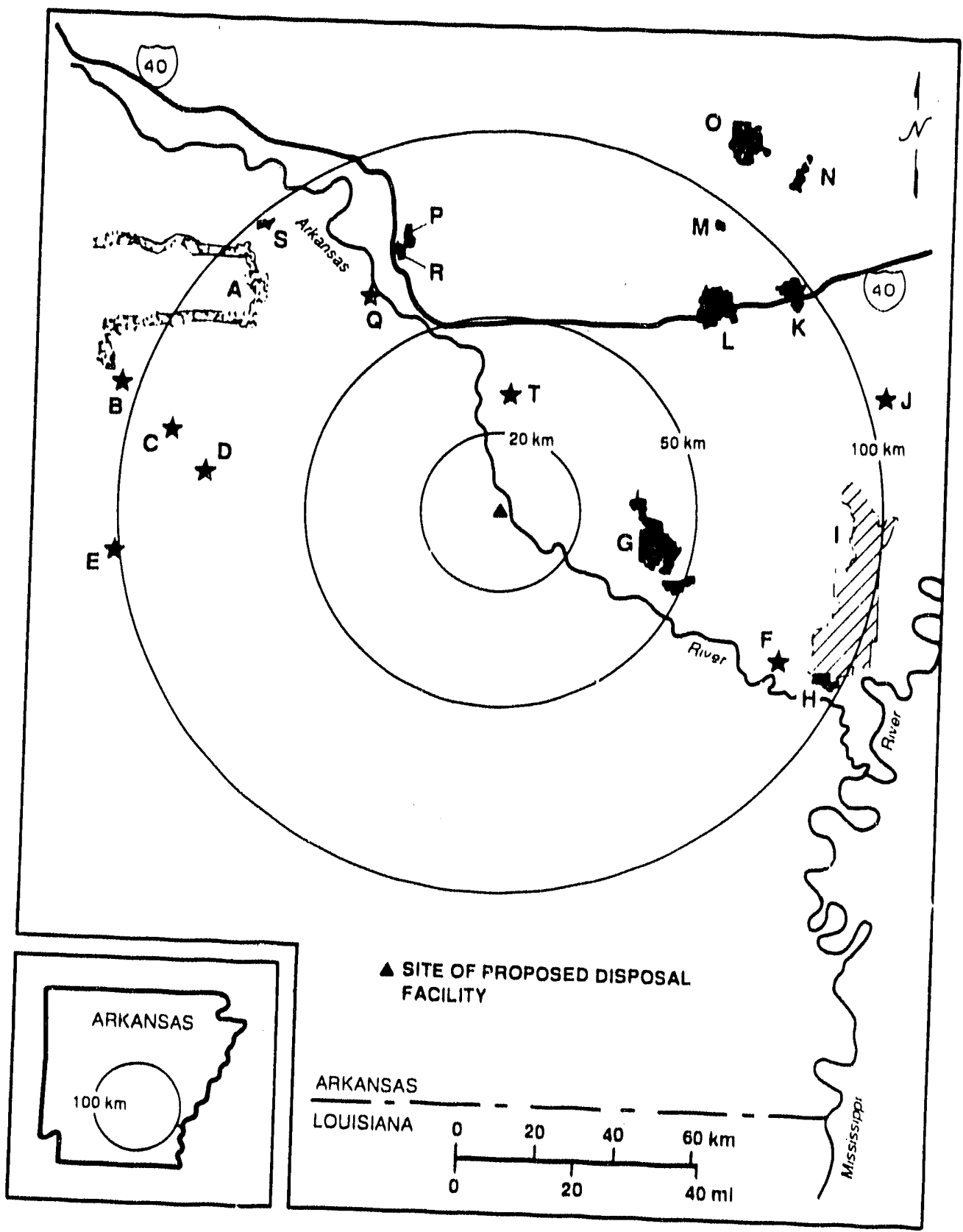

Fig. 13. Location of important ecological resources within the 100-km (62-mile) zone around Pine Bluff Arsenal 
alternative. Information obtained during preparation of the Phase I report has verified the geoecclogy data obtained for Arkansas during preparation of the FPEIS. Additional information has been obtained on the numbers of national forests (one), state parks (six), and state wildlife management areas (eight) (see Table 10 and Fig. 13). Comparison of information about threatened and endangered species in the FPEIS and the Phase I report show that the information obtained for the FPEIS is still valid. Two speciesGeocarpon minimum (no common name) and Arctic peregrine falcon-have been included in the Region IV Threatened and Endangered Species Notebook since the endangered species information was obtained in 1986 from the U.S. Fish and Wildlife Service (FWS). Consultation has been initiated with the Jackson, Mississippi, Endangered Species Office of FWS for the $100-\mathrm{km}$ (62-mile) zone around PBA, and resulting information will be included in the Phase II site-specific EIS.

The bald eagle, Arctic peregrine falcon, least tern, and piping plover migrate through and could feed in the area, but are not residents. The red-cockaded woodpecker and Geocarpon minimum occur in the southern portion and the pink mucket pearly mussel in the western portion of the $100-\mathrm{km}(62-\mathrm{mile})$ zone. The Florida panther is known historically from Arkansas, including the $100-\mathrm{km}$ (62-mile) zone; and the American alligator nests within the $100-\mathrm{km}(62-\mathrm{mile})$ zone. The potential impacts to these species that could result from a release of chemical agent will be addressed in the site-specific EIS.

Data collection during preparation of the Phase I report does not alter the conclusions of the ecological resources section of the FPEIS that in the event of an accidental release of chemical agent impacts to ecological resources will occur. The addition of state parks, wildlife management areas, and important natural areas to the list of resources within the $100-\mathrm{km}$ (62 miles) zone does not alter the conclusions of the FPEIS. These resources are distributed throughout the impact zone and are not concentrated in the general downwind direction from the site. This additional information will help to better estimate the extent of effects to important ecological resources.

\subsection{Social, Economic and Cultural Resources}

Since the completion of the FPEIS, updated and additional data on community resources surrounding PBA have been collected. Data on community resources are relevant for two purposes: (1) to identify concentrations of population and other resources that may be affected by a release of chemical agent and (2) to estimate the potential socioeconomic impacts from population growth and other activities associated with the construction and incident-free operation of the disposal facility. The zone of impact relevant for socioeconomic data collection during the Phase I process varies according to whether the resource potentially could be affected by an accident or by project-induced growth.

Site-specific populations that have been characterized since the FPEIS include worker and resident populations located both on-post at PBA and off-post; potentially sensitive populations (i.e., children and the elderly) by county of residence; transient populations, defined as concentrations of people visiting or gathering in the vicinity on 
an intermittent or irregular basis (e.g. recreational events); and special populations, which include day-to-day concentrations of people with special needs who are dependent on others for protection and require special attention in an emergency. There are no federally recognized Indian settlements within $100 \mathrm{~km}$ (62 miles) of PBA (EPA 1989).

The FPEIS considered residential population to $100 \mathrm{~km}$ (62 miles) to estimate human fatalities. It did not consider daytime population, nonresidential data, or on-post population on a site-specific basis. Data on daytime (i.e., place-of-work) population for the area surrounding PBA will be collected and analyzed for inclusion in the site-specific EIS. In lieu of more detailed place-of-work data, nearby industries with 100 or more employees and other large employers in Pine Bluff are identified in Appendix B.

Normal working hours for PBA employees are from 7:30 a.m. to 4:00 p.m. Shift work between the hours of 4:00 p.m. and 7:30 a.m. varies depending upon the work load. Employment on the installation during the evening and night shifts is estimated at 75 workers in Buildings 31-000 through 34-000, 45 security officers located throughout the arsenal, and 10 fire department workers in Building 10-050. Shift workers at NCTR are estimated at 20.

An estimated one-third of PBA's 1400 dayshift employees work in the vicinities of buildings numbered in the 10-000s, 57-000s, and 63-000s. There are approximately 2230 contractors permanently badged at PBA. Of these, 1900 are badged to work on PBA on a daily basis, and 325 are badged to visit PBA as necessary. Of the latter, 40 enter on a daily basis. Approximately 50 contractors and vendors and $\mathbf{4 0}$ commercial carriers without permanent access badges enter PBA on a daily basis. Approximately 175 miner visitors enter PBA each day. In addition to PBA employees, contractors, and visitors, day-shift employment at NCTR totals approximately 600 .

The on-post resident population consists of occupants in barracks and family housing. There are also 21 guest units on-post. The on-post resident population is shown in Table 13.

Because data in Sect. 3.1 and in the FPEIS consider human fatalities in the resident population to $100 \mathrm{~km}$ (62 miles), the Phase I process has collected data for off-post human resources for the region within a $100-\mathrm{km}$ (62-mile) zone. Because the Protective Action Zone (PAZ) (the second of two emergency response zones) roughly approximates a $50-\mathrm{km}$ (31-mile) zone for PBA, data are shown separately for the $50-\mathrm{km}$ and $100-\mathrm{km}$ zones. In some cases, detailed data are delineated only for Jefferson and Grant counties, which include the Immediate Response Zone (IRZ) (Jefferson County Office of Emergency Services 1989).

Figure 14 shows the portions of 11 counties that lie within a $50-\mathrm{km}$ (31-mile) zone of PBA. The incorporated places and their populations that make up the $50-\mathrm{km}$ (31-mile) zone are shown in Table 14. Data on off-post resident population trends and potentially sensitive age groups in the resident population are presented in Appendix B. Transient and special population data within the $100-\mathrm{km}$ and $50-\mathrm{km}$ zones are also presented in Appendix B.

Land use, although considered in Sect. 3.2.3, has been characterized here with a focus on economic value that might be affected as a result of contamination of land or property. Because land use could be affected by an accidental release of chemical agent 
Table 13. On-post housing capacity and occupancy

\begin{tabular}{lccc}
\hline Housing & Capacity & \multicolumn{2}{c}{ Average occupancy } \\
\cline { 3 - 4 } & & Rate (\%) & $\begin{array}{c}\text { Number of } \\
\text { persons }\end{array}$ \\
\hline Family housing & 44 units & 100 & $\sim 150^{\circ}$ \\
Guest house & 21 units & $90^{b}$ & 19 \\
Barracks & 43 units & 80 & 35 \\
\hline
\end{tabular}

'As of April 1989, military personnel living in family housing had, on average, 2.58 dependents.

This is the rate for Monday through Friday. Occupancy during weekends is lower.

during a worst case storage accident, data are presented for a 100-km (62-mile) zone. These data are presented in Appendix B.

The FPEIS did not evaluate in detail archaeological and historic sites and structures beyond the boundary of PBA. Appendix B enumerates the sites that are in counties located wholly or partially within the $50-\mathrm{km}(31-\mathrm{mile})$ and $100-\mathrm{km}$ (62-mile) zones.

Additional data on socioeconomic resources are important for assessing impacts during construction and incident-free operations. Project-induced population growth during the construction and operations phases of the project could affect employment, infrastructure, and the provision of public services in the immediate vicinity of PBA. Based on the current locations of the residences of civilian employees at PBA, the following approximate distribution of inmigrating population associated with the proposed disposal facility could be expected.

\begin{tabular}{lc} 
Pine Bluff (Jefferson Co.) & $60.1 \%$ \\
White Hall (Jefferson Co.) & 16.5 \\
Little Rock (Pulaski Co.) & 3.3 \\
Sheridan (Grant Co.) & 5.6 \\
Other & 14.5 \\
\hline
\end{tabular}

Total

$100.0 \%$ 


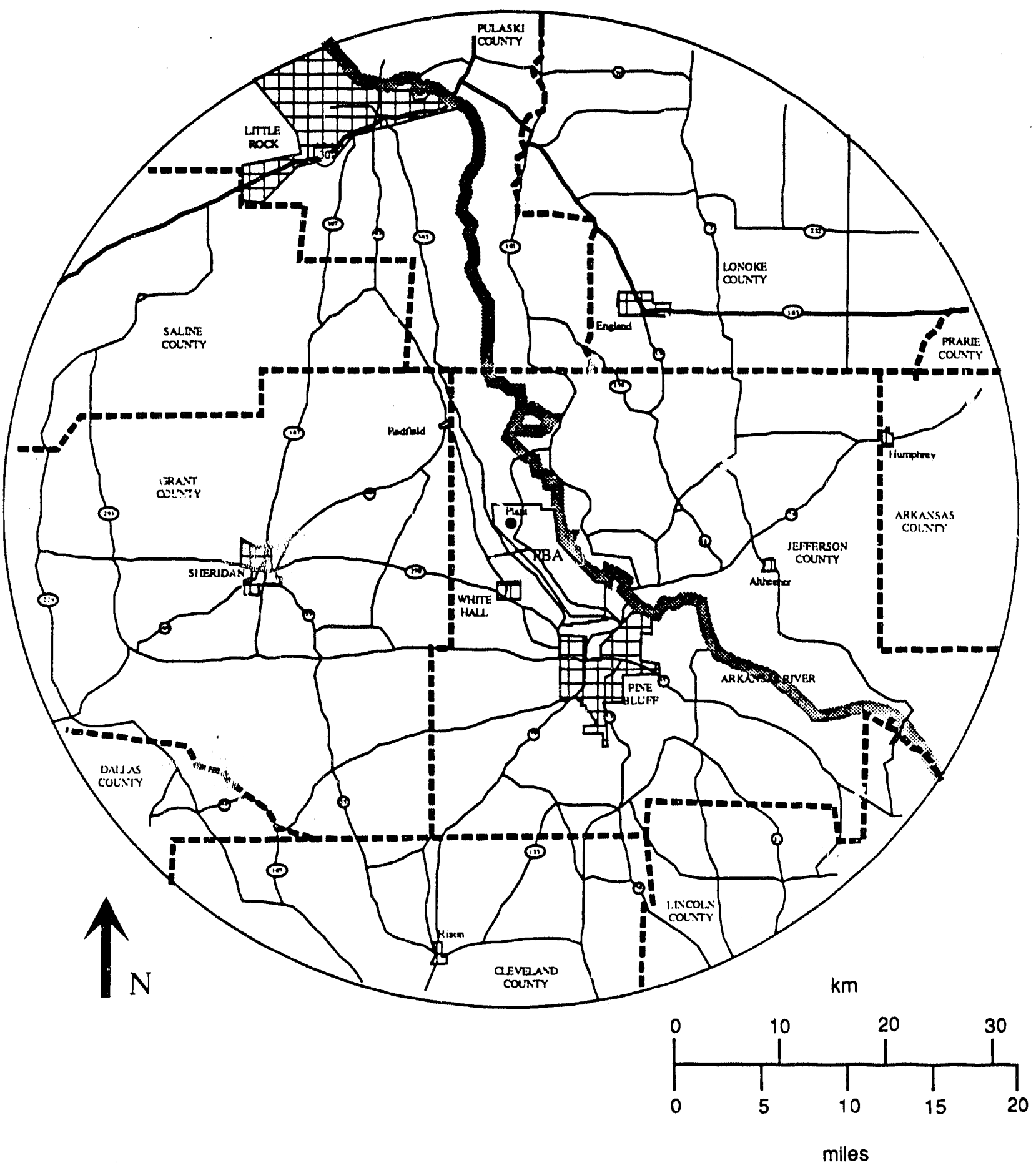

Fig. 14. 50-km zone for Pine Bluff Arsenal Source: S. A. Carnes et al., Emergency Response Concept Plan for Pine Bluff Arsenal and Vicinity, ORNL/TM-11092,

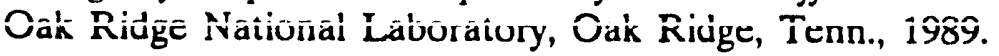


Table 14. Population of incorporated areas within the 50-km (31-mile) zone for Pine Bluff Arsenal

\begin{tabular}{|c|c|c|}
\hline County & Incorporated areas & $\begin{array}{l}\text { Estimated } \\
\text { population }\end{array}$ \\
\hline Jefferson & $\begin{array}{l}\text { Pine Bluff } \\
\text { Altheimer } \\
\text { Sherrill } \\
\text { Redfield } \\
\text { White Hall } \\
\text { Humphrey } \\
\text { Wabbeseka }\end{array}$ & $\begin{array}{r}63,232 \\
1,120 \\
160 \\
1,020 \\
4,095 \\
1,570^{b} \\
360\end{array}$ \\
\hline Grant & $\begin{array}{l}\text { Leola } \\
\text { Poyen } \\
\text { Prattsville } \\
\text { Sheridan } \\
\text { Tull }\end{array}$ & $\begin{array}{r}420 \\
290 \\
350 \\
3,050 \\
290\end{array}$ \\
\hline Lonoke & $\begin{array}{l}\text { Allport } \\
\text { Coy } \\
\text { England } \\
\text { Humnoke } \\
\text { Keo } \\
\text { Lonoke }\end{array}$ & $\begin{array}{r}300 \\
170 \\
3,290 \\
450 \\
280 \\
4,090\end{array}$ \\
\hline Pulaski & $\begin{array}{l}\text { Alexander } \\
\text { Little Rock } \\
\text { Wrightsville }\end{array}$ & $\begin{array}{r}280 \\
181,030 \\
1,510\end{array}$ \\
\hline Saline & $\begin{array}{l}\text { Bauxite } \\
\text { Benton } \\
\text { Bryant } \\
\text { Haskell } \\
\text { Shannon Hills } \\
\text { Traskwood }\end{array}$ & $\begin{array}{r}480 \\
18,220 \\
4,490 \\
1,280 \\
1,910 \\
430\end{array}$ \\
\hline Dallas & Carthage & 580 \\
\hline Cleveland & Rison & 1,280 \\
\hline Lincoln & $\begin{array}{l}\text { Star City } \\
\text { Grady }\end{array}$ & $\begin{array}{r}2,030 \\
550\end{array}$ \\
\hline Arikansas & Stuttgart & 10,470 \\
\hline
\end{tabular}

'All estimates are for 1986, except those for White Hall and Pine Bluff, which are 1988 estimates, received from SE Arkansas Regional Planning Office.

The town of Humphrey is inciuded in both Arkansas and Jefferson County. The Jefferson County portion of Humphrey has a population of 1,120, and the Arkansas County portion has 450 .

Sources: U.S. Bureau of the Census, Current Population Reports, South-1986 Population and 1985 per Capita Inrome Frtimntes for Counties and Incopmonted Places, Series D-26, No. \&6 5 5C, U.S. Goverameni Printing Office, Washington, D.C., 1988. A. Skinner, Southeast Arkansas Economic Development District, Inc., Pine Bluff, Ark, personal communication with J. Morrissey, SAIC, Oak Ridge, Tenn., Jan. 31, 1990. 
The "Other" category includes a number of small towns in the area within about $50 \mathrm{~km}$ (31 miles) of PBA Socioeconomic data collection relevant to project-induced growth during the Phase I process has focused primarily on Jefferson County and the Sheridan community in Grant County, although data for other counties to $50 \mathrm{~km}$ (31 miles) have been included where available. Data on Little Rock (pop. 181,000) were not included because the small magnitude of growth expected in Little Rock would represent a negligible population increase in that city. Some data relevant to project-induced growth, such as population, schools, and land use, have been presented elsewhere in this section. Supplemental data on employment, income, housing, facilities and services, and transportation are presented in Appendix B.

\subsection{Aircraft Activity}

Information about aircraft activity in the FPEIS was taken from risk analyses by GA Technologies, Inc., judged against criteria set up by the Nuclear Regulatory Commission (NRC) for risks to the nuclear industry from aircraft crashes. The NRC criteria for low probability of aircraft accidents at a site are met when:

- the site-to-airport distance is between 8 and $16 \mathrm{~km}$ (5 and 10 miles) and the annual number of air operations is less than $\mathbf{5 0 0}$ times this distance squared, or the site-to-airport distance is greater than $16 \mathrm{~km}$ (10 miles) and the projected annual number of operations is less than 1000 times this distance squared;

- the site is at least $8 \mathrm{~km}$ ( 5 miles) from the edge of military training routes;

- the site is at least $3.2 \mathrm{~km}$ ( 2 miles) from the nearest edge of a federal airway, holding pattern, or approach pattern.

A survey of the most recent Flight Information Publication for the area around PBA still indicates the existence of three private airfields 16 to $22 \mathrm{~km}$ (10 to 14 miles) distant from the proposed site. Grider Field at Pine Bluff is about $26 \mathrm{~km}$ (16 miles) southeast of the proposed site; in 1987, Grider Field had a total of 483 instrument approaches, composed of $\mathbf{4 5 2}$ general aviation, 13 air taxis, and 18 military aircraft (FAA 1988). A helipad is on-site about $3 \mathrm{~km}$ (2 miles) from the chemical munitions storage area boundary. The flight frequency is estimated to be $\mathbf{3 0}$ or fewer flights per month.

There are no military training routes, military operations areas, or restricted areas in the vicinity. Low altitude federal airways V74, V305, and V16 pass at distances of 10 , 17 , and $18 \mathrm{~km}(6,10$, and 11 miles), respectively. High altitude jet route J42 passes over the proposed site. site.

The NRC criteria are met for low probability of aircraft accidents at the proposed 


\subsection{Emergency Planning and Preparedneas}

Emergency planning and preparedness played a key role in identifying the programmatic environmentally preferred alternative. The difficulty of planning emergency response activities for an accident along any off-sice transportation route was an important consideration in rejecting those alternativenuiring off-site transport. The Army has begun enhancement of emergency plannizy. preparedness at each installation regardless of the proposed action; thus, everyncy planning will benefit equally each of the alternatives under consideration in this report (continued storage, on-site disposal, and on-site activities associated with off-site disposal) and was not a key factor in reexamining the environmentally preferred alternative in Sect. 3.1. Consequently, emergency planning and preparedness are discussed in the context of new information affecting on-site disposal that will be addressed in the site-specific EIS. The following is a brief discussion of emergency planning activities in the PBA vicinity.

The Army has begun enhancement of emergency response capabilities by requesting funds from Congress to implement the Emergency Response Concept Plan (ERCP) (Jacobs Engineering Group, Inc., and Schneider EC Planning and Management Services 1987) at all eight storage sites, including PBA. The Army also has funded planners to work with local governments to upgrade existing plans. In addition, the Army is committed to provide technical assistance and coordinate local planning efforts. Furthermore, the Army intends to request funds to improve emergency response capabilities through capital improvements in fiscal years 1990 and 1991 . Combined, these enhancements are aimed at upgrading the emergency response capabilities commensurate with ERCP and should greatly improve emergency response capabilities in the PBA vicinity.

Response to a chemical release at PBA is the cooperative responsibility of PBA, Jefferson County Office of Emergency Services, and the state of Arkansas. PBA's emergency plan is provided in the Chemical Accident Incident Response and Assistance (CAIRA) Plan dated May 1, 1985. In the event of an incident involving the release of chemical agent, whether or not it is expected to result in off-post consequences, PBA is responsible for prompt notification to the official off-post contact, the Jefferson County Sheriff's Department. Initial response actions would be based on an emergency classification system developed by PBA and protective actions recommended by PBA officials.

The emergency classification system contains six levels of emergency response, which vary with the severity of the release and atmospheric conditions. The Emergency Response Level would be declared by PBA officials. Jefferson County officials have the lead responsibility to coordinate all off-post emergency response activities. The Jefferson County Emergency Response Plan details the actions to be taken by the different government, private, and volunteer organizations within the county according to each Emergency Response Level.

The main concentration of resources to be drawn upon in an emergency situation would be in the IRZ, which defines the jurisdictions within an approximate $15-\mathrm{km}$ (9.3-mile) radial distance from PBA. The Jefferson County Office of Emergency 
Services assists the activities of the Grant County Office of Emergency Services. Jefferson County would be automatically notified of a release (J. Palmateer, Jefferson County Emergency Services Coordinator, personal communication with D. Feldman, ORNL, Oak Ridge, Tenn., Aug. 28, 1989). The Arkansas State Office of Emergency Services in Conway would be contacted next and would provide additional support if the off-post consequences of an accident exceeded the capabilities and resources of Jefferson and Grant counties (Jacobs Engineering Group 1989a).

Jefferson County officials would next alert adjacent counties. Counties located outside the Immediate Response Zone (IRZ) but within the PAZ are not currently included in the coordinated emergency planning efforts among PBA, Jefferson County, and Grant County, although officials are hopeful that funding in FY 1990 will allow for the extension of coordinated planning to communities in the PAZ (J. Palmateer, Jefferson County Emergency Services Coordinator, personal communication with J. Morrissey, SAIC, Oak Ridge, Tenn. July 18, 1989).

The Jefferson County Office of Emergency Services has an annual operating budget of $\$ 59,000$. Every participating agency and jurisdiction has its own budget. Three cities within Jefferson County-Redfield, Altheimer, and White Hall-have their own Emergency Response Plans, which are coordinated with the Jefferson County Emergency Services Coordinator. The Jefferson County Emergency Response Plan serves as the plan for the City of Pine Bluff, which accounts for about two-thirds of the Jefferson County population.

During the week of April 12,1989, a major full-field exercise was conducted at PBA, involving all public safety agencies and organizations within the IRZ. About 350 personnel from Jefferson, Grant, and Cleveland counties participated in the exercise. Government agencies and community facilities that participated included the State Health Department, Arkansas Department of Pollution Control and Ecology, Office of Emergency Services, State Police, Little Rock AFB, Camp Robinson, University of Arkansas Medical Center, Baptist Medical Center, Jefferson Regional Medicai Center, Watson Chapel, and White Hall Schools (Lt. C. Sachs, PBA, Ark., personal communication with J. Morrissey, SAIC, Oak Ridge, Tenn., July 3, 1989). The Jefferson County Office of Emergency Services and the Grant County Civil Defense Division currently are in the process of incorporating what was learned from the exercise; into existing emergency response plans. Communications between on-post and off-post officials was the area deemed most in need of improvement (J. Palmateer, Jefferson County Emergency Services Coordinator, Pine Bluff, Ark, personal communication with J. Morrissey, SAIC, Oak Ridge, Tenn., July 10, 1989; J. Wynne, Grant County Civil Defense Coordinator, Sheridan, Ark., personal communication with J. Morrissey, SAIC, Oak Ridge, Tenn., July 18, 1989). A particularly important weakness that surfaced during the exercise was a problem with information flow among agencies, i.e., participating agencies understood their own responsibilities but were unsure of the responsibilities of other agencies (J. Palmateer, Jefferson County Emergency Services Coordinator, Pine Bluff, Ark, personal communication with D. Feldman, ORNL, Oak Ridge, Tenn., Aug. 28, 1989). As a result of the exercise, stepped-up training is being undertaken to ensure interagency coordination. Jefferson County officials have suggested that county, 
state, federal, and PBA officials may require a memorandum of understanding to develop an efficient message flow between on-post and off-post officials (G. Jones, Federal Emergency Management Agency, Region 6, Denton, Tex, personal communication to D. Feldman, Oak Ridge National Laboratory, Oak Ridge, Tenn., June 19, 1989).

An Updated Site Assessment for Pine Bluff Arsenal and Adjacent Jurisdictions (Jacobs Engineering Group Inc. 1989a) concluded that written plans lack a coordinated, well-defined system to guide the efforts of participants. While the PBA CAIRA Plan is highly detailed with respect to roles, responsibilities, and procedures for on-post emergency response activities, it does not detail the decision-making process that must precede off-post actions. PBA officials are aware of the need to improve in this area. Jefferson County's most recent disaster was a 1985 train derailment involving a major commercial chemical spill. The disaster involved the evacuation of approximately 3000 people within a mile of the spill for a period of 6 days. County officials implemented the evacuation successfully and without injuries. The American Red Cross and Salvation Army effectively activated and supported mass care centers during the evacuation (J. Palmateer, Jefferson County Emergency Services Coordinator, Pine Bluff, Ark., personal communication with J. Morrissey, SAIC, Oak Ridge, Tenn., July 10, 1989). As a result of emergency response to the chemical spill, Jefferson County emergency officials adopted the practice of relying, whenever possible, upon the organization responsible for the accident (i.e., the railroad in this case) for information, recommendations, and guidance. Likewise, local officials would rely upon the arsenal for such guidance in the event of a chemical agent release. Also as a result of the train derailment, a system of obtaining input and developing consensus among participants was established (J. Palmateer, Jefferson County Emergency Services Coordinator, personal communication with D. Feldman, ORNL, Oak Ridge, Tenn., Aug. 28, 1989).

The primary goal of the Jefferson County Office of Emergency Services is to prevent loss of life through immediate action following an accident. Therefore, adequate resources must be locally available. However, the lack of sufficient funds to obtain the necessary equipment, sheltering, and medical capabilities is an ever-present problem (J. Palmateer, Jefferson County Emergency Services Coordinator, Pine Bluff, Ark. personal communication with J. Morrissey, SAIC, Oak Ridge, Tenn., July 10, 1989). Concern also has been expressed by county and state officials that guidelines for the use of federal funds lack adequate flexibility for local communities to follow in upgrading emergency systems (Judge Jack Jones, Jefferson County, Pine Bluff, Ark., comments made at National Intergovernmental Consultation Coordination Board Meeting, Denver, Colo., June 27, 1989).

The Jefferson County emergency operations center (EOC) is located in the basement of the Pine Bluff Civic Center, although emergency services officials actually rely on command post operations near PBA, including a mobile EOC unit. The EOC's location, layout, space, parking facilities, and equipment have been identified as areas in need of improvement in the Updated Site Assessment for Pine Bluff Arsenal and Adjacent Jurisdictions. The assessment recommended that Jefferson County should have a fixed EOC from which to direct emergency response operations and that the EOC 
should be located far enough away from the arsenal that it would not be at risk from an accident at PBA. Plans are being discussed to build a new EOC, although the location is still undetermined (Jacobs Engineering Group Inc. 1989a).

\subsection{TECHNOLOGY STATUS AND MATURTYY}

This section provides a status report on the developments in the proposed disposal technology since the FPEIS, with an emphasis on the continuing operational experience being gained during this time. Technology status and maturity refers to the continuing refinement of designs and procedures from the conceptual design stage to the operation of the initial disposal facility, through the time the chemical stockpile is destroyed. The design and procedures are further refined through state and U.S. Environmental Protection Agency (EPA) regulatory reviews. Regulatory approvals of the design are required from the state of Arkansas prior to the start of construction and operation of the PBA facility. This section focuses on technology developments that have occurred since the FPEIS.

As the implementation of the CSDP progresses, an increasing amount of the stockpile would be destroyed. Facilities built and operated in the latter stages of the program would benefit from the lessons learned in the design and operation of earlier facilities. Table 15 presents the projected cumulative stockpile destruction in future years as the site-specific facilities are built and operated. A revised schedule was presented to Congress in April 1990. The Army has officially requested an extension from 1997, as approved in P.L. 100-456, to 1998 as a completion date. By March 1996, when the PBA facility is projected to begin disposal operation, about $26 \%$ of the total U.S. stockpile is projected to have been destroyed.

Chemical demilitarization operations have been conducted in demilitarization facilities in former production facilities at Rocky Mountain Arsenal (RMA), located in Denver, and at the Chemical Agent Munitions Disposal System (CAMDS), located at TEAD, Utah. Through calendar year 1989, about 6.7 million kg (14.8 million lb) of agent had been destroyed at RMA and at CAMDS. Table 16 summarizes the U.S. Army's experience in industrial scale disposal of lethal chemical agents and munitions.

New experience since the FPEIS is compared in this section with estimated emissions and projected plant operating conditions in the FPEIS to determine if recent technological experience continues to support the selection of on-site disposal. Because no accident conditions during chemical agent disposal operations have occurred since the FPEIS, experience can only be compared with conditions which were expected during normal operations. Normal operations are defined as operations which occur without a release of chemical agent which exceeds regulatory limits into the environment.

No significant human health impacts were expected in the FPEIS during normal plant disposal operations. This is supported by operational experience and equipment advancements since the FPEIS. During recent VX testing at CAMDS, no agent emissions exceeded the regulated limits as presented in Table 4.1.2 of the FPEIS. In fact, agent was not detected in the stack gas at any time during these tests. To further safeguard the 
Table 15. Projected chemical agent stockpile destruction schedule

\begin{tabular}{lllc}
\hline Year & $\begin{array}{l}\text { Sites starting } \\
\text { operations }\end{array}$ & $\begin{array}{c}\text { Sites ending } \\
\text { operations }\end{array}$ & $\begin{array}{c}\text { Chemical inventory } \\
\text { remaining at year end (\%) }\end{array}$ \\
\hline 1990 & JACADS & -- & 99.6 \\
1991 & -- & -- & 98.2 \\
1992 & -- & -- & 96.5 \\
1993 & TEAD & JACADS (36)" & 93.1 \\
1994 & -- & -- & 88.6 \\
1995 & ANAD & -- & 75.5 \\
1996 & UMDA, PBA, & APG (13), NAAP (11) & 40.0 \\
1997 & APG, NAAP & TEAD (63), ANAD (36), & 0.0 (Dec. 1998) \\
1998 & LBAD, PUDA & UMDA (32), PBA (33), & \\
& -- & LBAD (16), PUDA (21)
\end{tabular}

Months of incinerator operations. 


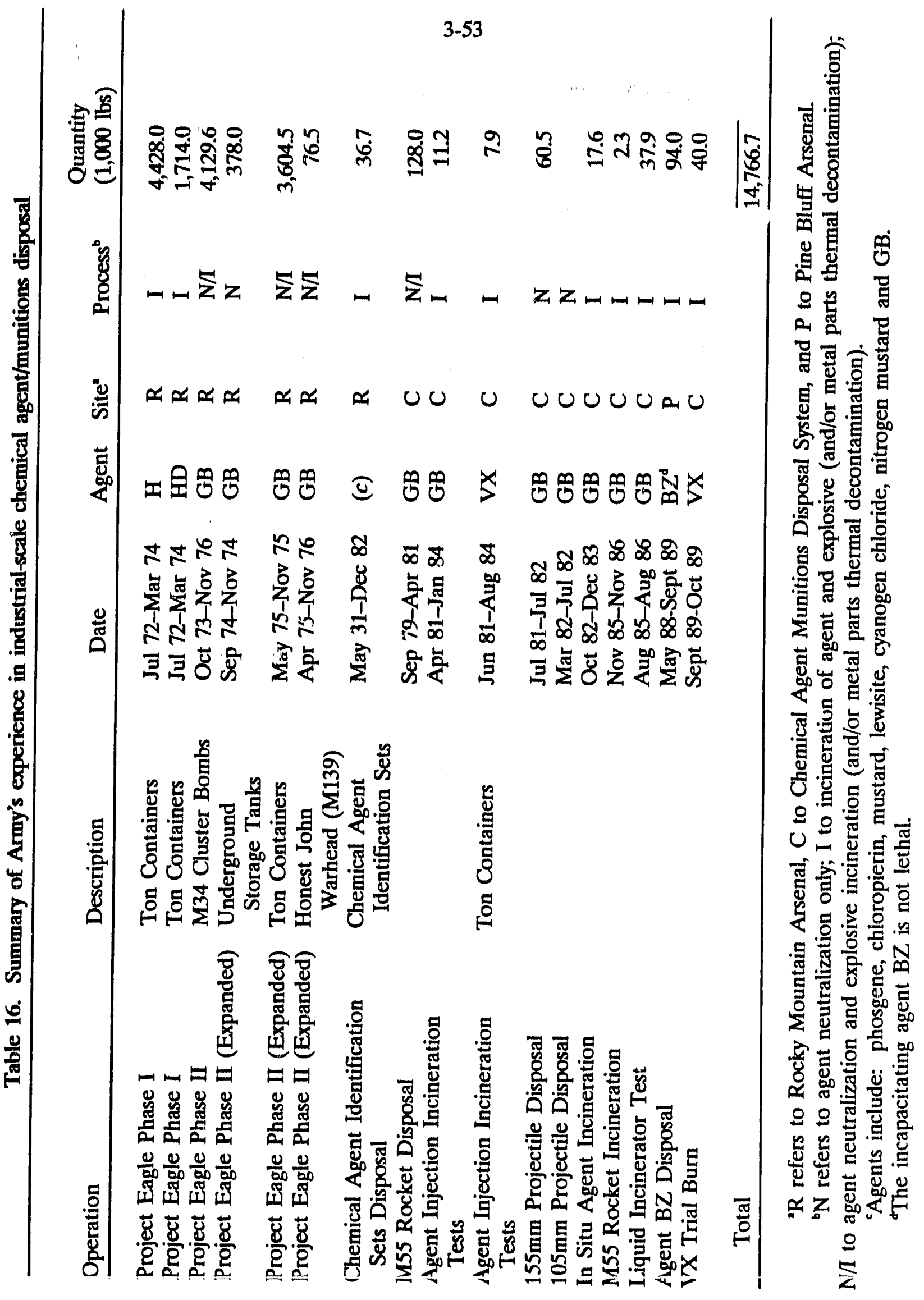


public and the work force, agent monitoring technology has improved since the FPEIS resulting in shorter agent detection response times (see Sect. 3.3.8). At the time the FPEIS was published, initial PCB incineration tests at CAMDS had been conducted. Based on these tests, it was concluded PCB incineration would result in no significant human health effects. This conclusion is reinforced by recent TSCA R\&D burns conducted at JACADS in which emissions were substantially lower than commercial PCB permitted units within the continental United States.

Air quality impacts from emissions during normal operation of the proposed disposal facilities were evaluated in the FPEIS. In acco dance with FPEIS assumptions, $\mathrm{HCl}, \mathrm{NO}_{x}$, particulate, and $\mathrm{SO}_{2}$ emissions were monitored and found to be within EPA regulatory limits during the recent VX incineration tests at CAMDS. The FPEIS further indicated studies were incomplete of products of incomplete combustion (PIC) that would result from emissions during normal operation of the proposed disposal facilities, but to date had found PIC amounts to be negligible. Recent VX testing at CAMDS support this claim. Those PICs detected during this testing were below the emission standard by a factor of $10^{6}$.

\subsubsection{BZ Demilitarization Operations}

Since issuance of the FPEIS, the Army initiated the operation of a demilitarization facility at PBA for the destruction of the nonlethal but incapacitating agent $\mathrm{BZ}$. The facility was constructed to dispose of $1500 \mathrm{BZ}$ munitions, approximately 2000 drums of contaminated residue, and more than 200 drums of neat $\mathrm{BZ}$ that were stockpiled at PBA. Operations began on May 9, 1988. All neat BZ was destroyed by September 1988. All BZ munitions had been destroyed by September 1989, and all of the BZ-contaminated inventory had been destroyed by January 1990. Approximately $42,600 \mathrm{~kg}(94,000 \mathrm{lb})$ of agent $\mathrm{BZ}$ were destroyed by incineration. During these demilitarization operations, no facility enissions were detected that exceeded regulatory limits.

Two Chemical Occurrences were reported during toxic operations at the BZ Demilitarization Facility. The first Chemical Occurrence, in November 1988, involved an operations worker who demonstrated partial symptoms of $\mathrm{BZ}$ agent exposure. A technical investigation of the first Chemical Occurrence revealed inconclusive evidence of worker exposure to $\mathrm{BZ}$ agent: yet enhancements were made to existing personnel entry and egress procedures for access to contaminated plant areas during demilitarization operations. The second Chemical Occurrence, in April 1989, involved a maintenance worker who demonstrated more pronounced symptoms of $\mathrm{BZ}$ agent exposure. A technical investigation of the second Chemical Occurrence could not determine the mechanism for $\mathrm{BZ}$ agent exposure; nevertheless, further enhancements were made to personnel entry and egress procedures, quality control, and medical monitoring procedures. Both workers returned to duty after conclusion of each technical investigation.

The $\mathrm{BZ}$ disposal process was developed based on knowledge gained from disposal operations at CAMDS and RMA. Selected BZ equipment, including the deactivation 
furnace system and heated discharge conveyor, was purchased based on equipment technical data packages from CAMDS. Because the disposal procedures for BZ and the lethal unitary agents and munitions are based on a common technology, much of what was learned from disposal of the BZ has been applicable to the CSDP. In addition, although BZ is a nonlethal agunt, the BZ disposal plant was operated in terms of safety, surety inspections, and guidelines as if it were disposing of lethal agents. The BZ facility and the CSDP facilities have been designed for maximum agent containment and destruction as well as maximum protection of both workers and the public from agent exposure. Specific contributions from the BZ disposal operations are as follows.

- The BZ training program included extensive hands-on training which, because of its success, will be implemented at Johnston Atoll Chemical Agent Disposal System (JACADS) (Sect. 3.3.2) and the Chemical Demilitarization Training Facility (CDTF) to support the CSDP.

- At the end of systemization and before startup of the BZ disposal operations, a preoperational survey was conducted by a team of experts (U.S. Army and DHHS) to ensure that the BZ disposal system conformed to all applicable safety, environmental, quality assurance, security and safety standards and that an acceptable level of performance could be maintained during the BZ disposal operations. All findings essential to the safe and/or efficient operation of the BZ facility required correction prior to start of operations. Many of the problems identified during the BZ preoperational survey could have been resolved much earlier in the systemization period. For this reason, Operational and Readiness Evaluations are being cunuucted at JACADS and CONUS CSDP facilities before the formal preoperational survey. These evaluations will be conducted periodically during the plant systemization periods to inspect designated systemis and subsystems for compliance with regulatory requirements; to assess the progress of the facility toward achieving an operational status in accordance with the schedule; and, to the maximum extent possible, to identify and resolve problems before the formal preoperational survey, thereby minimizing schedule impacts.

- The BZ disposal facility is the first government owned, contractor operated facility managed by the Program Manager for Chemical Demilitarization (PMCD). Experience has been gained regarding schedule durations and potential problems associated with hiring contractor personnel under the Chemical Personnel Reliability Program. This program ensures personnel assigned to positions involving access to chemical surety material are emotionally stable, loyal to the United States, trustworthy, and physically fit to perform assigned duties. This program will also be instituted at the JACADS and CSDP facilities.

In January 1990, cleanup and closure operations of the BZ facility was initiated in accordance with all state, Resource Conservation and Recovery Act of 1976 (RCRA) and Army regulations. As of March 20,1990, all of the major process equipment, except furnaces, had been removed from the facility. It is estimated that closure procedures will 
be completed by June 1990. At that time the plant will be configured for incorporation into the CSDP.

\subsubsection{Johnston Atoll}

Johnston Atoll is a coral atoll located in the central Pacific Ocean about 700 miles southwest of Honolulu, Hawail. Johnston Island, the largest island of the atoll, is a storage site for three types of chemical agents and munitions: GB, VX, and mustard ( $\mathrm{H}$ and $\mathrm{HD})$. These agents are present in rockets, mines, projectiles, bombs, and ton containers.

JACADS is aiso located on Johnston Island. This facility, which is scheduled to become operational in May 1990, will be the first full-scale plant capable of destroying all types of munitions and agent. The JACADS process utilizes the reverse assembly incineration process endorsed by the National Research Council as the best available method of disposal for meeting the environmental and safety requirements. The JACADS munition disassembly equipment and incinerators were developed as a result of experience gained during disposal of the stockpile at Rocky Mountain Arsenal and more recently at the CAMDS, the Army's development center in Tooele, Utah. The JACADS technology is also planned to be used at the CONUS facilities.

\section{JACADS Operational Verification Testing}

In September 1988, Congress, in Pub. L. 100-456, required the Army to successfully complete operational verification of the JACADS technology at Johnston Atoll before proceeding with destruction of the CONUS stockpile of munitions and agent. To meet this requirement, the Army plans to conduct Operational Verification Testing (OVT) at JACADS to demonstrate that chemical munitions and agent can be destroyed safely and efficiently in an environmentally sound manner. The JACADS Test and Evaluation Master Plan (Duff et al. 1989) for the OVT program has been reviewed by DHHS and the National Research Council.

JACADS OVT is to be conducted during the first 16 months of JACADS operations. During this period, the overall JACADS process, and in particular the performance of the incinerator systems, will be evaluated with all three chemical agents (mustard, GB, and VX) in conjunction with the processing of rockets, projectiles, and ton containers. The general objective of the OVT is to demonstrate the operability of the entire plant, including personnel and all support systems, under toxic operating conditions. The overall JACADS system will be evaluated for environmental compliance, industrial and chemical agent safety, and system reliability.

Four tests are planned during OVT, each lasting from 2 to 4 months. A sufficient number of munitions will be destroyed during each test to allow confidence to be developed in the ability of the process to function under normal operating conditions. Representative items in the chemical stockpile and all three agent types will be destroyed. The tests, in order of their planned occurrence, are as follows. 
- M55 rockets containing nerve agent GB. Total attainment of design goals, depending upon the level of success achieved, will result in the destruction of between 12,000 and 16,500 rockets during OVT.

- M55 rockets containing nerve agent VX. It is intended that approximately 13,889 rockets will be destroyed during OVT, based on achieving full production rates.

- One-ton containers containing blister agent HD. Each container holds about $1700 \mathrm{lb}$ of agent. Approximately 67 will be destroyed during OVT, based on achieving full production rate.

- 155-mm projectiles containing HD. Approximately 5670 will be destroyed during OVT, based on achieving full production rates.

Each test will start out at low production rates, with a carefully orchestrated rate increase to complete the test at full production rates. During periods of full production rates, trial burns will be conducted in all four incinerators as required by the permit issued under RCRA. All environmental requirements of the RCRA permit must be met during OVT in order for full operation of JACADS to be allowed following OVT completion.

Test data from JACADS NVT will be evaluated for implementation into all CONUS facilities except the TEAD facility prior to construction. Test data will be evaluated and incorporated into the TEAD facility as necessary, prior to the start of operations. The Army has selected MITRE Corporation to be the JACADS OVT evaluation contractor. MITRE is a not-for-profit, federally funded research and development (R\&D) center with experience in the evaluation of both incineration technologies and chemical munitions demilitarization processes. In addition, the National Research Council is responsible for oversight of the CSDP and of the JACADS facility. Participation by this body could include on-site inspections, review of data, and input to the final OVT reports.

Findings from the OVT will be incorporated into the PBA design and equi?ment specifications prior to construction. A 4-month design and procurement verification period following OVT has been incorporated into the PBA schedule. This verification period will be used for corrections dictated from OVT and from the experience gained trom the program. In addition, the OVT findings will be evaluated after each phase of OVT and will be implemented immediately into the PBA design as necessary.

\section{Status of the JACADS facility}

In January 1986, the U.S. Army began construction of JACADS. JACADS equipment procurement was initiated in October 1985 and completed in November 1988. Equipment installation and field testing of the equipment required for disposal of M55 rockets was completed in August 1988. As of April 1990, systemization of rocket systems at JACADS 
has been completed, and the operations and maintenance contractor (OMC), Stearns-Roger Division, United Engineers and Contractors, is in the final stages of personnel training and documentation review.

Since the fall of 1988, a significant effort has been expended at the JACADS lacility to perform precision and accuracy tests on the agent monitoring systems. These tests consist of challenging the systems with varying concentrations of the three chemical agents to ensure that the systems are operating properly and to certify the operators. To date, approximately 28,000 man hours have been expended to collect, enter, and analyze data from this testing. This extensive effort ensures that the monitors achieve the required precision and accuracy at the low agent concentration detection limit.

In addition, extensive efforts have been conducted in personnel training. As of April 1990 , operations and maintenance personnel collectively attended over 100,000 hours of training. This program consists of approximately $60 \%$ classroom instruction and $40 \%$ field training and practical exercises. Members of the OMC work force are being cross trained to serve in several functions. This is essential for the JACADS project due to the remote location and the difficulty of employee replacement. The OMC is attempting to conduct the majority of the work force training prior to toxic operations. This will allow unrestricted access to the plant for training purposes. Upon completion of the classroom training, all personnel must take an exam for the course. Each person must achieve a score of $80 \%$ or better on the exam to become qualified and be able to proceed to the field training part. As of 23 March 1990, 88\% of all classroom training for operations and mainteance personnel had been completed. Approximately $50 \%$ of the classroom instruction for contingency training bas been completed.

The field portion of the training program consists of providing instruction to the work force on the Standing Operating Procedures (SOPs). After this period of instruction is complete, each member of the work force must perform the procedures in the SOPs which govern operations in his or her area of responsibility. This performance will be monitored by a Certifying Official who will attest that the person is proficient or certified in his or her job. As of 23 March 1990, 54\% of all certification of operations and maintenance personnel had been completed. Approximately $30 \%$ of the field training for Contingency Procedures have been completed.

Representatives from DHHS, NRC, and EPA have provided oversight for the JACADS startup. In late February 1990, a site visit was conducted by representatives from DHHS including an Assistant Surgeon General of the Public Health Service. Their review was concentrated in the area of perimeter and workplace monitoring and medical support capabilities. In a letter documenting the results of this visit, DHHS made various recommendations but concluded that they believe everything possible in the engineering field has been done to ensure safety of the workers and the island population.

Representatives from DHHS will also participate in the preoperational survey prior to the start of JACADS operations. EPA has provided oversight during the permitting process and ensured that this has been started before TSCA R\&D trial burns. In addition, NRC 
has provided oversight to the program by reviewing OVT plans, performing site visits, and evaluating overall progress of the program.

Based on an NRC recommendation, a perimeter monitoring system is being implemented at Johnston Island similar to the system currently in use at TEAD for the CAMDS facility. The JACADS perimeter system will be an integral part of the demilitarization technology validation testing. The purpose of the system is not to control disposal activities or to provide an early warning of an accidental release but to provide a historical record of any major release of agent. The perimeter monitoring system will consist of eight agent sampling stations around the perimeter of the JACADS facility and chemical storage area. In addition, four meteorological stations will be used to collect data to model a potential agent release. Data for certain pollutants for which ambient standards have been established under the Clean Air Act will also be collected at four of the stations. These criteria pollutants are ozone, sulfur dioxide, nitrogen dioxide, and total suspended particulates. This additional monitoring is not required by regulation but is a voluntary commitment by the Army to provide a general check on the ambient air quality impact of JACADS emissions. This perimeter monitoring system is scheduled to become operational in the fall of 1990 . In the interim, a temporary meteorological station is available in the event of an agent release. In regard to monitoring for agent emissions, the JACADS RCRA permit requires all stacks from the facility to be continuously monitored for the presence of agent.

Two TSCA R\&D trial burns were conducted in the Deactivation Furnace System in February 1990. These trial burns are required due to the presence of polychlorinated biphenyls (PCBs) in the rocket shipping and firing tubes. R\&D trial burns followed by demonstrations burns are required by the EPA prior to granting an operating permit to incinerate PCBs. The R\&D trial burns consisted of feeding PCB-contaminated shipping and firing tubes and the complete rocket motor section into the Deactivation Furnace System. Chemical agents were not present in the M55 rockets during these tests. Representatives from Headquarters, EPA witnessed the TSCA R\&D test burns. Results have been received from the first $R \& D$ burn, which was conducted at a feed rate of 30 rockets per hour. These analyses were conducted and results obtained by a contractor under the direction of Headquarters, EPA. Dioxins and furans were not detected in the stack effluent with the exception of octachlorodibenzo-p-dioxin which was found at near ambient levels. A PCB destruction and removal efficiency of $99.9999 \%$, as required by the TSCA regulations, was achieved.

The highesi monitored concentration of PCB's in the JACADS stack gas from the DFS test burn was $5.6 \times 10^{-4} \mathrm{~g} / \mathrm{h}$. This low concentration is achieved due to the low concentration of PCB in the feedstock (average concentration of $2700 \mathrm{ppm}$ ) and the attainment of the required 99.9999\% PCB Destruction and Removal efficiency. Table 17 provides a comparison of these PCB emissions with three of the largest commercial EPApermitted PCB incinerators located within the United States. The lowest emissions values from the PCB incinerators and the highest value measured from the JACADS DFS unit are presented.

The PCB emissions monitored from the JACADS DFS were significantly lower than permitted units in the continental U.S. It should be further noted that an even 
Table 17. Comparieon of JACADS PCB emissions with three commercial EPA-permittod PCB incinerators

\begin{tabular}{lll}
\hline Rollins & 0.0181 & $\mathrm{~g} / \mathrm{h}$ (calculated-low value) \\
ENSCO & 0.0548 & $\mathrm{~g} / \mathrm{h}$ (calculated-low level) \\
SCA & 0.0630 & $\mathrm{~g} / \mathrm{h}$ (measured-low value) \\
JACADS DFS & $0.00056 \mathrm{~g} / \mathrm{h}$ (measured-high value) \\
\hline
\end{tabular}

higher destruction and removal efficiency is expected to be achieved at the CONUS facilities. The DFS afterburners for the CONUS CSDP facilities are being designed to operate at $2200^{\circ} \mathrm{F}$ with a 2.0 -s residence time as compared with the JACADS DFS afterburner which operates at $2000^{\circ} \mathrm{F}$ with a 0.5 -s residence time.

\subsubsection{VX Test Program at CAMDS}

CAMDS is the Army's pilot plant for proof testing chemical demilitarization technology using agents and munitions stored at TEAD. It is located at TEAD, about $50 \mathrm{~km}$ (30 miles) west of Salt Lake City, Utah.

In September 1989, VX testing began at CAMDS. Although VX has been incinerated at CAMDS in the past, this testing provided additional experien'e prior to the beginning of JACADS OVT. During this test period, the performance of the demilitarization equipment was further evaluated and VX incinerator tests were conducted in the liquid incinerator (LIC). A test burn was also conducted in the LIC to characterize effluents and solid residues and compare them against regulatory standards. The feed to the LIC was varied to characterize furnace performance under varying operating
conditions.

The CAMDS LIC was operated between September 10 and November 2, 1989. The test plan was based on feeding agent VX to the primary chamber and water or spent decontaminating solutions (decons) into the secondary chamber. The spent decon solution was $1 \%$ sodium hypochlorite $(\mathrm{NaOCl})$. The LIC successfully incinerated $18,240 \mathrm{~kg}$ $(40,215 \mathrm{lb})$ of agent $\mathrm{VX}$ during the test period. The average $\mathrm{VX}$ feed rate to the primary chamber was $92.5 \mathrm{~kg} / \mathrm{h}(204 \mathrm{lb} / \mathrm{h})$ during approximately $200 \mathrm{~h}$ of agent feed to the LIC. Approximately $25 \mathrm{~m}^{3}$ (6530 gal) of $1 \%$ sodium hypochlorite solution were incinerated in the secondary chamber at an average feed rate of $0.3 \mathrm{~m}^{3} / \mathrm{h}(1.3 \mathrm{gpm})$ for the $84 \mathrm{~h}$ of decon operation. The chemical agent detectors did not measure agent in the stack or surrounding area at any time during the testing.

RCRA demonstration burns were conducted as part of the VX testing. Representatives from the Utah Bureau of Solid and Hazardous Wastes witnessed four agent incineration tests conducted between September 18 and 22, 1989. The carbon monoxide emissions never exceeded the proposed Tier I hourly limit of $100 \mathrm{ppm}$. The VX destruction and removal efficiency exceeded $99.9999 \%$. The particulate emissions averaged $135 \mathrm{mg} / \mathrm{m}^{3}$ over the RCRA demonstration period with only one run exceeding 
the limit of $180 \mathrm{mg} / \mathrm{m}^{3}$. Hydrogen chloride $(\mathrm{HCl})$ emissions never exceeded the $1.36 \mathrm{~g} / \mathrm{h}$ $(0.003 \mathrm{lb} / \mathrm{h})$ limit. A less formal test burn was conducted with the incineration of $\mathrm{VX}$ in the primary chamber and $1 \%$ sodium hypochlorite in the secondary chamber. The emissions results from the burn indicated compliance with RCRA regulations.

One problem that developed during the VX testing was that a glassy green slag formed in the bottom of the secondaiy chamber. Subsequent analysis indicated the slag had been generated from a reaction involving the phosphorus from the agent, sodium from the spent decontamination solution, and silica and alumina from the furnace chamber refractory. Additionally, the secondary chamber refractory was damaged. Additional tests are planned with the CAMDS LIC utilizing a high phosphorus simulant, dimethyl phosphite (DEP), in mid-1990. The LIC will be operated under various conditions to promote better understanding of the slag formation. The removal of the slag from the secondary chamber is also being studied. The current salt removal system did not appear to perform effectively during the VX tests. Section 3.3.8 provides recommended improvements to the JACADS LIC based on these findings.

\subsubsection{Mustard Agent (HD) Test Program at CAMDS}

In the fall of 1990 , testing with mustard agent (HD) is scheduled to begin at CAMDS. Although agent HD has been incinerated at RMA in the past, the CAMDS testing will provide additional experience before agent $\mathrm{HD}$ is incinerated during the JACADS OVT. During the proposed mustard tests, the performance of the demilitarization equipment will be further evaluated and incineration tests of agent HD will be conducted in the LIC and Metal Parts Furnace (MPF). A test burn will be conducted in the LIC and MPF to characterize effluents and solid residues and to compare them to the regulatory standards. The feed to the LIC will be varied to characterize furnace performance under varying operation conditions. Drained ton containers and projectile bodies will be thermally decontaminated in the MPF to confirm processing rates and to characterize emissions and residues.

\subsubsection{Award of the Systems Contract for the Chemical Demilitarization Training Facility}

In July 1989, the systems contract for the construction and operation of a CDTF was awarded to General Physics Corporation of Columbia, Maryland. This facility, which is being constructed at the Aberdeen Proving Ground, Maryland, will be used to ensure uniform and consistent training is provided to workers who will operate the eight demilitarization facilities planned for construction. The CDTF is scheduled to begin training operations in late 1990.

The CDTF will provide basic and prerequisite instruction in chemical agent and munition destruction for both government and contractor personnel involved in operation of the CONUS facilities. The CDTF will provide classroom instruction, hands-on equipment operation, computer simulation and continuation/refresher courses. A centralized training facility will enable workers to obtain training in a nonhazardous environment and will facilitate standardization of operations and maintenance procedures 
between the eight CONUS facilities. A single contractor is being used to train workers at the CDTF to facilitate incorporation of lessons learned and to centralize the training expertise, increasing overall training effectiveness.

\subsubsection{Award of the Syatems Contract for the Tooele Chemical Agent Disposal Facility}

In September 1989, the systems contract for the Tooele chemical agent disposal facility was awarded to EG\&G, Inc., of Falls Church, Virginia. EG\&G, Inc., is responsible for the construction, operation, and decommissioning of the first full-scale CONUS chemical agent and munitions disposal facility. This facility is to be constructed at the Tooele Army Depot, Utah. Operation of the Tooele facility is scheduled to begin in 1993.

\subsubsection{Equipment Acquisition Contracts}

In November 1988, an equipment acquisition contract was awarded to Bechtel National, Inc. Bechtel is responsible for the acquisition of process equipment to be standardized between the eight CONUS demilitarization facilities. Examples of equipment to be purchased by Bechtel include the demilitarization equipment used to disassemble the munitions prior to incineration, the blast doors for the explosive containment room, and the brine reduction equipment.

Major process equipment critical to the safe operation of the facilities (e.g., furnaces, control systems and pollution abatement systems) are being purchased by Stearns-Rogers, Inc., the JACADS equipment acquisition and operations contractor. The JACADS equipment acquisition contract contains options to purchase major equipment systems for the eight CONUS demilitarization facilities from the JACADS equipment vendors. This acquisition strategy will result in purchasing systems critical to the safe operation of the facility that are essentially identical to those purchased for JACADS. As a result, safety and environmental compliance aspects of this equipment will be able to be demonstrated during JACADS OVT.

Equipment acquisition for all sites through a single equipment acquisition contractor (either Bechtel or Stearns-Rogers) will result in obtaining uniformity and standardization of equipment between the CONUS sites and will facilitate incorporation
of lessons learned.

\subsubsection{Individual Equipment Advancements}

In addition to experience gained from ongoing demilitarization programs, separate test programs and research and development efforts are ongoing to improve the performance of individual equipment systems and ensure that state-of-the-art technology is continually incorporated into the CSDP facilities. For example, since the FPEIS was written, major advancements have been made to the automatic continuous air monitoring system (ACAMS) and ventilation filtration system. 
During 1988, a research and development program was initiated to modify the ACAMS so that it could detect time-weighted average (TWA) concentrations of the agents HD, GB, and VX within a 3- to 5-min cycle. This was an improvement over the response time cited in the FPEIS, in which high-level detection was assumed to be achieved within $5 \mathrm{~min}$, but detection to the TWA level could only be achieved within 8 to $22 \mathrm{~min}$. These reduced response times were successfully achieved during demonstration tests in mid-1988, and the JACADS ACAMS were modified to include this new technology prior to the start of operations.

Dugway Proving Ground is currently conducting adsorption tests on carbon to determine the effects of agent GB concentration, relative humidity, and temperature on adsorption and desorption performance of carbon filters. Test conditions were selected based on an experimental design chosen to provide a response surface at carbon bed depths of 5,10 , and $20 \mathrm{~cm}(2,4$, and $8 \mathrm{in}$.). The results should indicate the optimal operating conditions for the carbon and will enable the Army to assess the optimal carbon depth and the optimal operating conditions for the filters.

The FPEIS made a public commitment to rransport munitions from the storage area to the disposal facility in an ONC that would meet certain puncture, drop, fire, and crush performance criteria. The ONC was necessary to mitigate the risk of chemical munition transportation accidents during demilitarization operations. Since the publication of the FPEIS, the Army has pursued the development of this container. As of April 1990, the ONC design has been completed, puncture and fire tests have been successfully completed on a full scale mock-up ONC, and fabrication of a prototype ONC has been initiated. Prototype testing, to include projectile penetration tests, rocket drop tests, handling demonstrations, and a compliance test are scheduled to be completed at the end of 1990. Following prototype testing, acquisition of the ONCs for the CONUS facilities will be initiated.

As discussed in Sect. 3.3.3, two areas of concern were identified with the LIC secondary chamber during CAMDS VX testing in late 1989. During these tests, a glassy green slag formed in the bottom of the secondary chamber, and the secondary chamber refractory became damaged. These findings were not of concern from an operational safety standpoint but have the potential to increase plant downtimes. Studies have been initiated to develop a slag removal system and identify a new refractory for the LIC secondary chamber with a longer life than that of the chamber currently installed. The results of further investigations and planned improvements to be implemented in the JACADS LIC are described here.

The secondary chamber refractory had been damaged primarily as a result of a reaction between the phosphorus from the VX and sodium in the spent agent decontamination solution and the silica and alumina in the refractory. Following an industry search and consultation with major refractory manufacturers, it was concluded that Ruby SR ( $90 \%$ alumina-10\% chromia) brick had the properties to best withstand the conditions (high temperature, high phosphorus, and alkali content) in the LIC secondary chamber. This refractory is planned to be installed in the JACADS LIC when the life of the current refractory is expended. 
The green slag generated at CAMDS during the $\mathrm{VX}$ and decon tests predominantly consisted of $58 \%$ phosphorus pentoxide, $9 \%$ lime, $12 \%$ alumina, $8 \%$ silica, $4 \%$ magnesia, and $7 \%$ soda. It is believed that less slag will be formed when the secondary chamber refractory is replaced with Ruby SR; however, because of the presence of phosphorus in the LIC feed, some slag formation will still occur. A slag removal system is being designed to facilitate maintenance operations at the JACADS facility. The proposed system will consist of a removable cart on tracks with a hydraulic mechanism to seal the cart to a port at the base of the secondary chamber.

A manhole is planned to be installed in the JACADS LIC secondary chamber to facilitate inspections. In addition, the more toxic primary chamber will be physically divided from the secondary chamber by a wall. Maintenance operations and the removal of the slag will be facilitated by this measure.

\subsection{RISK ASSURANCE}

The FPEIS risk analysis was based on the JACADS $60 \%$ design as modified by conceptual changes planned for implementation at the eight proposed CONUS facilities. A risk assurance study is under way in support of the site-specific NEPA process to examine the ramifications of major procedural and conceptual changes to the design analyzed in the FPEIS. Such design changes have resulted from Army efforts to make the disposal operation safer; to make the plant more efficient in disassembling munitions and in destroying agents; to incorporate lessons learned from CAMDS, JACADS, and other facilities (as discussed in Sect. 3.3); and to comply with environmental permit requirements that change over time and vary from state to state.

Major changes will be examined as part of the risk assurance study to determine if they have the potential to significantly increase the risk of on-site disposal from that presented in the FPEIS. If such a potential increase is identified, the resultant risk will be calculated and a determination will be made (using the FPEIS decision methodology) as to whether on-site disposal is still the preferred alternative for that site. The effectiveness of potential mitigation measures reducing the change in risk to insignificant levels would also be examined.

As individual facility designs further evolve from the concepts presented in the site-specific EIS, additional design and procedural changes may be made. Prior to finalizing these design changes, a rigorous safety review will be conducted in accordance with the System Safety Management Plan for the CSDP. This plan outlines the various safety reviews and checkpoints to be implemented during the design, construction, and operation of the proposed disposal facility, including various hazard analyses, fault tree analyses, and safety assessments and inspections. All proposed design changes will be subjected to the same extent of safety analysis as the original design. For this reason, additional site-specific risk analysis beyond that presented in the FPEIS and updated in the risk assurance study is not planned. This section highlights the results of this risk assurance process and presents conclusions about selected design changes relevant to
PBA. 


\subsubsection{Rationale and Basis for Risk Assurance at the Pine Bluff Arsenal}

The JACADS design (at its $60 \%$ completion level) provided the basis for the FPEIS risk analysis. Table 18 provides a summary of the principal changes in design and operating procedures for PBA that have been approved by the Army since publication of the FPEIS. Many other minor changes are not shown in Table 18; however, based on an assessment of the potential for changes to affect risk, the items in Table 18 have been identified as warranting a closer examination of their associated risk values and how those values might differ from the values presented in the FPEIS for PBA.

"Risk" is determined by the probability of an accident and its consequences. Any design change that has the potential for increasing either the probability or consequence of an accident will, therefore, increase the risk and will require close examination for the purpose of risk assurance. One criterion for identifying changes that require further examination is the number of additional steps in the procedures implementing the new design. For example, if the FPEIS assumed that munition pallets were handled three times prior to their unpacking and individual munition disassembly, but the new design allows for six such handling steps, then risk must be reexamined to determine if the frequency of an accident has increased.

Another criterion involves the quantity of agent that could be involved in an accident. For example, if the accident sequence in the FPEIS assumed that only small quantities of agent could be involved, but the new design allows for larger agent quantities to be present, then reexamination of the risk implications for that design change is warranted by the potential increase in the quantity of chemical agent accidentally released.

Applying the above criteria to the potential for design changes to affect risk, the items in Table 18, with the exception of the new construction at the BZ site, were identified for further examination. The risk implications of these items are discussed below. A report on the reassessment of the risk implications for the complete set of changes in design and operating procedures from those presented in the FPEIS is currently being prepared as part of the risk assurance study.

\subsubsection{Design Changes Requiring Recramination of Risk at the Pine Bluff Arsenal}

\subsubsection{Container handling building}

The FPEIS assumed that agents and munitions would be removed from their existing storage, placed inside on-site transportation containers, and transported to a munitions holding igloo (MHI). The MHI provided temporary storage of sufficient munition quantities to operate the plant during non-daylight hours (i.e., when $c$ "ite transport from existing storage directly to the plant could not occur). The MHI concept involved storing packaged munitions in a standard earth-covered magazine (igloo), 
Table 18. Summary of major changes in design and operating procedures for the proposed disposal facilities at the Pine Bluff Arsenal

\begin{tabular}{ll}
\hline \multicolumn{1}{c}{ FPEIS design } & \multicolumn{1}{c}{ Current design } \\
\hline $\begin{array}{l}\text { Munitions handling igloo (MHI) used for } \\
\text { temporary storage of sufficient munitions } \\
\text { to support multishift plant operations. }\end{array}$ & $\begin{array}{l}\text { MHI replaced by container handling } \\
\text { building (CHB) that has a mustard thaw } \\
\text { capability. }\end{array}$ \\
$\begin{array}{l}\text { On-site container (ONC) used to } \\
\text { safeguard munitions during transport. }\end{array}$ & $\begin{array}{l}\text { ONC will still be used but has been } \\
\text { redesigned; ONC holds up to nine pallets } \\
\text { of munitions. Two ONCs per munition } \\
\text { munitions. Four ONCs to be transported } \\
\text { transporter. } \\
\text { transporter per convoy. }\end{array}$ \\
$\begin{array}{l}\text { Existing BZ plant to be modified for } \\
\text { destroying the entire PBA stockpile. }\end{array}$ & $\begin{array}{l}\text { Only support facilities from the BZ plant } \\
\text { will be used. A new munitions } \\
\text { demilitarization building is to be } \\
\text { constructed to destroy the PBA stockpile. }\end{array}$ \\
\hline
\end{tabular}

handling the packages with forklifts inside the igloo, and moving the packages by forklift across an open area to the demilitarization building.

The MHI concept was subsequently found to be inadequate because its capacity was insufficient and there were too many handling steps to support the throughput and processing rates required by the demilitarization plant. The new PBA design incorporates a container handling building (CHB) that eliminates these inadequacies of the MHI concept; however, the CHB introduces new design features that warrant a reexamination of risk. Because the CHB has a larger capacity than the MHI and is not as well protected from external events as was the MHI (i.e., the MHI was to have been an earth-covered concrete structure), there exists a potential for more agent to be involved in an accidental release. In addition, there are fewer handling steps-and a reduced probability of accidents-for the CHB than for the MHI. While these may appear to be offsetting factors, their relative contribution to risk is unclear. Thus, a reexamination of risk was required to define the overall risks associated with the replacement of the MHI by the
$\mathrm{CHB}$ design. Results of examining CHB risks. The result of examining the risks of this new design indicates that none of the five FPEIS measures of risk for PBA are higher with the CHB than with the MHI. The risks (primarily those risks from munitions handling) associated with the MHI were eliminated from the accident data base, and new risks were 
developed for the CHB and added back into the data base. The net result was a decrease in the three probability-related measures of risk (i.e., the "probability ot one or more fatalities," the "expected fatalities," and the "expected plume area"). The minimum decrease in risk was $45 \%$ for each of these three measures of risk. Because the size (i.e., downwind no-deaths distance) of the largest CHB accident was no larger than other dominant accidents at PBA (i.e., it was in the 50-km accident distance category), the other two measures of risk-the "maximum number of fatalities" and the "person-years at risk"-did not change. The risks associated with the new CHB design are, therefore, less than or equal to the risks associated with the MHI in the FPEIS for PBA.

\subsubsection{Redesigned on-site container}

The FPEIS assumed that pallets or boxes of munitions would be removed from existing storage, placed individually inside an on-site container (ONC) for protection during on-site movement, and transported to the disposal facility (either directly to the plant or to the MHI). During on-site movement, four ONCs would be loaded onto a munitions vehicle, and only one munitions vehicle svould be in the convoy as it moved between the existing storage area and the disposal facility.

Resolving the inadequacies of the MHI, as described above, by using the new CHB also required redesigning the ONC. The redesigned ONC will now carry more than one pallet or box of munitions (e.g., up to nine pallets of projectiles can be simultaneously transported inside the new ONC). Two of the new ONCs will be loaded onto a munitions vehicle for transport between the storage area and the disposal facility.

Because the new ONC has a larger capacity than the ONC concept assumed in the FPEIS risk analysis, a potential exists for a transport accident to release larger quantities of chemical agent than in the FPEIS. Furthermore, the larger capacity of the new ONC will require fewer trips between the storage area and the disposal facility. Fewer vehicle miles will be trave'led, and the probability of an accident during transport will, therefore, decrease. The potential offsetting effects of these two factors (larger capacity and fewer vehicle miles) makes the impact on the FPEIS risk values for PBA unclear. Therefore, a
reexamination of ONC risks is warranted.

Results of reexamining $O N C$ risks. The result of reexamining the risks of the new ONC design and its accompanying transportation procedures, indicates that none of the five FPEIS measures of risk for PBA are higher than with the old ONC conceptual design. There was a decrease in the three probability-related measures of risk (i.e., the "probability of one or more fatalities," the "expected fatalities," and the "expected plume area"). The decrease in risk was $8 \%$ or less for each of these three measures of risk. Because the size (i.e., downwind no-deaths distance) of the largest ONC accident with the new design was no larger than other dominant accidents at PBA [i.e., the largest accident would still be placed into the $50-\mathrm{km}(31-\mathrm{mile})$ accident distance category], the "maximum number of fatalities" and the "person-years at risk" measures of risk did not change. Therefore, the risks associated with the new ONC design are less than or equal to the risks associated with the ONC concept in the FPEIS for PBA. 


\subsubsection{Use of the existing BZ farilities at Pine Bluff Arsenal}

The FPEIS stated that the existing BZ plant (see Sect. 3.3) at PBA would be modified and used to destroy the entire PBA stockpile; however, the risk assessment supporting the FPEIS analysis did not take into consideration site-specific design changes to the BZ facility at PBA. Instead, the risk assessment assumed that the PBA disposal plant would be a clone of the other CSDP facilities. The Army's current plan is to utilize only the support facilities from the existing $B Z$ plant and to construct a new munitions demilitarization building (MDB) adjacent to the BZ plant at PBA. This new facility would be used to destroy the entire lethal chemical stockpile at PBA. The PBA MDB would be downsized from the TEAD and JACADS facilities, because it would not require projectile disassembly equipment.

The implication of this change in PBA design strategy from that presented in the FPEIS is that the assumptions in the FPEIS risk assessment for PBA remain valid. The FPEIS risk assessment has adequately accounted for the similarity between the proposed PBA disposal facilities and the facilities at the other CONUS sites.

\subsection{REFERENCES}

Algermissen, S. T., D. M. Perkins, P. C. Thenhaus, S. L. Hanson, and B. L. Bender 1982. Probabilistic Estimates of Maximum Acceleration and Velocity in Rock in the Contiguous United States, U.S. Geological Survey Open-File Report 82-1033, Denver, Colo.

Algermissen, S. T. and M. G. Hopper 1984. "Estimated Maximum Regional Seismic Intensities Associated with an Ensemble of Great Earthquakes that might occur along the New Madrid Seismic Zone, East-Central United States," U.S. Geological Survey, Miscellaneous Field Studies, Map MF-1712, Reston, Va.

ATC (Applied Technology Council) 1978. Tentative Provisions for the Development of Seismic Regulations for Buildings, Applied Technology Council/National Bureau of Standards, Special Publication 510, U.S. Department of Commerce, Washington, D.C.

Carnes, S. A, et al. 1989. Emergency Response Concept Plan for Pine Bluff Arsenal and Vicinity, ORNL/TM-11092, Oak Ridge National Laboratory, Oak Ridge, Tenn.

Duff, W. W., et al. 1989. Operational Verification Test and Evaluation Master Plan for the Johnston Atoll Chemical Agent Disposal System (JACADS), MTR-88W250, The MITRE Corporation, McLean, Va.

EPA (U.S. Environmental Protection Agency) 1989.

EPRI (Electric Power Research Institute) 1975. Seismic Design of Nuclear Power Plants, Electric Power Research Institute, Palo Alto, Calif.

FAA (Federal Aviation Administration) 1988. FAA Air Traffic Activity, FY 1987, Government Printing Office. 
FEMA (Federal Emergency Management Agency) 1988. NEHRP (National Earthquake Hazard Reduction Program) Recommended Provisions for the Development of Seismic Regulations for New Buildings, Part 2, Earthquake Hazard Reduction Series 18, Building Seismic Safety Council, Washington, D.C.

Heyl, A V. and F. A. McKeown 1978. "Preliminary Seismotectonic Map of Central Mississippi Valley and Environs," U.S. Geological Survey, Miscellaneous Field Studies, Map MF-1011, Reston, Va.

Holzworth, G. C. 1972. Mixing Heights, Wind Speeds, and Potential for Urban Air Pollution throughout the Contiguous United States, Environmental Protection Agency, Office of Air Programs, Research Triangle Park, N.C.

Jacobs Engineering Group, Inc., and Schneider EC Planning and Management Services 1987. Emergency Response Concept Plan for the Chemical Stockpile Disposal Program, SAPEO-CDE-IS-87007, Program Executive Officer-Program Manager for Chemical Demilitarization, Aberdeen Proving Ground, Md.

Jaccbs Engineering Group, Inc., and URS/John A. Blume and Associates 1987. Geological-Seismological Investigation of Earthquake Hazards for a Chemical Stockpile Disposal Ficility at the Pine Bluff Arsenah Arkansas, contractor report by engineers to U.S. Army Engineer Division, Huntsville, Ala., contract no. DACA87. 86-0085, prepared for the Office of the Program Manager for Chemical Demilitarization, Aberdeen Proving Ground, Md.

NRC (U.S. Nuclear Regularory Commission) 1981. Safety Analysis Report Related to the Operation of Grand Gulf Nuclear Station, Units 1 and 2, U.S. Nuclear Regulatory Commission, Docket Nos. 50-416 and 50-417, NUREG-0968, Office of Nuclear Reactor Regulation, Washington, D.C.

Nuttli, O. W. 1981. "Similarities and Differences Between Western and Eastern United States Earthquakes and Their Consequences for Earthquake Engineering," in Proceedings of Earthquakes and Earthquake Engineering: The Eastern United States, ed. J. E. Beavers, Ann Arbor, Mich.

Russell, E. B. and W. S. Parks 1975. Stratigraphy of the Outcropping Upper Cretaceous, Paleocene, and Lower Eocene in Western Tennessee, Bulletin 75, Tennessee Division of Geology, Nashville, Tennessee.

Seed, II. B. and I. M. Idriss 1971. "Simplified Procedure for Evaluating Soil Liquefaction Potential," Joumal of the Soil Mechanics and Foundations Division, American Society of Civil Engineers.

Thenhaus, P. C. 1983. Summary of Workshops Concerning Regional Seismic Source Zones of Parts of the Conterminous United States Convened by the U.S. Geological Survey 1979-1980, Golden, Colorado, USGS Circular 898, Alexandria, Va.

U.S. Army 1986. Pive Bluff Arsenal Installation Hazardous Waste Management Plan, AR 420-47, Environmental Office, Pine Bluff Arsenal, Pine Bluff, Ark.

U.S. Army 1988. Chemical Stockpile Disposal Program Final Programmatic Environmental Impact Statement, Vols. 1, 2, and 3, Program Executive Officer, Manager for Chemical Demilitarization, Aberdeen Proving Ground, Md.

USGS (U.S. Geological Survey) 1982. Investigations of the New Madrid, Missouri Earthquake Region, Professional Paper 1236, U.S. Government Printing Office. 


\section{FINDINGS AND CONCLUSIONS}

\subsection{REEXAMINING ON-SITE DISPOSAL AS THE ENVIRONMENTALLY PREFERRED ALTERNATIVE}

The data used in the FPEIS to select the environmentally preferred alternative were identified, and more recent and more detailed site-specific data of the same types were gathered during the Phase I process. These new data were then examined and compared with the FPEIS data to determine if they have changed enough to warrant recomputation of the five measures of risk used to identify the programmatic environmentally preferred alternative. Residential population (off-post) was identified as having changed encugh to warrant recomputation of risk. This is due primarily to population growth (from 1980 data in the FPEIS to 1986 data now available) and to a change in the location of the residents [instead of 120 persons living within $2 \mathbf{~ k m}$ (1.2 miles) of the site of the proposed disposal plant, as was assumed in the FPEIS, residents were assumed to be located no closer than the actual installation boundary]. Furthermore, the proposed disposal site geographic coordinates were revised to more accurately reflect the location of the proposed disposal site. It was also determined that the CML meteorological conditions at PBA warrant additional study. Instead of the FPEIS CML conditions [D stability, wind speed $3 \mathrm{~m} / \mathrm{s}$, and $750 \mathrm{~m}$ mixing height], a new CML condition was defined as D stability, wind speed $1 \mathrm{~m} / \mathrm{s}$, and a mixing height of $500 \mathrm{~m}$. For the areas of road conditions, aircraft activity, meteorite frequency, and seismicity, either new data were not identified during the Phase I process or, if located, were not sufficiently different from data used in the FPEIS risk assessment to warrant recalculation of risk.

As a first step in reassessing risk, the new population data were used to compute average and maximum fatalities using the same computation methods as in the FPEIS and using the programmatic values for all other parameters. The revised fatality estimates were then used to compute the five measures of risk for on-site disposal, continued storage, and on-site activities associated with off-site transport. These risk measures were summarized in pictogram form as was done in the FPEIS. Examination of the Phase I pictogram indicates that the alternatives are indistinguishable. However, risks from on-site disposal are in all cases equal to or less than risks from other alternatives.

The meteorological conditions of CML and WC scenarios assumed in the FPEIS risk analysis were found to be appropriate for PBA. Consideration of one other viable meteorological condition for the CML scenario produced the conclusion that there 
would have been no difference in FPEIS risk values if $i=$ alternate CML scenario had been used.

The conclusion is that on-site disposal remains valid as the environmentally preferred alternative for PBA. From the perspective of the population near PBA, on-site disposal is at least equivalent to all other alternatives in terms of the potential for human health impacts. If one adds the off-site transportation risks (not addressed in this document because they are beyond the scope), the on-site alternative is clearly preferable given the opportunity for risk reductions associated with emergency planning and preparedness activities that are under way at PBA.

\subsection{RESOURCE DATA REILATED TO IMPLEMENTATION OF ON-SITE DISPOSAL AT PINE BLUFF ARSENAL}

During the Phase I process, data on resources that could be affected by on-site disposal at PBA were gathered to determine if any significant new or site-specific resources are present that could affect construction and operation of the on-site disposal facility (including incident-free operations and accident scenarios): population (including residential, on-post, daytime, and special populations), meteorology and air quality, surface and groundwater, land use, ecology, socioeconomics, and aircraft activity. Some of these resources were examined in the FPEIS in assessing potential impacts of the programmatic alternatives, whereas others represent new information that was not appropriate for examination on the programmatic level. No assessment of potential impacts was done during the Phase I process. Rather, the data were examined to help identify potential issues to be analyzed under Phase II. Results for the principal resource areas are presented below.

- Population. Residential population within the 100-km (62-mile) zone of the site of the proposed disposal facility at PBA increased about $2 \%$ from 1980 (FPEIS data) to 1986 (Phase I data). Using the actual PBA boundary, no off-post residential population was found within $2 \mathrm{~km}$ ( 1.2 miles) of the proposed disposal site; however, the chemical agent storage area was found to be within $0.8 \mathrm{~km}(0.5 \mathrm{mile})$ of off-site residents. The significance of these changes has been discussed in Section 3.1. On-post population was found to range from 1382 in the daytime to 140 in the nights and evenings. Special populations (infrequent events) have been identified on areas at and near PBA. All of these data will be considered, in conjunction with data on residential population, in estimating fatalities in the site-specific EIS for PBA. Additional data were also collected regarding American Indian entities. No legally designated Indian country or federally recognized Indian communities exist within $100 \mathrm{~km}$ (62 miles) of the disposal site. 
- Meteorology and air quality. The weather conditions of CML and WC assumed in the FPEIS were found to be appropriate for PBA. Wind data from within the PBA installation differ from data at Pine Bluff Municipal Airport (used in the FPEIS to assess the impacts of incident-free operations) and are more representative of the wind pattern at the site of the proposed disposal facility. The data from PBA Tower 6 will be used as input for atmospheric dispersion models in assessing potential impacts from construction and normal incident-free operations. A Class I prevention of significant deterioration (PSD) area located $184 \mathrm{~km}$ (115 miles) west of PBA was identified. Potential impacts of air emissions from the proposed disposal facility on this area of pristine air quality will be considered in the sitespecific EIS for PBA.

- Water resources. Additional site-specific data collected since publication of the FPEIS reinforce the programmatic conclusions. The site for the disposal facility is located on the northern portiou of PBA. Runoff from this site drains to nearby lakes and ponds or to creeks which do not meander through the city of Pine Bluff. Instead, these creeks discharge into the Arkansas River upstream from the city. Runoff is diluted by both the flow of the creek, and the relatively high, sustained flow of the Arkansas River before reaching Pine Bluff. Rainwater runoff will be collected in a holding pond before being discharged to the environment.

Accidental spills of chemical agent that could seep into the groundwater beneath PBA could enter the surficial Quaternary Aquifer or the Cockfield-Jackson Aquifer directly beneath it. Both of these aquifers have outcrops on PBA. Seepage of contaminants into the deeper Sparta Sand Aquifer, which serves as the municipal water supply for Pine Bluff, is prevented by an aquitard (the Cook Mountain Formation) consisting of relatively thick, silty to sandy clay.

- Land use. No unique resources have been identified after examining more recent and detailed data.

- Ecological resources. Since the FPEIS, Geocarpon minimum has been listed as occurring in the impact zone and Arctic peregrine falcons as using the area for feeding during migration. This brings the number of threatened and endangered species that could occur within the $100-\mathrm{km}(62$-mile) impact zone to a total of eight species. This list may be revised and expanded after a response to the request for site-specific information is obtained from FWS and will be addressed in the site-specific EIS.

The identification of additional threatened and endangered species listed since data collection for the FPEIS and the addition of state parks, wildlife management areas, and important natural areas does not alter the 
conclusions of the FPEIS; the additional information will help to better estimate the extent of effects to important ecological resources. Information con wind direction and other meteorological conditions, the quantities of agent that could be released under worst-rase accident scenarios, and the location and densities (where information can be cbtained) of ecological resources potentially at risk will be used to estimate the extent of impacts that could occur to ecological resources in the site-specific EIS.

- Sociah economic, and cultural resources. Additional data were collected beyond the 10-km (6.2-mile) zone used in the FPEIS. These data include worker and resident populations located both off-post and on-post at PBA; potentially sensitive populations (i.e., children and the elderly) by county of residence within a $100-\mathrm{km}$ (62-mile) zone; large transient populations within the 50-km (31-mile) zone; special populations (e.g., schools, health care facilities, day care facilities, corrections facilities, and post-secondary schools) within a $100-\mathrm{km}$ (62-mile) zone; industries within Jefferson and Grant Counties; land use in the city of Pine Bluff and agricultural land use within the $100-\mathrm{km}$ (62-mile) zone; historic and archaeological sites within the 100-km (62-mile) zone; public safety services in Jefferson and Grant Counties; and economics and infrastructure within Jefferson and Grant Counties, the zone likely to experience project-related population growth. No unique cultural resources have been identified.

- Aircraft activity. There is no significant change in aircraft activity near the proposed site as compared with that presented in the FPEIS.

- Emergency preparedness. Emergency preparedness and response enhancements on-site bave been initiated since the FPEIS. The Army has begun implementing an emergency response plan at PBA, has funded planners to work with local governments to upgrade existing plans, and is committed to providing technical essistance and coordination to local planning efforts.

\section{OTHER FACTORS}

Technology maturity and technology tracking and risk assurance were also examined during the Phase I process, although neither factor was instrumental in reaching conclusions identified in the previous two sections for PBA.

For technology maturity, four principal technology developments have occurred since the FPEIS and should be of value in the implementation of on-site disposal at PBA: BZ disposal, systemization of JACADS, VX disposal tests at CAMDS, and 
equipment advances. BZ destruction at PBA has helped to establish preoperational surveys, personnel hiring practices, operations schedules, and operation procedures that will be of value to PBA disposal operations. Destruction of lethal unitary chemical agents and munitions at Johnston Atoll will provide data from equipment startup, personnel training, and OVT that will be evaluated for incorporation into the PBA facility before construction. At TEAD, CAMDS tests have been conducted with the agent VX, which should provide valuable information to the Johnston Atoll operations, as well as PBA, on equipment performance, emissions, and effluents. Last, advances have occurred since the FPEIS in the areas of air monitoring and air filters. Advances in air monitoring technology now allow detection of a TWA concentration of agent within 3 to $5 \mathrm{~min}$, which is a substantial improvement over the 8 to $22 \mathrm{~min}$ assumed in the FPEIS. Filter tests are ongoing to optimize the performance of filters designed to remove agent GB from an air stream.

Technology tracking and risk assurance refer to tracking the disposal facility design changes that have occurred since the FPEIS to ensure that the relative ranking of alternatives as presented in the FPEIS risk pictograms for PBA will not change. The FPEIS was based on a facility design that was largely conceptual. Since then, the design has progressed toward completion and thus may have changed in some respects from that used to develop the FPEIS risk levels. Other factors that can change the design include incorporating lessons learned from technology maturity and responding to changing environmental permit requirements. No currently proposed design changes have been found that result in a different ranking of the various alternatives based upon their respective levels of risk. 


\section{APPENDIX A \\ MMPACT ANALYSES IN THE FINAL PROGRAMMATC ENVIRONMENTAL IMPACT STATEMENT}

This appendix provides a summary of the impact analysis conducted in the final programmatic environmental impact statement (FPEIS), including the method and data used to identify the programmatic environmentally preferred alternative, the examination of the acceptability of the alternative for Pine Bluff Arsenal (PBA), and non-risk impact analyses conducted for the stockpile at PBA. Because the Army's stockpile of chemical agents contains some of the most toxic materials in the world, and because some of the present storage installations are located near highly populated areas, public concern about the safety of the proposed disposal alternatives was the key issue addressed in the Final Programmatic Environmental Impact Statement (FPEIS). Specifically, concerns about the safety of incineration operations and about impacts to human health from both incident-free operations and accidental releases of chemical agent became the primary focus of the FPEIS impact analyses.

\section{A.1 IDENTIFYNG THE ENVIRONMENTALLY PREFERRED ALTERNATIVE}

\section{A.1.1 Approach Taken in the Programmatic Asecssment}

In order to categorize the environmental impacts of the programmatic disposal alternatives, the FPEIS identified three distinct activities required for the destruction of the continental United States (CONUS) stockpile: (1) construction (or modification) of disposal facilities (incinerators or shipping and receiving facilities); (2) disposal operations, including transportation (off-site, as well as on-site); and (3) decommissioning of all disposal facilities upon completion of the program. These activity categories existed for each progranmatic disposal alternative, although the applicability and phasing of these activities at each storage installation were dependent on each particular alternative.

Early on, the construction and decommissioning activities were determined to be rather insignificant in regard to the ability to use impacts from these activities in distinguishing among the various programmatic disposal alternatives. In fact, construction activity at each storage location (irrespective of the alternative) would be typical of that for any sinedium-scale industrial facility.

In contrast, the nature and significance of the environmental impact of disposal operations depend upon whether or not the operations would be incident-free. 
Therefore, incident-free disposal operations were defined as occurring without any intentional release of chemical agent above prescribed emission levels; abnormal operations were defined as those involving major accidents with off-site consequences. It is obvious that accidents could have environmental consequences of major proportions. These consequences could include human fatalities and chronic illnesses, destruction of wildlife and wildlife habitat, destruction of economic resources, and adverse impacts on the quality of life in the affected areas.

Fortunately, such high-consequence accidents would be unlikely. This low likelihood would be ensured principally through plant design, munition packaging, and well-conceived and well-implemented transportation and operating procedures. The area affected by (and the potential severity of accidents would be specific both to the storage site and the point of occurrence along the transportation corridor. The impacts from potential accidents would be largely dependent upon population distributions, the chemical agents and munitions involved, and natural conditions and features at the accident location. Hence, the principal thrust of the FPEIS was directed toward the examination of accident scenarios, their probabilities of occurrence, and attendant environmental impacts.

\section{A1.2 Approach to the Analycis of Accidents}

In support of the FPEIS, a comprehensive study was performed to identify the credible accidents and the expected effects on human health, ecological systems, water resources, and socioeconomic resources. Such accidents were identified in risk analyses (GA Technologies 1987a, 1987b, and 1987c) and integrated by MTRE Corporation and Oak Ridge National Laboratory (ORNL) (see U.S. Army 1988; Vol. 3, Appendix J).

Each programmatic disposal alteruative was included in the study. The principal areas of focus were plant operations; off-site transportation (for national, regional, and partial relocation options); on-site transportation via truck; and munition-handling operations. Accident initiators that were considered included equipment failures and human error, as well as external events (seismic events, meteorites, tornadoes and high winds, lightning, and air crashes). In addition, crashes (truck, train, and airplane) and train derailment were considered as initiators for the transportation accidents. Except for the inventory differences among storage installations and certain site-specific events, such as earthquakes and tornadoes, the hazards associated with plant operations are the same for all sites and all disposal alternatives.

Some $\mathbf{3 0 0 0}$ potential accidents were identified and included in the programmatic analysis. Each potential accident was characterized by its probability (i.e., its expected frequency); its source size (i.e., the size of the release as expressed by weight of specific chemical agent); the type of agent released; its mode of release (e.g., spill, detonation, fire); the possible accident location (e.g., storage area, disposal plant, along a transportation corridor); and the duration of time during which that accident could occur (i.e., the total time during which agent could be released, from the onset of the disposal program until the completion of that particular activity). A computerized atmospheric dispersion method was used to characterize each accident involving agent release in 
terms of its plume geometry and its lethal downwind distance; fatalities were estimated for these accidents using 1980 census data (U.S. Dept. of Commerce, Bureau of the Census 1980) around the appropriate site of release.

Because it is impossible to develop a "no risk" alternative for the disposal of the chemical agent stockpile, the possibilities of an accident and the resulting adverse impacts were included in a hazards analysis to determine the relative importance of each accident. The selected measure of the hazard was the "risk." The risks associated with the numerous activities of the programmatic disposal alternatives were quantified and were then used to compare the hazards associated with each programmatic alternative. Risk analyses have been widely used in the nuclear and chemical industries to evaluate related hazards and to communicate these results to both the public and decision makers.

To assess the impacts of accidents on human health and environmental and socioeconomic resources, various probabilistic measures of risk were developed and applied to each programmatic alternative for comparison. Five measures of risk were chosen as follows:

- Probability of one or more fatalities. The chance that there will be at least one fatality at a given site or along a transportation corridor, or for the nation as a whole, during implementation of a given programmatic alternative. This measure was computed mathematically as the sum of probabilities for only those credible accidents that result in one or more fatalities under most likely meteorological conditions; this measure of risk was expressed as a probability or frequency per stockpile (e.g., $2 \times 10^{-5}$ ).

- Maximum number of fatalities. The maximum human health consequences among all credible accidents at a site or along a transportation corridor, or for the nation as a whole, for a given programmatic alternative. This measure was computed as equal to the largest number of fatalities associated with that single credible accident that has the greatest lethal downwind distance under worst-case meteorological conditions; this measure of risk was expressed as fatalities (e.g., 2100 people).

- Expected fatalities. A statistical measure equal to the sum of the risk contribution of all credible accidents at a site or along a transportation corridor, or for the nation as a whole, for a given programmatic alternative. This measure was computed mathematically as the summed product of probabilities for all credible accidents and the fatalities for those same accidents under most likely meteorological conditions. This measure of risk was expressed as fatalities (e.g., $\left.9 \times 10^{-4}\right)$. This risk measure is widely used in the nuclear and chemical industries to evaluate the hazards associated with these industries; it is regarded to be the best measure for representing the integrated hazards associated with numerous activities for a particular action.

- Person-years at risk. A statistical measure equal to the product of the number of persons near a site or along a transportation corridor who are at risk from the credible accident that has the greatest lethal downwind distance for a given programmatic alternative and the length of time during which that accident could 

occur. This measure of risk was expressed in person-years (e.g., $5 \times 10^{6}$ person-
years).

- Expected plume area. A statistical measure expressing the cumulative risk contribution of all potential plume areas from all credible accidental agent releases for a given programmatic alternative. This measure was computed mathematically as the summed product of all accident probabilities and the resulting plume areas; it is analogous to expected fatalities and is computed in an identical manner except that the piume area is used instead of the number of fatalities. This measure of risk, expressed in units of area $\left(e . g ., 3 \times 10^{-3} \mathrm{~km}^{2}\right)$, is sensitive not only to the size of the areas potentially affected by releases, but also to the probabilities of those releases. This risk measure was used as the surrogate for (or indicator of) impacts to environmental, cultural, and socioeconomic resources.

Pictograms (as shown in Figs. A.1 and A.2) were developed to present the results of this rist analysis in a format that could be easily comprehended by the public and would not reveal classified details (such as agent or munition quantities) for the sitespecific stockpiles. Pictograms display a pictorial indicator (the darkness of the shading) of the relative magnitude of each of the preceding measures of risk. This array of data allows direct comparison of risk at all sites for a given programmatic disposal alternative or, alternatively, comparison among all alternatives for a given site. Both sets of pictograms are employed and presented in the FPEIS (U.S. Army 1988). These risk pictograms provide a visual impression of the relative magnitude of public risk for all combinations of alternatives and locations; they contain the data used in the method for the selection of the environmentally preferred alternative.

\section{A.13 Method fir Identifying the Environmentally Preferred Alternative}

The Army and its subcontractors developed a method (U.S. Army 1988) for systematically comparing the programmatic choices to select an environmentally preferred alternative. That method was based on a comparison of alternatives in terms of the activities associated with implementing each alternative and the impacts of those activities under both normal operations and accident scenarios. Although the principal purpose of the method was to facilitate the selection of the environmentally preferred alternative, the method as presented in the FPEIS also allowed other interested and affected groups to (1) compare the public health and environmental impacts of the various alternatives and (2) identify the public health and environmental trade-offs associated with each programmatic alternative.

The method used to identify the environmentally preferred alternative consisted of a sequential consideration and comparison of the factors embracing the programmatic objectives of no fatalities and minimal or no environmental impact. This comparison involved three consecutive tiers of examination for each programmatic alternative: (1) the comparisons were first made for human health impacts using the previously defined measures of risk; (2) the "expected plume area" was then used for comparison of ecosystem and environmental impacts; and finally, (3) the feasibility and potential 


\section{A-5}

ORNL-DWG 87.18558

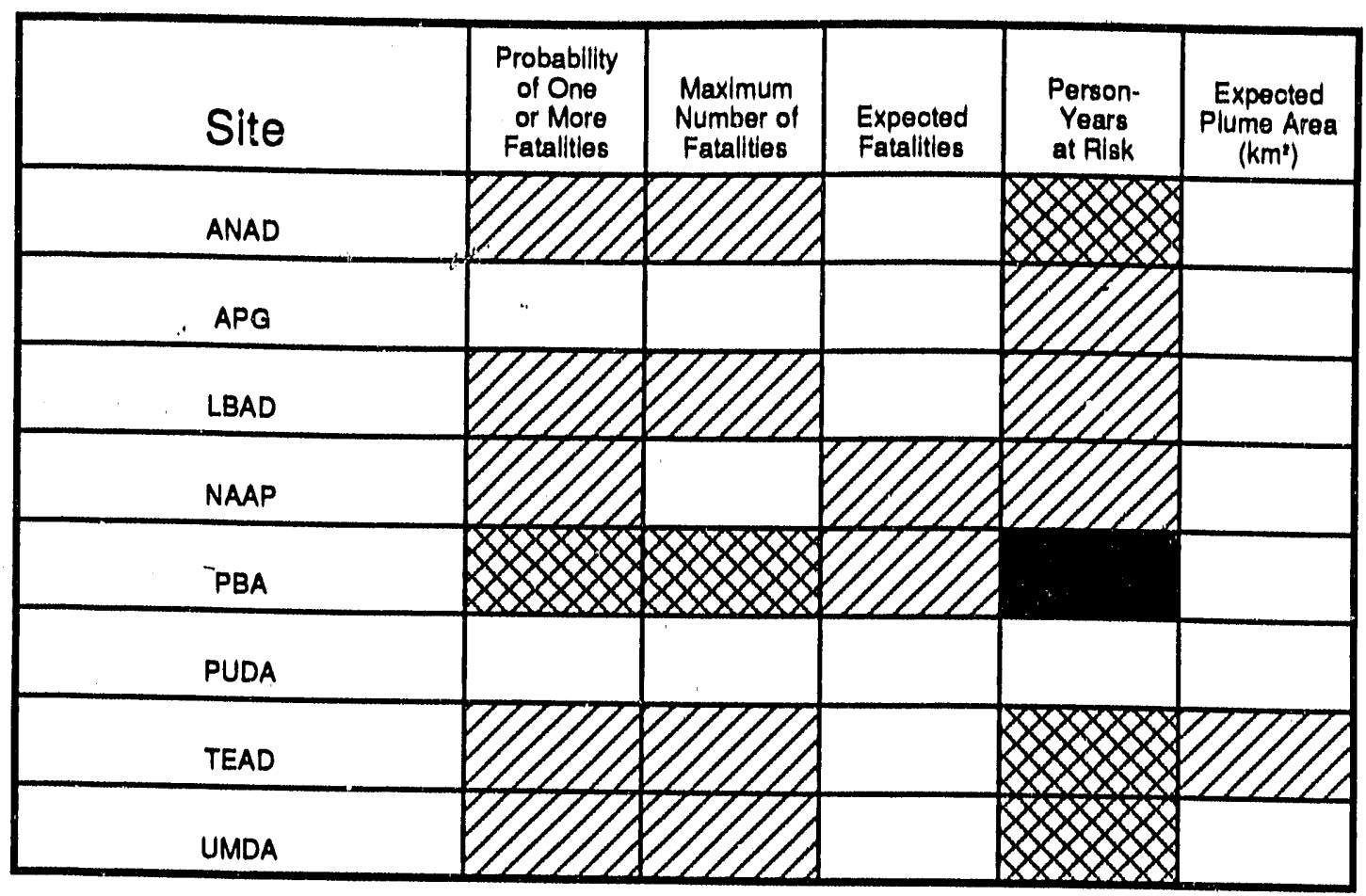

\begin{tabular}{|c|c|c|c|c|c|c|}
\hline \multirow[b]{2}{*}{ Legend } & \multicolumn{6}{|c|}{ Numerical Equivalents } \\
\hline & $\begin{array}{l}\text { Relative } \\
\text { Shading }\end{array}$ & $\begin{array}{c}\text { Probability } \\
\text { of One } \\
\text { or More } \\
\text { Fatalities }\end{array}$ & $\begin{array}{c}\text { Maximum } \\
\text { Number of } \\
\text { Fatalities }\end{array}$ & $\begin{array}{l}\text { Expeoted } \\
\text { Fatalities }\end{array}$ & $\begin{array}{c}\text { Person- } \\
\text { Years } \\
\text { at Risk }\end{array}$ & $\begin{array}{c}\text { Expeoted } \\
\text { Plume } \\
\text { Area } \\
\left(\mathrm{km}^{2}\right)\end{array}$ \\
\hline Higher & & $>10^{3}$ & $>10,000$ & $>10^{4}$ & $>10^{\circ}$ & $>10^{\prime}$ \\
\hline & & $10^{-4}-10^{-5}$ & $\begin{array}{l}5,000 \\
10,000\end{array}$ & $10^{-9}-10^{-2}$ & $10^{5}-10^{5}$ & $10^{-3}-10^{-2}$ \\
\hline & & $10^{-4}-10^{-4}$ & $1,000-5,000$ & $10^{-4}-10^{-3}$ & $10^{4}-10^{5}$ & $10^{-4}-10^{-3}$ \\
\hline Lower & & $<10$ & $<1,000$ & $<10^{-1}$ & $<10^{\circ}$ & $<10^{-4}$ \\
\hline
\end{tabular}

Fig. A-1. Risk with mitigation: site-specific comparison for on-site disposal. (Risk along transportation corridors not included. This diagram does not include the risk associated with approximately 3 years of stockpile storage at the existing facilities.) 


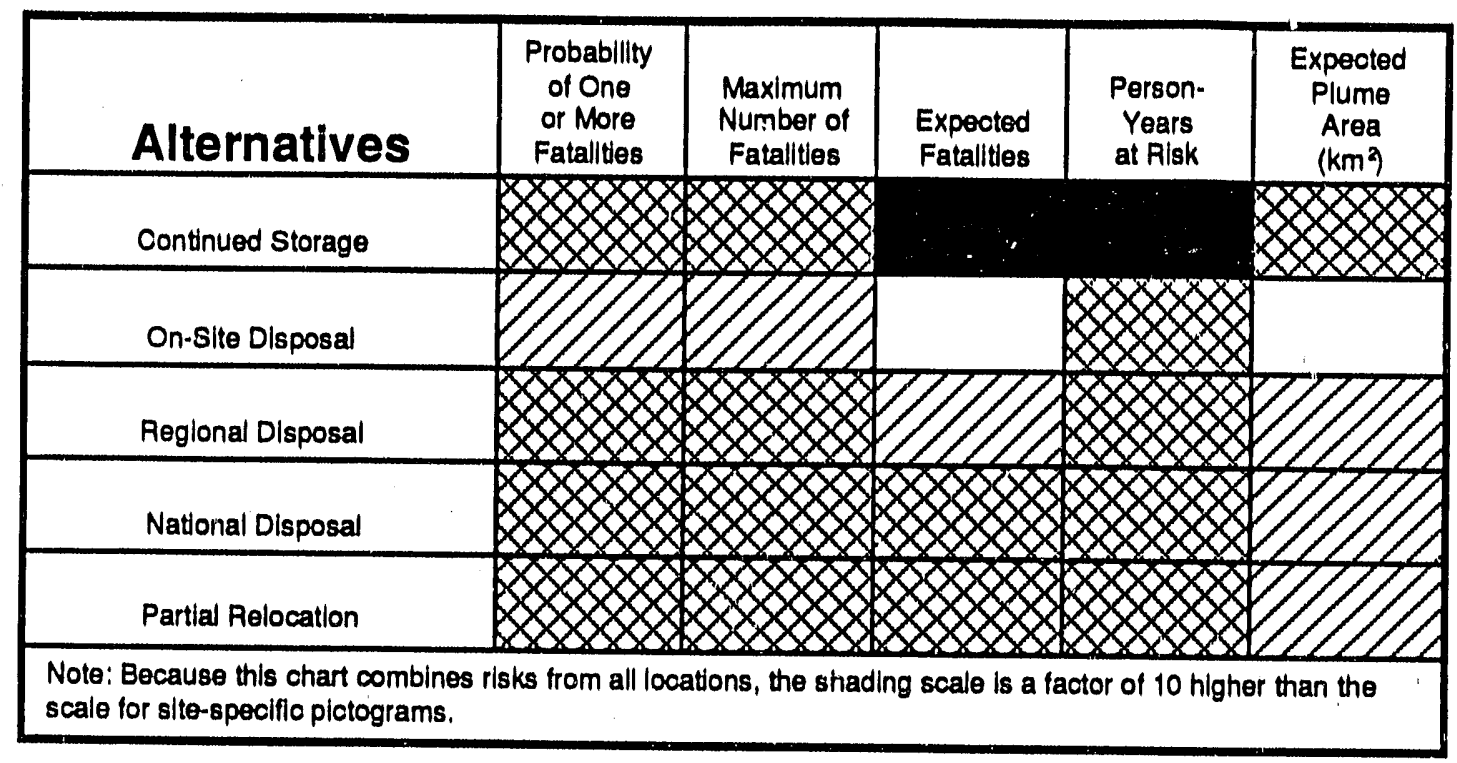

\begin{tabular}{|c|c|c|c|c|c|c|}
\hline \multirow[b]{2}{*}{ Legend } & \multicolumn{6}{|c|}{ Numerical Equivalents } \\
\hline & $\begin{array}{l}\text { Relative } \\
\text { Shading }\end{array}$ & $\begin{array}{c}\text { Probability } \\
\text { of One } \\
\text { or More } \\
\text { Fatalities }\end{array}$ & $\begin{array}{l}\text { Maximum } \\
\text { Number of } \\
\text { Fatalities }\end{array}$ & $\begin{array}{l}\text { Expected } \\
\text { Fatalities }\end{array}$ & $\begin{array}{l}\text { Person- } \\
\text { Years } \\
\text { at Alisk }\end{array}$ & $\begin{array}{c}\text { Expected } \\
\text { Plume } \\
\text { Area } \\
\left(\mathrm{km}^{2}\right)\end{array}$ \\
\hline \multirow[t]{3}{*}{ Higher } & & $>10^{-2}$ & $>100,000$ & $>0.1$ & $>10^{\prime}$ & $>0.1$ \\
\hline & & $10^{-9}-10^{-2}$ & $\begin{array}{l}10,000- \\
100,000\end{array}$ & $10^{-2}-0.1$ & $10^{\prime}-10^{7}$ & $10^{-4}-0.1$ \\
\hline & & $10^{-4}-10^{-3}$ & $1,000-10,000$ & $10^{-3}-10^{-2}$ & $10^{s}-10^{s}$ & $10^{-3}-10^{-2}$ \\
\hline Lower & & $<10^{-4}$ & $<1,000$ & $<10^{-3}$ & $<10^{\circ}$ & $<100$ \\
\hline
\end{tabular}

Fig. A-2 Risk (with mitigation) comparison for programmatic alternatives all locations. 
effectiveness for emergency planning and preparedness was used as a basis for comparison.

These three tiers of comparison were applied sequentially; if an alternative proved to be significantly worse than others on the basis of human health impacts, it was removed from further consideration. Similarly, if a single alternative was significantly superior to all others on the basis of human health impacts, it was to be selected as the environmentally preferred alternative. If two or more alternatives proved to be relatively equivalent (but superior to the other, rejected alternatives) during this first tier of comparison, then these alternatives were selected for inclusion in the next tier of comparison (i.e., ecosystem and environmental impacts).

The same technique was used in the second tier of comparison to compare only those alternatives that survived the first tier; this second tier of comparison considered the potential for ecosystem and environmental impacts. If there were still alternatives that were judged to be relatively equivalent following this comparison, they were compared on the basis of the feasibility and potential effectiveness for emergency planning and preparedness (i.e., the third and final tier of the selection method).

Improved emergency response planning and preparedness can significantly reduce both the maximum number of fatalities and the expected fatalities in the unlikely event of catastrophic agent release. However, no proven or acceptable method exists to quantify this potential for reduction in impacts. Nevertheless, implementation of an emergency response program yielding comparable reductions would be more difficult, if not impossible, along the transportation routes as compared with implementation at any or all of the eight existing storage installations.

Finally, if no clear choice could be made after three levels of comparison, then no single environmentally preferred alternative exists. In any event, at whichever tier a final choice was made, the environmentally preferred alternative would then be examined with respect to the stockpile at each installation to ensure that the selection method had indeed identified an alternative that was correct for each stockpile.

For the purpose of accepting or rejecting alternatives at each tier, a determination of the relative significance of the risk measures was made. The accident and risk analyses attempted to ensure that uncertainties about the values for the five measures of risk were treated consistently and systematically for all alternatives. It was acknowledged that these values might be in error by as much as a factor of 10 in either direction. However, the maximum number of fatalities did not depend on accident probabilities or frequencies and therefore had no expressed uncertainty. At each tier in the selection method, a comparison was made between those risk values shown in the pictograms for each alternative. Because actual numerical values for the five measures of risk were classified and could not be released for public review and because the pictograms used shadings and patterns to depict the range of each measure of iisk, it was determined that two differences in shading (i.e., a difference of two orders of magnitude or a factor of 100 ) would be used as the criterion to define the statistical significance of differences between alternatives.

In view of the preceding criterion, it is important not to emphasize the absolute values of the risk measures; rather, differences between the risk measures become the 
key to the comparisons. Significant (i.e., valid) differences in one or more measures of risk depict a definite risk difference and are sufficient to reject the more risky alternative(s). Furthermore, if there are consistent differences in the measures of risk between alternatives (even at one order of magnitude of difference in the pictograms), this consistent difference is an indication that significant differences between alternatives may exist from an overall perspective. However, such consistent differences were never used in the selection method to either select or reject an alternative.

\section{A.1.4 Data Used in the Programmatic Ascessment}

Data needed for the FPEIS assessment were drawn from several support studies, each of which was separately published and incorporated by reference into the FPEIS. Key support studies addressed (1) packaging, (2) transportation, (3) safety improvements, (4) hazards, (5) risk, (6) monitoring, and (7) emergency response. Of these, the analysis and results of the risk study were the most important in the selection of the environmentally preferred alternative.

The data used in the FPEIS risk analysis were of two broad types: (1) historical data, derived from records of a large number of actual events that are related to specific types of accidents or events leading to accidents, and (2) hypothesized data, derived from largely subjective modeling of assumed accident sequences with the aid of fault and event trees. The use of fault and event trees is a standard procedure to investigate sequences of occurrences in a complex system.

GA Technologies (GA Technologies 1987a, 1987b, 1987c), with technical assistance from H\&R Technical Associates, JBF Associates, and Battelle-Columbus Laboratories, conducted the comprehensive assessment of accident probabilities for all munition types. The event and fault tree analyses, together with information on mechanical and thermal threshold conditions for each munition type, were used to estimate the probability of agent release and the quantity of agent released. Some accidents were postulated to be caused by external initiating events (i.e., those outside U.S. Army control). Table A.1 summarizes the assumed frequencies of these accidents for PBA.

The human health impact at downwind locations following an accidental release of agent would be dependent on meteorological conditions, which dictate the extent of atmospheric dispersion. The FPEIS used the D2PC atmospheric dispersion model (Whitacre et al. 1986) to predict downwind transport of agent. The D2PC computer program (or code) is an air dispersion model that assumes a Gaussian distribution of agent in the vertical and cross-wind directions as the agent disperses downwind. This assumption has been documented extensively in the literature and is used by a multitude of current models (EPRI 1985). Although more sophisticated dispersion codes are available, the assumption of straight-line transport with unvarying meteorological conditions results in conservative estimates of the effects of releases because the major parameter used in subsequent analyses was the distance to a given dose rate. This simple, conservative approach, while inappropriate for estimating the impacts of any given release under real-time conditions, is appropriate for analyzing and comparing the 
Table A1. Site-specific frequencics of esternal initiating events for Pine Blufi Anensl

Large aircraft crash (events/year.mile ${ }^{2}$ )

Small aircraft crash (events/year·mile ${ }^{2}$ )

Meteorite (> $1.0 \mathrm{lb})$

strikes (events/year $\cdot \mathrm{ft}^{2}$ )

Earthquakes (events/year)

$0.15 \mathrm{~g}$

$0.2 \mathrm{~g}$

$0.25 \mathrm{~g}$

$0.3 \mathrm{~g}$

$0.4 \mathrm{~g}$

$0.5 \mathrm{~g}$

$0.6 \mathrm{~g}$

$0.7 \mathrm{~g}$
$1.5 \times 10^{-6}$

$1.1 \times 10^{-4}$

$6.4 \times 10^{-13}$

$1.5 \times 10^{-4}$

$7.0 \times 10^{-5}$

$4.0 \times 10^{-5}$

$2.5 \times 10^{-5}$

$1.2 \times 10^{-5}$

$6.0 \times 10^{-6}$

$3.5 \times 10^{-6}$

$2.5 \times 10^{-6}$

Tornadoes (events/year)

$200 \mathrm{mph}$ windspeed

$1.0 \times 10^{-5}$

260 mph windspeed

$1.0 \times 10^{-6}$

$320 \mathrm{mph}$ windspeed

potential effects of postulated accidental releases. A particular location was not specified in the D2PC model runs, but rather a generic location was used because of the number of potential release sites at each facility as well as the potential for release during transportation. Therefore, identical downwind distances were obtained for identical accidents for all alternatives.

In the FPEIS, results from the D2PC model were obtained for two generic meteorological conditions: "conservative most likely" (CML) and "worst case" (WC). The CML scenario represents a frequently occurring meteorological condition that results in relatively large doses compared with other frequently occurring conditions. Specifically, neutral atmospheric stability (Class D) with a wind speed of $3 \mathrm{~m} / \mathrm{s}(6.7 \mathrm{miles} / \mathrm{h})$ was selected for the CML condition. The WC scenario represents a credible condition that results in near-maximum doses. Specifically, a stable atmosphere (Class E) with a wind speed of $1 \mathrm{~m} / \mathrm{s}(2.2 \mathrm{miles} / \mathrm{h})$ was chosen for the WC condition. Cther atmospheric conditions were kept constant for the two meteorological scenarios. Wind direction was not specified but was assumed to remain constant throughout individual runs of the D2PC model. Downwind distances and areas that were predicted by the model were 
subsequently rotated about the point of release to evaluate all directions of interest. The height of the mixed layer of the atmosphere was assumed to be $750 \mathrm{~m}(2460 \mathrm{ft})$.

The D2PC code predicts the "dose" of agent (defined as the mathematical product of agent concentration and the duration of exposure) expected at locations downwind of the release point. Within each downwind dispersion plume were three dose-response contours, representing fatality rates of 0,1 , and $50 \%$. The dose corresponding to the $0 \%$ rate (also called the "nodeaths" dose in the FPEIS) is the largest dose that would result in no fatalities to healthy adults. Figure A.3 illustrates the plume geometries and dose-response contours under the two meteorological conditions used in the FPEIS.

To simplify the analysis of the many accidents identified in the FPEIS risk analysis, the accidents were grouped into categories defined by their downwind "nodeaths" distance. These "downwind no-deaths distance categories" were used generically in the FPEIS to (1) define all accidents by category and (2) estimate fatalities by category. The distance categories used in the FPEIS are shown in Table A.2. Every accidental release was assigned a distance category, and the maximum downwind boundary of that category was used to represent the entire class of similar releases. For example, an accidental release that was predicted by the D2PC code to result in a downwind no-deaths distance of $11 \mathrm{~km}$ was placed into the 10 to $20-\mathrm{km}$ accident category, and a distance of $20 \mathrm{~km}$ was used to characterize that particular accident in the FPEIS. Human health impacts, as defined by potential fatalities, were based upon the generic plumes described by these distance categories.

In the FPEIS, the description of the distribution of population around each Army installation was taken from 1980 Bureau of the Census data. The coordinates of the census enumeration district centroids were first used to estimate the boundaries and areas of each district. Next, a population density was estimated within these areas. Finally, a predefined grid of very small cells [roughly $370 \times 370 \mathrm{~m}(1200 \times 1200 \mathrm{ft})$ ] was overlaid on the distributed population, and the number of people per cell was determined. This grid-based population was used in the estimation of fatalities from accidental releases of agent.

Fatality estimates were developed by overlaying the plume geometries [including the three dose-response contours (50\% lethal dose, $1 \%$ lethal dose, and no deaths)] on the population grid. First, the number of people between each dose-response contour was counted. Then "fatality multipliers" were applied to the populations in each zone as follows: of the people inside the $50 \%$ dose-response contour, $75 \%$ were assumed to die; $25 \%$ of the people in the region between the $50 \%$ and the $1 \%$ dose-response contours were assumed to die; and $0.5 \%$ of the people in the region between the $1 \%$ doseresponse and the no-deaths contours were assumed to die.

This fatality estimation process was repeated 360 times for each downwind nodeaths distance caítegory and for each of the two meteorological conditions. That is, each plume was rotated in increments of one compass degree around the point of release, and fatality estimates were computed for each of these increments. Among all 360 computations, the absolute largest number of fatalities was identified in the FPEIS 


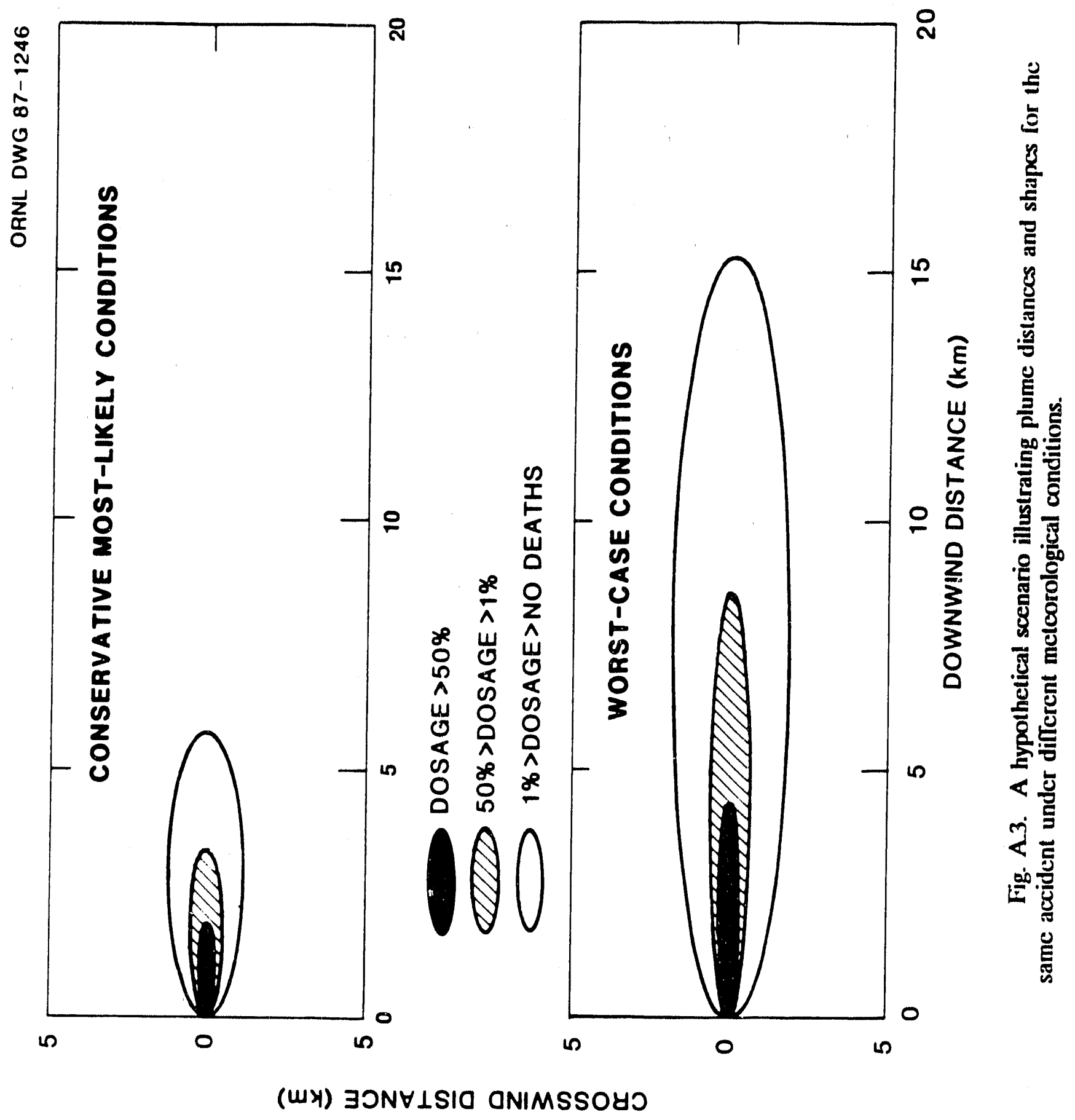


A-12

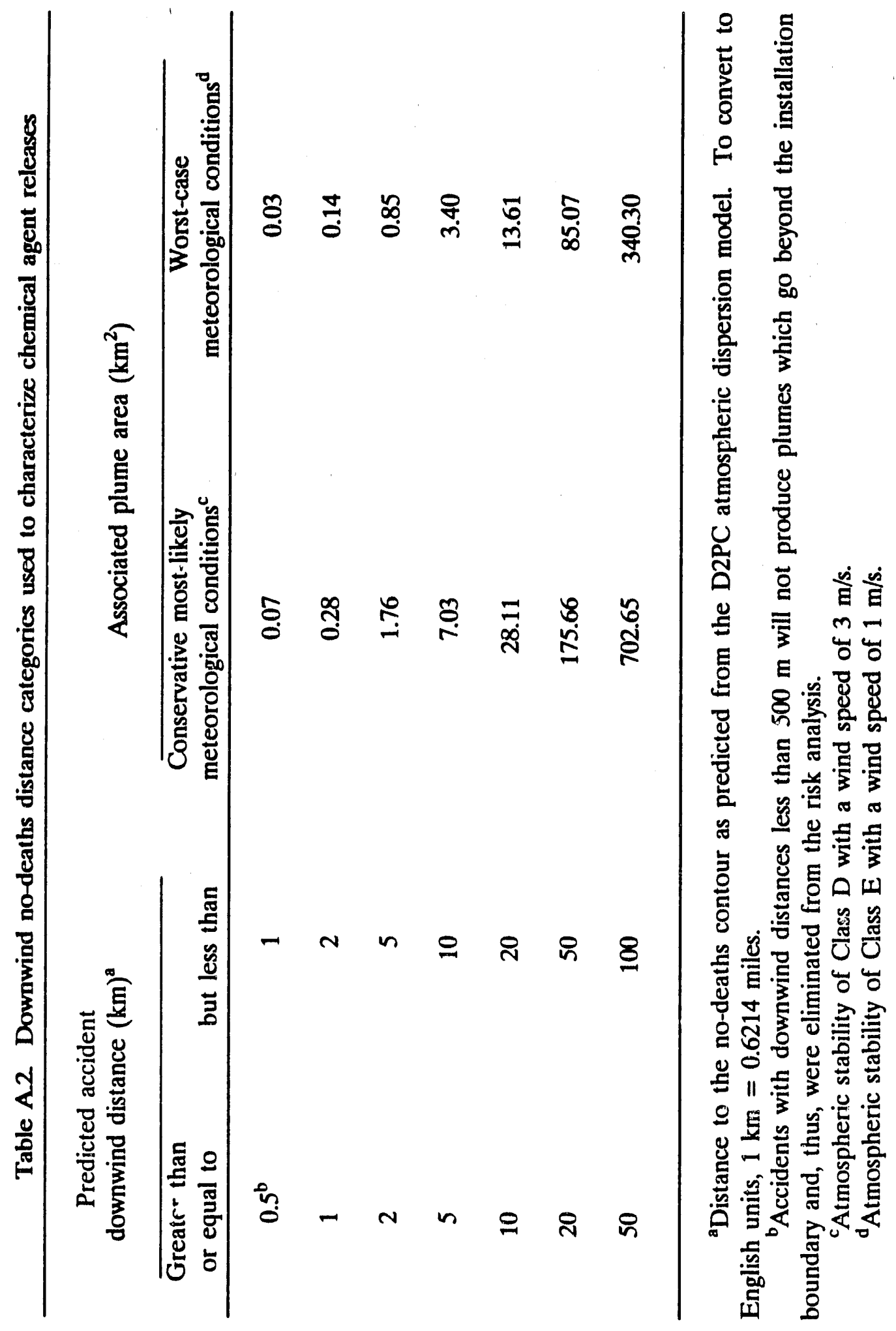


as the "maximum number of fatalities" associated with that particular downwind no-deaths distance category. This computational technique does not take wind direction into account; instead, it assumes conservatively that the wind has some nonzero probability of blowing in the direction that would cause the most fatalities in the event of a release.

The following assumptions and qualifications of the fatality estimation process were enumerated in the FPEIS (U.S. Dept. of the Army 1988).

1. The assurned values of the fatality multipliers were based on linear variations of agent doses within each dose-response contour. In actuality, the doses decrease with distance from the release point at a greater than linear rate; thus, the FYEIS estimates of maximum fatalities are conservatively high.

2. The D2PC atmospheric dispersion model was originally developed as a planning tool for estimating the magnitude of battlefield casualties under war-game scenarios. The model predicts dose-response contours based on the expected response of healthy adult males to battlefield agent concentrations. The variation of dose response among age classes (e.g., infants, children, and the elderly) was not included in the estimation of fatalities in the FPEIS. It was assumed that the dose response of healthy adult males would closely approximate the response of an average member of the general public.

3. Downwind no-deaths distance estimates from D2PC are accurate to within only $\pm 50 \%$. This limitation of the atmospheric dispersion model resulted in a systematic uncertainty that applied equally to all fatality estimates for all alternatives.

4. Variations in wind direction, atmospheric stability, and terrain during a release would cause the plume to have a much more complex geometry than the simplistic ellipsoidal shape used in the FPEIS. The longer the time period over which the plume develops, the greater the likelihood that changes in the wind conditions will affect the plume geometry.

5. The same variations in wind direction, atmospheric stability, and terrain make it impossible to reliably predict the shape of a very large plume contour. For this reason, fatality counts for accidents with extremely large downwind no-deaths distances were truncated at $100 \mathrm{~km}$ (62 miles) in the FPEIS.

6. The census data used to develop the distribution of population around each site are representative of the place of residence; thus, these data more closely depict nighttime populations than daytime populations. Furthermore, transient populations (such as people in shopping centers or at major sporting events) and on-post employees were not included in the population data in the FPEIS.

7. The grid-based population allowed all grid cells beyond this zone to be filled with a distributed population even though, in reality, no such population existed for certain cells. Likewise, other known uninhabited regions (such as lakes, forested areas, federally restricted areas, as well as the actual site boundaries) were not accounted for in the FPEIS grid-based population; all such zones were filled with population according to the method described previously. 
8. The locations used in the FPEIS for the source of every chemical agent release were assumed to be the proposed location of the CSDP disposal facilities as estimated from a $1: 250,000$-scale map. All plumes used this release point for estimating fatalities. In the accident analyses, where storage area accidents or onsite transportation accidents resulted in agent release, the release point may not be exact in the FPEIS; however, the implication of this assumption would be more significant for small releases of agent than for large releases. That is, for large releases, the downwind distances predicted by the atmospheric dispersion model are significantly larger than the distance between any possible points of release at a particular site.

The probability data from GA Technologies, agent release data from GA Technologies, meteorological data from ORNL, and fatality estimates from ORNL were integrated by the MTTRE Corporation (MITRE 1987) to develop the five measures of risk described above.

\section{A.1.5 Summary of Results}

For accidental agent releases, the five measures of risk were used to distinguish among alternatives. Implementation of the three-tiered selection method resulted in the following conclusions:

1. The continued storage, national relocation, and partial relocation alternatives were rejected from further consideration based on the method's first tier of comparing human health impacts.

2. The on-site disposal and regional alternatives stood the test of the first tier of comparison and were then subjected to the second tier. Of note, however, was that the on-site disposal alternative was consistently less risky in all areas (except person-years at risk) than the regional alternative, but not at a significant level. Nevertheless, the consistency of less risk for the on-site option was an important factor in the overall selection method.

3. In the comparison of on-site and regional alternatives at the second tier (ecosystem and environmental impacts), again the on-site disposal alternative was better than the regional alternative, but not to a significant level. Therefore, both alternatives were allowed to pass to the third tier of comparison.

4. Considering the greater degree and extent of mitigation (potential for saving lives) afforded by emergency response for the on-site alternative as compared with the regional alternative, the on-site alternative was determined to be better than the regional alternative. This conclusion is strengthened by the consistently better ranking of the on-site alternative at the first and second tiers of comparison.

The key findings of t'ne FPEIS have resulted in the Army's selecting the on-site disposal alternative as its envircumentally preferred alternative. The CONUS stockpile of chemical agents and munitions can be destroyed in a safe, environmentally acceptable 
manner. The environmental impacts of construction and incident-free disposal operations would be minimal. The risk of catastrophic accidents is relatively low for all programmatic alternatives; however, on-site disposal poses less risk than those alternatives involving off-site movement of the stockpile and is therefore the best choice from public health and environmental perspectives.

\section{A.2 SITE-SPECIFIC ACCEPTABILITY OF PROGRAMMATIC PREFERENCE}

After the environmentally preferred alternative was identified, the final step in the analysis was to examine this alternative (on-site disposal) against each installation inventory to ensure that the method did not identify an alternative that was incorrect for inventories of one or more installations. The following discussion examines the selected alternative for PBA, comparing the selected alternative against the site- and corridorspecific risk pictograms.

The two-risk shadings decision rule discussed previously was used to help identify the likely site preference (where possible) and to compare it with the programmatic preference for on-site disposal. Because the Army will implement enhanced emergency planning and preparedness at the installation regardless of the alternative selected, the benefits or risk reductions attributable to emergency planning and preparedness, although more relevant to the maximum fatalities and expected fatalities measures, should not affect site preference and have not been considered.

The preliminary selection of the on-site disposal alternative as the environmentally preferred alternative from a programmatic viewpoin! was verified for each storage site to ensure that this alternative did not present an unusual problem or risk based on its inventories, population, geography, or any other feature unique to the site. Therefore, the purpose of this exercise was not to depict that on-site destruction is significantly better than other alternatives but rather to demonstrate that on-site disposal was at least equal.

From the perspective of the population near PBA, on-site disposal was found to be at least equivalent to all other options in terms of human health effects measures; there was no clear choice among programmatic alternatives for PBA. However, with the addition of the transportation risks, the on-site alternative has the advantage, given the opportunity of risk reductions associated with emergency planning and preparedness that was not afforded off-site transportation alternatives.

\section{A.3 FPEIS IMPACT ASSESSMENT FOR PINE BLUFF ARSENAL}

In addition to the risk-based impact assessment used to select the environmentally preferred alternative, the FPEIS also presented potential environmental impacts from implementing the programmatic alternatives at each of the sites (as appropriate). Potential effects from construction and incident-free operations are described. This section summarizes this part of the FPEIS as applicable to PBA. 
Disposal activities can be viewed as a three-phased set of activities. Construction involves activities to procure and build the disposal plant(s) and support functions. Operations activities involve disposal of the chemical munitions. This includes activities at the site of existing storage, movement of stockpiles from those storage sites to disposal plants, and disposal plant operations. Movement is defined to include on-site handling and transport, as well as off-site transport. Decommissioning involves closure and dismantlement of disposal facilities.

\section{A.3.1 Construction Impacts}

Minor impacts from increased spending, the creation of new employment, and the ecological disruption at the plant site are expected. No significant impacts to human health, air quality: or water quality are expected.

The construction of a disposal facility will produce an average of 150 new jobs during the time required for construction. The construction will also probably result in increased sales in construction-related industries in the region. Additional tax revenues will be produced. The total economic impact of the creation of jobs and increased spending at each site under on-site disposal will be minor. The direct and indirect employment will not result in significant in-migration, and impacts to local economic infrastructures are unlikely.

Minor impacts were expected on ecological resources from construction of the disposal facilities. Construction at PBA under the on-site disposal alternative was estamated to require about 4 ha (11 acres) of land. Best available technologies for sediment control during construction were estimated to minimize any potential effects to surface waters.

\section{A.3.2 Incident-Free Operations Impacts}

Overall, the impacts of disposal are quite limited in scope and significance. Construction impacts include the socioeconomic impacts of increased spending, the creation of new employment, and the ecological disruption at the plant site. By definition, incident-free operations are characterized by no releases of agent above emission criteria. Operations impacts of concern include possible exposure to low (below detectable), but permitted, levels of chemical agent, air quality impacts, socioeconomic impacts to community resources and well-being, solid waste disposal, and water use. Impacts to socioeconomic resources come primarily from the need for local communities to upgrade emergency response planning for an accidental release of agent. Finally, decommissioning impacts of concern include the socioeconomic impacts of plant closure and disposal of hazardous wastes.

\section{A.3.3 Aocident Impacts}

In order to assess the environmental impacts of accidents it is necessary to identify the credible accidents that could occur and ways that agent released in those 
accidents is dispersed in the environment. The identification of an accident also involves an understanding of the amount of agent released, which is frequently referred to as an agent source term. Identification also requires a knowledge of how the agent is released. It can be spilled, vaporized by an explosion, or released by a fire or some combination of release modes. Furthermore, information on the duration of release is required.

The ways in which the agent is dispersed after a release are called environmental pathways. The basic paths include the movement of small droplets of agent in the air; the movement of vapor in the air; the deposition of agent from air movement onto underlying lands, vegetation, or water; the movement of agent into water-bodies through runoff or deposition; and the movement into groundwater.

When agent is released into the environment, it may have effects on human health, ecological systems, water use, or socioeconomic resources. Any effects would be estimated by the dispersion processes that give information about the form and level of the agent in the environment and the response of various ecological systems to the agent.

It is important to realize that each of the three stages of the analysis is associated with uncertainties and error bounds. These uncertainties are largely a function of imperfect knowledge. The application of these methods to the specific areas of concern (i.e., the installations and their environs, and the transportation corridors) provides assessments of impacts.

The pictogram in Fig. A4 summarizes the risks for PBA. The "probability of one or more fatalities" is largest for continued storage. The primary contributor to this is the possibility of a plane crashing into the storage area. The large maximum fatalities values for the regional, national, and continued storage alternatives are also the result of plane crashes onto the storage or rail yard holding area. Although infrequent, this accident results in a large release and large off-site consequences. Values for person-years at risk are large because of the density of the nearby population and the large and varied stockpile stored at PBA. Individual time at risk is between 4.5 and 5.5 years for all alternatives. Because the expected fatalities measure incorporates all of the aspects that influence the risk, this measure will be described in detail by alternative. In the following discussions, the dominant risks are those accidents that have the largest number of expected fatalities. The cumulative risk is the sum of the expected fatalities for all accidents contributing to the risk for a specific alternative.

\section{Continued storage alternative}

The risk at PBA is dominated by accidents resulting from aircraft crashes onto the storage area and the dropping of munitions during handling. The expected fatalities resulting from these events are both in the range of $10^{-6}$ to $10^{-5}$ per year. The cumulative risk associated with this alternative is in the range of $10^{-5}$ to $10^{-4}$ expected fatalities per year. The continued storage alternative is assumed to continue for 25 years. 
A-18

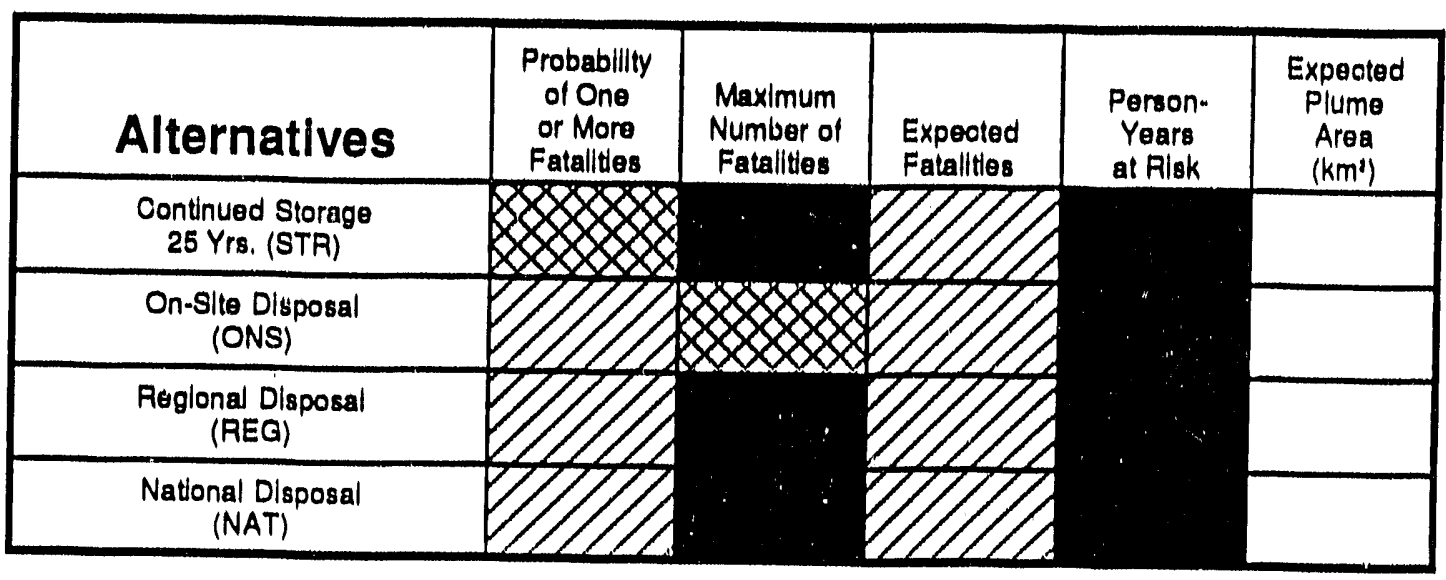

\begin{tabular}{|c|c|c|c|c|c|c|}
\hline \multirow[b]{2}{*}{ Legend } & \multicolumn{6}{|c|}{ Numerical Equivalents } \\
\hline & $\begin{array}{l}\text { Relative } \\
\text { Shading }\end{array}$ & $\begin{array}{c}\text { Probabillity } \\
\text { of One } \\
\text { or More } \\
\text { Fatallties }\end{array}$ & $\begin{array}{l}\text { Maximum } \\
\text { Number of } \\
\text { Fatailties }\end{array}$ & $\begin{array}{l}\text { Expeoted } \\
\text { Fatalities }\end{array}$ & $\begin{array}{l}\text { Person- } \\
\text { Years } \\
\text { at Rlsk }\end{array}$ & $\begin{array}{c}\text { Expected } \\
\text { Plume } \\
\text { Aroa } \\
\text { (km') }\end{array}$ \\
\hline Higher & & $>10^{-9}$ & $>10,000$ & $210-4$ & $>10$ & $>10^{2}$ \\
\hline & & $10^{-4}-10^{-4}$ & $\begin{array}{l}5,000 \\
10,000\end{array}$ & $10^{-3}-10^{-2}$ & $10^{4}-10^{4}$ & $10^{-1}-10^{-4}$ \\
\hline & & $10^{-6}-10^{-4}$ & $1,000-5,000$ & $10-4-10-5$ & $10^{4}-10^{5}$ & $10^{-4}-10^{-4}$ \\
\hline Lower & & $<10^{-1}$ & $<1,000$ & $<10^{-4}$ & $<10^{4}$ & $<10^{-4}$ \\
\hline
\end{tabular}

Fig. A-4. Risk, with mitigation, in the vicinity of Pine Blulf Arsenal (PBA) for programmatic alternatives. (Risk along transportation corridors or at destination sites not included. For the disposal alternatives, this diagram does not include the risk associated with approximately 3 years of stockpile storage at PBA.) 


\section{On-ite dirpoual alternativo}

The largest risks are from (1) earthquakes that cause extensive plant damage, (2) on-site vehicle accidents resulting in munition detonation, and (3) feeding of a burstered munition into the dunnage furnace. These risks yield a range of expected fatalities of (1) $10^{-6}$ to $10^{-5}$, (2) $10^{-4}$ to $10^{-3}$, and (3) $10^{-5}$ to $10^{-4}$ per stockpile, respectively. The cumulative risk associated with this alternative is in the range of $10^{-4}$ to $10^{-3}$ per stockpile.

\section{Regional disposal alternative}

The dominant rislos for this alternative are (1) on-site vehicle accidents,

(2) detonation resulting from dropping a bare munition or pallet of munitions, and

(3) an aircraft crash into the holding area containing off-site packages. These accidents result in a range of expected fatalities of (1) $10^{-5}$ to $10^{-4}$, (2) $10^{-5}$ to $10^{-4}$, and

(3) $10^{-5}$ to $10^{-5}$, per stockpile, respectively. The cumulative risk associated with this alternative is in the range of $10^{-4}$ to $10^{-3}$ expected fatalities per stockpile.

\section{National disposal alternative} alternative.

The national disposal alternative risks are the same as those for the regional

\section{A.3.4 Decommiscioning Impacts}

Based on the information available on the procedures for decommissioning (dismantling and disposing) disposal facilities, minor but insignificant impacts would occur to socioeconomics and solid waste. Prior to implementing decommissioning, further NEPA documentation is required and more detailed impact assessments will be conducted.

On completion of a disposal program at a site, the decommissioning of a facility will involve the employment of both construction- and industrial-type work force. When decommissioning ends, local economic impacts from the increased jobs from construction, operations and decommissioning will no longer be experienced. When operation ends, the risk of an accident and the potential for any associated impacts also end. Overall, no significant impacts are expected from decommissioning.

Final closure activities for the chemical stockpile disposal facilities will result in removal or decontamination of all process equipment, structures, soils, or other materials containing or contaminated with hazardous waste or hazardous constituents. Amounts of containerized wastes that will be shipped to off-site permitted waste facilities are unknown; projected types of these wastes are (1) brine salt generated during closure, (2) incinerator ash, (3) baghouse dust and cyclone residue, and (4) miscellaneous nonagent-related wastes generated during facility closure. The metal parts of agent 
tanks, furnaces, and incinerators will be disassembled and decontaminated to $5 \mathrm{X}$ level $\left(1000^{\circ} \mathrm{F}\right.$ for $\left.15 \mathrm{~min}\right)$, which means that an item is clean and may be released from government control. Closure plans for the sites are described in Sect. I of Part B of the Resource Conservation and Recovery Act of 1976 permit applications for each site.

\section{REFERENCES FOR APPENDIX A}

EPRI (Electric Power Research Institute) 1985. Operational Validation of Gaussian and First-Order Closure Plume Models at a Moderately Complex Terrain Site, EA-3759, Project 1616-9, Palo Alto, Calif.

GA Technologies, Inc. 1987a. Risk Analysis of the On-Site Disposal of Chemical Munitions, Reports GAC-18562 and SAPEO-CDE-IS-87010, prepared for Program Executive Officer-Program Manager for Chemical Demilitarization by GA Technologies, Inc., La Jolla, Calif.

GA Technologies, Inc. 1987b. Risk Analysis of the Disposal of Chemical Munitions at National or Regional Sites, Reports GAC-18563 and SAPEO-CDE-IS-87008, prepared for Program Executive Officer-Program Manager for Chemical Demilitarization by GA Technologies, Inc., La Jolla, Calif.

GA Technologies, Inc. 1987c. Risk Analysis of the Continued Storage of Chemical Munitions, Reports GAC-18564 and SAPEO-CDE-IS-87009, prepared for Program Executive Officer-Program Manager for Chemical Demilitarization by GA Technologies, Inc., La Jolla, Calif.

MITRE Corp. 1987. Risk Analysis Supporting the Chemical Stockpile Disposal Program, SAPEO-CDE-IS-87014, Mclean Va., for Program Executive Officer-Program Manager for Chemical Demilitarization, Aberdeen Proving Ground, Md.

U.S. Army 1988. Chemical Stockpile Disposal Program Final Programmatic Environmental Impact Statement, Vols. 1, 2, and 3, Program Manager for Chemical Demilitarization, Aberdeen Proving Ground, Md., January, 1988.

U.S. Department of Commerce, Bureau of the Census 1980. Census of Population, Vol. 1, Characteristics of the Population, U.S. Government Printing Office, Washington, D.C.

Whitacre et al. 1986. Personal Computer Program for Chemical Hazard Prediction $(D 2 P C)$, U.S. Army Chemical Research and Development Centers, Aberdeen Proving Ground, Md. 


\section{APPENDIX B \\ DESCRIPTION OF SITE-SPECIFIC COMMUNTTY RESOURCES}

\section{B.1 OFF-POST RESIDENT AND WORKER POPULATIONS}

Table B.1 lists the counties that lie wholly or partially within a $100-\mathrm{km}$ (62-mile) zone of Pine Bluff Arsenal (PBA) and indicates the estimated population trends from 1980 through 1986. The 100-km (62-mile) zone is discussed here because the Final Programmatic Environmental Impact Statement accident analysis indicated that resources as far away as $100 \mathrm{~km}$ (62 miles) could be affected by low-probability but highconsequence events associated with the no action alternative. Data for counties included within the 50-km (31-mile) zone of PBA [roughly equivalent to the Protective Action Zone (PAZ)] are shown separately.

Table B.2 presents the distribution of residential populations by potentially sensitive age groups. Age groups that may be sensitive to lower concentrations of chemical agent are infants (defined as individuals under the age of 5), children 5 to 14 years old, and the elderly (aged 65 years or more). It has been suggested that infants, children, or the elderly might experience fatalities when exposed to chemical agent concentrations that are somewhat less than five times lower than the no-deaths dose for healthy adult males (V. Houk, Center for Environmental Health, Department of Health and Human Service, Atlanta, Ga., letter to Brigadier General D. Nydam, Office of the Program Manager for Chemical Munitions, Aberdeen Proving Ground, Md., June 1987) (see Appendix Q, FPEIS, for further detail).

Place-of-work populations will be discussed in the forthcoming EIS for PBA. Table B.3 presents manufacturing industries that have 100 or more employees and are located in Jefferson and Grant counties, which are the counties included in the Immediate Response Zone (IRZ). Additionally, the National Center for Toxicological Research, whose property is included within the northern boundary of PBA, is a federal installation that employs approximately 600 persons. Other large concentrations of employment include Jefferson Regional Medical Center, with a staff of 1600 (Arkansas Gazette, Dec. 17, 1989); the Pines Mall, with 1000 employees [R. Rechter, Assistant Manager, Pines Mall, Pine Bluff, Ark., personal communication to J. Morrissey, Science Applications International Corporation (SAIC), Oak Ridge, Tenn., Jan. 31, 1990]; and Jefferson Square Shopping Center, with approximately 200 employees (T. Mitsch, Shickel Development, Pine Bluff, Ark., personal communication to J. Morrissey, SAIC, Oak Ridge, Tenn., Jan. 31, 1990). 
Table B.1. Population trends in counties located wholly or partially within the $50-\mathrm{km}$ and $100 \mathrm{~km}$ zones of the PBA

\begin{tabular}{ccccccc}
\hline & Estimated & Estimated & & & Estimated \\
population & $\begin{array}{c}\text { population } \\
\text { per mile }\end{array}$ & Population & $\begin{array}{c}\text { Population } \\
\text { change }\end{array}$ & $\begin{array}{c}\text { Population } \\
\% \text { change }\end{array}$ & $\begin{array}{c}\text { net } \\
\text { migration }\end{array}$ \\
County & 1986 & 1986 & 1980 & $1980-86^{\wedge}$ & $1980-86^{4}$ & $1980-86^{4}$ \\
\hline
\end{tabular}

\section{Within $50 \mathrm{~km}$}

$\begin{array}{lrrrcrr}\text { Arkansas } & 23,100 & 23 & 24,175 & (1,100) & (4.6) & (1,500) \\ \text { Cleveland } & 8,300 & 14 & 7,868 & 400 & 5.5 & 300 \\ \text { Dallas } & 10,400 & 16 & 10,515 & (100) & (0.9) & (200) \\ \text { Grant } & 13,500 & 21 & 13,008 & 500 & 4.0 & 300 \\ \text { Jefferson } & 90,000 & 102 & 90,718 & (700) & (0.8) & (4,800) \\ \text { Lincoln } & 13,200 & 24 & 13,369 & (200) & (1.3) & (600) \\ \text { Lonoke } & 38,400 & 49 & 34,518 & 3,800 & 11.1 & 2,400 \\ \text { Prairie } & 10,100 & 15 & 10,140 & 0 & (0.3) & (200) \\ \text { Pulaski } & 356,300 & 465 & 340,598 & 15,700 & 4.6 & (4,800) \\ \text { Saline } & 58,000 & 80 & 53,156 & 4,800 & 9.1 & 2,600\end{array}$

50 to $100 \mathrm{~km}$

$\begin{array}{lrrrcrr}\text { Bradley } & 13,200 & 20 & 13,803 & (600) & (4.4) & (600) \\ \text { Calhoun } & 6,100 & 10 & 6,079 & 0 & 0.3 & 0 \\ \text { Clark } & 22,700 & 26 & 23,326 & (700) & (2.9) & (1,100) \\ \text { Conway } & 19,200 & 34 & 19,505 & (300) & (1.4) & (800) \\ \text { Desha } & 19,400 & 26 & 19,760 & (400) & (1.9) & (1,400) \\ \text { Drew } & 18,000 & 22 & 17,910 & 100 & 0.3 & (600) \\ \text { Faulkner } & 52,900 & 82 & 46,192 & 6,700 & 14.5 & 4,600 \\ \text { Garland } & 75,300 & 115 & 70,531 & 4,700 & 6.7 & 5,000 \\ \text { Hot Spring } & 27,400 & 45 & 26,819 & 500 & 2.0 & 0 \\ \text { Monroe } & 12,900 & 21 & 14,052 & (1,100) & (8.1) & (1,500) \\ \text { Ouachita } & 33,800 & 46 & 30,541 & 3,200 & 10.6 & 2,500 \\ \text { Perry } & 7,900 & 14 & 7,266 & 600 & 8.1 & 500 \\ \text { Phillips } & 33,100 & 48 & 34,772 & (1,700) & (4.9) & (3,700) \\ \text { White } & 53,200 & 51 & 50,835 & 2,300 & 4.6 & 800 \\ \text { Woodruff } & 10,500 & 18 & 11,222 & (800) & (6.8) & (1,000) \\ \end{array}$

"Estimates enclosed in parentheses indicate a negative change.

Source: U.S. Department of Commerce, County and Ciry Data Book, computer data file, U.S. Bureau of the Census, Washington D.C., 1986. 
B-3

Table B2 Sensitive age groups in the $50 \mathrm{~km}$ and 100 tom zones of PBA, 1986

\begin{tabular}{|c|c|c|c|c|}
\hline County & $\begin{array}{c}\text { Persons } \\
<5 \text { years old } \\
(\%)\end{array}$ & $\begin{array}{l}\text { Persons } \\
5 \text { to } 14 \text { years old } \\
(\%)\end{array}$ & $\begin{array}{c}\text { Persons } \\
65 \text { to } 74 \text { years old } \\
(\%)\end{array}$ & $\begin{array}{c}\text { Persons } \\
275 \text { years old } \\
(\%)\end{array}$ \\
\hline \multicolumn{5}{|c|}{ Within $50 \mathrm{~km}$} \\
\hline $\begin{array}{l}\text { Arkansas } \\
\text { Cleveland } \\
\text { Dallas } \\
\text { Grant } \\
\text { Jefferson } \\
\text { Cincoln } \\
\text { Lonoke } \\
\text { Prairie } \\
\text { Pulaski } \\
\text { Saline }\end{array}$ & $\begin{array}{l}6.9 \\
\text { NA. } \\
\text { NA } \\
\text { NA } \\
8.6 \\
\text { NA } \\
6.8 \\
\text { NA } \\
8.3 \\
6.8\end{array}$ & $\begin{array}{c}16.2 \\
\text { NA } \\
\text { NA } \\
\text { NA } \\
15.4 \\
\text { NA } \\
18.6 \\
\text { NA } \\
15.2 \\
17.4\end{array}$ & $\begin{array}{l}8.6 \\
\text { NA } \\
\text { NA } \\
\text { NA } \\
7.4 \\
\text { NA } \\
6.7 \\
\text { NA } \\
6.0 \\
5.9\end{array}$ & $\begin{array}{l}6.2 \\
\text { NA } \\
\text { NA } \\
\text { NA } \\
5.4 \\
\text { NA } \\
4.9 \\
\text { NA } \\
4.2 \\
3.7\end{array}$ \\
\hline \multicolumn{5}{|c|}{50 to $100 \mathrm{~km}$} \\
\hline $\begin{array}{l}\text { Bradley } \\
\text { Calhoun } \\
\text { Clark } \\
\text { Conway } \\
\text { Dasha } \\
\text { Drew } \\
\text { Faulikner } \\
\text { Garland } \\
\text { Hot Spring } \\
\text { Monroe } \\
\text { Ouachita } \\
\text { Perry } \\
\text { Phillips } \\
\text { White } \\
\text { Woodruff }\end{array}$ & $\begin{array}{c}\text { NA } \\
\text { NA } \\
6.8 \\
\text { NA } \\
\text { NA } \\
\text { NA } \\
7.1 \\
5.6 \\
7.2 \\
\text { NA } \\
7.8 \\
\text { NA } \\
10.0 \\
6.5 \\
\text { NA }\end{array}$ & $\begin{array}{c}\text { NA } \\
\text { NA } \\
13.5 \\
\text { NA } \\
\text { NA } \\
\text { NA } \\
14.1 \\
12.5 \\
16.1 \\
\text { NA } \\
16.3 \\
\text { NA } \\
19.9 \\
15.6 \\
\text { NA }\end{array}$ & $\begin{array}{c}\text { NA } \\
\text { NA } \\
8.8 \\
\text { NA } \\
\text { NA } \\
\text { NA } \\
6.6 \\
11.7 \\
9.1 \\
\text { NA } \\
8.7 \\
\text { NA } \\
7.8 \\
8.2 \\
\text { NA }\end{array}$ & $\begin{array}{l}\text { NA } \\
\text { NA } \\
6.5 \\
\text { NA } \\
\text { NA } \\
\text { NA } \\
4.5 \\
8.2 \\
6.0 \\
\text { NA } \\
6.6 \\
\text { NA } \\
5.8 \\
5.9 \\
\text { NA }\end{array}$ \\
\hline
\end{tabular}

"NA = not available. 1986 estimates at the county level are unavailable for these counties from the U.S Bureau of the Census.

Source: U.S. Department of Commerce, County and City Data Book, computer data file, U.S. Bureau of the Census, Washington, D.C., 1986. 
Table B.3. Industries employing more then 100 persons in Jefferson and Grant counties

\begin{tabular}{lll}
\hline \multicolumn{1}{c}{ Manufacturer } & Location & Number of Employees \\
\hline Cotton Belt Railroada & Barraque St, Pine Bluff & $100-199^{b}$ \\
Cotton Belt Railroad" & Port Area, Pine Bluff & $300-499$ \\
Arkansas Oak Flooring Co. & Pine Bluff & $300-499$ \\
Camden Wire Co. & Pine Bluff & $100-199$ \\
Central Moloney Transformer & Pine Bluff & $500-999$ \\
Century Tube Corp. & Pine Bluff & $200-299$ \\
Eclipse Industrial Products & Pine Bluff & $200-299$ \\
Gaylord Container Corp. & Pine Bluff & $100-199$ \\
Georgia Pacific Corp. & Pine Bluff & $200-299$ \\
International Paper Co. & Pine Bluff & 1400 \\
Mid-America Packaging, Inc. & Pine Bluff & $200-299$ \\
Ben Pearson Archery Co. & Pine Bluff & $100-199$ \\
Ben Pearson Tubemaster & Pine Bluff & $200-299$ \\
Pine Bluff Commercial & Pine Bluff & $100-199$ \\
Stant Inc. & Pine Bluff & $300-499$ \\
Tyson Foods, Inc. & Pine Bluff & $300-499$ \\
Varco-Pruden Buildings & Pine Bluff & $200-299$ \\
Viking Bag Division & Pine Bluff & $100-199$ \\
Wheeling Machine Division & Pine Bluff & $100-199$ \\
Arkansas Oak Flooring & Sheridan & $100-199$ \\
Sterling Faucet Co. & Sheridan & $200-299$ \\
West Bend Co. & Sheridan & $100-199$ \\
Guardpack, Inc. (Stone Container) & Sheridan & $100-199$ \\
H.H. Robertson Co. & Sheridan & $100-199$ \\
Rohr Industries & Sheridan & $100-199$ \\
& & \\
\hline & &
\end{tabular}

There are 1281 employees of Cotton Belt Railroed in the Pine Bluff area. Shown here are the two concentrations of employment; other employees are bocated throughout Pine Bluff.

'Approximatety 300 employees work during the dry shift, and 150 to 200 work during the evening and aight shifts.

Souces: Jefferson County Industrial Foundation, Directory of Pinc Btuff Manufacturers, Pine Bluff, Art., 1988; Southeast Artansas Economic Development District, Inc., Community Profile, Pine Bluff, Ark, 1989; Artansas Industrial Development Commission, Lagest and Major Employers, Little Rock, Ark; Sandra C. Trotter, Project Administrator, Southeast Artansas Economic Development District, Inc., Pine Bluff, Ark. personal communication to J. Morrissey, SAIC, Oak Rjdge, Tenn., June 21, 1989; M. Bradley, Superintendent, Cotton Belt Railroad, Pine Bluff, Art., personal communication to S. Schernayder, Oak Ridge National Laboratory, Oak Ridge, Tenn., July 20, 1989, Arkansas Gazethe, Sunday, Dec. 17, 1989. 


\section{B.2 TRANSIENT POPULATIONS}

Transient populations are defined as concentrations of people visiting the base or vicinity for a common event or purpose on an intermittent basis. They include special events and training exercises held on-post, special events held off-post, public areas, convention centers, and recreation reas.

Annual events held on-post include Armed Forces Day, in May (100 visitors); Change of Command, in June or July (50 visitors); and a July 4th Celebration (50 visitors).

In addition, PBA conducts a one-week training course 20 times each year from December through August for members of the Army Reserve and Army National Guard. Each class has a maximum attendance of 36 personnel. Most of the students are housed on-post in military housing and in bachelor officer quarters. Some officers and female students may be housed in a local motel.

Transient populations in Jefferson and Grant counties were identified during the Phase I process. Annual events held at Pine Bluff Regional Park include Freedom Fest, July 2-4 (30,000 total visitors); BassMasters Tournament, July 21-22 (1500 visitors); and State and Regional Baseball Tournament, April-August (2000 per event) (J. Jumper, Pine Bluff Parks and Recreation, Pine Bluff, Ark, personal communication to S. Schexnayder, Oak Ridge National Laboratory, Oak Ridge, Tenn., June 21, 1989). The Pine Bluff Convention Center, which has a 10,000-seat capacity, hosts large events throughout the year such as basketball games, trade shows, business conventions, and a circus. Peak usage occurs during February-May and September-December. The King Cotton Basketball Tournament, which attracts approximately 8000 people, is held December 26-28 each year at the Pine Bluff Convention Center (J. Blankenship, Greater Pine Bluff Convention Center, Pine Bluff, Ark, personal communication to J. Morrissey, SAIC, Oak Ridge, Tenn., Feb. 12, 1990). Total attendance at the convention center for 1988 was more than 200,000 people (D. Homberg, Pine Bluff Convention Center, Pine Bluff, Ark, personal communication to D. Lasley, Oak Ridge National Laboratory, Oak Ridge, Tenn., Apr. 18, 1989). Other crowd-drawing events in the Pine Bluff area include The Confederate Air Force/Razorback Wing air show, held the last week of August and first week of September at Grider Field (attendance 6000); the Southeast Arkansas Livestock Show and Championship Rodeo at Hestand Stadium (attendance 8000); and the University of Arkansas at Pine Bluff (UAPB) Homecoming in October (attendance 25,000) (J. Blankenship, Greater Pine Bluff Chamber of Commerce, Pine Bluff, Ark. personal communication to J. Morrissey, SAIC, Oak Ridge, Tenn., Jan. 31, 1990).

State and federal public areas located within the $50-\mathrm{km}(31-$ mile) and the $100-\mathrm{km}$ (62-mile) zones are listed in Table B.4, which indicates visitor-use data as available. 
Table B.4. Public areas within the 50-km and 100-km zones of PBA

\begin{tabular}{cccc}
\hline Area & County & $\begin{array}{c}\text { Distance } \\
\text { from site }\end{array}$ & $\begin{array}{c}\text { Visitors } \\
\text { (in 1000s) }\end{array}$ \\
\hline
\end{tabular}

\section{Within $50 \mathrm{~km}$}

State Wildlife Management Areas

Bayou Meto State Game Area

State Parks (SP)

Toltec Mounds SP

Jenkins Ferry Battleground Historical Monument

Locks and Dams, Arkansas River

Lock and Dam 3

Lock and Dam 4

Lock and Dam 5

Lock and Dam 6

National Forests (NF)

Ouachita NF

National Parks (NP)

Hot Springs NP

National Register Sites

Arkansas Post National Memorial

National Wildlife Refuges (NWR)

White River NWR

$$
\begin{aligned}
& \text { Arkansas } \\
& \text { Jefferson }
\end{aligned}
$$

$35 \mathrm{~km} \mathrm{E}$

NA*

Lonoke

$30 \mathrm{~km} \mathrm{~N}$

64.5

Grant

$45 \mathrm{~km}$ WSW

NA

$\begin{array}{lcc}\text { Jefferson } & 45 \mathrm{~km} \mathrm{ESE} & 92.5 \\ \text { Jefferson } & 25 \mathrm{~km} \mathrm{ESE} & 82.6 \mathrm{RVD}^{\circ} \\ \text { Jefferson } & 5 \mathrm{~km} \mathrm{~N} & 106.2 \mathrm{RVD} \\ \text { Pulaski } & 35 \mathrm{~km} \mathrm{~N} & 626.6 \mathrm{RVD}\end{array}$

\section{0 to $100 \mathrm{~km}$}

Saline

Perry

$80 \mathrm{~km} \mathrm{NW}$

1,462.1 RVD

(1986)

Arkansas

$80 \mathrm{~km}$ ESE

8.6 RVD (1988)

Garland

$90 \mathrm{~km} \mathrm{WNW}$

74.1 RVD (1988)

$90 \mathrm{~km}$ ESE

508.4 (FY 87)

Arkansas

Phillips

Monroe 
Table B.4 (continued)

\begin{tabular}{|c|c|c|c|}
\hline Area & County & $\begin{array}{l}\text { Distance } \\
\text { from site }\end{array}$ & $\begin{array}{l}\text { Visitors } \\
\text { (in 1000s) }\end{array}$ \\
\hline \multicolumn{4}{|l|}{ State Fish Hatcheries } \\
\hline Hogan State Fish Hatchery & Lonoke & $50 \mathrm{~km} \mathrm{NNE}$ & NA \\
\hline \multicolumn{4}{|l|}{ State Parks (SP) } \\
\hline $\begin{array}{l}\text { DeGray SP } \\
\text { Lake Catherine SP } \\
\text { Pinnacle Mtn SP } \\
\text { Marks Mill Battleground }\end{array}$ & $\begin{array}{l}\text { Hot Spring } \\
\text { Hot Spring } \\
\text { Pulaski }\end{array}$ & $\begin{array}{l}100 \mathrm{~km} \mathrm{~W} \\
80 \mathrm{~km} \mathrm{~W} \\
65 \mathrm{~km} \mathrm{NW}\end{array}$ & $\begin{array}{l}516.2 \\
318.1 \\
329.0\end{array}$ \\
\hline Historical Monument & Cleveland & $65 \mathrm{~km} \mathrm{~S}$ & NA \\
\hline \multicolumn{4}{|c|}{ State Wildlife Management Areas (SWMA) } \\
\hline $\begin{array}{l}\text { Bayou des Arc SWMA } \\
\text { Bell Slough SWMA } \\
\text { Camp Robinson SWMA } \\
\text { Dagmar SWMA } \\
\text { Harris Brake SWMA } \\
\text { Trusten Holder SWMA } \\
\text { Wattensaw SWMA }\end{array}$ & $\begin{array}{l}\text { Prairie } \\
\text { Faulkner } \\
\text { Faulkner } \\
\text { Monroe } \\
\text { Perry } \\
\text { Arkansas } \\
\text { Prairie }\end{array}$ & $\begin{array}{l}90 \mathrm{~km} \mathrm{ENE} \\
70 \mathrm{~km} \mathrm{NNW} \\
60 \mathrm{~km} \mathrm{NNW} \\
90 \mathrm{~km} \mathrm{NE} \\
95 \mathrm{~km} \mathrm{NW} \\
90 \mathrm{~km} \mathrm{ESE} \\
70 \mathrm{~km} \mathrm{NE}\end{array}$ & $\begin{array}{l}\text { NA } \\
\text { NA } \\
\text { NA } \\
\text { NA } \\
\text { NA } \\
\text { NA } \\
\text { NA }\end{array}$ \\
\hline \multicolumn{4}{|l|}{ Locks and Dams, Arkansas River } \\
\hline $\begin{array}{l}\text { Lock and Dam } 1 \\
\text { Lock and Dam } 2 \\
\text { Lock and Dam } 7 . \\
\text { Lock and Dam } 8\end{array}$ & $\begin{array}{l}\text { Arkansas } \\
\text { Arkansas } \\
\text { Pulaskd } \\
\text { Perry }\end{array}$ & $\begin{array}{l}90 \mathrm{~km} \text { ESE } \\
85 \mathrm{~km} \text { ESE } \\
55 \mathrm{~km} \mathrm{NNW} \\
90 \mathrm{~km} \mathrm{NNW}\end{array}$ & $\begin{array}{l}\text { 10.6 RVD (1988) } \\
276.2 \\
408.9 \\
328.5\end{array}$ \\
\hline
\end{tabular}

NA = not available

RVD = recreation visitor days. One RVD equals one visitor in the area for twelve hours, twelve visitors present for one hour each, or any combination thereof.

Sounces: U.S. Army Corps of Engineers, Little Rock District, Recreational Visitation Data 1988, Little Rock, Ark, 1988; U.S. Forest Service, Land Areas of the National Forest System as of September 30, 1988, U.S. Government Printing Office, Washington, D.C., 1988; U.S. Naticnal Park Service, National Park Service Statistical Abstract 1988, U.S. Government Printing Office, Washington, D.C., 1989; J. Hendric and R. Freedman, Arkansas State Parts, Little Rock, Ark, personal communication to S. Schexnayder, Oak Ridge National Laboratory, Oak
Ridge, Tenn., June 28, 1989. 


\section{B3 SPECIAL POPULATIONS}

Special populations are defined as potentially affected people who recuire additional effort and special attention in the event of an emergency (Jacobs Eingineering Group, Inc., 1989a). Concentrations of special populations occur primarily in institutional settings. The Updated Sitc Assessment for Pine Bluff Arsenal and Adjacent Jurisdictions (Jacobs Engineering Group, Inc., 1989a) noted a need to identify persons with special needs living in the community. Examples of institutionalized populations with special needs include the populations of schools, day care centers, hospitals, nursing homes, and correctional facilities. Schools and child care facilities have been recognized as those populations that should be given priority in the planning process and first attention in an emergency (Jacobs Engineering Group, Inc. 1989a). Other noninstitutionalized special populations also need to be identified-for example, the blind, hearing impaired, and bedfast (Jacobs Engineering Group, Inc. 1989a). The Jefferson County Emergency Response Plan (Jacobs Engineering Group, Inc. 1989b) also places homeless people and people who have no private transportation within the category of special populations requiring additional attention.

Because special populations are an important aspect of emergency planning activities and because of the need to identify concentrations of people who may be affected by an accident associated with the proposed disposal program, the Phase I process has attempted to identify and characterize special populations located in institutional settings such as schools, correctional facilities, nursing homes, hospitals, and child care centers located within the $50-\mathrm{km}(31-\mathrm{mile})$ and $100-\mathrm{km}(62-\mathrm{mile})$ zones. The Phase I process has not attempted to identify individuals with special needs who are not associated with a particular facility or institution. Data on the various special populations are presented in Tables B.5 to B.11.

Table B.5 presents enrollment and staffing data for individual school buildings in Jefferson and Grant counties and for total school districts in other counties within the $100-\mathrm{km}$ (62-mile) radius. Table B.6 provides supplemental data (e.g., average daily attendance and student-teacher ratios) necessary to assess enrollment impacts on school districts in Jefferson and Grant counties, which are most likely to experience population increases. White Hall and Pine Bluff school districts currently are not experiencing capacity difficulties (J. Hawkins, Principal Planner, City of Pine Bluff, Pine Bluff, Ark., personal communication to J. Morrisse;, SAIC, Oak Ridge, Tenn., July 24, 1989).

Table B.7 presents the capacity of day care facilities within $100 \mathrm{~km}$ of PBA; facilities are listed individually for Grant and Jefferson counties.

Table B.8 presents colleges and vocational technical schools within the $50-\mathrm{km}$ (31-mile) and $100-\mathrm{km}$ (62-mile) zones. UAPB, which has an enrollment of 2765 , is located within $14 \mathrm{~km}$ (9 miles) of the proposed disposal facility. UAPB residence halls have a capacity of 750; occupancy during 1985-86 was 450 (Lehman 1987a).

Table B.9 presents hospitals within the $50-\mathrm{km}(31-\mathrm{mile})$ and $100-\mathrm{km}$ (62-mile)

zones. The Jefferson Regional Medical Center, with an average occupancy of 
Table B.5. Schook within the 50-km and 100-km zones of PBA

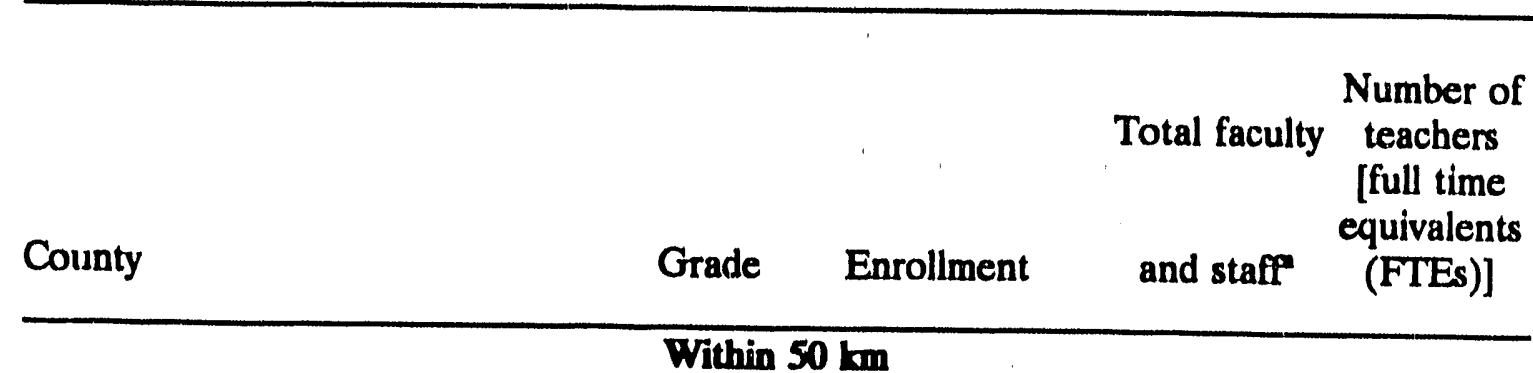

Jefferson County

Trinity Episcopal Day School ${ }^{\mathrm{b}}$

St. Peter Catholic School ${ }^{b}$

New Life Christian ${ }^{b}$

$\mathrm{K}-6 \quad 205$

$\mathrm{K}-6 \quad 165$

Maranatha Christian School ${ }^{c}$

$\mathrm{K}-12$

145

Pine Bluff Christian School ${ }^{\circ}$

$\mathrm{K}-12$

55

$\mathrm{K}, 4-12$

65

15

13

14

5

8

12

8

11

5

6

Pine Bluff District

Bel-Air Elem.

Broadmoor Elem.

Carver Elem.

4-6

$\mathrm{K}-3$

663

335

First Ward Elem.

$\mathrm{K}-3$

158

Forrest Park Elem.

$\mathrm{K}-3$

223

Gabe Meyer Elem.

$\mathrm{K}-3$

380

$\mathrm{K}-3 \quad 265$

Greenville Elem.

K-3

178

Indiana Street Elem.

K-3

310

Jack Robey Jr. High

8-9

1,137

Lakeside Elem.

K-3

227

Oak Park Elem.

4-6

396

Pine Bluff High

$10-12 \quad 1,600$

Sam Taylor Elem.

4-6

341

Southeast Middle

7

576

Southwood Elem.

Thirty-Fourth Ave. Elem.

K-3 487

4-6 274

274

$\begin{array}{ll}1-2 & 437 \\ 3-4 & 326 \\ \text { K,5-6 } & 504 \\ 7-9 & 508 \\ 10-12 & 405\end{array}$

44

39

$31 \quad 19$

$30 \quad 11$

$34 \quad 16$

$44 \quad 25$

$27 \quad 15$

$38 \quad 13$

$37 \quad 20$

$79 \quad 63$

$42 \quad 20$

$38 \quad 27$

$151 \quad 96$

$35 \quad 22$

$40 \quad 36$

$48 \quad 28$

$35 \quad 22$

Dollarway District

Matthews Dollarway Elem.

Pinecrest Elem.

Townsend Park Elem.

Dollarway Jr. High

Dollarway High School

10-12 405 
Table B.5 (continued)

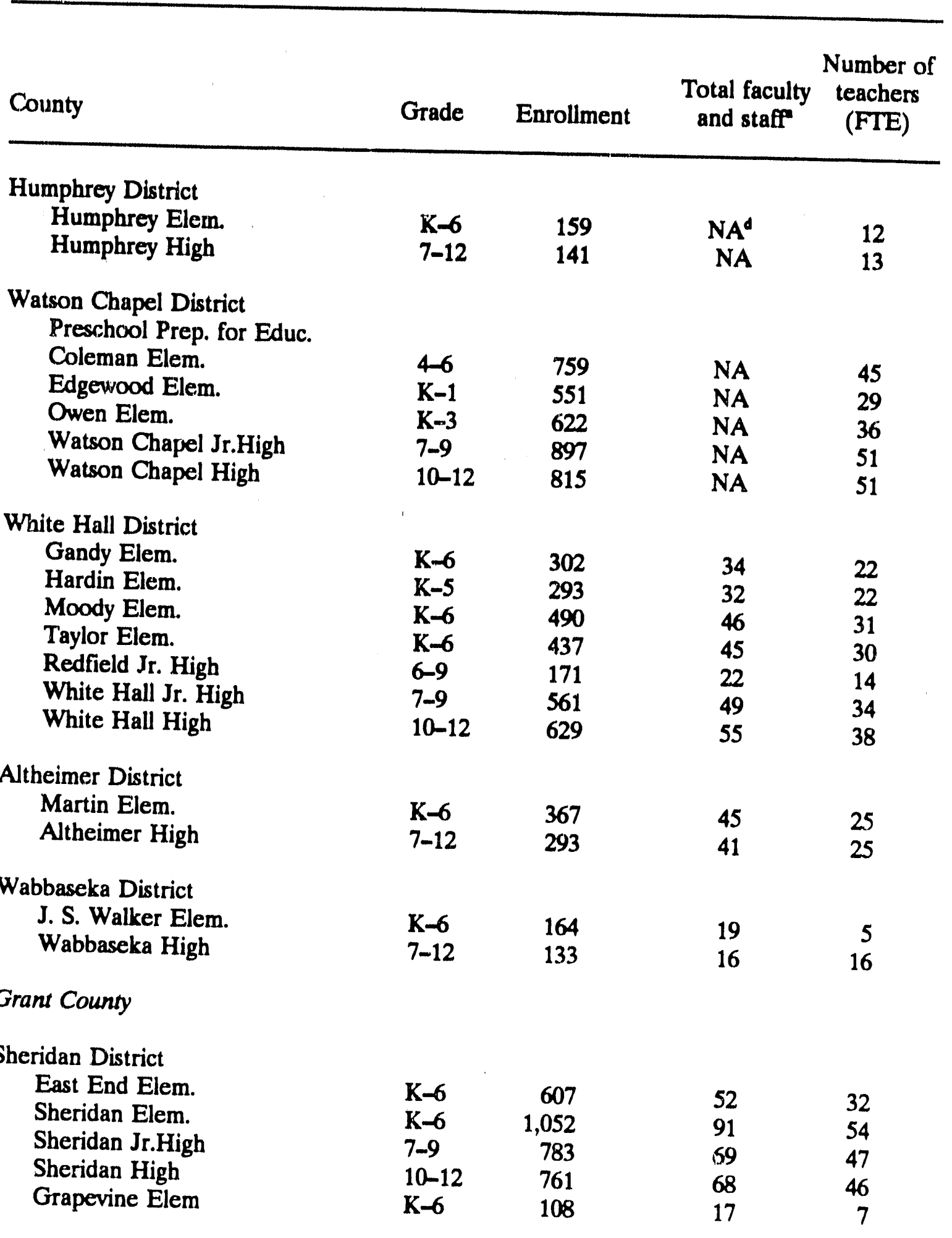


Table B.5 (continued)

\begin{tabular}{|c|c|c|c|c|}
\hline County & Grade & Enrollment & $\begin{array}{l}\text { Total faculty } \\
\text { and staff }\end{array}$ & $\begin{array}{l}\text { Number of } \\
\text { teachers } \\
\text { (FTE) }\end{array}$ \\
\hline $\begin{array}{l}\text { Poyen District } \\
\text { Poyen Elem. } \\
\text { Poyen High }\end{array}$ & $\begin{array}{l}K-6 \\
7-12\end{array}$ & $\begin{array}{l}124 \\
100\end{array}$ & $\begin{array}{l}\mathbf{N A} \\
\mathbf{N A}\end{array}$ & $\begin{array}{r}9 \\
11\end{array}$ \\
\hline $\begin{array}{l}\text { Prattsville District } \\
\text { Prattsville Elem. } \\
\text { Prattsville High }\end{array}$ & $\begin{array}{l}K-6 \\
7-12\end{array}$ & $\begin{array}{l}143 \\
138\end{array}$ & $\begin{array}{l}\text { NA } \\
\text { NA }\end{array}$ & $\begin{array}{r}10 \\
8\end{array}$ \\
\hline Cleveland County & & & & \\
\hline $\begin{array}{l}\text { Kingsland District (2) } \\
\text { Woodlawn District (2) } \\
\text { Rison District (2) }\end{array}$ & $\begin{array}{l}\mathrm{K}-12 \\
\mathrm{~K}-12 \\
\mathrm{~K}-12\end{array}$ & $\begin{array}{l}403 \\
430 \\
650\end{array}$ & $\begin{array}{l}30 \\
30 \\
44\end{array}$ & $\begin{array}{l}27 \\
27 \\
41\end{array}$ \\
\hline Lonoke County & & & & \\
\hline $\begin{array}{l}\text { Humnoke District (2) } \\
\text { England District (2) } \\
\text { Lonoke District (4) } \\
\text { Carlisle District (2) } \\
\text { Cabot District (7) }\end{array}$ & $\begin{array}{l}\mathrm{K}-12 \\
\mathrm{~K}-12 \\
\mathrm{~K}-12 \\
\mathrm{~K}-12 \\
\mathrm{~K}-12\end{array}$ & $\begin{array}{r}203 \\
1,151 \\
1,680 \\
766 \\
4,157\end{array}$ & $\begin{array}{r}\text { NA } \\
\text { NA } \\
112 \\
54 \\
237\end{array}$ & $\begin{array}{r}24 \\
68 \\
105 \\
48 \\
224\end{array}$ \\
\hline Saline County & & & & \\
\hline $\begin{array}{l}\text { Bauxite District (2) } \\
\text { Benton District (7) } \\
\text { Bryant District (4) } \\
\text { Harmony Grove District (2) }\end{array}$ & $\begin{array}{l}\mathrm{K}-12 \\
\mathrm{~K}-12 \\
\mathrm{~K}-12 \\
\mathrm{~K}-12\end{array}$ & $\begin{array}{r}619 \\
3,882 \\
5,063 \\
609\end{array}$ & $\begin{array}{l}\text { NA } \\
233 \\
\text { NA } \\
\text { NA }\end{array}$ & $\begin{array}{r}37 \\
219 \\
265 \\
35\end{array}$ \\
\hline Dallas County & & & & \\
\hline $\begin{array}{l}\text { Carthage District (2) } \\
\text { Fordyce District (3) } \\
\text { Sparkman District (2) }\end{array}$ & $\begin{array}{l}\mathrm{K}-12 \\
\mathrm{~K}-12 \\
\mathrm{~K}-12\end{array}$ & $\begin{array}{r}194 \\
1,403 \\
430\end{array}$ & $\begin{array}{l}17 \\
82 \\
35\end{array}$ & $\begin{array}{l}15 \\
77 \\
32\end{array}$ \\
\hline
\end{tabular}


Table B.5 (continued)

\begin{tabular}{|c|c|c|c|c|}
\hline County & Grade & Enrollment & $\begin{array}{l}\text { Total faculty } \\
\text { and staff }\end{array}$ & $\begin{array}{l}\text { Number of } \\
\text { teachers } \\
\text { (FTE) }\end{array}$ \\
\hline \multicolumn{5}{|l|}{ Arkansas County } \\
\hline $\begin{array}{l}\text { Dewitt District (4) } \\
\text { Gilette (2) } \\
\text { Stuttgart (6) }\end{array}$ & $\begin{array}{l}\mathrm{K}-12 \\
\mathrm{~K}-12 \\
\mathrm{~K}-12\end{array}$ & $\begin{array}{r}1,498 \\
298 \\
2,466\end{array}$ & $\begin{array}{l}101.1 \\
26 \\
155\end{array}$ & $\begin{array}{l}94.6 \\
24 \\
144.3\end{array}$ \\
\hline \multicolumn{5}{|l|}{ Lincoln County } \\
\hline $\begin{array}{l}\text { Grady District (2) } \\
\text { Gould District (2) } \\
\text { Star City District (3) }\end{array}$ & $\begin{array}{l}\mathrm{K}-12 \\
\mathrm{~K}-12 \\
\mathrm{~K}-12\end{array}$ & $\begin{array}{r}349 \\
398 \\
1,429\end{array}$ & $\begin{array}{l}29 \\
31 \\
88\end{array}$ & $\begin{array}{l}26 \\
28 \\
81\end{array}$ \\
\hline \multicolumn{5}{|l|}{ Pulaski County } \\
\hline $\begin{array}{l}\text { Little Rock District (50) } \\
\text { Pulaski County Spec. District (37) } \\
\text { North Little Rock District (23) } \\
\text { Arkansas School for the Blind } \\
\text { Arkansas School for the Deaf }\end{array}$ & $\begin{array}{l}\mathrm{K}-12 \\
\mathrm{~K}-12 \\
\mathrm{~K}-12 \\
\mathrm{~K}-12, \text { Voc.' } \\
\mathrm{P}-12\end{array}$ & $\begin{array}{r}24,605 \\
30,321 \\
9,626 \\
120^{8} \\
198^{\mathrm{h}}\end{array}$ & $\begin{array}{r}1,199 \\
1,779 \\
663 \\
128 \\
168\end{array}$ & $\begin{array}{r}1,095 \\
1,549 \\
606 \\
47 \\
47\end{array}$ \\
\hline \multicolumn{5}{|l|}{ Prairie County } \\
\hline $\begin{array}{l}\text { Des Arc District (2) } \\
\text { Devalls Bluff District (2) } \\
\text { Hazen District (2) }\end{array}$ & $\begin{array}{l}\mathrm{K}-12 \\
\mathrm{~K}-12 \\
\mathrm{~K}-12 \\
50 \text { to } 100 \mathrm{~km}\end{array}$ & $\begin{array}{l}714 \\
489 \\
594\end{array}$ & $\begin{array}{l}50 \\
38 \\
40\end{array}$ & $\begin{array}{l}47 \\
35 \\
37\end{array}$ \\
\hline \multicolumn{5}{|l|}{ Bradley County } \\
\hline $\begin{array}{l}\text { Hermitage District (2) } \\
\text { Warren District (4) } \\
\text { Calhoun County }\end{array}$ & $\begin{array}{l}\mathrm{K}-12 \\
\mathrm{~K}-12\end{array}$ & $\begin{array}{r}592 \\
1,904\end{array}$ & $\begin{array}{c}40 \\
124.2\end{array}$ & $\begin{array}{l}37 \\
115.5\end{array}$ \\
\hline Hampton District (2) & $\mathrm{K}-12$ & 900 & 60 & 56.7 \\
\hline
\end{tabular}




\section{B-13}

Table B.5 (continued)

\begin{tabular}{|c|c|c|c|c|}
\hline County & Grade & Enrollment & $\begin{array}{l}\text { Total faculty } \\
\text { and staff }\end{array}$ & $\begin{array}{l}\text { Number of } \\
\text { teachers } \\
\text { (FTE) }\end{array}$ \\
\hline \multicolumn{5}{|l|}{ Clark County } \\
\hline $\begin{array}{l}\text { Amity District (2) } \\
\text { Arkadelphia District (5) } \\
\text { Gurdon District (3) }\end{array}$ & $\begin{array}{l}\mathrm{K}-12 \\
\mathrm{~K}-12 \\
\mathrm{~K}-12\end{array}$ & $\begin{array}{r}295 \\
2,318 \\
984\end{array}$ & $\begin{array}{r}23.1 \\
151.9 \\
71.8\end{array}$ & $\begin{array}{c}21 \\
141 \\
69.7\end{array}$ \\
\hline \multicolumn{5}{|l|}{ Conway County } \\
\hline $\begin{array}{l}\text { Nomo Vista District (2) } \\
\text { Wonderview District (2) } \\
\text { So. Conway County District (7) }\end{array}$ & $\begin{array}{l}\mathrm{K}-12 \\
\mathrm{~K}-12 \\
\mathrm{~K}-12\end{array}$ & $\begin{array}{r}407 \\
451 \\
2,626\end{array}$ & $\begin{array}{r}28.9 \\
31.1 \\
171.3\end{array}$ & $\begin{array}{c}27.3 \\
28.1 \\
158\end{array}$ \\
\hline \multicolumn{5}{|l|}{ Perry County } \\
\hline $\begin{array}{l}\text { East End District (2) } \\
\text { Perry-Case District (2) } \\
\text { Perryville District (2) }\end{array}$ & $\begin{array}{l}\mathrm{K}-12 \\
\mathrm{~K}-12 \\
\mathrm{~K}-12\end{array}$ & $\begin{array}{l}523 \\
204 \\
863\end{array}$ & $\begin{array}{l}32 \\
25 \\
55\end{array}$ & $\begin{array}{l}31 \\
23 \\
52\end{array}$ \\
\hline \multicolumn{5}{|l|}{ Desha County } \\
\hline $\begin{array}{l}\text { Arkansas City Distr: (2) } \\
\text { Delta Special District (2) } \\
\text { Desha-Drew District (1) } \\
\text { Dumas District (4) } \\
\text { McGehee District (2) }\end{array}$ & $\begin{array}{l}\mathrm{K}-12 \\
\mathrm{~K}-12 \\
\mathrm{~K}-8 \\
\mathrm{~K}-12 \\
\mathrm{~K}-12\end{array}$ & $\begin{array}{r}151 \\
387 \\
222 \\
2,406 \\
1,326\end{array}$ & $\begin{array}{r}23 \\
33 \\
19 \\
135 \\
83\end{array}$ & $\begin{array}{r}21 \\
30 \\
17 \\
125 \\
77\end{array}$ \\
\hline \multicolumn{5}{|l|}{ Drew County } \\
\hline $\begin{array}{l}\text { Drew Central District (2) } \\
\text { Monticello District (5) } \\
\text { Wilmar District (2) }\end{array}$ & $\begin{array}{l}\mathrm{K}-12 \\
\mathrm{~K}-12 \\
\mathrm{~K}-12\end{array}$ & $\begin{array}{r}848 \\
2,235 \\
238\end{array}$ & $\begin{array}{r}56 \\
136 \\
21\end{array}$ & $\begin{array}{r}53 \\
127 \\
20\end{array}$ \\
\hline
\end{tabular}


Table B.5 (continued)

\begin{tabular}{|c|c|c|c|c|}
\hline County & Grade & Enrollment & $\begin{array}{l}\text { Total faculty } \\
\text { and staff }\end{array}$ & $\begin{array}{l}\text { Number of } \\
\text { teachers } \\
\text { (FTE) }\end{array}$ \\
\hline \multicolumn{5}{|l|}{ Faulkner County } \\
\hline $\begin{array}{l}\text { Conway District (9) } \\
\text { Enola District (2) } \\
\text { Greenbrier District (3) } \\
\text { Guy-Perkins District (2) } \\
\text { Mayflower District (2) } \\
\text { Mt. Vernon District (2) } \\
\text { Vilonia District (2) }\end{array}$ & $\begin{array}{l}\mathrm{K}-12 \\
\mathrm{~K}-12 \\
\mathrm{~K}-12 \\
\mathrm{~K}-12 \\
\mathrm{~K}-12 \\
\mathrm{~K}-12 \\
\mathrm{~K}-12\end{array}$ & $\begin{array}{r}5,090 \\
144 \\
1,399 \\
264 \\
606 \\
219 \\
1,357\end{array}$ & $\begin{array}{r}320 \\
16 \\
76 \\
25 \\
38 \\
20 \\
78\end{array}$ & $\begin{array}{r}300 \\
14 \\
71 \\
23 \\
35 \\
18 \\
72\end{array}$ \\
\hline \multicolumn{5}{|l|}{ Garland County } \\
\hline $\begin{array}{l}\text { Cutter-Morning Star District (2) } \\
\text { Fountain Lake District (2) } \\
\text { Hot Springs District (9) } \\
\text { Jessieville District (2) } \\
\text { Lake Hamilton District (4) } \\
\text { Lakeside District (3) } \\
\text { Mountain Pine District (2) }\end{array}$ & $\begin{array}{l}\mathrm{K}-12 \\
\mathrm{~K}-12 \\
\mathrm{~K}-12 \\
\mathrm{~K}-12 \\
\mathrm{~K}-12 \\
\mathrm{~K}-12 \\
\mathrm{~K}-12\end{array}$ & $\begin{array}{r}529 \\
931 \\
3,891 \\
588 \\
2,983 \\
2,164 \\
661\end{array}$ & $\begin{array}{r}36 \\
64 \\
265 \\
44 \\
173 \\
128 \\
41\end{array}$ & $\begin{array}{r}33 \\
59 \\
248 \\
40 \\
162 \\
120 \\
38\end{array}$ \\
\hline \multicolumn{5}{|l|}{ Hot Spring County } \\
\hline $\begin{array}{l}\text { Bismark District (2) } \\
\text { Glen Rose District (2) } \\
\text { Magnet Cove District (2) } \\
\text { Malvern District (6) } \\
\text { Ouachita District (2) }\end{array}$ & $\begin{array}{l}\mathrm{K}-12 \\
\mathrm{~K}-12 \\
\mathrm{~K}-12 \\
\mathrm{~K}-12 \\
\mathrm{~K}-12\end{array}$ & $\begin{array}{r}703 \\
778 \\
656 \\
2,958 \\
379\end{array}$ & $\begin{array}{r}43 \\
50 \\
46 \\
179 \\
28\end{array}$ & $\begin{array}{r}40 \\
47 \\
43 \\
169 \\
25\end{array}$ \\
\hline \multicolumn{5}{|l|}{ Monroe County } \\
\hline $\begin{array}{l}\text { Brinkley District }(2) \\
\text { Clarendon District }(2) \\
\text { Holly Grove District (2) }\end{array}$ & $\begin{array}{l}\mathrm{K}-12 \\
\mathrm{~K}-12 \\
\mathrm{~K}-12\end{array}$ & $\begin{array}{r}1,479 \\
636 \\
438\end{array}$ & $\begin{array}{l}92 \\
46 \\
35\end{array}$ & $\begin{array}{l}85 \\
42 \\
32\end{array}$ \\
\hline
\end{tabular}


Table B.5 (continued)

\begin{tabular}{|c|c|c|c|c|}
\hline County & Grade & Enrollment & $\begin{array}{l}\text { Total faculty } \\
\text { and staff }\end{array}$ & $\begin{array}{l}\text { Number of } \\
\text { teachers } \\
\text { (FTE) }\end{array}$ \\
\hline
\end{tabular}

Ouachita County

Bearden District (3)

Camden District (4)

K-12 871

$\mathrm{K}-12 \quad 2,167$

56

52

Chidester District

Fairview District (4)

$\begin{array}{rr} & 214 \\ K-12 \quad 1,852\end{array}$

Harnony Grove District (2)

$\mathrm{K}-12 \quad 786$

Stephens District (2)

$\mathrm{K}-12$

517

153

146

21

113

105

46

43

37

34

Perry County

East End District (2)

Perry-Casa District (2)

Perryville District (2)

$\mathrm{K}-12 \quad 523$

$\mathrm{K}-12$

204

863

55

31

$\mathrm{K}-12$

$\mathrm{K}-12$

777

802

46

56

$\begin{array}{lr}\mathrm{K}-12 & 802 \\ \mathrm{~K}-12 & 4,703\end{array}$

301

$\mathrm{K}-12 \quad 1,009$

75

$\mathrm{K}-12$

265

22

23

52

Lake View District

White County

Bald Knob District (2)

Beebe District (4)

Bradford District (2)

Central District (2)

Griffithville District (2)

Judsonia District (2)

Kensett District (2)

McRae District (2)

Pangburn District (2)

Rosebud District (2)

Searcy District (7)

$\begin{array}{rr}\mathbf{K}-12 & 1,443 \\ \mathbf{K}-12 & 1,658 \\ \mathrm{~K}-12 & 578 \\ \mathrm{~K}-12 & 533 \\ \mathrm{~K}-12 & 160 \\ \mathrm{~K}-12 & 550 \\ \mathrm{~K}-12 & 534 \\ \mathbf{K}-12 & 314 \\ \mathrm{~K}-12 & 623 \\ \mathrm{~K}-12 & 523 \\ \mathrm{~K}-12 & 2,878\end{array}$

86

80

$99 \quad 93$

$40 \quad 37$

$35 \quad 33$

$38 \quad 16$

$38 \quad 35$

$36 \quad 33$

$27 \quad 25$

$41 \quad 38$

$\begin{array}{rrrr}K-12 & 523 & 36 & 33 \\ K-12 & 2,878 & 187 & 174\end{array}$ 
Table B.5 (continued)

\begin{tabular}{|c|c|c|c|c|}
\hline County & Grade & Enrollment & $\begin{array}{l}\text { Total faculty } \\
\text { and staff }\end{array}$ & $\begin{array}{l}\text { Number of } \\
\text { teachers } \\
\text { (FTE) }\end{array}$ \\
\hline \multicolumn{5}{|l|}{ Woodruff County } \\
\hline $\begin{array}{l}\text { Augusta District (2) } \\
\text { Cotton Plant District (2) } \\
\text { McCrory District (2) }\end{array}$ & $\begin{array}{l}\mathrm{K}-12 \\
\mathrm{~K}-12 \\
\mathrm{~K}-12 \\
\end{array}$ & $\begin{array}{l}775 \\
360 \\
961 \\
\end{array}$ & $\begin{array}{l}53 \\
31 \\
57 \\
\end{array}$ & $\begin{array}{l}50 \\
28 \\
53 \\
\end{array}$ \\
\hline \multicolumn{5}{|c|}{ 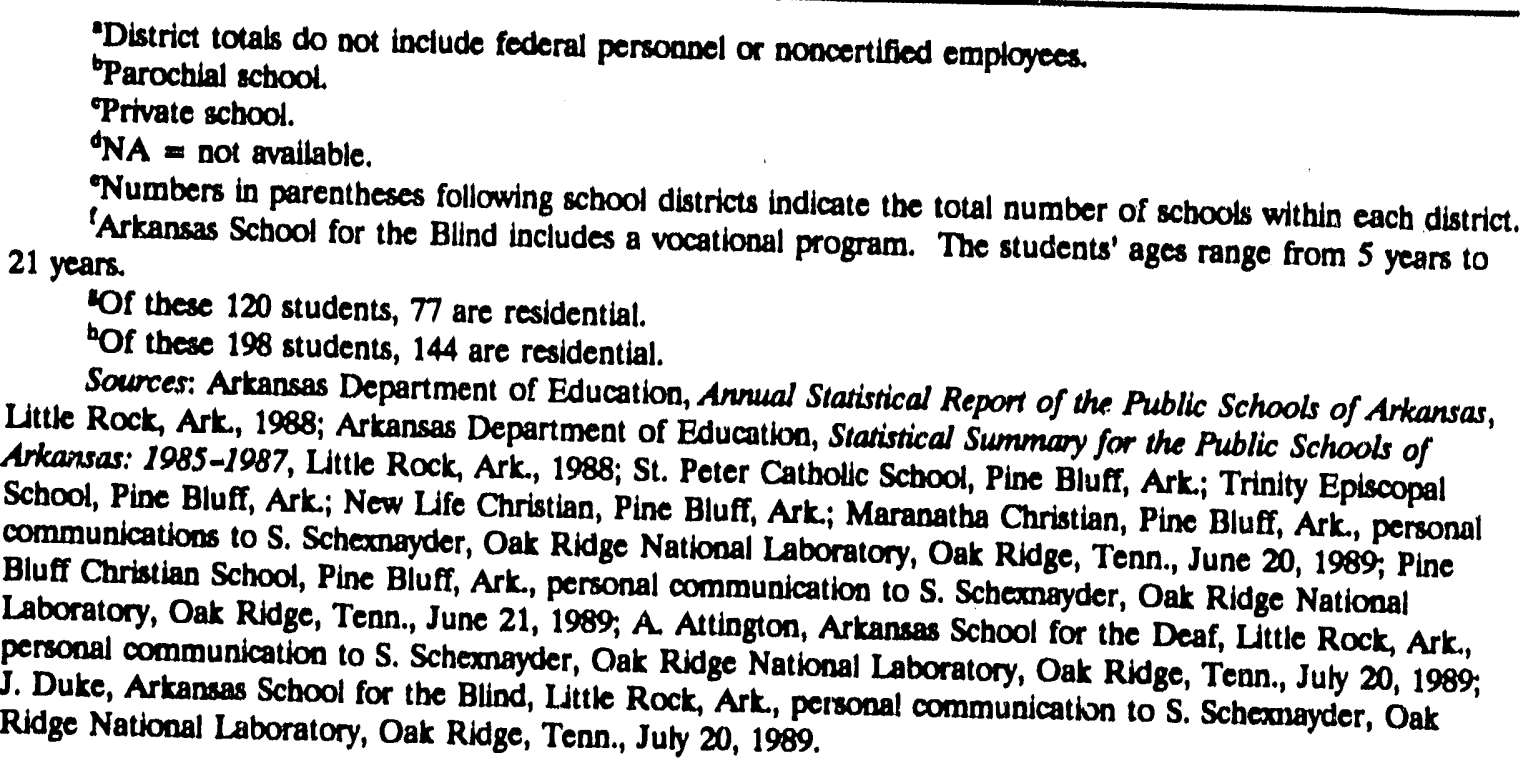 } \\
\hline
\end{tabular}


B-17

Table B.6. Student to teacher ratio of public schools in Jefferson and Grant countiese

\begin{tabular}{lrrr}
\hline School district & $\begin{array}{c}\text { Average daily } \\
\text { attendance }^{\text {b.c }}\end{array}$ & Teachers $^{\text {s. }}$ & $\begin{array}{c}\text { Student to teacher } \\
\text { ratio }^{d}\end{array}$ \\
\hline Altheimer & 632 & 42.0 & 15.0 \\
Dollarway & 2026 & 118.5 & 17.1 \\
Humphrey & 272 & 20.4 & 13.3 \\
Pine Bluff & 6956 & 407.5 & 17.1 \\
Sheridan & 2897 & 170.1 & 17.0 \\
Wabbaseka & 283 & 24.7 & 11.5 \\
Watson Chapel & 3372 & 194.6 & 17.3 \\
White Hall & 2608 & 170.0 & 15.3 \\
\hline
\end{tabular}

Parochial schools in Pine Bluff include Aenon Bethesda Christian (Preschool), Trinity Episcopal Day School (K-6), St. Peter Catholic School (K-3), and New Life Christian (K-12). Private schools in Pine Bluff include Maranatha Christian School (K-12) and Pine Bluff Christian School (K, 4-12).

Exítudes tindergarten.

'Annual average number of students enrolled.

"Average daily attendance divided by number of teachers.

Source: Department of Education, Anvual Statistical Report of the Public Schools of Anteansas, Little Rock, Art, January 1988. 
Table B.7. Day care facilities' capacities within the 50-km and 100-km zones of PBA

\section{Facility}

Address
Capacity

\section{Grant County}

First United Methodist Church

Miss Betty's Day Care

Keep and Teach

Millie Mayers

Jo Hopkins

Kathy Finley

Annie Howard

\section{Jefferson County}

Edgar Morales

Theodore Wallace

Ruben McClain

Southside Baptist Kindercare

Wrights Child Dev. Center

Immanuel Baptist

Davis Kiddie Land

Playhouse Nursery

UAPB Child Dev. Center

Miss Carolyn's Day Nursery

Oak Park Free Will Baptist

First Ward Headstart

Terry's Tots and Toddlers

Wesley Preschool

Ann's Day Care Center

David Vaughn Headstart

Olive St. Baptist Church

Working Parents Child Care

Watson Chapel Baptist Wee Care

Child Center, Inc.

Trinity Temple Headstart

Newlife Child Care Center

Trinity Episcopal Day School

Jefferson Prep School

Eddie's Early Learning Center

The Learning Center

Morgan Headstart

Altheimer Headstart

Delane's Daycare
Within $50 \mathrm{~km}$

P.O. Box 357, Sheridan 75

Rt. 5, Box 79, Sheridan 58

Rt. 5, Box 272, Sheridan 49

P.O. Box 131, Sheridan 10

Rt. 2, Box 594, Sheridan 12

Rt. 3, Box 198C, Sheridan 10

107 N. Cumberland, Sheridan 8

Qtrs 13-701A, PBA

Qtrs 13-705A, PBA

Qtrs 12-300B, PBA

2309 Poplar, Pine Bluff

1213 Marion Dr., Pine Bluff

1801 West 17th, Pine Bluff

4218 W. Short 4th, Pine Bluff 87

118 Rutherford, Pine Bluff 48

Univ, of Ark, Pine Bluff 24

203 W. Harding Pine Bluff 24

3000 Orange Pine Bluff

P.O. Box 1285, Pine Bluff 152

9408 Dollarway, Pine Bluff

$3010 \mathrm{Hazel}$ Pine Bluff 43

1406 Humac, Pine Bluff 105

23

103

1923 Olive, Pine Bluff 151

Pine Bluff $\quad 38$

Rt. 7, Box 777, Pine Bluff 147

1000 West 4th, Pine Bluff 48

P.O. Box 1285, Pine Bluff 55

3201 Ridgeway, Pine Bluff 67

P.O. Box 8069, Pine Bluff 28

2206 Ridgeway, Pine Bluff $\quad 52$

1108 N. Hazel, Pine Bluff 25

819 West 26th, Pine Bluff $\quad 69$

P.O. Box 1285, Pine Bluff 20

3rd St., Altheimer 44

1501 Blake, Pine Bluff 4 
Table B.7 (continued)

\begin{tabular}{|c|c|c|}
\hline Facility & Address & Capacity \\
\hline The Village Child Center & 2205 W. 34th, Pine Bluff & 45 \\
\hline LaPetite Prep School & 702 Linden, Pine Bluff & 30 \\
\hline Elite Petite & 1616 Linden, Pine Bluff & 36 \\
\hline Lollipop Tree, Inc. & 3901 Hazel, Pine Bluff & 66 \\
\hline Coleman Daycase & 4111 Tennessee, Pine Bluff & 25 \\
\hline Miss Di's & P.O. Box 255, Redfield & 18 \\
\hline Jenkins Headstart Center & 2410 Rike Dr., Pine Bluff & 20 \\
\hline First Step & 608 S. Dakota, Pine Bluff & 23 \\
\hline Elite Petite Academy & 408 W. Harding, Pine Bluff & 36 \\
\hline Tender Years & 5810 Malcomb, Pine Bluff & 30 \\
\hline T L C & 4014 Oldwarren, Pine Bluff & 96 \\
\hline Tiny Tot & 2213 Hill St., Pine Bluff & 30 \\
\hline Sixth Avenue Day Care Center & 1702 W. 6th, Pine Bluff & 28 \\
\hline Wabbaseka Headstart & Wabbaseka & 36 \\
\hline First Baptist & 6th and Cherry, Pine Bluff & 176 \\
\hline Hallmark Headstart & P.O. Box 1285, Pine Bluff & 20 \\
\hline 21st St. Headstart & 906 E. 21st, Pine Bluff & 39 \\
\hline The Ark Youth Center & 11th, Cypress Sts., Pine Bluff & 24 \\
\hline Demery's Early Childhood & 33 Cypress, Pine Bluff & 10 \\
\hline Lucille Spiller & 1516 W. 15th, Pine Bluff & 10 \\
\hline Lula Hudson & 1200 E. 8th, Pine Bluff & 10 \\
\hline Mother Goose & 343 S. Richard, Pine Bluff & 10 \\
\hline Olivia Stocker & 1408 University, Pine Bluff & 7 \\
\hline Margaret Phillips & 1905 W. 28th, Pine Bluff & 10 \\
\hline Flora Raglon & 1709 Virginia, Pine Bluff & 10 \\
\hline Claudette Denton & 2515 W. 16th, Pine Bluff & 8 \\
\hline Essie Threets & 1105 Poplar, Pine Bluff & 16 \\
\hline Billie Jean Jackson & 4103 W. 17th, Pine Blufi & 10 \\
\hline Johnnye Gray & 2002 Hickory, Pine Bluff & 10 \\
\hline Alice Erwin & 1705 W. 26th, Pine Bluff & 10 \\
\hline Whitiker's Childcare & 1312 Cypress, Pine Bluff & 10 \\
\hline Jan Detor & 3805 S. Mulberry, Pine Bluff & 9 \\
\hline Ann Meyer & 1406 Humac, Pine Bluff & 16 \\
\hline Shirley Jackson & 916 W. 2nd, Pine Bluff & 10 \\
\hline Connie Reed & 3412 Rose, Pine Bluff & 10 \\
\hline Carrie Morehead & 1301 S. Oak, Pine Bluff & 10 \\
\hline Johnson's Firststep & 1901 W. 21st, Pine Bluff & 10 \\
\hline Odessa King & 913 E. 11th, Pine Bluff & 10 \\
\hline Youth .Iome & 1303 Poplar, Pine Bluff & 9 \\
\hline Sonshine Care & 300 Church Dr., Whitehall & 20 \\
\hline
\end{tabular}


Table B.7 (continued)

\begin{tabular}{lrr} 
County & Number of licenses & Total capacity \\
\hline & 10 & \\
Arkansas & 0 & 193 \\
Cleveland & 5 & 0 \\
Dallas & 8 & 118 \\
Lincoln & 15 & 77 \\
Lonoke & 3 & 364 \\
Prairie & 427 & 40 \\
Pulaski & 28 & 16,820 \\
Saline & 50 to 100 km & 982 \\
& & \\
& 15 & \\
Bradley & 2 & 284 \\
Calhoun & 23 & 30 \\
Clark & 26 & 568 \\
Conway & 10 & 516 \\
Desha & 13 & 231 \\
Drew & 44 & 218 \\
Faulkner & 65 & 1296 \\
Garland & 16 & 2045 \\
Hot Spring & 7 & 456 \\
Monroe & 20 & 73 \\
Ouachita & 6 & 381 \\
Perry & 19 & 119 \\
Phillips & 19 & 676 \\
White & 5 & 376 \\
Woodruff & & 100 \\
& & \\
\hline & & \\
& & \\
& &
\end{tabular}
"Number of licenses is not necessarily equal to the number of day care facilities because a single facility
can be granted more than one license.

Source: Data compiled from information provided by the Arkansas Department of Human Services, 1989 Listing of Day Care Centers, Division of Children and Family, Child Care Licensing, Little Rock, Ark., 1989. 
Table B. Irstitutions of higher education within the 50-km (31-mile) and 100-km (62-mile) zones of PBA

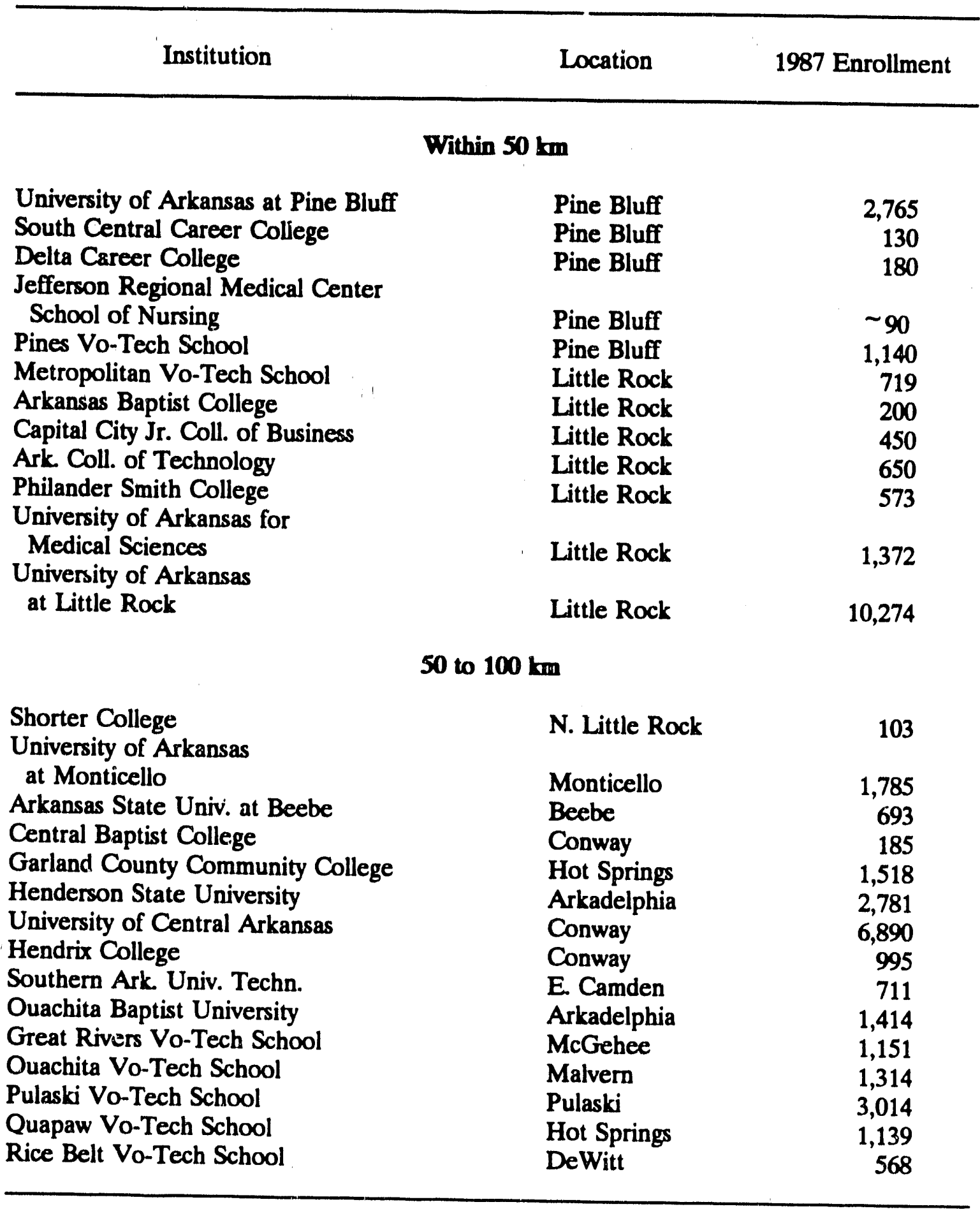


Table B8 (continued)

Sources: B. Font, Jefferson Regional Medical Center School of Nursing, Pine Bluff, Ark, personal communication to S. Schexnayder, Oak Ridge National Laboratory, Oak Ridge, Tenn., July 20, 1989, A. E. Lehman, Guide to Four-Year Colleges 1987, 17th edition, Peterson's Guides, Princeton, NJ., 1987; A. E. Lehman, Guide to Twa-Year Colleges 1987, 17th edition, Peterson's Guides, Princeton, NJ., 1987; M. Braswell, Vocational \& Technical Educational Division, Little Rock, State Department of Education, Little Rock, Ark. personal communication to J. Morrissey, SAIC, Oak Ridge, Tenn., June 28, 1989; M. William, South Central Career College, Pine Bluff, Ark, personal communication to S. Schexnayder, Oak Ridge National Laboratory, Oak Ridge, Tenn., July 19, 1987; K Mezger, Delta Career College, Pine Bluff, Ark, personal communication to J. Morrissey, SAIC, Oak Ridge, Tenn., Feb. 12, 1990. 
Table B.9. Hospitals within the 50-km (31-mile) and 100-km (62-mile) zones of the PBA site

\begin{tabular}{|c|c|c|c|}
\hline Facility name & City & $\begin{array}{l}\text { Number } \\
\text { of beds }\end{array}$ & $\begin{array}{l}\text { Occupancy } \\
\text { rate }(\%)\end{array}$ \\
\hline \multicolumn{4}{|c|}{ Within $50 \mathrm{~km}$} \\
\hline Jefferson Regional Medical Center & Pine Bluff & 500 & 64.4 \\
\hline Arlransas Children's Hospital & Little Rock & 188 & 79.3 \\
\hline Arkansas Rehabilitation Institute & Little Rock & 132 & 78.8 \\
\hline Arkansas State Hospital & Little Rock & 360 & $\mathrm{NA}^{*}$ \\
\hline Baptist Medical Center & Little Rock & 617 & 82.7 \\
\hline Doctors Hospital & Little Rock & 310 & 48.4 \\
\hline $\begin{array}{l}\text { John L. Mclellan Memorial } \\
\text { Veterans Hospital }\end{array}$ & Little Rock & 1505 & 66.6 \\
\hline Southwest Hospital & Little Rock & 125 & NA \\
\hline St. Vincent Infirmary Med. Center & Little Rock & 604 & 82.6 \\
\hline University Hospital of Arkansas & Little Rock & 344 & 69.5 \\
\hline US Air Foice Hospital & Little Rock AFB & 25 & 41.2 \\
\hline Rivendell Children \& Youth Center & Benton & 64 & NA \\
\hline Saline Memorial Hospital & Benton & 121 & 53.7 \\
\hline Stuttgart Memorial Hospital & Stuttgart & 99 & NA \\
\hline \multicolumn{4}{|c|}{50 to $100 \mathrm{~km}$} \\
\hline Rebsamen Regional Medical Center & Jacksonville & 93 & 51.6 \\
\hline DeWitt City Hospital & DeWitt & 34 & 29.4 \\
\hline Bradley Co. Memorial Hospital & Warren & 49 & 65.3 \\
\hline Twin Rivers Medical Center & Arkadelphia & 57 & 43.9 \\
\hline Dallas Co. Hospital & Fordyce & 79 & NA \\
\hline Delta Memorial Hospital & Dumas & 59 & 30.0 \\
\hline Drew Memorial Hospital & Monticello & 50 & 42.0 \\
\hline Conway Regional Hospital & Conway & 106 & 39.8 \\
\hline Ami National Park Medical Center & Hot Springs & 155 & 66.5 \\
\hline Levi Arthritis Hospital & $\begin{array}{l}\text { Hot Springs } \\
\text { Nat'l Park }\end{array}$ & 62 & 40.3 \\
\hline St. Joseph's Regional Health Center & $\begin{array}{l}\text { Hot Springs } \\
\text { Nat'l Park }\end{array}$ & 261 & 67.9 \\
\hline Hot Spring Co. Memorial Hospital & Malvern & 77 & 41.6 \\
\hline
\end{tabular}


Table B.10. Nuring homes within the 50-km (31-mile) and 100-km (62-mile) zones of PBA

Facility name

Location

(city, county)

Capacity

\section{Within $50 \mathrm{~km}$}

Arkansas Convalescent Center Davis Skilled Care Jefferson County Nursing Home Loma Linda Rest Home, Inc. Oak Park Nursing Home, Inc. Trinity Village Medical Center Pine Bluff Nursing Home Grant County Nursing Home England Manor Nursing Home England Nursing Center Alexander Human Development Center Crestpark Inn

Rose Care Center

Cleveland County Nursing Home

Carthage Nursing Home

Gardner Nursing Home

Star City Nursing Center

Golden Years Manor

Lonoke Nursing Home

Briarwood Nursing Center

Easter Seal Residential Center

Hillhaven of Little Rock

Little Rock Nursing Center

The Oaks Nursing Center

Parkway Health Center, Inc.

Riley's Oak Hill Manor, South

Rose Care Center of Little Rock

Southwest Homes

Trinity Court Nursing Home

Vantage Conv. Center

Williamsburg Retirement Inn

Benton Services Center, SNF

Benton Services Center, Nursing Home

Ouachita Valley Nursing Center

Rose Care Center

Rose Care Center II
Pine Bluff, Jefferson $\quad 73$

Pine Bluff, Jefferson $\quad 100$

Pine Bluff, Jefferson $\quad 50$

Pine Bluff, Jefferson 205

Pine Bluff, Jefferson 66

Pine Bluff, Jefferson $\quad 70$

Pine Bluff, Jefferson 245

Sheridan, Grant $\quad 110$

England, Lonoke

England, Lonoke 113

Alexander, Saline $\quad 150$

Stuttgart, Arkansas $\quad 74$

Stuttgart, Arkansas $\quad 90$

Rison, Cleveland 67

Carthage, Dallas 85

Star City, Lincoln 72

Star City, Lincoln 87

Lonoke, Lonoke 101

Lonoke, Lonoke 53

Little Rock, Pulaski 61

Little Rock, Pulaski 25

Little Rock, Pulaski $\quad 174$

Little Rock, Pulaski 204

Little Rock, Pulaski 97

Little Rock, Pulaski 75

Little Rock, Pulaski 224

Little Rock, Pulaski 143

Little Rock, Pulaski 125

Little Rock, Pulaski $\quad 160$

Little Rock, Pulaski 160

Little Rock, Pulaski 101

Benton, Saline 112

Benton, Saline 290

Benton, Saline 150

Benton, Saline 103

Benton, Saline $\quad 140$ 
Table B.10 (continued)

Location

(city, county) Capacity

50 to $100 \mathrm{~km}$

DeWitt City Nursing Home

Leisure Lodge, Inc.

Pine Lodge

Siouiheast Arkansas Human Development Center

Wagnon Place, Inc.

Hampton Nursing Home

Dallas County Nursing Home

Millcreek of Arkansas

Southern Nursing Home

Dumas Nursing Center

Leisure Lodge, Inc.

Leisure Lodge, Inc.

Conway Human Development Center

Faulkner Nursing Center

Heritage Center, Inc.

Johnson's Meadowlake Home, Inc.

Salem Place Nursing Center

Arkansas Healthcare Nursing Center

Garland Convalescent Center

Garland Pines Convalescent Center

Hot Springs Nursing Home

Lakewood Convalescent Home

Nucare Convalescent Center

Quality Care Nursing Center

Longmeadow Nursing Home

Malvern Nursing Home

Stillmeadow Convalescent Center

Crestpark Inn of Marianna

Cabot Manor Nursing Home

Chambers Nursing Home

J.W. Comer Nursing Home

Zimmerman Nursing Home

Cla-Cliff Home for the Aged

St. Joseph's Home

Leisure Lod e, Inc. (Magnolia Rd.)

Leisure Lodge, Inc. (Bruce St.)
Dewitt, Arkansas $\quad 54$

Dewith, Arkansas $\quad 140$

Warren, Bradley 99

Warren, Bradley 70

Warren, Bradley $\quad 105$

Hampton, Calhoun $\quad \mathbf{7 4}$

Fordyce, Dallas 34

Fordyce, Dallas $\quad 61$

Fordyce, Dallas 105

Dumas, Desha $\quad 80$

McGehee, Desha $\quad 140$

Monticello, Drew 124

Conway, Faulkner $\quad 640$

Conway, Faulkner $\quad 105$

Conway, Faulkner $\quad 55$

Conway, Faulkner $\quad 70$

Conway, Faulkner $\quad 117$

Hot Springs, Garland $\quad 152$

Hot Springs, Garland $\quad 105$

Hot Springs, Garland $\quad 70$

Hot Springs, Garland $\quad 140$

Hot Springs, Garland $\quad 50$

Hot Springs, Garland $\quad 100$

Hot Springs, Garland $\quad 113$

Malvern, Hot Spring $\quad 69$

Malvern, Hot Spring $\quad 95$

Malvern, Hot Spring $\quad 104$

Marianna; Lee $\quad 90$

Cabot, Lonoke $\quad 75$

Carlisle, Lonoke $\quad 52$

Carlisle, Lonoke 22

Carlisle, Lonoke 41

Brinkley, Monroe $\quad 77$

Brinkley, Monroe 28

Camden, Ouachita $\quad 106$

Camden, Ouachita $\quad 70$ 
Table B.10 (continued)

Facility name

Location

(city, county)

Capacity

Longmeadow Nursing Home

Ouichita Convalescent Center

Perry County Nursing Center

Cedar Lodge Nursing Home

Des Arc Convalescent Center

Jean's Nursing Home

Arkansas Pediatric Facility

Mercy Nursing Home, Inc.

Riley's Oak Hill Manor

Jacksonville Nursing Center

Rose Care Center

Good Samaritan Cedar Lodge

Beebe Retirement Center, Inc.

Byrd Haven Nursing Home

Leisure Lodge, Inc.

Oakdale Nursing Home

Woodruff County Nursing Home

$\begin{array}{lr}\text { Camden, Ouachita } & 69 \\ \text { Camden, Ouachita } & 142 \\ \text { Perryville, Perry } & 70 \\ \text { Marvell, Phillips } & 132 \\ \text { Des Arc, Prairie } & 80 \\ \text { College Station, Pulaski } & 105 \\ \text { North Little Rock, Pulaski } & 53 \\ \text { North Little Rock, Pulaski } & 85 \\ \text { North Little Rock, Pulaski } & 224 \\ \text { Jacksonville, Pulaski } & 245 \\ \text { Jacksonville, Pulaski } & 58 \\ \text { Hot Springs Village, Saline } & 40 \\ \text { Beebe, White } & 105 \\ \text { Searcy, White } & 75 \\ \text { Searcy, White } & 245 \\ \text { Judsonia, White } & 100 \\ \text { McCrory, Woodruff } & 105\end{array}$

Sources: S. Frazer, Arkansas Dept. of Human Services, Office of Long Term Care, Little Rock, Ark.,

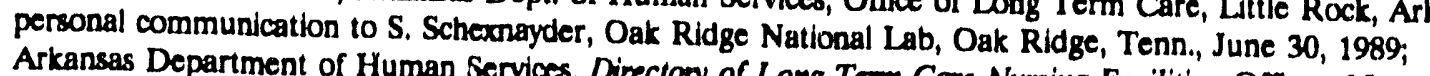
Arkansas Department of Human Services, Directory of Long Term Care Nursing Facilities, Office of Long Term
Care, Little Rock, Ark. 1989. 
Table B.11. Correctional Facilities within the 50-km (31-mile) and $100-\mathrm{km}$ (62-mile) zones of the PBA xite

\begin{tabular}{|c|c|c|c|}
\hline (as of & $\begin{array}{l}\text { Inmate } \\
\text { capacity } \\
\text { Jan. 31, 1990) }\end{array}$ & $\begin{array}{l}\text { Total budgeted } \\
\text { employee positions" } \\
\text { (as of Jan. 31, 1990) }\end{array}$ & $\begin{array}{c}\text { Direction and } \\
\text { distance from } \\
\text { arsenal }\end{array}$ \\
\hline \multicolumn{4}{|c|}{ Within $50 \mathrm{~km}$} \\
\hline Tucker Unit \& Modular Barracks & 796 & 150 & $22 \mathrm{~km} \mathrm{NE}$ \\
\hline Maximum Security, Tucker & 432 & 185 & $22 \mathrm{~km} \mathrm{NE}$ \\
\hline Diagnostic Unit & 488 & 152 & $13 \mathrm{~km} \mathrm{~S}$ \\
\hline Women's Unit & $288^{b}$ & 77 & $13 \mathrm{~km} \mathrm{~S}$ \\
\hline Jefferson County Regional Facility ${ }^{\circ}$ & 272 & $\mathbf{N A}^{d}$ & $13 \mathrm{~km} \mathrm{~S}$ \\
\hline Wrightsville Unit & $650^{\circ}$ & 150 & $32 \mathrm{~km} \mathrm{~N}$ \\
\hline \multicolumn{4}{|l|}{ Arkansas Boys Training } \\
\hline School & 142 & 9 & $15 \mathrm{~km} \mathrm{~S}$ \\
\hline Benton Unit & 225 & 41 & $48 \mathrm{~km} \mathrm{NNW}$ \\
\hline \multicolumn{4}{|c|}{50 to $100 \mathrm{~km}$} \\
\hline Varner Unit & 1,100 & 186 & $56 \mathrm{~km} \mathrm{SE}$ \\
\hline \multicolumn{4}{|c|}{ Cummins Unit \& Modular Minimum } \\
\hline
\end{tabular}

SSecurtty staff work 12-hour shifts, 24 hours per day, 7 days per week.

"Women's Unit will expand by 100 beds by 1991.

Not yet built. It is planned for October 1991.

$\mathrm{NA}=$ not available.

"Wrightsville will expand by 150 beds by 1991.

Sources: W. Ferrell, Superintendent, Arkansas Boys Training Unit, Pine Bluff, Ark., personal communication to S. Schexnayder, Oak Ridge National Laboratory, Oak Ridge, Tenn., July 11, 1989; D. White, Assistant to the Director, Public and Legislative 'Kilations, Arkansas Department of Corrections, Little Rock, Arkansas, personal communication to J. Morrissey, SAIC, Oak Ridge, Tenn., Feb. 12, 1990. 
322 patients, is located in Pine Bluff. In addition, PBA Health Clinic supplies all emergency and outpatient services. No inpatient facilities are available at PBA (Lt. C. Sachs, PBA, personal communication to J. Morrissey, SAIC, Oak Ridge, Tenn., June 23,1989 ). Table B.10 presents a list of nursing homes located within the $50-\mathrm{km}$ (31-mile) and 100-km (62-mile) zones.

State corrections facilities within the 50-km (31-mile) and the 100-km (62-mile) zones are presented in Table B.11. Eight of the ten existing or proposed corrections facilities in the $100-\mathrm{km}$ (62-mile) zone are located within $50 \mathrm{~km}$ (31 miles); these eight facilities have a combined inmate and employee population of more than 4000 people.

\section{B.4 LAND USE}

PBA's southern boundary is located approximately $2 \mathrm{~km}$ (1.24 miles) north of the city limits of Pine Bluff. A 314-ha (785-acre) industrial park is located just north of the city limits at the southern end of PBA. PBA is bounded on the east by the Arkansas River. On the west, it is bounded by the Missouri Pacific Railroad; State Route 365; the city of White Hall; and the unincorporated communities of Samples, Dexter, and Baldwin. Its northern boundary encompasses the National Center for Toxicological Research. The incorporated community of Redfield is located approximately $17 \mathrm{~km}$ (11 miles) northwest of PBA. Other nearby unincorporated communities include Jefferson, Tucker, and Cornerstone.

The Land Use Plan for the city of Pine Bluff indicated a ratio of 0.075 ha ( 0.187 acre) per dwelling unit in the city. In 1980, 1593 ha (3983 acres) were devoted to residential usage in the city. As of $1981,47 \%$ of the land within the city limits was vacant, undeveloped, or used for agricultural purposes. Table B.12 shows 1981 data on land use within Pine Bluff. In 1985, approximately 4000 ha (10,000 acres) were annexed, adding 125 businesses and 3388 new residences to the city. The approximate mix of uses for the annexed area was nearly identical to that of the city as a whole (Federal Highway Administration 1988).

In spite of Pine Bluff's urban character, agriculture is a major contributor to the economy of Jefferson County. Because of the quantity of underground water available, rice, cotton, soybeans, and wheat are the major money-producing crops in the county. In 1981 , some 26,000 ha $(65,000$ acres) of rice generated approximately $\$ 30$ million to Jefferson County producers. The value of 17,600 ha ( 44,000 acres) of cotton totaled $\$ 19$ million. Wheat has become an important crop, and in 1981, the value of this crop exceeded $\$ 7$ million for 20,400 ha ( 51,000 acres). Other crops include corn, hay, oats, grain, sorghum, potatoes, fruits, nuts, berries, and vegetables. In 1981, the value of all crops was approximately $\$ 80$ million (City of Pine Bluff Planning Department 1984). Table B.13 illustrates the extent of farming in counties within the $100-\mathrm{km}(62-\mathrm{mile})$ zone of PBA. Additional land use data may be found in Sect. 3.2.3. 


\section{B-29}

Table B.12 Land we by category, city of Pine Bluff, Artansas, 1981

\begin{tabular}{lcc}
\hline \multicolumn{1}{c}{ Land use category } & Acreage & \% of total land \\
\hline Residential & 3,983 & 21.8 \\
Commercial & 366 & 3.1 \\
Industrial & 241 & 1.3 \\
Public and semipublic & 396 & 11.0 \\
Water & 412 & 2.3 \\
Transportation & 2,549 & 14.0 \\
Vacant or undeveloped & $\mathbb{8 , 4 9 3}$ & $\underline{46.5}$ \\
\multicolumn{1}{c}{ Total } & 16,640 & 100.0 \\
\hline
\end{tabular}

Sounce: Federal Highway Administration, Final Environmental Impact Stasement, U.S. Highway 6S Bypass, Arkansas State Highway and Transportation Department, Little Rock, Ark, 1988. 
Table B.13. Agricultural land wo within $100 \mathrm{~km}$ (62 miles) of PBA

\begin{tabular}{|c|c|c|c|c|c|c|c|}
\hline $\begin{array}{l}\text { County } \\
\text { name }\end{array}$ & $\begin{array}{c}\text { Number of } \\
\text { farms } \\
1982\end{array}$ & $\begin{array}{c}\% \text { farms } \\
<50 \\
\text { acres } \\
1982\end{array}$ & $\begin{array}{c}\% \text { farms } \\
2500 \\
\text { acres } \\
1982\end{array}$ & $\begin{array}{c}\text { Farm } \\
\text { acreage } \\
(\times 1000)\end{array}$ & $\begin{array}{c}\text { Farm } \\
\text { acreage } \\
\% \text { change } \\
1978-82\end{array}$ & $\begin{array}{c}\text { Average } \\
\text { size } \\
\text { of farm } \\
\text { (acres) }\end{array}$ & $\begin{array}{l}\text { Crop- } \\
\text { land } \\
(\times 1000 \\
\text { acres })\end{array}$ \\
\hline Arkansas & 636 & 9.7 & 54.1 & 446 & -4.8 & 700 & 370 \\
\hline Bradley & 332 & 37.0 & 3.6 & 39 & -16.8 & 117 & 18 \\
\hline Calhoun & 146 & 21.2 & 5.5 & 23 & -17.3 & 160 & 12 \\
\hline Clark & 460 & 21.5 & 13.7 & 131 & -1.2 & 284 & 69 \\
\hline Cleveland & 272 & 28.7 & 5.5 & 42 & -16.1 & 154 & 20 \\
\hline Conway & 746 & 18.8 & 8.3 & 171 & -4.2 & 229 & 97 \\
\hline Dallas & 143 & 22.4 & 7.7 & 26 & -25.0 & 180 & 12 \\
\hline Desha & 427 & 13.8 & 43.3 & 295 & -2.4 & 692 & 269 \\
\hline Drew & 424 & 22.2 & 20.3 & 146 & -0.7 & 343 & 107 \\
\hline Faulkner & 1169 & 24.9 & 9.0 & 228 & -6.9 & 195 & 141 \\
\hline Garland & 372 & 39.0 & 1.3 & 40 & -15.8 & 107 & 16 \\
\hline Grant & 255 & 28.6 & 2.7 & 35 & -1.2 & 138 & 17 \\
\hline Hot Spring & 512 & 32.6 & 4.9 & 72 & -8.2 & 141 & 32 \\
\hline Jefferson & 497 & 29.8 & 35.0 & 296 & -10.3 & 595 & 255 \\
\hline Lincoln & 420 & 21.4 & 29.0 & 218 & -1.7 & 520 & 173 \\
\hline Lonoke & 984 & 23.2 & 29.7 & 415 & -1.1 & 422 & 341 \\
\hline Monroe & 369 & 9.5 & 45.8 & 235 & -0.1 & 638 & 204 \\
\hline Ouachita & 259 & 34.4 & 7.3 & 41 & -20.3 & 160 & 20 \\
\hline Perry & 381 & 27.3 & 5.8 & 65 & -13.3 & 170 & 38 \\
\hline Phillips & 544 & 22.4 & 37.5 & 365 & 3.2 & 671 & 336 \\
\hline Prairie & 489 & 10.6 & 45.0 & 301 & -8.3 & 616 & 259 \\
\hline Pulaski & 529 & 37.6 & 12.1 & 147 & 8.5 & 277 & 106 \\
\hline Saline & 421 & 39.9 & 4.3 & 59 & 0.7 & 140 & 26 \\
\hline White & 1651 & 21.4 & 11.8 & 406 & -0.4 & 246 & 287 \\
\hline Woodruff & 325 & 12.9 & 51.1 & 271 & -7.3 & 833 & 243 \\
\hline
\end{tabular}

Sounce: U.S. Department of Commerce, County and Ciry Data Book, computer data file, U.S. Bureau of the Census, Washington, D.C., 1986. 


\section{B5 CULTURAL, ARCHAEOLOGICAL, AND HISTORIC RESOURCES}

The area around Pine Bluff was settled sometime prior to 1819 by individuals and families moving up river from the Post of Arkansas. Pine Bluff is one of the oldest white settlements in Arkansas. The first white settler was Joseph Bonne, a Frenchman, who started a trading post on the high bluffs about 1820 . Jefferson County was created in 1829. A settlement known as Mount Marie had grown up around Bonne's trading post, and in 1832 the settlement was renamed Pine Bluff. In the same year, John E Graham, an engineer and surveyor, designed a town consisting of 45 blocks and a court square. It was incorporated on Jan. 10, 1839 (Federal Highway Administration 1988). Old Town Pine Bluff, located near the downtown area of Pine Bluff, contains numerous homes or sites listed on the National Register of Historic Places (Greater Pine Bluff Chamber of Commerce 1989).

A 1985 review of the existing data concerning the physical setting and the cultural environment of the Pine Bluff Arsenal, including previous archaeological investigations and known sites in the arsenal surroundings, revealed that the facility contains known prehistoric archaeological sites and early historic homestead sites (Heartfield et al. 1985). Further, archival research has revealed that the arsenal property has a very high potential for unrecorded historic sites such as early 1900 s homes and farmsteads. Nine active historic cemeteries also are present.

No federally recognized Indian lands are located within $100 \mathrm{~km}$ (62 miles) of PBA (Environmental Protection Agency 1989). The Arkansas State Historic Preservation Officer was contacted for a listing of properties of architectural, historical, or archaeological significance within the $100-\mathrm{km}$ zone. The results of that inquiry are presented in Table B.14.

\section{B.6 ECONOMY AND INFRASTRUCTURE}

Data on resources included in this section are relevant to assess socioeconomic impacts resulting from project-induced growth that may occur during construction and incident-free operations of the demilitarization plant or from the cumulative effects of other projects in the community. Some of the data related to population, land use, health care, schools, and historical sites were discussed in earlier sections. Additionally required data primarily concern the economic base and public service infrastructure. Some data, such as information concerning police and fire protection and transportation, are also necessary for emergency preparedness.

The presentation of data for population-related impacts focuses on the communities in which workers might be expected to locate, particularly those in Jefferson and Grant counties. If available, data were presented for a $50-\mathrm{km}(31-\mathrm{mile})$ zone that represents a reasonable commuting distance for many workers.

Employment trends in counties within $50 \mathrm{~km}$ ( 31 miles) are shown in Table B.15. The civilian labor force in the area totaled more than 325,000 in May 1989, with an overall unemployment rate of $7.2 \%$. Table B.16 shows data on estimated personal 


\section{B-32}

Table B.14. Archreological and historic sites located within the PAZ and $100 \mathrm{~km}$ (62 miles) of PBA

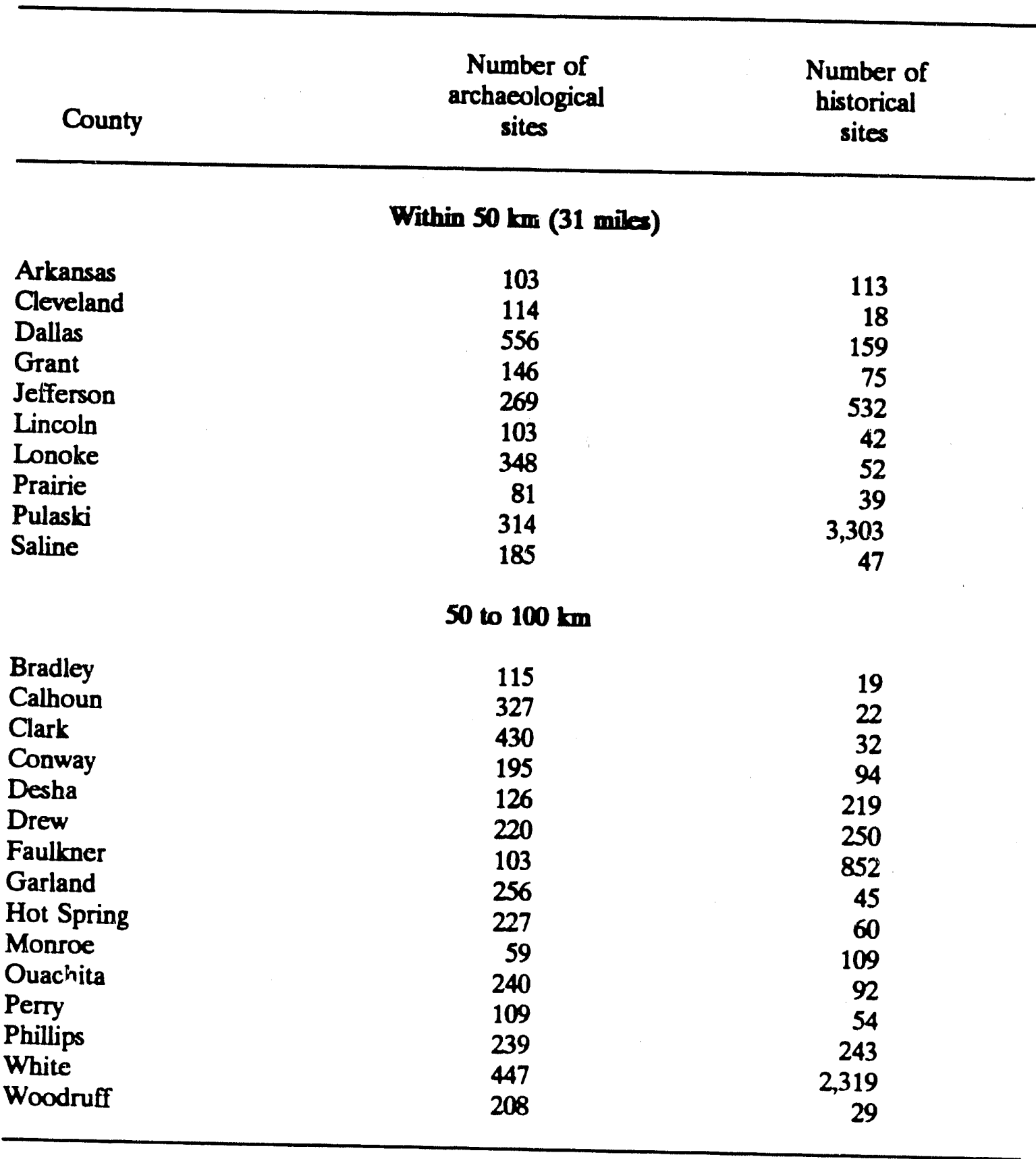

Source: C. Buford, State Historic Preservation Officer, Arkansas Historic Preservation Program, Little Rock, Ark, ketter to L W. Rickert, Oak Ridge National Laboratory, Sept. 20, 1989. 
Table B.15. Employment trends in the civilian labor force in counties within the 50-km (31-mile) zone of PBA

\begin{tabular}{lccc}
\hline & $\begin{array}{c}\text { Civilian } \\
\text { labor } \\
\text { force, } \\
\text { May 1989 }\end{array}$ & $\begin{array}{c}\text { Unemployment, } \\
\text { May 1989 }\end{array}$ & $\begin{array}{c}\text { Unemployment } \\
\text { rate, } \\
\text { May 1989 } \\
(\%)\end{array}$ \\
County & 11,075 & 575 & 5.2 \\
\hline Arkansas & 4,150 & 300 & 7.2 \\
Cleveland & 4,525 & 350 & 7.7 \\
Dallas & 7,225 & 525 & 7.3 \\
Grant & 39,075 & 3,375 & 8.6 \\
Jefferson & 4,750 & 425 & 8.9 \\
Lincoln & 18,775 & 1,650 & 8.8 \\
Lonoke & 5,275 & 500 & 6.8 \\
Prairie & 199,125 & 13,475 & 6.8 \\
Pulaski & 31,400 & 2,150 & 7.2 \\
Saline & & & \\
\multicolumn{1}{c}{ Total } & 325,375 & 23,325 & \\
\hline
\end{tabular}

"Average unemployment rate during May 1989.

Source: Artansas Employment Security Division, Labor Market Information for Arkansas Counries, County Summary for May, Labor Market Information Section, Little Rock, Art., June 29, 1989. 
Table B.16. Perconal income and carnings within $50 \mathrm{~km}$ (31 miles) of PBA

\begin{tabular}{|c|c|c|c|c|}
\hline County & $\begin{array}{c}\text { Personal } \\
\text { income } \\
1984 \\
\text { (\$ million) }\end{array}$ & $\begin{array}{c}\text { Personal } \\
\text { income } \\
\% \text { change } \\
1980-84 \\
(\$ \text { million })\end{array}$ & $\begin{array}{l}\text { Personal } \\
\text { income } \\
\text { per } \\
\text { capita } \\
(1984 \$)\end{array}$ & $\begin{array}{c}\text { Personal } \\
\text { income } \\
\text { earnings } \\
1984 \\
\text { ( } \$ \text { million) }\end{array}$ \\
\hline $\begin{array}{l}\text { Arkansas } \\
\text { Cleveland } \\
\text { Dallas } \\
\text { Grant } \\
\text { Jefferson } \\
\text { Lincoln } \\
\text { Lonoke } \\
\text { Prairie } \\
\text { Pulaski } \\
\text { Saline }\end{array}$ & $\begin{array}{r}255.1 \\
65.8 \\
90.6 \\
121.6 \\
865.0 \\
89.7 \\
338.6 \\
84.4 \\
4427.8 \\
555.8\end{array}$ & $\begin{array}{l}36.2 \\
44.1 \\
35.1 \\
35.9 \\
25.3 \\
36.7 \\
41.5 \\
36.2 \\
39.6 \\
37.8\end{array}$ & $\begin{array}{r}10,685 \\
8,147 \\
8,295 \\
9,240 \\
9,550 \\
6,834 \\
9,222 \\
8,373 \\
12,630 \\
9,987\end{array}$ & $\begin{array}{r}165.2 \\
18.9 \\
58.4 \\
42.6 \\
646.4 \\
42.8 \\
129.3 \\
41.1 \\
4006.9 \\
211.2\end{array}$ \\
\hline
\end{tabular}
Source: U.S. Department of Commerce, County and City Data Book, computer data file, U.S. Bureau of
the Census, Washington, D.C., 1986. 
income and earnings for the same area from 1980 to 1984. Estimated earnings and per capita personal income were highest in Pulaski County in 1984. Gross sales receipts in Jefferson County for CY 1987 totaled $\$ 996$ million (Arkansas State Data Center 1989). The economy of Pine Bluff is based on agriculture and the railroad. The difficulties that have been experienced nationally in agriculture have also seriously affected the local economy and all of eastern Arkansas. The trends in the 1980s toward the consolidation of small farms, conversion or idling of land, and frequent bankruptcy among farmers have had a negative influence on the local economy. Additionally, the acquisition of the Cotton Belt Railroad by Southern Pacific and the subsequent movement of key personnel to jobs in Missouri and Kansas also have had a negative effect on local employment. However, since 1985, the area's economic outlook has improved with the International Paper Company's investment of $\$ 250$ million for a new plant and with a series of smaller business and industrial expansions. Business development in Pine Bluff since 1985 suggests a transition to a service-based economy with a strong base remaining in heavy manufacturing (Federal Highway Administration 1988).

In December 1989, Tyson Foods, Inc., announced plans to build a \$30 million poultry processing plant in Pine Bluff's Jefferson Industrial Park that will employ 1016 people (Arkansas Gazette December 17, 1989). Tyson already has one processing plant in Pine Bluff that employs 427. The new plant, which will complete the first phase of its construction in one year, will make Tyson Foods the largest private employer in Jefferson County. Tyson representatives say that hiring will be done locally. Additionally, expansion is expected at more than 200 southeast Arkansas farms that supply chickens for Tyson (Arkansas Gazette December 17, 1989). In May 1989, a European company that produces steel cord for radial automobile tires announced plans to locate its first North American manufacturing plant in Pine Bluff, thus creating as many as 450 new jobs in the Pine Bluff area; construction is expected to begin soon on the $36,000-\mathrm{m}^{2}\left(400,000-\mathrm{ft}^{2}\right)$, $\$ 70$-million facility, and production is scheduled to begin in late 1990. The International Paper Company expects to suspend production of coated er because of an oversupply, temporarily laying off 150 to 200 workers (Arkansas Employment Security Division 1989). A project recently approved by the Senate Appropriations Committee and currently under review by the full Senate is a new biotechnology center at the National Center for Toxicological Research, which borders PBA to the north. Of the \$2.8 million proposed for the project in FY 1990, the majority would be used for engineering and design work. The center also plans to upgrade its water treatment facility, which represents $\$ 300,000$ of the total (Arkansas Gazette July 26, 1989). Additionally, plans are being made for a distribution facility for Southern Pacific that would provide $\mathbf{4 0 0}$ to 500 new jobs in Pine Bluff (J. Hawkins, Principal Planner, City of Pine Bluff, Ark, personal communication to J. Morrissey, SAIC, Oak Ridge, Tenn., July 24, 1989).

Census data for 1980 and estimates for 1986 on housing in the $50-\mathrm{km}$ (31-mile) area are provided in Table B.17. In 1980, there were approximately 33,00J housing units in Jefferson County, with a vacancy rate of $7.4 \%$. More recent housing surveys were not available within the local area. However, city planning officials estimate that 
Table B.17. Housing and vacancy summary for countics within a 50-km (31-mile) radius of PBA

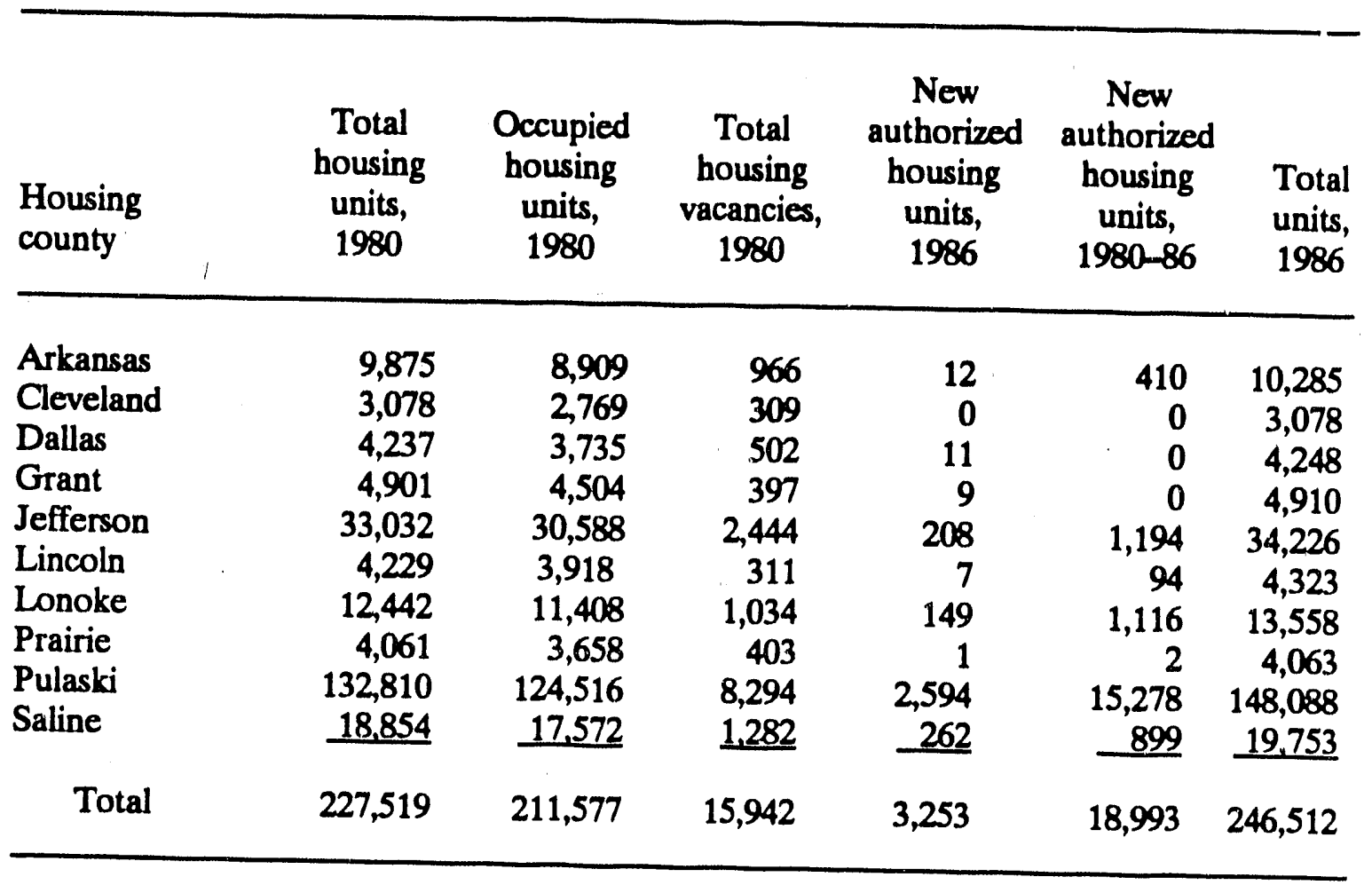
Source: U.S. Department of Commerce, County and City Data Book, computer data file, U.S. Bureau of
the Census, Washington, D.C., 1986. 
there are approximately 700 houses on the market in Pine Bluff (J. Hawkins, Principal Planner, City of Pine Bluff, Ark, personal communication to J. Morrissey, SAIC, Oak Ridge, Tenn., July 23, 1989). Twenty-seven new dwelling units were built in White Hall in 1988 (A. Skinner, Southeast Arkansas Economic Development District, Inc., Pine Bluff, Ark., personal communication to J. Morrissey, SAIC, Oak Ridge, Tenn., Jan. 31, 1990).

Data on law enforcement and fire protection in Jefferson and Grant counties (roughly equivalent to the IRZ) are shown in Tables B.18 and B.19 respectively. Law enforcement staffing is totaled by county, showing the ratio of officers to 1000 citizens. Fire protection personnel and equipment are shown by individual jurisdictions in the counties. Emergency personnel at PBA include the Nuclear Biological Chemical (NBC) team, 27; security police, 141; and fire department, 23. Coordination agreements are in effect between PBA and the following jurisdictions: City of Pine Bluff, City of White Hall, Arkansas State Police Department, Jefferson County Sheriffs Department, Pine Bluff Police Department, White Hall Police Department, Jefferson Regional Medical Center, and the Pine Bluff-Jefferson County Health Department (Lt. C. Sachs, PBA, Ark. personal communication to J. Morrissey, SAIC, Oak Ridge, Tenn., June 23, 1989).

Utilities in the towns most likely to be affected by population increases (Pine Bluff, White Hall, and Sheridan) include municipal water and wastewater services, natural gas, and electricity. All of the study area is supplied with gas and electricity by Arkansas-Louisiana Gas Company and Arkansas Power \& Light, respectively, which are large utilities that serve the entire state. Municipal sewage collection and treatment systems in Pine Bluff, White Hall, and Sheridan are reported to be adequate. The city of White Hall hopes to build a new sewage treatment facility, pending the outcome of a referendum (Southeast Arkansas Economic Development District, Inc., 1989; Greater Pine Bluff Chamber of Commerce 1989; T. Ashcraft, Mayor, City of White Hall, Ark. personal communication to S. Schexnayder, Oak Ridge National Laboratory, Oak Ridge, Tenn. June 21, 1989; J. Hawkins, Principal Planner, city of Pine Bluff, Ark, personal communication to J. Morrissey, SAIC, Oak Ridge, Tenn., July 24, 1989). Table B.20 shows capacity and use rates for the municipal water systems in the three towns. All water systems are adequate to meet increased demand in the foreseeable future. The water supply for the area is obtained from the Sparta Sands Aquifer. The water supply has been determined to be adequate through 2020 , based on population projections. None of the area water associations is experiencing system capacity problems (J. Hawkins, Principal Planner, city of Pine Bluff, Ark, personal communication to J. Morrissey, SAIC, Oak Ridge, Tenn., July 24, 1989).

Major highways serving the Jefferson County area are U.S. routes 65,79 , and 270 and State routes $15,54,81,88,104$, and 365 . The distance to an interstate interchange (I-30 and I-40) is $60 \mathrm{~km}$ (38 miles) north from Pine Bluff via divided 4-lane U.S. 65. Main highways in Grant County are U.S. routes 167 and 270 and State routes 35 and 46 . Access to I-30 from Sheridan is 25 miles north.

Airports in the vicinity include Grider Field in Pine Bluff, the Sheridan-Grant County Airport, and the Little Rock Airport. Grider Field is a municipal facility with a 6000-by-150-foot lighted asphalt runway and is served by Jet South. Sheridan-Grant 


\section{B-38}

Table B.18. Law enforcement staffing in Jefferson and Grant counties

\begin{tabular}{|c|c|c|c|c|}
\hline Jurisdiction & $\begin{array}{c}\text { Full-time } \\
\text { officers }\end{array}$ & $\begin{array}{l}\text { Reserve } \\
\text { officers }\end{array}$ & $\begin{array}{l}\text { County } \\
\text { population }\end{array}$ & $\begin{array}{c}\text { Ratio } \\
\text { (officers/ } \\
1000 \text { people) }\end{array}$ \\
\hline Jefferson County Sheriff & 31 & 40 & & \\
\hline Pine Bluff Police & 116 & $\mathbf{0}$ & & \\
\hline White Hall Police & 4 & 10 & & \\
\hline Redfield Police & 2 & 0 & & \\
\hline Altheimer Police & $\underline{3}$ & $\underline{0}$ & & \\
\hline County total & 156 & 50 & 90,000 & 1.7 \\
\hline Grant County Sheriff & 9 & 25 & & \\
\hline $\begin{array}{l}\text { Sheridan Police (within } \\
\text { Grant County) }\end{array}$ & $\underline{5}$ & 10 & & \\
\hline County total & 14 & 35 & 13,500 & 1.0 \\
\hline
\end{tabular}

Total number of officers (county and city, excluding reserves) in the county divided by county population, multiplied by 1000 .

The generally accepted standard for adequate $\mathrm{l}$ iw enforcement is a ratio of one officer per 1000 population (B. Brown, Arkansas State Law Enforcement Standards, Litte Rock, Ark, personal communication to S. Schexnayder, Oak Ridge National Laboratory, Oak Ridge, Tenn., July 20, 1989).

Sounces: Jacobs Engineering Group, Inc., Jefferson County Emergency Response Plan for Chemical Accidents at Pine Bluff Arsenal; Census Ciry and County Data Book, 1986, computer data file, 1989. 
Table B.19. Fire department perconnel and equipment in Jefferion and Grant counties

\begin{tabular}{|c|c|c|c|}
\hline Jurisdiction & $\begin{array}{c}\text { Paid } \\
\text { personnel }\end{array}$ & Volunteers & $\begin{array}{c}\text { Total } \\
\text { vehicles }\end{array}$ \\
\hline \multicolumn{4}{|l|}{ Jefferson County } \\
\hline Jefferson County Mounted Patrol & 22 & 0 & $3^{b}$ \\
\hline Jefferson County Rescue \& Patrol & 26 & $\mathbf{0}$ & $8^{c}$ \\
\hline Pine Bluff Fire Department & 92 & $\mathbf{0}$ & 13 \\
\hline Redfield Fire Department & $\mathbf{0}$ & 33 & 9 \\
\hline White Hall Fire Department & $\mathbf{0}$ & 26 & $4^{d}$ \\
\hline Wright Pastoria Fire Department & $\mathbf{0}$ & 10 & 3 \\
\hline SE Jefferson County Fire Department & $\mathbf{0}$ & 29 & $9^{d}$ \\
\hline Sherill Fire Department & $\mathbf{0}$ & 13 & 1 \\
\hline Tucker Fire Department & $\mathbf{0}$ & 6 & 3 \\
\hline Altheimer Fire Department & $\mathbf{0}$ & 20 & 2 \\
\hline Hardin Fire Department & 0 & 30 & $7^{d}$ \\
\hline Highway 15 South Fire Department & $\mathbf{0}$ & 30 & $4^{d}$ \\
\hline Watson Chapel & 0 & 22 & 8 \\
\hline Forestry Service & $37^{\prime}$ & $\mathbf{0}$ & $10^{c}$ \\
\hline Wabbaseka Fire Department & $\mathbf{0}$ & 23 & 3 \\
\hline Humphrey Fire Department & $\mathbf{0}$ & 10 & 21 \\
\hline \multicolumn{4}{|l|}{ Grant County } \\
\hline Grapevine Fire Department & 0 & 25 & 3 \\
\hline Sheridan Fire Department & $\mathbf{0}$ & 17 & 3 \\
\hline Calvert Township Fire Department & $\mathbf{0}$ & 19 & 1 \\
\hline Center Grove Fire Department & $\mathbf{0}$ & 21 & 4 \\
\hline Forestry Service & 6 & 0 & $2^{c}$ \\
\hline Tull Fire Department & $\mathbf{0}$ & 16 & 3 \\
\hline Poyen Fire Department & 0 & 20 & 3 \\
\hline Palestine Fire Department & $\mathbf{0}$ & 10 & 0 \\
\hline Cane Creek Fire Department & $\mathbf{0}$ & 15 & 3 \\
\hline Leola Fire Department & 0 & 10 & 1 \\
\hline
\end{tabular}

Includes rescue trucks, four-wheel drive vehicles, pumpers, and tankers.

'Also have one or more large river boats.

"Bulldozers.

¿Also have two or more small boats.

Forestry Service personnel and equipment avallable to county judge for 24 hours or indefinitely in state of emergency.

'Two in :efferson County; 35 can be called in from district.

Sources: Jacobs Engineering Group, Inc., Jefferson County Emergency Response Plan for Chemical Accidents at Pine Bluff Arsenal, 1989; Census City and County Data Book, 1986, computer data file. 
Table B.20. City water system use rates and capacity in Jefferion and Grant counties, 1989

\begin{tabular}{|c|c|c|c|c|c|}
\hline $\begin{array}{l}\text { Municipal } \\
\text { system }\end{array}$ & $\begin{array}{l}\text { Capacity } \\
\text { (Mgd) }\end{array}$ & $\begin{array}{l}\text { Average use } \\
\text { (Mgd) }\end{array}$ & $\begin{array}{l}\text { Peak use } \\
\text { (Mgd) }\end{array}$ & Source & $\begin{array}{l}\text { Persons } \\
\text { served }\end{array}$ \\
\hline \multicolumn{6}{|l|}{ Pine Bluff } \\
\hline $\begin{array}{l}\text { General Waterworles } \\
\text { Hardin Water Association } \\
\text { Ladd Water Users } \\
\text { Watson Chapel Water }\end{array}$ & $\begin{array}{l}14.5 \\
N^{b} \\
0.7\end{array}$ & $\begin{array}{r}8.5 \\
0.25 \\
0.45\end{array}$ & $\begin{array}{l}12.5 \\
\text { NA } \\
0.65\end{array}$ & $\begin{array}{l}9 \text { wells } \\
2 \text { wells } \\
\text { NA }\end{array}$ & $\begin{array}{r}21,000 \\
1,664 \\
12,000\end{array}$ \\
\hline Association & 0.9 & 0.5 & 0.75 & NA & 7,300 \\
\hline City of White Hall & 0.2 & $>70.1$ & $\mathbf{N A}$ & $\mathbf{N A}$ & 3,357 \\
\hline City of Sheridan & 4 & 1.5 & NA & 5 wells & 3,000 \\
\hline
\end{tabular}

'Mgd = million gallons per day

bNA $=$ not avallabte Sounces: T. Ashcraft, Mayor, City of White Hall, personal communication to S. Schexnayder, Oak Ridge
National Laboratory, Oak Ridge, Tenn., June 21, 1989; Greater Pine Bluff Chamber of Commerce, Pine
Bluff/Jefferson County Profile, Pine Bluff, Ark. 1989; Southeast Artansas Bconomic Devepments Bluff/Jefferson Counny Profile, Pine Bluff, Ark., 1989; Southeast Arkansas Bconomic Development District, Inc., Community Profile, Pine Bluff, Ark, 1989; M. Hanes, Ladd Water Users, Pine Bluff, Ark, personal Watson Chapel Water Association, Pine Bluff, Art penal Laboratory, Oak Ridge, Tenn., July 20, 1989; B. Ross, National Laboratory, Oak Ridge, Tenn Bluff, Ark, personal communication to S. Schexnayder, Oak Ridge personal communication to S. Schernayder, Oat Ridge Rathodes, Hardin Water Association, Pine Bluff, Ark., 
County Airport is located $5 \mathrm{~km}$ (3 miles) east of Sheridan and has a 3000-ft hard-surface runway. The Little Rock Airport, approximately $65 \mathrm{~km}$ (40 miles) from Pine Bluff, provides scheduled commercial service by a number of major airlines.

Rail service in Jefferson and Grant counties is provided by St. Louis Southwestern Railroad (Cotton Belt) and the Missouri Pacific Railroad. Navigable waterways in the area are provided by the Arkansas River Navigation System, which includes a 9-ft channel. The Port of Pine Bluff is a 20-acre, barge-rail truck terminal offering barge loading, unloading, and material storage. Barge service is provided by 16 certified common carrier barge lines and 5 contract carriers. The terminal is a focal point for waterborne commerce in the Pine Bluff area (Greater Pine Bluff Chamber of Commerce 1989; Southeast Arkansas Economic Development District, Inc. 1989). 


\section{REFERENCES FOR APPENDIX B}

Arkansas Employment Security Division 1989. Labor Market Information for Arkansas Counties, County Summary for May, June 29, 1989, Labor Market Information Section, Little Rock, Ark

The Arkansas Gazette 1989. "Appropriations Committee Approves Arkansas Projects," July 26.

Arkansas State Data Center 1989. Arkansas Statistical Abstract 1989, Center for Research and Public Policy, Research and Public Service, University of Arkansas at Little Rock, Little Rock, Ark.

City of Pine Bluff Planning Department 1984. Land Use Plan, Pine Bluff, Ark.

Environmental Protection Agency 1989. Office of Federal Activities, U.S. Indian Tribes, Alaskan Villages and Related Indian Files, Washington, D.C.

Federal Highway Administration 1988. Final Environmental Impact Statement, U.S. Highway 65 Bypass, Arkansas State Highway and Transportation Department, Little Rock, Ark.

Greater Pine Bluff Chamber of Commerce 1989. Pine Bluff Jefferson County Profile, Pine Bluff, Ark.

Heartfield, L. et al. 1985. An Anchaeological Overview and Management Plan for the Pine Bluff Arsenal, Jefferson County, Arkansas, under contract CS-5000-3-0771 with the National Park Service, U.S. Department of the Interior, Atlanta, Ga., for the U.S. Army Materiel Development and Readiness Command, Heartfield, Price and Greene, Inc., Monroe, La.

Jacobs Engineering Group, Inc. 1989a. Updated Site Assessment for Pine Bluff Arsenal and Adjarient Jurisdictions.

Jacobs Engineering Group, Inc. 1989b. Jefferson County Emergency Response Plan for Chemical Accidents at Pine Bluff Arsenal.

Lehman, A. E. 1987a, Guide to Four-Year Colleges 1987, 17th edition, Peterson's Guides, Princeton, N.J.

Southeast Arkansas Economic Development District, Inc. 1989. Community Profile, Pine Bluff, Ark. 


\section{APPENDIX C \\ DESCRIPTION OF STIE-SPECIFIC SURFACE WATER AND GROUNDWATER RESOURCES}

This appendix describes site-specific surface water and groundwater regimes in the vicinity of Pine Bluff Arsenal (PBA). Pathways are identified along which contaminants could migrate if discharged into the hydrosphere. Water resources that could be affected by the contaminants are identified. Surface water pathways are determined by a consideration of topography, while groundwater pathways require an evaluation of geologic structure, stratigraphy, and geohydrologic conditions. Water quality, stream flowrates, well locations, consumption, and potential yield determine which water resources are important. Evaluation of the site for the proposed disposal facility at PBA requires an identification of on-site and off-site pathways and resources that could be affected by accidental spills. No liquid discharges enter the hydrosphere during normal operation of the plant.

\section{C.1 SURFACE WATER}

PBA is located in a section of the United States typified by sluggish meandering streams, abandoned meanders, and oxbow lakes. The gentle slope of the terrain, coupled with the slow flow of streams, provides for numerous wetland areas, or bayous. Ninety-five watersheds have been identified in the surface water regime of Jefferson County (Southeast Arkansas Regional Planning Commission 1980). Watersheds near PBA include Bayou Bartholomew, Bayou Meto, Plum Bayou, the Saline River, and the Caney Bayou-Arkansas River system. Bayou Bartholomew downstream from PBA has been designated a high-priority waterway by the Arkansas Natural and Scenic Rivers Commission (Southeast Arkansas Regional Planning Commission 1981).

The Caney Bayou-Arkansas River watershed completely surrounds PBA (see Fig. C.1). Surface drainage from PBA ultimately flows into the Arkansas River. Caney Bayou and the Arkansas River form the southwestern and northeastern boundaries of PBA, respectively. Lock and dam numbers 4 and 5, located east of Pine Bluff and northwest of PBA, respectively, regulate the flow of the Arkansas River near the arsenal. The flow of the Arkansas River at Little Rock, located $48 \mathrm{~km}$ (30 miles) northwest of PBA, equals or exceeds $570 \mathrm{~m}^{3} / \mathrm{s}\left(20,000 \mathrm{ft}^{3} / \mathrm{s}\right) 50 \%$ of the time (Hines 1965).

Two bayous and six creeks drain PBA (see Fig. C.2) in a southeasterly direction ultimately diccharging into the Arkansas River (Pinkham et al. 1975). Eastwood Bayou, 


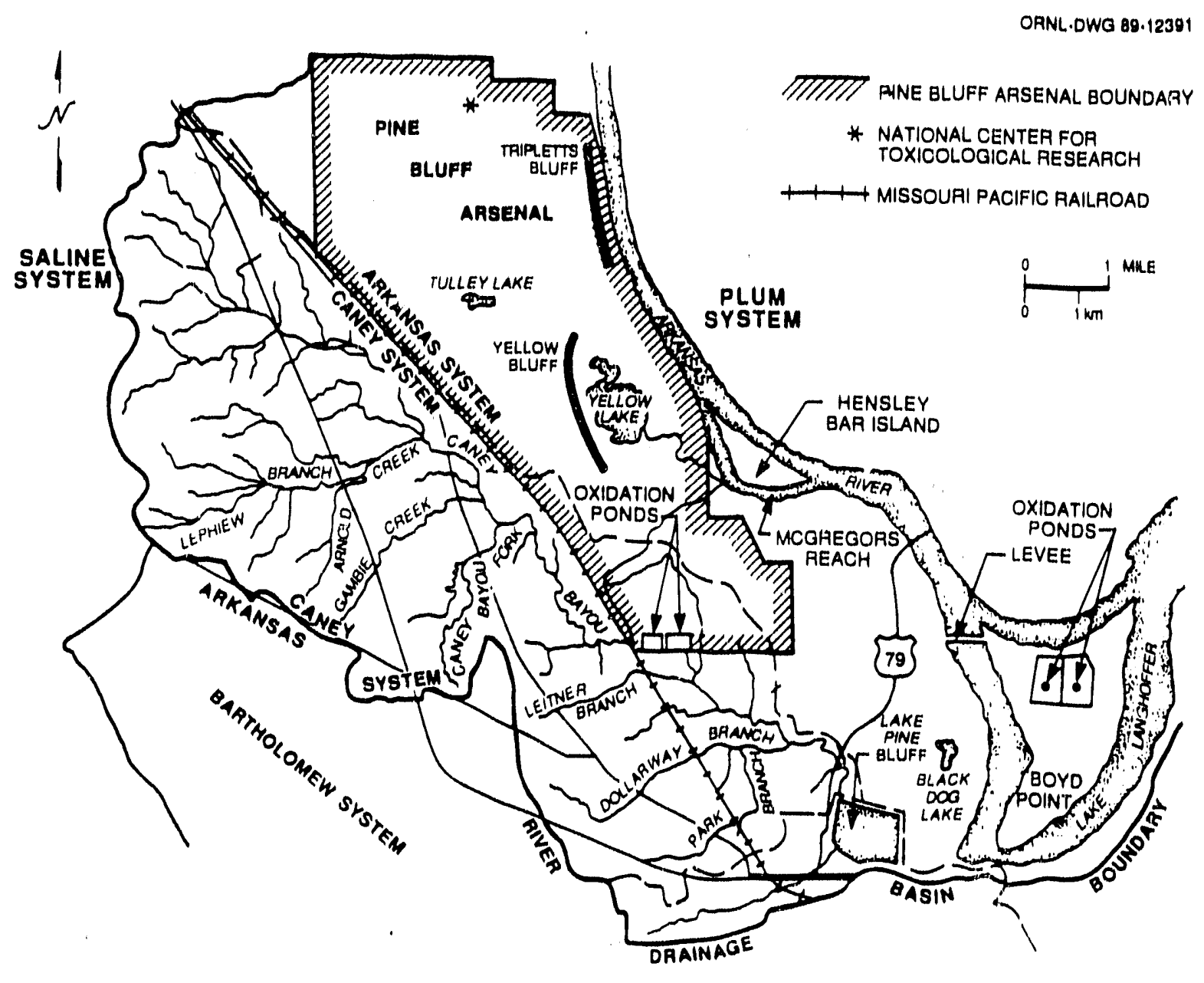

Fig. C.1. The Caney Bayou-Arkansas River drainage basin immediately surrounding Pine Bluff Arsenal. Source: Southeast Arkansas Regional Planning Commission, Natural Resources of Jefferson County, Pine Bluff, Ark., 1980. 


\section{C-3}

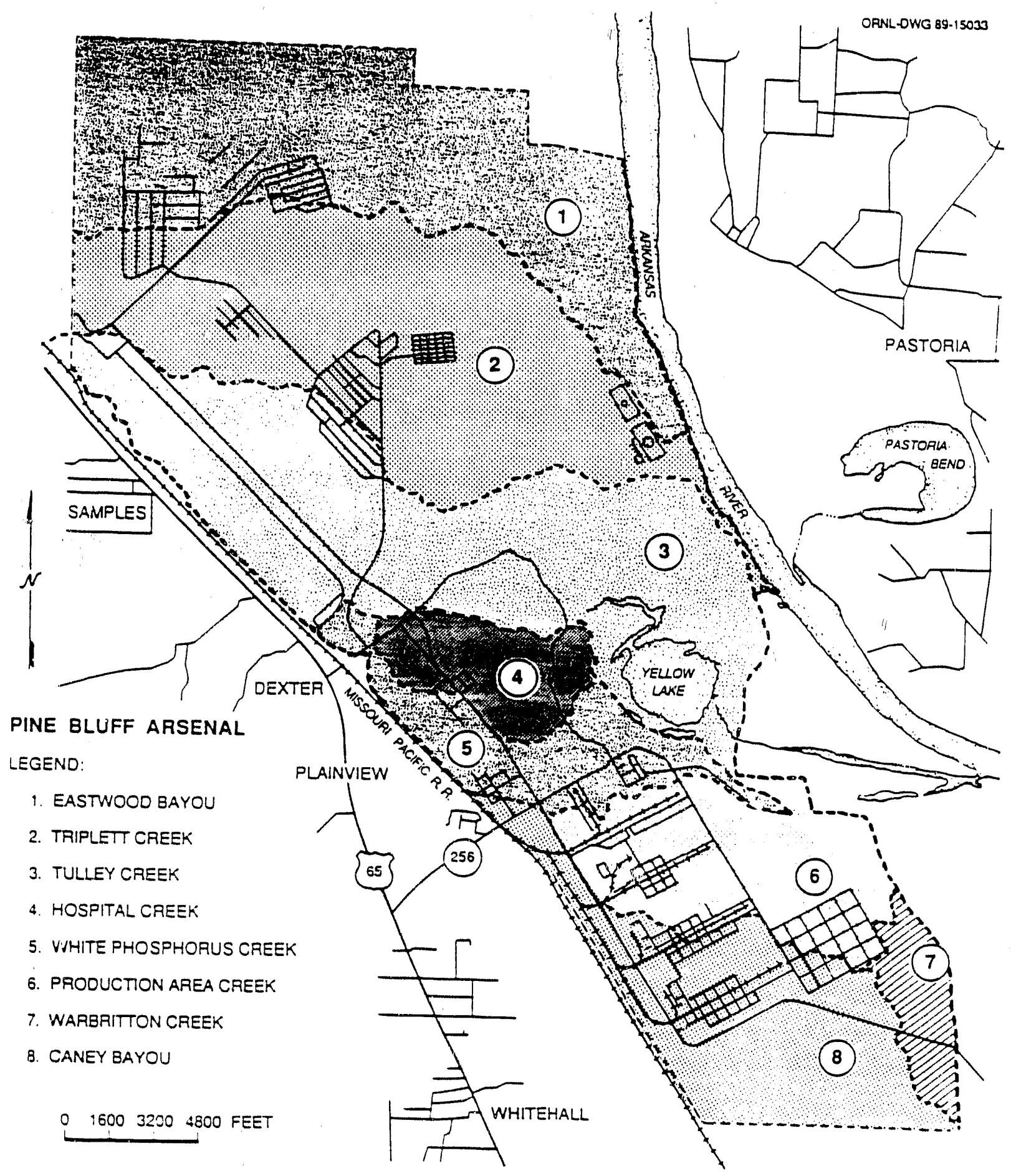

Fig. C.2 Drainage areas of U.S. Army Pine Bluff Arsenal, Pine Bluff, Arkansas. Source: C. F. A Pinkham, et al., Preliminary Environmental Survey, Pine Bluff Arsenal, Pine Bluff, Arkansas, December 1972, Edgewood Arsenal Special Publication EB-SP74025, Department of the Army, Headquarters. Edgewood Arsenal. Aberdeen Prnving Ground, Md., 1975. 
which originates off-site on farmland and timberland, drains the northern part of the arsenal, including the old biological agent storage area and the National Center for Toxicological Research, before emptying into the Arkansas River. Triplett Creek, which discharges into the Arkansas River, drains the toxic storage yard, chemical manufacturing area, and storage depot. Triplett Creek has the largest drainage area of any creek on PBA.

Tulley, Hospital, and White Phosphorous creeks empty into Yellow Lake, which is located on the southeastern portion of PBA below Yellow Bluff. Yellow Lake was formed when an old meander of the Arkansas River was cut off by flooding some time after 1936 (U.S. Army 1986). The main channel of the river has been straightened by construction of the Hensley Bar Cutoff. Dikes and revetments along the shoreline prevent the river from reclaiming its original channel through McGregor's Reach (Southeast Arkansas Regional Planning Commission 1980). Discharges from Yellow Lake meander through swampy lowlands before entering this side channel of the Arkansas River. Tulley Creek and Tulley Lake, which comprise a man-made impoundment, drain part of the old chemical manufacturing area, the site of the old chlorine plant, and the storage depot. Hospital Creek drains the quarters, administration, and hospital areas. Runoff from the maintenance shop and white-phosphorous production areas enters White Phosphorous Creek.

Production Area Creek drains the bomb-storage and pyrotechnic-production areas, and receives treated discharge from the sanitary and industrial wastewater treatment plants. These discharges are regulated by NPDES permit D0001678. This creek meanders through the swampy lowlands, joins the discharge stream from Yellow Lake, and enters the Arkansas River along McGregor's Reach. Warbritton Creek and Caney Bayou drain the production and bomb-storage areas at the south end of the arsenal and empty into the Arkansas River after traveling through several small communities and northern Pine Bluff (U.S. Army 1986).

Many small lakes and ponds are present on PBA (see Table C.1). The southeastern boundary of PBA is adjacent to the Pine Bluff sewage oxidation lagoons, Black Dog Lake, and Lake Pine Bluff [a 202-ha (500-acre) impoundment]. Black Dog Lake receives most of its water from Caney Bayou and links the bayou to the Arkansas River by way of Lake Langhofer, a slack-water harbor in northeastern Pine Bluff. The primary source of water entering Lake Pine Bluff is Brumps Bayou, although a sluice gate connects the lake directly to Caney Bayou. No known springs on PBA discharge groundwater to the surface water regime.

No developed areas within PBA are subject to flooding (Pinkham et al. 1975; U.S. Army 1975). Tripletts and Yellow bluffs, which extend along the southwestern bank of the Arkansas River and form the northeasternmost limits of the floodplain, are natural barriers that prevent the arsenal from flooding. Yellow Lake and the lowlands adjacent to McGregor's Reach are subject to periodic flooding by the Arkansas River. Minor flooding has occurred on PBA during periods of excessive precipitat,on. Several poncis and drainage channels have overflowed during such rainfalls and caused siight damage. 
Table C.1. Lint of ponds on Pine Bluff Arzenal

\begin{tabular}{lc}
\hline Name ci pond & Surface area [ha (acres)] \\
\hline Yellow Lake & $80.9(200)$ \\
Tulley Lake & $14.2(35)$ \\
Duck reservoirs (2) & $8.1(20)$ total \\
Clear Pond & $0.8(2)$ \\
Dilly Pond & $1.2(3)$ \\
Gibson Pond & $0.8(2)$ \\
Big Transportation Pond & $0.8(2)$ \\
Big Area 3 Pond & $1.6(4)$ \\
Grassy Pond & $1.2(3)$ \\
Arkla Pond & $0.8(2)$ \\
Bomb Storage Pond & $0.4(1)$ \\
Little Transportation Pond & $0.4(1)$ \\
Horseshoe Pond & $0.4(1)$ \\
Dexter Pond & $0.4(1)$ \\
Bunler Pond & $0.4(1)$ \\
King P'ond & $0.6(1)$ \\
Thompson Pond & $0.4(1)$ \\
Staff Pond & $0.8(2)$ \\
Total surface area & \\
\hline
\end{tabular}

Source: U.S. Army, Pine Bluff Arsenal Installation Hazandous Waste Management Plan, AR 420-47, Appendix B, p. 5, Environmental Management Office, Pine Bluff Arsenal, Pine Bluff, Ark., December 1986.

Water in the Arkansas River is moderately hard and of fair quality (Southeast Arkansas Regional Planning Commission 1980). Biochemical oxygen demand and dissolved oxygen are high. Chloride content is relatively high (Sniegocki and Bedinger 1969). A major problem affecting water quality in the Arkansas River is the use of pesticides in this primarily agricultural region.

The water quality of Caney Bayou, Bayou Bartholomew, Brumps Bayou, and Black Dog Lake is generally poor (Southeast Arkansas Regional Planning Commission 1980). The dissolved oxygen level is low but phosphorous, total nitrogen, biochemical oxygen demand, and fecal bacteria levels are elevated. Contact recreation is potentially unsafe and in some places a public health hazard may exist. The water quality in Bayou Meto also is poor. Runoff from nearby agricultural areas has contaminated Bayou Meto with metals and pesticides. The water quality of Lake Pine Bluff has not been degraded 
by the discharge entering it from Brumps Bayou. Precipitation-induced runoff entering Lake Pine Bluff is sufficient to maintain good water quality.

The water quality of streams within PBA is fair, and the water quality of most lakes and ponds is good (Pinkham et al. 1975). White Phosphorous and Production Area creeks, as well as Yellow Lake are improving. Contaminants include the chlorinated pesticide DDT, its isomers and degradation products; elemental phosphorous, phosphates, and metals (U.S. Army 1988; Vol. 1, Sect. 3.25.4). The installation of pollution abatement fazilities, which began in 1980, has reduced the amount of contaminated runoff that now enters the aquatic environment at PBA. The two creeks and the lake are monitored through regular bioassays. No aquatic impacts are currently being detected, thus indicating that the major sources of pollution have been abated.

Twenty-two public-water-supply intakes are located downstream of PBA on the Mississippi River (U.S. Army 1988; Vol. 1, Section 3.2.5.4). None of these intakes withdraws surface water directly from the Arkansas River. Approximately $15 \%$ of the water consumed in Jefferson County is supplied by surface water (Holland 1987). Water usage is split almost equally between agriculture and production of electricity. No surface water supplies public water within Jefferson County (Southeast Arkansas Regional Planning Commission 1980). The water supplies for PBA and the city of Pine Bluff are obtained from groundwater (see Sect. C.2.2).

The expected quantity of wastewater discharged from the incineration facility is $114 \mathrm{~m}^{3} / \mathrm{d}(30,100 \mathrm{gal} / \mathrm{d})$ and consists entirely of effluent from bathroom, shower, and laundry facilities as well as laboratory-cleaning and monitoring devices (Forsgren-Perkins Engineering 1988). No process water or hazardous material of any type will be discharged into the wastewater system. Sanitary waste will be treated and used as process water. Liquid wastes from the incineration process will be concentrated in an evaporator, and the remaining salts then will be precipitated in a dryer. The resulting solids will be packaged and stored on-site prior to transportation to a regulated, off-site, hazardous waste disposal facility. No liquid effluents are discharged directly into the environment by the incineration process during normal operation.

\section{C2 GROUNDWATER}

\section{C21 Geology}

Jefferson County, Arkansas, is located in the Gulf Coastal Plain physiographic province (Jacobs Engineering Group 1987). In the vicinity of PBA, the Arkansas River divides the physiographic province into the West Gulf Coastal Plain to the southwest, and the Mississippi Alluvial Plain to the northeast (Southeast Arkansas Regional Planning Commission 1980). The landscape on the West Gulf Coastal Plain consists of rolling hills. The terrain on the Mississippi Alluvial Plain is flat.

Table C.2 summarizes the geologic and hydrologic properties of strata in Jefferson County. The stratigraphy is typical of Arkansas counties in the Gulf Coastal Plai 2, which are characterized by well-consolidated rocks that dip gently to the east and 
C-7

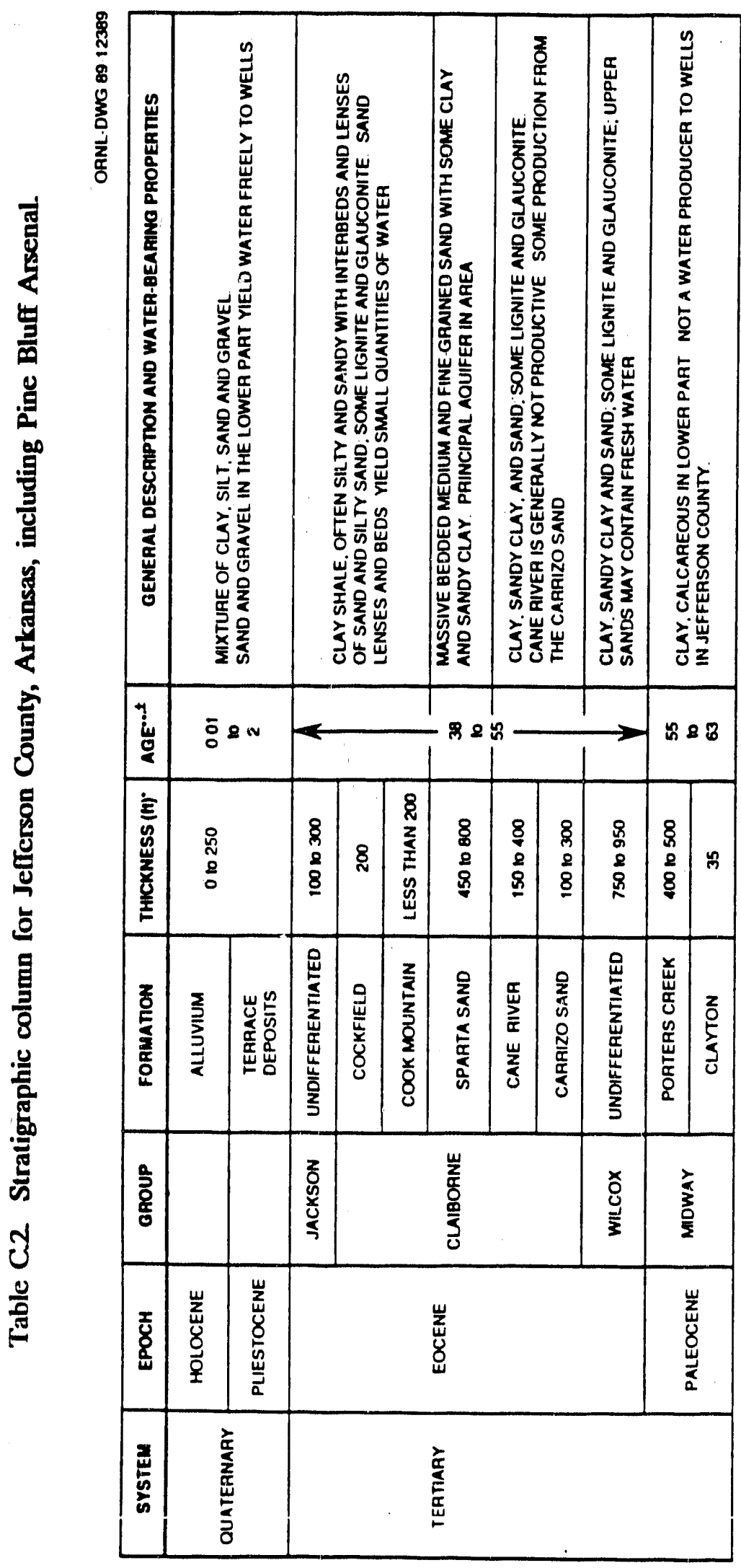
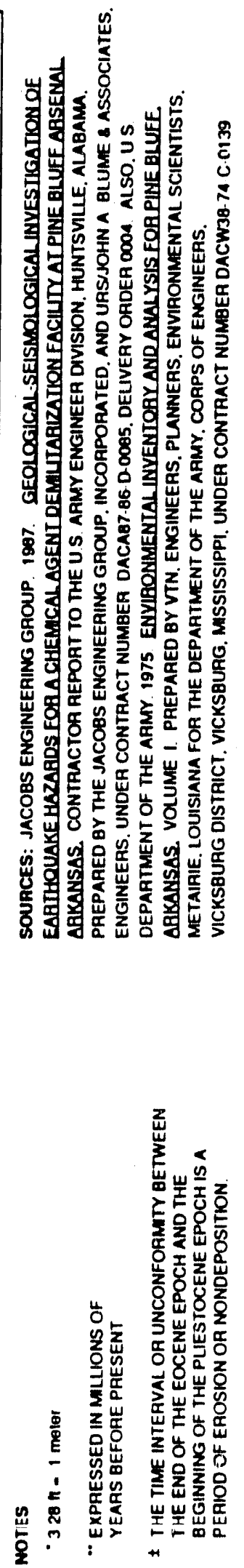
are unconformably overlain by nearly horizontal strata of unconsolidated material.

Approximately $840 \mathrm{~m}$ ( $2000 \mathrm{ft})$ of Tertiary and Quaternary sediments cover the bedrock in the western part of Jefferson County, while increasing in thickness to as much as $1680 \mathrm{~m}$ $(4000 \mathrm{ft})$ in the eastern portions of the county (U,S. Army 1975).

The surficial geology in the vicinity of PEA is displayed in Fig. C.3. Outcrops consist of Pleisiocene terrace (Qt) and Howntwo alluvial (Qal) deposits, as well as sediments of the Tertiary Jackson Group ( 4 in) / the Quaternary deposits vary in thickness

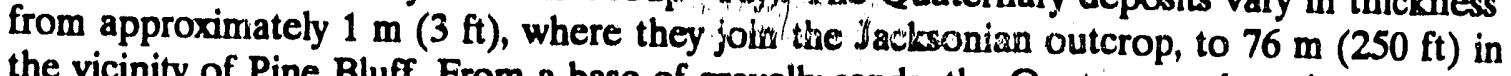
the vicinity of Pine Bluff. From a base of gravelly sands, the Quaternary deposits grade upward through a central section of sand overlain by silts and clays (U.S. Army 1975). The Jackson Group consists of a fairly even composition of marine sediments that includes clays, silty clays, and clayey sands overlain by silts and sands of continental origin (Jacobs Engineering Group 1987). Tripletts and Yellow bluffs, overlooking the Arkansas River floodplain, are composed of Jacksonian deposits overlain by Pleistocene terrace deposits.

\section{C.22 Geohydrology}

Principal aquifers in Jefferson County include the Sparta Sand Formation of Eocene age; the undifferentiated alluvial deposits next to the land surface of Quaternary age; and the upper sands of the Cockfield Formation, which belong to the Claiborne Group, and form a single hydrologic unit of Eocene age with the lower undifferentiated sands of the Jackson Group. The characteristics of these three aquifers are summarized in Table C.3. Additional water-bearing formations exist in Paleozoic strata as well as in Cretaceous and lower Tertiary systems that have not been developed because of their low groundwater yield potential, poor water quality, and extreme depth. These deeper aquifers are isolated hydraulically from the aforementioned shallower aquifers by the thick and relatively impermeable Porters Creek Formation, which consists mostly of clay.

The principal municipal and industrial water supply for southeastern Arkansas is provided by the Sparta Sand Aquifer. The regional easterly and southeasterly flow direction in this aquifer is moditied by a large cone of depression centered at Pine Bluff, from which $29,500 \mathrm{~m}^{3} / \mathrm{d}(7.8$ million $\mathrm{gal} / \mathrm{d})$ are withdrawn by the General Water Works (municipal water supply), and $159,000 \mathrm{~m}^{3} / \mathrm{d}$ (42 million gal/d) are withdrawn by industry and commerce (U.S. Army 1975; Arkansas Geological Commission, undated). This cone of depression extends laterally for several kilometers (miles). The water supply for PBA is supplied by 12 wells that tap the Sparta Sand Aquifer and have a combined maximum short-term production capacity of $78,400 \mathrm{~m}^{3} / \mathrm{d}(20.7$ million gal/d) (Pinkham et al. 1975). These wells range in depth from 213 to $335 \mathrm{~m}$ (700 to $1100 \mathrm{ft}$ ).

Water table declines as much as $49 \mathrm{~m}(160 \mathrm{ft})$ have been caused by the large groundwater withdrawals in the Sparta Sand Aquifer at Pine Bluff (U.S. Army 1975). The primary water supply for the proposed disposal facility, which will be obtained from the Sparta Sand Aquifer, will increase the depth of this cone of depression. The incremental increase in cone depth, which is attributable to the additional consumption of groundwater, will be a small fraction of the existing cone depth. Corresponding 


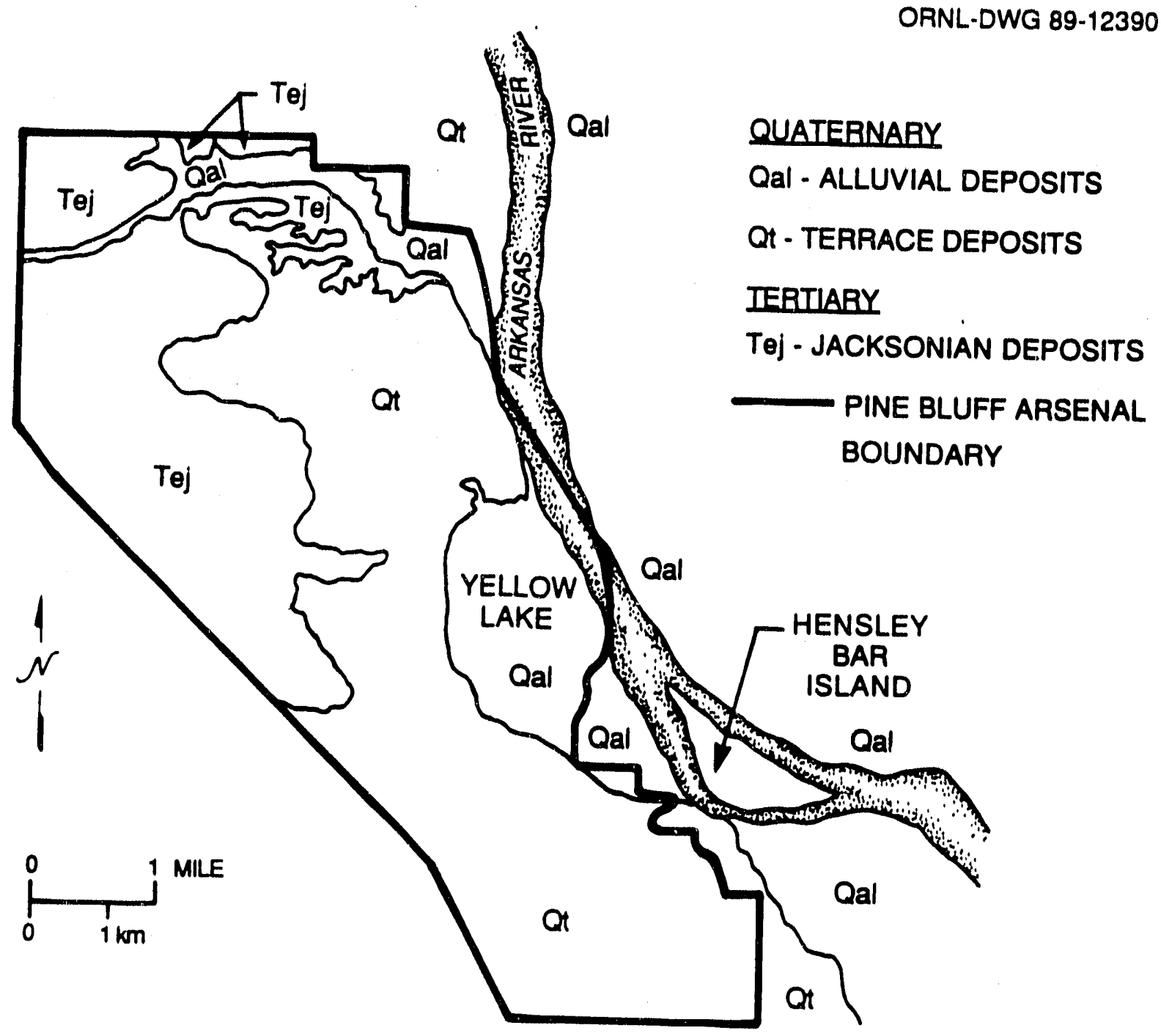

Fig. C3. Surficial geology of Pine Bluff Arsenal. Source: Jacobs Engineering Group, Geological-Seismological Investigation of Earthquake Hazards for a Chemical Agent Demilitarization Facility at Pine Bluff Arsenal, Arkansas, contractor report to the U.S. Army Engineer Division, Huntsville, Ala., prepared under contract DACA87-86-D-0085, Delivery Order 0004, by the Jacobs Engineering Group, Inc., and URS/John A. Blume \& Associates, Engineers, 1987. 


\section{C-10}

Table C.3. Summary of groundwater resources in Jefferson County, Artanses, including Pine Bluff Arsenal

\begin{tabular}{lclll} 
Aquifer & $\begin{array}{c}\text { Approximate } \\
\text { consumption } \\
{\left[\mathrm{m}^{3} / \mathrm{d}(\mathrm{million} \text { gal/d)] }\right.}\end{array}$ & $\begin{array}{c}\text { Water } \\
\text { quality }\end{array}$ & $\begin{array}{c}\text { Principal } \\
\text { use }\end{array}$ & $\begin{array}{c}\text { Approximate } \\
\text { depth } \\
{[\mathrm{m}(\mathrm{ft})]}\end{array}$ \\
\hline $\begin{array}{l}\text { Quaternary } \\
\begin{array}{l}\text { Cockfield- } \\
\text { Jackson }\end{array}\end{array}$ & $195,300(51.6)$ & variable & agricultural & surficial \\
Sparta Sand & $1,360(0.36)$ & good & domestic & $\begin{array}{l}46 \text { to } 92 \\
(150 \text { to } 300)\end{array}$ \\
\hline
\end{tabular}
reductions on the available yield of groundwater from the Sparta Sand Aquifer will be
small.

Water in the Sparta Sand Aquifer is soft and only slightly mineralized (U.S. Army 1975; Morris 1988). Most species concentrations, except sodium and bicarbonate, are low. Iron concentration levels, which are exceptionally high in the outcrop areas west of PBA, require treatment. The concentration of total dissolved solids increases in the downgradient direction, while calcium, magnesium, and iron concentrations exhibit an opposite trend. Groundwater quality is generally excellent and suitable for human consumption.

The Quaternary Aquifer residing in the surficial stratum consists of Pleistocene terrace deposits northwest of Bayou Bartholomew on PBA, and Holocene alluvial deposits to the east of the arsenal. Three zones exist in this stratum. The lowest basal zone, which comprises the principal aquifer capable of storing and transmitting groundwater, consists of lenses of coarse sand and gravel with some sand, clay, cobbles, and boulders. The intermediate zone is composed of medium and fine sand. The surficial zone, which forms a semiconfining cap, is predominantly silt and clay (U.S. Army 1975). Wells that tap the basal zone occur under artesian conditions; water table conditions may exist where large groundwater withdrawals occur, where the topmost zone is quite permeable, or in stream recharge areas in which hydraulic communication with the underlying aquifer has been established.

The Quaternary Aquifer is recharged to the north and west by precipitation that infiltrates alluvial outcrops, some of which are present on PBA, and in the east by Bayou Bartholomew and the Arkansas River. Many interrelationships between groundwater and surface water are possible because of the interactions between Bayou Bartholomew, the Arkansas River, and the Quaternary Aquifer. Groundwater consumption from the Quaternary Aquifer in Jefferson County exceeds $195,300 \mathrm{~m}^{3} / \mathrm{d}$ (51.6 million $\mathrm{gal} / \mathrm{d}$ ) and is used mostly for agricultural irrigation, fish farming, and industrial purposes (U.S. Army 1975). 
Water quality in the Quaternary Aquifer is extremely variable, and in some cases is undesirable for some uses. Groundwater in the western Pleistocene terrace deposits is of the sodium bicarbonate type, and the Holocene alluvium contains groundwater of the calcium bicarbonate type (U.S. Army 1975). Groundwater farther to the east, which is affected by streambed infiltration from the Arkansas River and Bayou Bartholomew, is appreciably lower in dissolved solids, hardness, and iron content relative to groundwater in the west.

The Cockfield-Jackson Aquifer, which extends throughout Jefferson County, is located above the Sparta Sand Aquifer and below the Quaternary Aquifer. In the 1970s, most wells that tapped this artesian aquifer were located in the western part of Jefferson County (U.S. Army 1975). Total pumpage was approximately $1360 \mathrm{~m}^{3} / \mathrm{d}$ ( 0.36 million gal/d). The water was used primarily for domestic and small, public-water supplies. Since 1975, the expansion of public water utilities have greatly reduced the need for domestic single-family water wells. Groundwater resides at 46 to $92 \mathrm{~m}$ (150 to $300 \mathrm{ft}$ ) or more below the surface near Pine Bluff.

Water quality in the Cockfield-Jackson Aquifer is moderately hard and mineralized (U.S. Army 1975). Silica, sodium bicarbonate, and sulfate levels are high. Sodium and bicarbonate concentrations increase in the downgradient direction to the southeast, but calcium, magnesium, and sulfate levels decrease. Groundwater from this aquifer is suitable for most uses.

Contamination of the Quaternary Aquifer has resulted from past operation of the munitions facilities at PBA (Lachapelle, Brooks, and Prescott 1969). A monitoring system that consists of 17 on-site and 3 off-site wells has been used to assess the extent and magnitude of this contamination. Elevated levels of chemical oxygen demand, sulfates, total dissolved solids, and chlorides have been observed near the Arkla Chemical Company. Elevated concentrations of phosphorous were recorded adjacent to areas that receive white phosphorous waste. Increased nitrate levels were encountered close to the $\mathrm{CN}$ and CS manufacturing area, which may have resulted from the disposal of starter mix. Elevated levels of total carbon were measured at the off-site wells, which presumably tap the Quaternary Aquifer. Groundwater quality at the remaining wells was generally good, and compared favorably with drinking water standards for chloride, nitrate, sulfate, zinc, and total dissolved solids. One of the on-site monitoring wells may have been completed in the Sparta Sand Aquifer. No contamination was observed in samples taken from this well.

In the PBA area, the Sparta Sand Aquifer is not hydraulically connected to the overlying aquifers or the surface water regime (U.S. Army 1977, p. I-13; U.S. Army 1988, p. 3-80). The Cook Mountain Formation, which is relatively thick and is composed of silty and sandy clay (Jacobs Engineering Group 1987, p. 25), serves as an aquitard between the Sparta Sand Aquifer and the overlying water-bearing formations. While the vertical hydraulic gradients associated with the large cone of depression centered at Pine Bluff could induce limited groundwater to flow downward through the Cook Mountain Formation, the low permeability of the aquitard restricts such leakage. The Cook Mountain Formation prevents contaminants that are discharged into the surface water 
regime, as well as into the Quaternary or Tertiary water-bearing formations, from seeping into the Sparta Sand Aquifer.

Some portion of any uncontrolled runoff at the site of the proposed disposal facility will seep into the ground. This runoff will migrate downward through the relatively porous Pleistocene terrace and Jacksonian deposits that outcrop on PBA and will enter either the Quaternary or Cockfield-Jackson Aquifer.

Contaminants that enter the Quaternary or Cockfield-Jackson Aquifer and emanate from any of the three candidate sites for the proposed disposal facility on PBA will migrate downgradient toward Pine Bluff. Several pathways are then possible: (1) entry into the Arkansas River or Bayou Bartholomew as baseflow, (2) induced leakage through the Cook Mountain Formation and subsequent contamination of the Sparta Sand Aquifer, (3) capture at a downgradient well in any of the three aquifers, and (4) continued downgradient migration through the aquifer in which the contaminant originated.

Appreciable seepage through the Cook Mountain Formation seems unlikely because the aquitard has low permeability. Additional pathways by which contaminants could enter the groundwater regime include leakage past poorly completed wells as well as abandoned wells that have been improperly closed. A spill of chemical agent would have to occur close to the well casing for this to be a viable pathway.

\section{REFERENCES FOR APPENDIX C}

Arkansas Geological Commission (undated). Ground-Water Levels in Observation Wells in Arkansas, Spring, 1980, Water Resources Summary 15, Little Rock, Ark.

Forsgren-Perkins Engineering 1988. Tooele Army Depot CSDP Facility Culinary Water and Wastewater Treatment Study, Forsgren-Perkins Engineering, P.A., Salt Lake City.

Hines, M. S. 1965. Water-Supply Characteristics of Selected Arkansas Streams, U.S. Geological Survey and Arkansas Geological Commission Water Resources Circular Number 9, Little Rock, Ark.

Holland, T. W. 1987. Use of Water in Arkansas, 1985, Water Resources Summary Number 16, Arkansas Geological Commission, Little Rock, Ark.

Jacobs Engineering Group 1987. Geological-Seismological Investigation of Earthquake Hazards for a Chemical Agent Demilitarization Facility at Pine Bluff Arsenal, Arkansas, contractor report to the U.S. Army Engineer Division, Huntsville, Alabama, prepared by jointly with URS/John A. Blume \& Associates, Engineers, under contract number DACA87-86-D-0085, Delivery Order 0004.

Lachapelle, D. G., Brooks, A. E., and Trescott, E. B., Jr. 1969. Groundwater Monitoring Pine Bluff Arsenal, Arkansas, Edgewood Arsenal Technical Report, EATR 4287, Department of the Army, Edgewood Arsenal, Weapons Development and Engineering Laboratories, Edgewood Arsenal, Md. 
Manuel, K. L., Bender, E. S., and Pearson, J. G. 1976. Results of Aquatic Surveys at Pine Bluff Arsenal, Arkansas, September 1973-October 1974. Edgewood Arsenal Technical Report EB-TR-76038, Department of the Army, Headquarters, Edgewood Arsenal, Aberdeen Proving Ground, Md.

Morris, E. E. 1988. "Arkansas Ground-Water Quality," pp. 165-172 in National Water Summary 1986-Hydrologic Events and Ground-Water Quality, United States Geological Survey Water-Supply Paper 2325, compiled by D. W. Moody, J. Carr, E. B. Chase, and R. W. Paulson, U.S. Government Printing Office, Washington, D.C.

Pinkham, C. F. A., et al. 1975. Preliminary Environmental Survey, Pine Bluff Arsenah, Pine Bluff, Arkansas, December 1972, Edgewood Arsenal Special Publication EB-SP-74025, Depariment of the Army, Headquarters, Edgewood Arsenal, Aberdeen Proving Ground, Md.

Sniegocki, R. T., and Bedinger, M. S. 1969. Water for Arkansas, Arkansas Geological Commission, Little Rock, Ark.

Southeast Arkansas Regional Planning Commission 1980. Natural Resounces of Jefferson County, Pine Bluff, Ark.

Southeast Arkansas Regional Planning Commission 1981. Bayou Bartholomew Groundwater-Wetlands, Pine Bluff, Ark.

U.S. Army 1975. Environmental Inventory and Analysis for Pine Bluff, Arkansas, vol. I, prepared by VTN, Engineers, Planners, Environmental Scientists, Metairie, La., under contract DACW38-74-C-0139, for the Department of the Army, Corps of Engineers, Vicksburg District, Vicksburg, Miss.

U.S. Army 1977. Installation-Wide Assessment Pine Bluff Arsenah, Pine Bluffi, Arkansas: Records Evaluation. Aberdeen Proving Ground, Md.

U.S. Army 1986. Pine Bl. If Arsenal Installation Hazardous Waste Management Plan (AR 420-47), Environmental Manageinent Office, Pine Bluff Arsenal, Pine Bluff, Ark.

U.S. Army 1988. Chemical Stockpile Disposal Program Final Programmatic Environmental Impact Statement, Vols. 1, 2, and 3, Program Executive Officer-Manager for Chemical Demilitarization, Aberdeen Proving Ground, Md., January. 


\section{APPENDIX D \\ DESCRIPTION OF STTE-SPECIFIC LAND USE}

The zone of potential impact within $100 \mathrm{~km}$ (62 miles) of the Pine Bluff Arsenal (PBA) is predominantly forested and has less farmland. Counties having the most farmland lie in the eastern and northern portions of the impact zone (Arkansas, Desha, Faulkner, Lincoln, Lonoke, Monroe, Prairie, and White counties) (see Table D.1). Cropland occupies most of the farmland acreage, but pasture land is relatively extensive in Faulkner and White counties to the north of PBA. Relatively large acreages of cropland in Arkansas, Lonoke, and Prairie counties are irrigated (see Table D.1). The Ouachita National Forest to the northwest of PBA (Perry and Saline counties) and the White River National Wildlife Refuge to the east-southeast (Arkansas and Desha counties) also occupy extensive acreages within the impact zone. Urban areas occupy relatively small acreages except in Pulaski County (which contains the cities of Little Rock, North Little Rock, and Jacksonville) and Jefferson County (in which PBA and Pine Bluff are located).

The importance of various agricultural land uses within the impact zone is indicated by commodity dollar values and the national and county rankings for the commodities (see Tables D.2 and D.3). Among the 50 states, Arkansas ranks first in the production of commercial broilers, fourth in turkeys, and fifth in eggs. Cash receipts for broilers far exceed any other Arkansas plant or animal commodity (see Table D.2). The counties within the impact zone are, overall, below average among Arkansas counties (total of 75 Arkansas counties) in both broilers and turkeys (see Table D.3) (county ranks for eggs were not available). Nevertheless, the high national rankings indicate that the commercial broiler industry and the agricultural land uses (e.g., crops for production of chicken feed) that support this industry are very important within the region. The highest ranking counties for broilers within the impact zone are Cleveland (19th), Lincoln (24th), and Perry (25th). Counties that rank high in cattle and calves, which is the second ranked animal commodity in Arkansas, include Faulkner (4th) and White (7th). Both counties are located at the north perimeter of the zone.

Arkansas also ranks first among the states in the production of rice, which has the second highest production value among Arkansas crops (see Table D.2). Counties that rank high in rice production are located in the eastern half of the impact zone, including Arkansas (2nd), Lonoke (4th), Prairie (9th), Jefferson (10th), Desha (13th), and Monrce (15th) counties. The number one Arkansas cash crop is soybeans, in which Arkansas ranks eighth nationally. High ranking counties include Arkansas (2nd), Prairie (10th), Lonoke (11th), Jefferson (16th), Monroe (17th), Desha (19th), and White (20th). Several counties also rank high in cotton, in which Arkansas ranks fifth nationally. The production ralue of other plant commodities in Arkansas is relatively low (see
Table D.2) (AASS 1988). 
D-2

Table D.1. Agricultural land we statistics in Artansas counties bying mosthy or wholly within $100 \mathrm{~km}$ (62 miles) of Pine Bluff Areenal

\begin{tabular}{lrrrrrr}
\hline County & $\begin{array}{c}\text { Area } \\
\text { (\% of } \\
\text { average }\end{array}$ & $\begin{array}{c}\text { Number } \\
\text { of farms }\end{array}$ & $\begin{array}{c}\text { Acres in } \\
\text { farms } \\
(\%)\end{array}$ & $\begin{array}{c}\text { Average farm } \\
\text { size } \\
\text { (acres) }\end{array}$ & $\begin{array}{c}\text { Cropland } \\
\text { harvested } \\
(\%)\end{array}$ & $\begin{array}{c}\text { Irrigated } \\
\text { land } \\
(\%)\end{array}$ \\
\hline Arkansas & 144 & 636 & 69 & 700 & 54 & 37 \\
Bradley & 94 & 332 & 9.3 & 117 & 1.6 & 0.2 \\
Calhoun & 91 & 146 & 5.8 & 160 & 1.0 & NR $^{\text {c }}$ \\
Clark & 125 & 460 & 24 & 284 & 7.8 & 0.5 \\
Cleveland & 86 & 272 & 11 & 154 & 1.6 & 0.08 \\
Dallas & 96 & 143 & 6.0 & 180 & 1.1 & NR \\
Desha & 108 & 427 & 62 & 692 & 53 & 16 \\
Drew & 120 & 424 & 27 & 343 & 16 & 4.7 \\
Faulkner & 93 & 1169 & 55 & 195 & 17 & 0.8 \\
Garland & 95 & 372 & 9.5 & 107 & 1.0 & 0.01 \\
Grant & 91 & 255 & 8.7 & 138 & 1.6 & NR \\
Hot Spring & 89 & 512 & 18 & 141 & 2.9 & 0.1 \\
Jefferson & 127 & 497 & 52 & 595 & 41 & 15 \\
Lincoln & 81 & 420 & 61 & 520 & 41 & 12 \\
Lonoke & 113 & 984 & 83 & 422 & 60 & 31 \\
Monroe & 88 & 369 & 60 & 638 & 49 & 16 \\
Ouachita & 106 & 259 & 8.8 & 160 & 1.8 & NR \\
Perry & 79 & 381 & 18 & 170 & 5.7 & 0.4 \\
Prairie & 94 & 489 & 72 & 616 & 57 & 31 \\
Pulaski & 110 & 529 & 30 & 277 & 18 & 2.4 \\
Saline & 104 & 421 & 13 & 140 & 2.1 & 0.07 \\
White & 150 & 1651 & 61 & 246 & 29 & 5.8 \\
\hline & & & & & & \\
\end{tabular}

'Most of the land in Conway, Woodruff, and Phillips counties lies beyond $100 \mathrm{~km}$ of Pine Bluff Arsenal and was not included.

The number given is the percent of the average size (444,401 acres) of Arkansas counties.

TR = not reported to avoid disclosing individual farms.

Service (1988).

Source: 1982 Federal statistics as reported in Arkansas Agricultural Statistics
(1988). 


\section{D-3}

Table D.2. Cach receipts, value of production, and national rant of agricultural commodities in Artansase

\begin{tabular}{|c|c|c|c|}
\hline \multirow[b]{2}{*}{ Commodity } & \multirow{2}{*}{$\begin{array}{c}\text { Rank } \\
\text { (production) }\end{array}$} & Production value & Cash receipts \\
\hline & & \multicolumn{2}{|c|}{ (millions of dollars) } \\
\hline Crops & & & 1004.6 \\
\hline $\begin{array}{l}\text { Soybeans } \\
\text { Rice } \\
\text { Cotton } \\
\text { Hay, all } \\
\text { Wheat, all } \\
\text { Sorghum, grain } \\
\text { Greenhouse/nursery } \\
\text { Cottonseed } \\
\text { Corn, grain } \\
\text { Tomatoes } \\
\text { Oats } \\
\text { Snap beans } \\
\text { Grapes } \\
\text { Pecans, all } \\
\text { Apples } \\
\text { Strawberries } \\
\text { Peaches } \\
\text { Other }\end{array}$ & $\begin{array}{r}8 \\
1 \\
5 \\
31 \\
18 \\
5 \\
- \\
6 \\
34 \\
8 \\
28 \\
8 \\
9 \\
11 \\
35 \\
13 \\
11 \\
-\end{array}$ & $\begin{array}{r}395.0 \\
381.8 \\
271.6 \\
91.2 \\
84.4 \\
44.9 \\
- \\
24.0 \\
12.7 \\
10.2 \\
2.1 \\
1.1 \\
1.3 \\
1.1 \\
0.5 \\
0.5 \\
0.4 \\
-\end{array}$ & $\begin{array}{r}349.8 \\
275.4 \\
153.0 \\
11.8 \\
72.3 \\
61.3 \\
15.2 \\
13.6 \\
13.1 \\
9.0 \\
1.5 \\
0.7 \\
1.1 \\
1.0 \\
1.3 \\
0.9 \\
1.6 \\
22.1\end{array}$ \\
\hline Livestock and poultry & & & 2017.5 \\
\hline $\begin{array}{l}\text { Commercial broilers } \\
\text { Cattle and calves } \\
\text { Eggs } \\
\text { Turkeys, raised } \\
\text { Milk \& dairy products } \\
\text { Farm chickens } \\
\text { Hogs and pigs } \\
\text { Rabbits } \\
\text { Other }\end{array}$ & $\begin{array}{r}1 \\
23 \\
5 \\
4 \\
35 \\
2 \\
18 \\
- \\
-\end{array}$ & $\begin{array}{r}1,107.0 \\
795.0 \\
230.8 \\
118.1 \\
106.2 \\
68.4 \\
30.9 \\
- \\
- \\
\end{array}$ & $\begin{array}{r}1161.3 \\
239.0 \\
228.2 \\
146.6 \\
98.0 \\
10.6 \\
91.7 \\
0.7 \\
41.5 \\
\end{array}$ \\
\hline
\end{tabular}

'Values provided by the source (Arkansas Agricaltural Statistics Service 1988) were
(production) and 1986 (cash receipts) for 1987 (production) and 1986 (cash receipts). 


\section{D-4}

Table D.3. Ranbs of study-area counties in Artanses for cropa, poultry, and livestocks

\begin{tabular}{|c|c|c|c|c|c|c|c|c|c|c|c|c|}
\hline County & Sy & Rc & Wh & $\mathrm{Ct}$ & $\mathrm{Sr}$ & $\mathrm{Cr}$ & $\mathbf{O t}$ & $\mathrm{CC}$ & MC & HP & $\mathrm{Br}$ & $\mathrm{Tr}$ \\
\hline Arkansas & 2 & 2 & 8 & - & 6 & 5 & 1 & 57 & - & 57 & - & - \\
\hline Bradley & 54 & - & - & - & 49 & - & - & 60 & - & 69 & 32 & - \\
\hline Calhoun & 55 & - & - & - & - & 29 & - & 65 & - & 75 & - & - \\
\hline Clark & 30 & 34 & 36 & - & 36 & 30 & - & 36 & 32 & 35 & - & - \\
\hline Cleveland & - & - & - & - & - & - & - & 54 & - & 61 & 19 & - \\
\hline Dallas & 50 & - & - & - & - & - & - & 63 & - & 70 & 45 & - \\
\hline Desha & 19 & 13 & 20 & 6 & 12. & 8 & - & 66 & - & 74 & - & - \\
\hline Drew & 27 & 25 & 34 & 13 & 27 & 23 & - & 44 & - & 47 & 38 & - \\
\hline Faullner & 34 & 31 & 35 & - & 38 & - & 12 & 4 & 9 & 43 & 46 & - \\
\hline Garland & - & - & - & - & - & - & - & 48 & - & 50 & - & - \\
\hline Grant & - & - & - & - & - & - & - & 49 & 37 & 65 & 40 & - \\
\hline Hot Spring & 40 & 37 & 42 & - & 45 & - & - & 40 & 28 & 45 & - & - \\
\hline Jefferson & 16 & 10 & 16 & 3 & 23 & 2 & 9 & 59 & - & 52 & 37 & - \\
\hline Lincoln & 22 & 18 & 28 & 10 & 25 & 19 & 14 & 52 & - & 68 & 24 & - \\
\hline Lonoke & 11 & 4 & 10 & 11 & 20 & 12 & - & 46 & 11 & 39 & 43 & - \\
\hline Monroe & 17 & 15 & 15 & 12 & 24 & - & 6 & 73 & - & 26 & - & - \\
\hline Ouachita & - & - & - & - & 46 & - & - & 53 & - & 63 & 36 & - \\
\hline Perry & 38 & 34 & 41 & - & 37 & - & - & 43 & - & 6 & 25 & - \\
\hline Prairie & 10 & 9 & 11 & 22 & 21 & 6 & 2 & 62 & 20 & 53 & - & - \\
\hline Pulaski & 23 & 29 & 22 & 23 & 34 & - & - & 45 & - & 46 & 39 & - \\
\hline Saline & 44 & - & - & - & - & - & - & 50 & 31 & 38 & - & - \\
\hline White & 20 & 19 & 23 & - & 16 & 15 & 7 & 7 & 6 & 42 & 35 & $\bar{z}$ \\
\hline $\begin{array}{l}\text { Number of } \\
\text { ranked }\end{array}$ & & & & & & & & & & & JJ & - \\
\hline counties & 55 & 40 & 47 & 23 & 49 & 32 & 14 & 75 & 39 & 75 & 46 & 15 \\
\hline
\end{tabular}

-Artansas has 75 counties. The dash $(-)$ indicates the county was not ranked. Sy = soybeans, $\mathrm{Rc}=$ rice, $\mathrm{Wh}=$ wheat, $\mathrm{Cl}=$ cotton, $\mathrm{Sr}=$ sorghum, $\mathrm{Cr}=$ corn, $\mathrm{Ot}=$ oats, $\mathrm{CC}=$ cattle and calves, $\mathrm{MC}=$ milk cows, $\mathrm{HP}=$ hogs and pigs, $\mathrm{Br}=$ broilers, $\mathrm{Tr}=$ turkeys.

Sounce: Artansas Agricultural Statistics Service (1988). 
D-5

\section{REFERENCE FOR APPENDIX D}

AASS (Arkansas Agricultural Statistics Service) 1988. Arkansas Agricultural Statistics, Little Rock, Ark. 


\section{APPENDIX E \\ DESCRIPTION OF STTESPECIFIC EOOLOGICAL RESOURCES}

Ecological resources include all living organisms except humans, as well as areas containing important terrestrial or aquatic resources (i.e., parklands, wilderness areas, nature conservancy areas, and wetlands). Terrestrial and aquatic species protected by the Endangered Species Act are identified in this appendix for the 20-, 50-, and 100-km (12-, 31-, and 62-mile) zones around Pine Bluff Arsenal (PBA). Aspects of land use related to ecological resources are described in this appendix, while the human aspects of land use are addressed in Appendix D.

The maximum no-effects radius [100 km (62 miles) for GB and VX] includes 15 counties or parts of counties in Arkansas. The no-deaths distance for mustard is $50 \mathrm{~km}$ (31 miles); mustard is carcinogenic and does not have a no-effects distance. The 50-km (31-mile) zone for mustard includes 10 counties within Arkansas. Additional site-specific information is found in the Installation Assessment of Pine Bluff Arsenal (U.S. Army 1977; 1983).

\section{E1 TERRESTRIAL RESOURCES}

The 100-km (62-mile) zone contains representatives of three major forest regions; oak hickory, oak pine, and southeastern evergreen. Black, post, and white oaks are the dominant oaks. Shortleaf is the dominant natural, and loblolly is the dominant planted pine (Braun 1950). The area supports four resident game species of birds (wood duck, bobwhite quail, wild turkey, and mourning dove), and several migratory ducks species are hunted in season (Bellrose 1978). Five resident game species of mammals include whitetail deer, gray and fox squirrel, and swamp and cottontail raisbit. Approximately 120 species of nongame birds are reported to nest within the zone (C. Becker, National Resources Specialist, Pine Bluff Arsenal, Pine Bluff, Ark, personal communication with D. West, Oak Ridge National Laboratory, Oak Ridge, Tenn., June 16, 1989).

\section{E2 AQUATIC RESOURCES}

The major body of water within the $100-\mathrm{km}(62-\mathrm{mile})$ zone around PBA is the Arkansas River. Under the proposed action of on-site disposal, the only transportation of agent will be from the storage area to the site of the proposed disposal facility; 
therefore, the only bodies of water in which aquatic resources could be adversely impacted by a spill would be the tributary to the Arkansas River and the river itself. The additional water bodies within the impact zone could be affected by deposition from atmospheric dispersion of chemical agent.

As discussed in Appendix C, drainage at the site of the proposed disposal facility is ultimately to the Arkansas River. Specific information on the aquatic resources of the Arkansas River and the calculated concentrations of agent that could occur following a spill or deposition onto the river will be used in preparation of the site-specific EIS to calculate the expected mortalities of fish that could occur both at the site and downstream in the event of an accidental release.

There are numerous lakes and small creels that occur on the PBA site. Information on the aquatic resources and the effects of an accidental release on these resources will be addressed in the site-specific EIS.

Information about wetlands has been requested from the Federal Emergency Management Agency (FEMA) and the U.S. Fish and Wildlife Service (FWS). Any information obtained from these and other agencies will be included as appropriate in the site-specific EIS for PBA.

\section{E3 THREATENED AND ENDANGERED SPECIES}

Six federally listed endangered species were listed in the FPEIS as occurring within the 100-km (62-mile) zone around PBA: pink mucket pearly mussel, red-cockaded woodpecker, bald eagle, interior least tern, Indiana bat, and Florida panther.

One federally listed asimal species, the American alligator, is known to have a breeding population within the $100-\mathrm{km}(62-\mathrm{mile})$ zone. The alligator was reintroduced to the area approximately 10 years ago (Newsome and Joanen 1986). The original release of about 10 specimens has increased to an estimated 50. The population remains confined primarily to the wetlands near PBA along the Arkansas River. Part of the geographical range of one endangered mammal species, the Indiana Bat, is the northern half of the $100-\mathrm{km}$ (62-mile) zone, but no known populations exist in the area (Brack 1988). The 100-km (62-mile) zone is also within the geographic ranges of two endangered bird species-the least tern and the piping plover-but neither has been recorded in the area. The woodstork (wood ibis) and bald eagle migrate through, but do not nest in, the area. Unconfirmed sitings of the Florida panther occur occasionally but actual presence of this endangered species remains doubtful (C. Becker, National Resources Specialist, Pine Bluff Arsenal, Pine Bluff, Ark, personal communication, to D. West, Dak Ridge National Laboratory, Oak Ridge, Tenn., June 16, 1989). No known endangered plant species exist within the 100-km (62-mile) zone.

The pink mucket pearly mussel occurs in the Ouachita River in Clark County and is located approximately $90 \mathrm{~km}$ (56 miles) west of PBA. Because the wind direction at PBA is primarily from the south and southwest, the potential for impacts to this species from an accidental release is fairly remote. 


\section{E-3}

FWS has been notified concerning updated information appearing in the FPEIS. The Region IV Threatened and Endangered Species Notebook was consulted in preparation of this Phase I Report to provide interim information on endangered species within the $100-\mathrm{km}$ (62-mile) zone. This source shows that, in addition to the species listed above, Arctic peregrine falcons occur as transients, and Geocarpon minimum comprises a resident plant population in Warren Prairie. This information will be verified or updated when information is received from FWS, Jacloson, Mississippi, Endangered Species Office.

\section{REFERENCES FOR APPENDIX E}

Bellrose, F. C. 1978. Ducks, Geese, and Swans of North America, Stackpole Books. Brack, V. 1988. The Indiana Bat, Audubon Wildlife Report, ed. W. J. Chandler, Harcourt Brace Jovanovich, New York.

Braun, E. L. 1950. Deciduous Forests of Eastem North America. Blakiston.

Newsome, J. D., and Joanen, T. 1986. Habitat Suitability Models: Alligator.

U.S. Fish and Wildlife Service, FWS/OBS, Washington, D.C.

U.S. Army 1977. Installation-Wide Assessment Pine Bluff Arsenal, Pine Bluff, Arkansas. Records Evaluation, Aberdeen Proving Ground, Md.

U.S. Army 1983. Construction and Operation of the Proposed BZ Demilitarization Facility at Pine Bluff, Arkansas. U.S. Army Toxic and Hazardous Materials Agency, Aberdeen Proving Ground, Md. 


\section{APPENDIX F}

\section{RESPONSES TO COMMENTS FROM STATE AND FEDERAL AGENCIES}

A draft version of this document was circulated among the relevant state and federal agencies, and comments were solicited. Written comments were received from

- U.S. Department of Health and Human Services, Centers for Disease Control;

- U.S. Environmental Protection Agency;

- Arkansas Department of Pollution Control and Ecology; and

- Arkansas Office of Emergency Services.

This appendix presents copies of the letters received (in Sect. F.1) and offers responses to those comments (in Sect. F.2).

\section{F.1 WRTTEN COMMENTS RECEIVED FROM STATE AND FEDERAL AGENCIES}

The specific page numbers or line numbers referenced in the following letters are related to the draft version of this document and, therefore, may not exactly match the corresponding page or line in this Final Phase I Environmental Report. 
Public Heal th Service

Colonel Ralph R. Carestia

Medical Services

Chief, Enviramental and Monitoring Division

Office of the Program Manager for Chemical Demilitarization

Aberdeen Prooving Ground, Maryland

Dear Col. Carestia:

We have reviewed the Cooperating Agencies Review Draft of the Phase I Enviramental Report for Pine Bluff Arsenal. The doament appears to be generally well written. The following comments are in addition to those of Dr. Ieffingwell which have previously been sent by FAX to Ms. Peggy Thalpson (copy enclosed).

1. There is an apparent discrepancy between lines 29-32, page 1-3 and lines $7-9$, page 3-50. In one case you state that the existing BZ munitions disposal facility will be utilized, in the other case you state that only the $B Z$ support facilities will be utilized.

2. There are several places where it could be more clear as to whether you are referring to distances from installation boundaries or fram the disposal facility (eg. page 3-14, lines 1-3; page 3-15, lines 9,11; page 3-19, line 5; page 4-1, line 28; page 4-2, lines 23-25).

3. It would be helpeul to the reader if Tables 3 and 4 could be combined so that a quick comparison could be made. Also Tables 5 and 6 .

4. We are sonewhat troubled by the apparent failure of the on-site acoustic sounder. (Page 3-4, lines 17-19). A discussion of any plans to upgrade meteorological instrumentation at PBA would be useful.

We appreciato the opportunity to review the Cooperating Agency Draft and apologize for the delay in forarding these comments.

\section{Sincerely,}

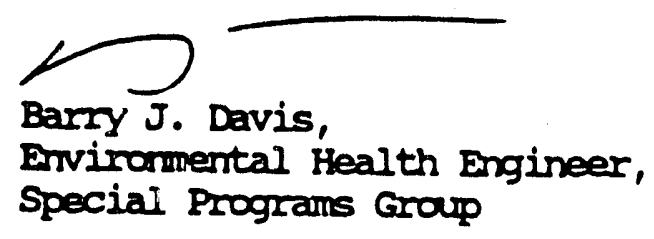


F-3

Comments on "Cooperating Agencies Review Jraft-Disposal of Chemical Rgents and Munitions Stored at Fine Bluft Arsenal, Fine Eluff, Arkansas. Phase I Environmental Feport."

Pagel

line Comment

1-8il-5 Why the difference in radii? The on-site alternative involves storage risks which continue until the stockpile is gone.

2-3/1-4 But CML conditions may under some circumstances be associated with higher numbers of fatalities than WC conditions. E.g., if the shorter but broader plume erosses a densely populated area near the orjoin.

2-5/1-2 "Comprised" is misused here. It should be "composed of" or "two principal types of data--internal and eiternal--comprise the risk measures."

2-9/10-11 There is an odd asymmetry here. If we are isting abbreviations, why not EFA?

j-4i1-? Is this argument with respect to the snakelike course at a plume valid for a puff (instantaneous) release?

3-4:2s-3t How much effect would altering the HML to $350 \mathrm{~m}$ or $500 \mathrm{~m}$ have on the conclusions? $750 \mathrm{~m}$ is. "realistic" as a mean, but might it not be preierable to include the percentages and consequences for ali weather situations when calculating eipe:ted fatalities? Would doing the calculation have any likelahood of significantly skewing the results? Ferhaps that is not essential for the Phase I report, but if not, it is definitely needed for the site-specific EIS.

j-5i: A conma is needed after the leading prepositional phrase, "When the FFEIS was prepared."

j-1!iz? A method is a way of doing something. "Methodology" is the science or stud; of methods. The word needed here is samply "method." Eince many seientists tend to use methodology as a high-iallutin' synonym for method, perhaps a global search inrough the document to see if the error cccurs elsewhere would be frudent.

j-14i4 I do not understand what is meant by "This change primarily resules fron including the installation boundary, thus excl :ding residents within the boundary. "How does inclubing the toundary, an imaginary line or at best a ienze, in the considerations exclude the people living within the installation boundary irom risk? 
F-4

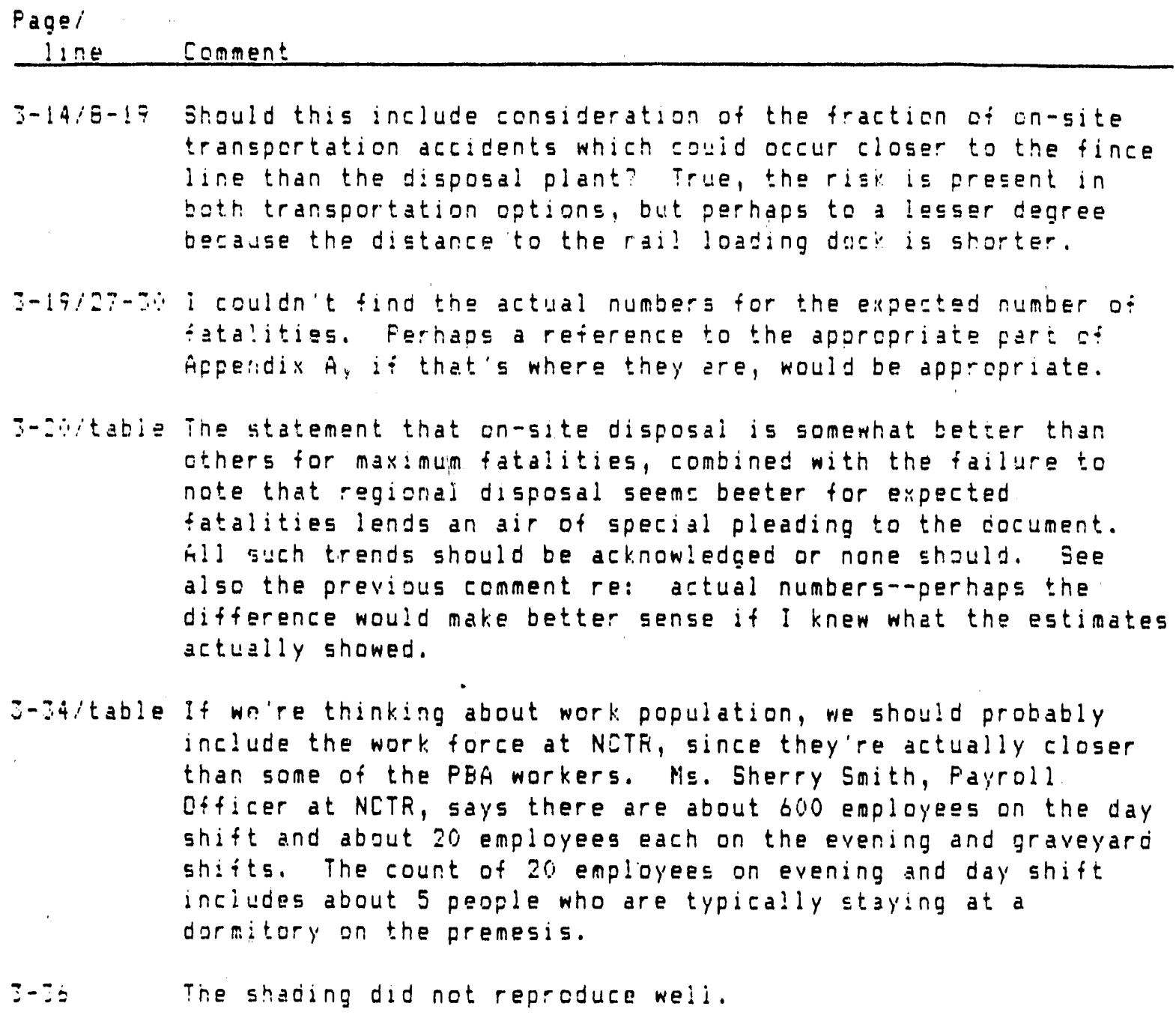

J-j4itable If wo're thinking about work population, we should probably include the work force at NETR, since they're actually closer than some of the PEA workers. Ms. Sherry Soith, Fayroll Officer at NCTR, says there are about boo enployees on the day shift and about 20 employees each on the evening and graveyaro shits. The count of 20 enployees on evening and day shift inciludes about 5 people who are typically staying at a darmitory on the premesis.

Z-is The shading did not reproduce weli. 


\section{F-5}

\section{UNITED STATES ENVIRONMENTAL PROTECTION AGENCY \\ WASHINGTON, D.C. 20460}

\section{JAN $3: 990$}

OFFICE OF

ENFORCEMENT AND COMPLIANCE MONITORING

Brigadier General David A. Nydam

U.S. Army

Program Manager for Chemical Demilitarization

Aberdeen Proving Ground, MD 21010-5401

ATTN: Environmental and Monitoring Division

Dear General Nydam:

In November, you requested that the Environmental Protection Agency (EPA) review the draft "Phase I" Report for the proposed chemical munitions incinerator at Pine Bluff Arsenal. The report contains new site-specific data relating to the selection of the Pine Bluff site for the Chemical Demilitarization Program. Based on this new information, the report's purpose is to verify the Army's prior decision for on-site disposal of the chemical munitions at Pine Bluff and to identify any significant resources that might be adversely affected at the site. To some extent, the report is a site-specific up-dating of the earlier Environmental Impact Statement (EIS) for the Chemical stockpile Disposal Program.

Pursuant to your request, EPA has reviewed the draft Phase I Report. Our review was based on both the draft Phase I Report as well as the earlier EIS and permit related materials. The report was reviewed by appropriate staff in EPA's headquarters and in EPA's Dallas Regional Office.

Based upon our review, we concur with the draft Phase I Report's conclusion that on-site disposal remains valid as the environmentally preferable alternative. Similarly, no unique resources were identilied in the report that would preciude the use of Pine Bluff Depot Activity in the disposal program. As you know, the disposal of the munitions is subject to a number of environmental requirements and will be regulated by EPA and Arkansas. EPA has identified several discrepancies or clarifications that are needed in the Phase I Report; further, EPA has identified several issues that need to be addressed in the site-specific EIS under preparation for the Pine Bluff site. These concerns are explained in more detail in the enclosure. 
F-6

We appreciate the opportunity of reviewing the draft phase I Report, and look forward to working with you and your staff on the site-specific EIS for the disposal facilities at Pine Bluff Arsenal.

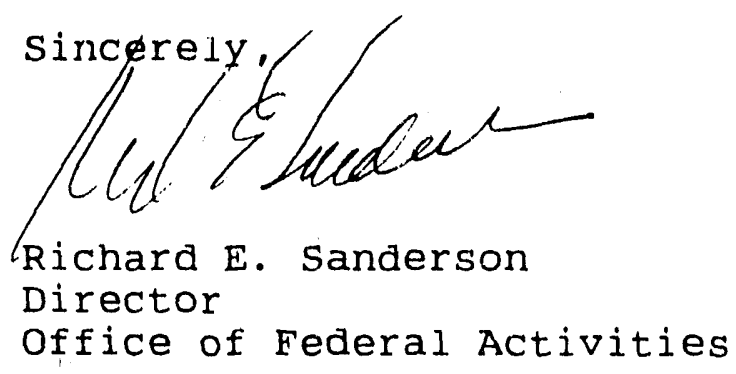

Enclosure 


\section{Specific Comments of the U.S. EPA on the Cooperating Agency Review Draft Phase I Report for Pine Bluff Arsenal}

1. The report contains no air pollutant emission data or characterization of ambient ground-level concentrations of priority or toxic pollutants emitted from the project. The emissions and the ground-level ambient concentrations should be modeled and presented in the site-specific EIS for the proposed Pine Bluff facility.

2. On page 3-24, the report discusses an existing permitted air emission point, but the existing permitted emissions summary is listed in Table 7 by permit number. We recommend that this be clarified by referencing the permit number on page 3-24.

3. We recommend that the Army consider the construction of the incinerator facilities as close to the chemical storage area as possible. This would minimize the risk from transportation accidents, and the costs and benefits from such siting could be analyzed in the site-specific EIS.

4. There are several corrections needed on page 3-27. Beginning on line 39, the text should read: "The final design of the disposal facility will be submitted to the state of Arkansas for review and, if acceptable, will be incorporated into the State's hazardous waste permit for PBA. The National Research Council will also be requested to review the design." In regard to the proposed review of the Pine Bluff design by the National Research Council, it would be helpful if the status of the review was presented. Was the design of the Tooele facility also submitted to the National Research Council, and, if so, what did the review show?

5. Section 3.3 needs to include a statement that regulatory approvals for design and construction technology will be acquired from the state. It would be helpful if all regulatory approvals were addressed in one section of the report.

6. Section 3.3.3 discusses a number of activities that were planned for CAMDS in mid-1989. This section discusses these planned activities in the future tense. We recommend that this section be updated.

7. The report suggests in several places that the Pine Bluff facility will use the "JACADS" technology instead of a modification to the existing BZ disposal plant. If this understanding is correct, the change in technological approach at Pine Bluff should be considered in the site-specific EIS. 
F-8

STATE OF ARKANSAS

DEPARTMENT OF POLLUTION CONTROL AND ECOLOGY

8001 NATIONAL DRIVE, P.O. BOX 9583

LITTLE ROCK, ARKANSAS 72209

PHONE: $(501) 562-7444$

December 20,1989

David A. Nydam

Brigadier General, U. S. Army

Program Manager for Chemical Demilitarization

Aberdeen Proving Ground, Maryland 21010-5401

Dear Gen. Nydam:

The Department has reviewed the NEPA Phase I report for the Pine Blufe Chemical Agent Disposal Facility. The staff agrees that the proper method of disposal is on-site incineration. This will provide disposal with the minimum of risk to health and to the envi ronment.

The operation of the $\mathrm{BZ}$ incinerator was accomplished with no adverse effects noted. If this incinerator is used again for the other chemical warfare agents, there should be little chance for accidental releases or upsets.

Thank you for the opportunity to comment.

sincerely,

Ajeck

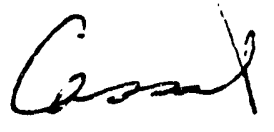

Dick Cassat, Chief

Technical Services Division

L106 


\section{STATE OF ARKANSAS \\ OFFICE OF EMERGENCY SERVICES \\ P. O. BOX 758 \\ CONWAY, ARKANSAS 72032 \\ 329-5601/374-1201}

January 31, 1990

Mrs. Peggy Thompson

Department of the Army

Office of the Program Manager for Chemical Demilitarization

Aberdeen Proving Ground, Maryland 21010-5401

Dear Mrs. Thompson:

Reference Disposal of Chemical Agents and Munitions Stored at Pine Bluff Arsenal Phase I Environment Report, dated September, 1989. The attached joint Arkansas State Office of Emergency Services, Jefferson County Office of Emergency Services and Pine Bluff Arsenal review of this report is submitted.

If you have any questions, please contact the undersigned or Ed Claunch, Arkansas State Office of Emergency Services

Sincerely,
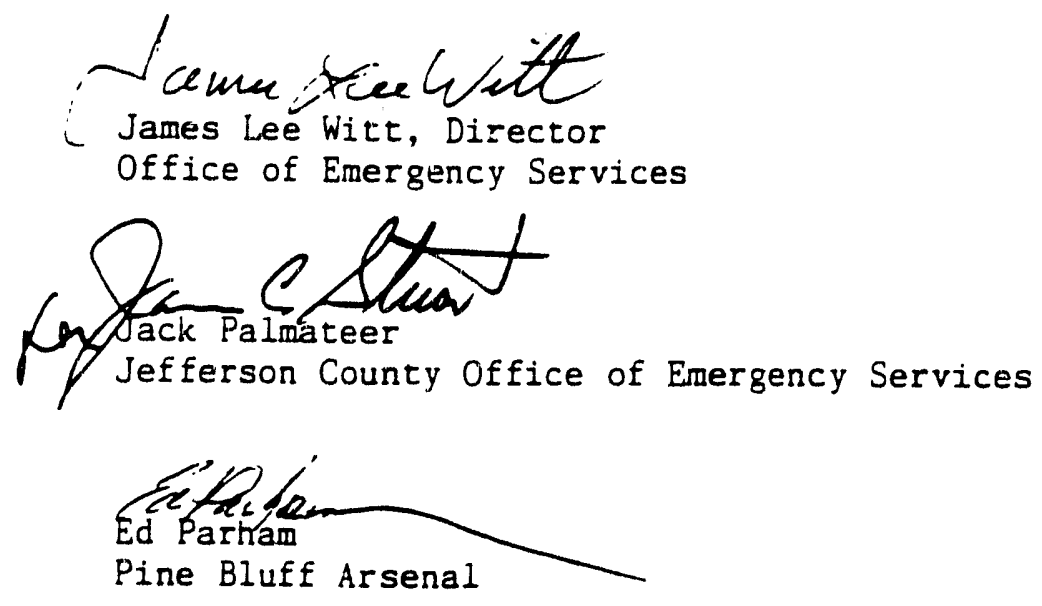
F-10

PHASE I ENVIRONMENTAL REPORT (DRAFT)

Dated September, 1989

Disposal of Chemical Agents and Munitions

Stored at Pine Bluff Arsenal

Pine Bluff, Arkansas

\begin{tabular}{|c|c|c|c|}
\hline $\begin{array}{r}\text { Page } \\
\text { No. }\end{array}$ & $\begin{array}{l}\text { Line } \\
\text { No. }\end{array}$ & Discrepancy & $\begin{array}{l}\text { Recommended } \\
\text { Correction } \\
\end{array}$ \\
\hline $1-2$ & Fig. 1 & $\begin{array}{l}\text { 1. "West end" listed on map } \\
\text { 2. "Bayou Metro" } \\
\text { 3. Prairie \& Dallas counties not } \\
\text { indicated }\end{array}$ & $\begin{array}{l}\text { 1. Delete } \\
\text { 2. Change to: Bayou Meto } \\
\text { 3. List as required }\end{array}$ \\
\hline $2-9$ & & State OES not listed & List (if contacted) \\
\hline $2-10$ & 22 & $\begin{array}{l}\text { 1. State OES Director listed as } \\
\text { Jefferson County Judge } \\
\text { 2. Jefferson County Judge Jack } \\
\text { Jones not listed }\end{array}$ & $\begin{array}{l}\text { 1. List James Lee Witt } \\
\text { as OES Director } \\
\text { 2. List Jack Jones as } \\
\text { Jefferson County Judge }\end{array}$ \\
\hline $3-36$ & Fig. 13 & $\begin{array}{l}\text { "Adjusted" EPZ map doesn't include } \\
5 \text { counties originally identified } \\
\text { as being within } 50 \mathrm{~K} \text { PAZ }\end{array}$ & $\begin{array}{l}\text { Restore - Dallas, Cleveland } \\
\text { Lincoln, Arkansas \& Prairie } \\
\text { counties to original PAZ }\end{array}$ \\
\hline $3-38$ & Table 12 & $\begin{array}{l}\text { 1. Only lists } 5 \text { counties in PAZ } \\
\text { 2. Doesn't include all } \\
\text { incorporated areas }\end{array}$ & $\begin{array}{l}\text { 1. Restore all } 10 \text { counties } \\
\text { and } 2 \text { entities to PAZ } \\
\text { 2. Include all incorporated } \\
\text { areas to original } 10 \\
\text { county PAZ }\end{array}$ \\
\hline $\begin{array}{l}B-2 \\
B-3\end{array}$ & $\begin{array}{l}\text { Table } B-1 \\
\& B-2\end{array}$ & Only lists 5 counties in PAZ & $\begin{array}{l}\text { List } 10 \text { counties and } 2 \\
\text { entities as in original } \\
\text { PAZ }\end{array}$ \\
\hline $\begin{array}{l}\text { B-9 } \\
\text { thru } \\
\text { B-15 }\end{array}$ & Table B-5 & $\begin{array}{l}\text { Schools that should be included } \\
\text { in } 10 \text { county PAZ are entered as: } \\
\text { PAZ to } 100 \mathrm{~K}\end{array}$ & $\begin{array}{l}\text { Use } 10 \text { county \& } 2 \text { entity } \\
\text { PAZ to include schools }\end{array}$ \\
\hline$B-15$ & able B-5 & $\begin{array}{l}\text { Perry County schools ( } 100 \mathrm{~K} \text { PAZ) } \\
\text { E.ltered under Ouachita County }\end{array}$ & $\begin{array}{l}\text { Delete Perry County schools } \\
\text { on Page B-15, Table B-5. } \\
\text { (Previously entered on } \\
\text { Page B-12) }\end{array}$ \\
\hline
\end{tabular}


F-11

\begin{tabular}{|c|c|c|c|}
\hline $\begin{array}{l}\text { Page } \\
\text { No. }\end{array}$ & $\begin{array}{l}\text { Line } \\
\text { No. }\end{array}$ & Discrepancy & $\begin{array}{l}\text { Recommended } \\
\text { Correction }\end{array}$ \\
\hline$B-20$ & Table $\mathrm{B}-7$ & $\begin{array}{l}\text { Day care facilities originally in } \\
10 \text { county PAZ are listed as: } \\
\text { PAZ to } 100 \mathrm{~K}\end{array}$ & $\begin{array}{l}\text { Original } 10 \text { county } 2 \text { entity } \\
\text { facilities should be listed } \\
\text { in PAZ }\end{array}$ \\
\hline B-21 & Table B-8 & $\begin{array}{l}\text { Some institutes of higher } \\
\text { learning from original } 10 \text { county } \\
\text { PAZ are listed as: PAZ to } 100 \mathrm{~K}\end{array}$ & $\begin{array}{l}\text { Original } 10 \text { county } 2 \text { entity } \\
\text { institutes should be listed } \\
\text { in PAZ. }\end{array}$ \\
\hline B-23 & Table B-9 & $\begin{array}{l}\text { Some hospitals in original } \\
10 \text { county PAZ listed as: } \\
\text { PAZ to } 100 \mathrm{~K}\end{array}$ & $\begin{array}{l}\text { Original } 10 \text { county, } 2 \text { entity } \\
\text { hospitals should be listed } \\
\text { in PAZ }\end{array}$ \\
\hline$B-46$ & $12 \& 13$ & $\begin{array}{l}\text { Jefferson County OES } \\
\text { assists \& coordinates activities } \\
\text { of the Grant County Civil Defense } \\
\text { division }\end{array}$ & $\begin{array}{l}\text { Change to read: Jefferson } \\
\text { County Office of Emergency } \\
\text { Services assists the activi- } \\
\text { ties of the Grant County } \\
\text { Office of Emergency Services }\end{array}$ \\
\hline$B-48$ & 8 & $\begin{array}{l}\text { James Witt listed as Jefferson } \\
\text { County Judge }\end{array}$ & $\begin{array}{l}\text { Change to: James Lee Witt, } \\
\text { Director, Arkansas State } \\
\text { Office of Emergency Services }\end{array}$ \\
\hline
\end{tabular}




\section{F2 RESPONSES TO COMMENTS}

\section{F21 Responses to Letter Dated January 29, 1990, from Barry J. Davis, Center for Disease Control, Department of Health and Human Services}

1. The text has been revised to indicate more clearly that the BZ support facilities will be used by the new disposal facility.

2. The text has been revised to indicate that the distances given are in relation to the disposal facility.

3. This option will be considered for the site-specific EIS.

4. The acoustic sounder has been shipped for repairs. However, because of the general uniformity of the mixed layer height in this area, the data from the National Weather Service is considered sufficient. Other possible sources of data are also being investigated.

5. The storage risks continue for each alternative until the stockpile is eliminated; therefore, the only way to differentiate is to look at the risks associated with the specific activities required by each alternative.

6. Although the plume is broader for conservative most likely (CML) than for worst case (WC) conditions in the sense that the distribution of agent is wider in the crosswind direction (i.e., the standard deviation of the assumed Gaussian distribution is larger for CML conditions), other factors such as wind speed and dilution of agent in the crosswind and vertical directions cause the width of the CML plume, as represented by contours of equal dosage (the multiplicative product of agent concentration and duration of exposure), to be slightly less than the width of the corresponding WC plume. For emample, because the uind speed for CML conditions is three times as great as for WC conditions ( 3 vs $1 \mathrm{~m} / \mathrm{s})$, the dose at a given location resulting from a passing puff or cloud of agent from an explosive release under CML conditions is one-third what it would be for $1-\mathrm{m} / \mathrm{s}$ winds (without changing other meteorological conditions) because it passes three times as quickly. Similarly, for a continuous plume release, the initial concentration and subsequent downwind doses are one-third what they would be under $1-\mathrm{m} / \mathrm{s}$ winds because the stronger wind initially dilutes the agent concentration by "stretching" it in the downwind direction. The CML contours are relatively wide in comparison with their length, while the WC contours are relatively narrow; the absolute widths, however, are slightly less for CML conditions than WC conditions. Because the WC contours encompass the corresponding CML contours, a larger number of fatalities will occur under WC conditions. 
7. Comment incorporated.

8. Comment incorporated.

9. As the puff from an instantaneous release expands because of diffusion, it becomes subject to changes in wind direction within the increasing volume of air that it occupies as it travels downwind. Therefore, although the effect is not as pronounced as for a continuous plume, actual maximum doses in a puff are also less than predicted doses because of stretching and shearing occurring along the puffs meandering path. For both puff and plume releases, the actual distance traveled during meandering is greater than the straight-line distance to a given location; consequently, the greater distance allows additional time for dispersion to occur, and actual doses are less than predicted.

10. It is unlikely that more intense stable conditions would occur above a surface inversion that causes stable conditions; therefore, when looking at the WC scenario, the height of the mixed layer is not a major concern. For CML conditions, the analysis has been expanded to include Class D stability, with wind speeds up to $2.1 \mathrm{~m} / \mathrm{s}$ and a mixing height of $500 \mathrm{~m}$. These conditions did not result in significant changes in the level of risk.

11. Comment incorporated.

12. Cumment incorporated.

13. The Army determined that the major consideration at this stage of the environmental assessment process should be effects to off-site population. The sitespecific EIS will consider on-post as well as off-site population for assessing impacts and siting the facility.

14. This section was rewritten to include risks associated with a potential accident within the storage yard, adjacent to the fence at PBA. This could affect risks of all the disposal alternatives as well as continued storage. Recalculation of risks did not show a significant increase for on-site disposal as compared to the other alternatives.

15. Calculation of the three probabilistic measures of risk, including expected fatalities, involves the use of classified data. The results are, therefore, also classified and are quantified only by the ranges represented by the pictogram shading levels.

16. Additional discussion of the differences in the measures of risk between the disposal alternatives has been added to the text. 
17. Data on NCTR has been added to Table 10.

18. Presentation of the data in Fig. 13 and the accompanying text has been revised. It is now based on the $50-\mathrm{km}$ (31-mile) radius; therefore, the shading is not necessary and has been removed.

\section{F22 Reapones to Letter Dated January 3, 1990 from Richard E Sanderion. Director, Ofíce of Federal activities, U.S. Environmental Protection Agency}

\section{Responses to EPA comments:}

1. Emission rates and maximum ambient ground level concentrations of criteria pollutants and chemical agents during normal operations of the proposed disposal facility will be presented in the site-specific EIS.

2. The Red Phosphorous Mix Facility has now been added to the table as Permit Number 958-A, and the reference in the text has been deleted.

3. Alternative sites to include a site in close proximity to the chemical storage area will be considered in the site-specific EIS. However, the facility would be closer to the installation boundary and populated areas if it were located near the chemical storage area.

4. The design for the Tooele disposal facility was made available to the National Research Council for their review. To date, the National Research Council has concentrated their review on agent monitoring, personnel training, and the CSDP management structure. Other suggested changes from EPA have been incorporated in the final Phase I document.

5. Section 3.3 of the Final Phase I report has been modified as requested. Required regulatory reviews and approvals prior to construction and operation of the PBA disposal facility will be further detailed in the site-specific EIS.

6. As suggested, this section has been updated to report the results of the CAMDS VX testing that occurred in late 1989.

7. The Army's intention at the time the FPEIS was published, if on-site disposal was selected (reference p. 2-26 FPEIS), was to convert the existing BZ Munition Demilitarization Building, based on the JACADS design concepts and to destroy the PBA chemical munition stockpile. The FPEIS risk analysis assumed the JACADS technology would be used to destroy the PBA chemical stockpile, and the facility would be essentially a clone of the TEAD facility. After further investigations, the Army has determined it would be as cost effective to build a new downsized 
Munition Demilitarization Building and use some support facilities from the BZ operation. The proposed technology to destroy the PBA stockpile continues to be the JACADS technology. Use of a modified BZ Munition Demilitarization Building, as originally intended in the FPEIS, will be considered as an alternative site in the site-specific EIS.

\section{F.23 Response to Letter Dated December 20, 1989 from Dick Careat, Chief, Technical Services Division, State of Artanam, Department of Pollution Control and Ecology}

We appreciate these comments from the State of Arkansas. To further clarify, current plans are to construct a new Munition Demilitarization Building adjacent to the existing BZ facility to destroy the PBA chemical munition stockpile. Although reuse of the $\mathrm{BZ}$ facilities and incinerators was considered at one time, current plans are to reuse only certain support facilities from the BZ operation. This decision was made to facilitate adherence to the more stringent safety criteria for the chemical munition demilitarization facility. In addition, costly design alterations to the $\mathrm{BZ}$ incinerators would be needed to obtain the required throughput rates, temperatures, and residence times for disposal of the PBA chemical stockpile. The primary benefit of purchasing new incinerators for the chemical disposal operation is that, as they will be essentially identical to the JACADS and other CONUS CSDP facilities, experience gained at these facilities will be more transferable.

\section{F24 Reaponec to Letter Dated January 31, 1990 from James L Witt, Director, State of Artansas Office of Emergency Services and Jack Palmateex, Jefferzon County Ofitice of Emergency Services}

Most of these comments have to do with the use of the IRZ and PAZ in presenting the data. The presentation of data has been revised and is now based on the $50-\mathrm{km}$ (31-mile) radius, with data to $100 \mathrm{~km}$ (62 miles) provided where available. All other comments have been incorporated into the report. 


\section{INTERNAL DISTRIBUTION}

1. T.J. Blasing

2. C.R. Boston

3. R.B. Braid

4. J.B. Cannon

5. S.A. Carnes

6. E.D. Copenhaver

7-11. J.T. Ensminger

12. R.K. Gryder

13. G. Harrison

14. E.L Hillsman

15. D.B. Hunsaker

16. R.D. Johnson

17. M.A. Kuliasha

18. D.P. Lombardi
19. J.A. Morrisey

20. R.M. Reed

21. M.L. Socolof

22. J.H. Sorensen

23. F. Southworth

24. W.P. Staub

25. V.R. Tolbert

26. T.G. Yow

27-31. G.P. Zimmerman

32. ORNL Patent Office

33-34. Central Research Library

35. Docuinent Research Section

36-37. Laboratory Records

38. Laboratory Records--RC

\section{EXTERNAL DISTRIBUTION}

39. Dr. Bruce G. Buchanan, Department of Computer Science, University of Pittsburg, 206 Mineral Industries Building, Pittsburgh, Pennsylvania, 15260

40. John J. Cuttica, Vice President, End Use Research and Development, Gas Research Institute, 8600 W. Bryn Mawr Avenue, Chicago, Illinois 60631

41. Frank Gouveia, Environmental Sciences Division, P. O. Box 5507, L-524, Lawrence Livermore National Laboratory, Livermore, California 94550

42. Dr. Allan Hirsch, Vice President, Environmental Sciences and Director, Washington Operations, Midwest Research Institute 5109 Leesburg Pike, Suite 414, Falls Church, Virginia 22041

43. Dr. Helen Ingram, Director, Udall Center for Studies in Public Policy, The University of Arizona, 803/811 East First Street, Tucson, Arizona 85719

44. Mr. Calvin D. MacCracken, President, Calmac Manufacturing Corporation, 101 West Sheffield Avenue, P.O. Box 710, Englewood, New Jersey 07631 
45. Dr. Denton E. Morrison, 333 Oxford Road, East Lansing, Michigan 48823

46. Ms. Jacquelin B. Shrago, Director, Office of Technology Transfer, 405 Kirkland Hall, Vanderbilt University, Nashville, TN 37240

47. Dr. Martin Williams, Professor, Department of Economics, Norther Illinois University, DeKalb, Illinois 60115

48. Office of Assistant Manager and Energy, Research, and Development, DOEORO, P.O. Box 2001, Oak Ridge, Tennessee 37831-8600

49. U.S. Department of the Army, Program Manager for Chemical Demilitarization, ATTN: SAIL-PMM (Major L.Y. Pilcher), Edgewood Area, Bldg.4517, Aberdeen Proving Ground, Md. 21010-5401

50. U.S. Department of the Army, Program Manager for Chemical Demilitarization, ATTN: SAIL-PMM (K. Piasecki), Edgewood Area, Bldg. 4517, Aberdeen Proving Ground, Md. 21010-5401

51. U.S. Department of the Army, Program Manager for Chemical Demilitarization, ATTN: SAIL-PMM (M. Satrape), Edgewood Area. Bldg. 4517, Aberdeen Proving Ground, Md. 21010-5401

52. U.S. Department of the Army, Program Manager for Chemical Demilitarization, ATTN: SAIL.PMI (M. Tischbin), Edgewood Area, Bldg. 4585, Aberdeen Proving Ground, Md. 21010-5401

53-62. Office of Scientific and Technical Information, U.S. Department of Energy, P.O. 5ox 62, Oak Ridge, Tennessee 37831 

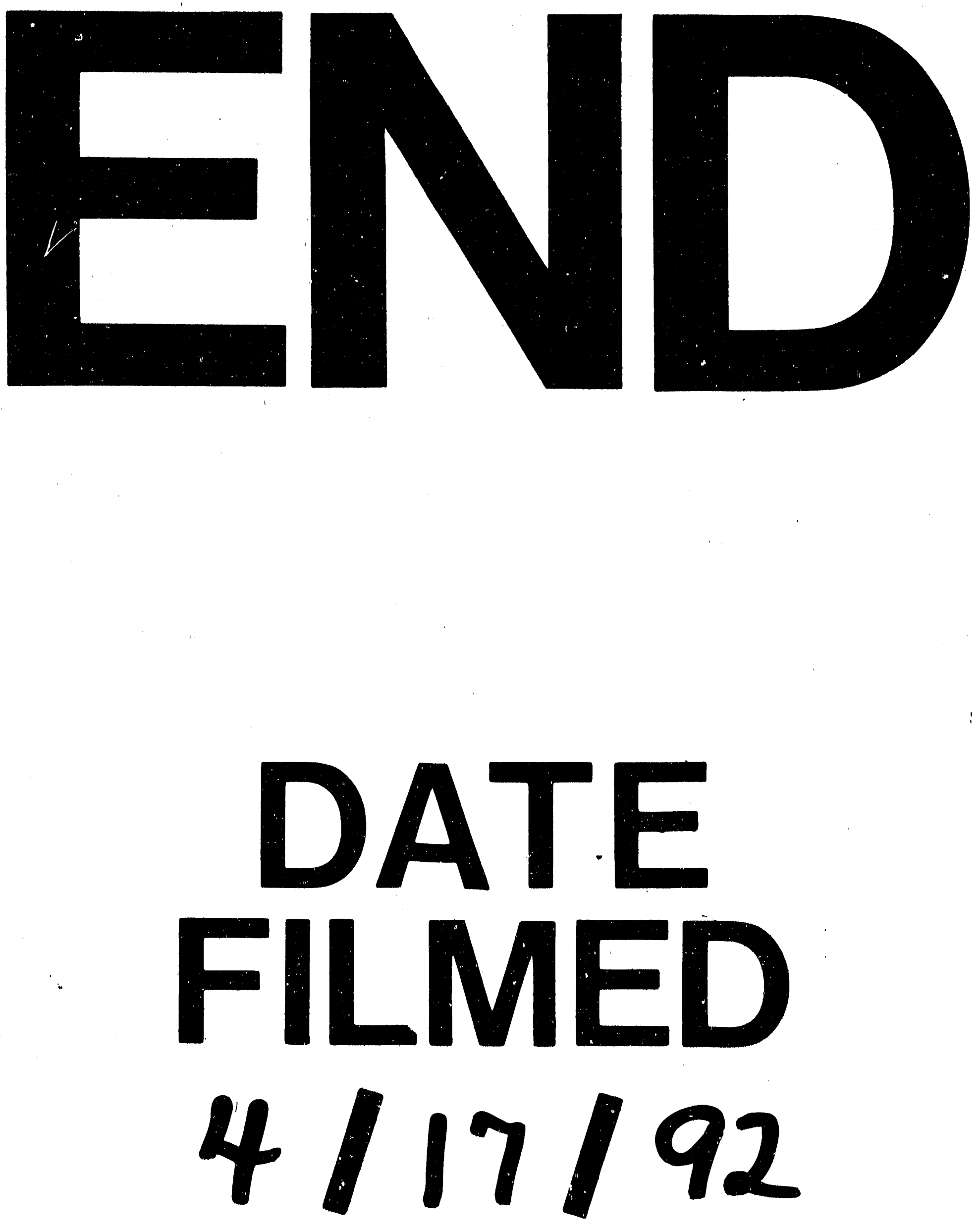
